Computational Physics and Engineering Division

\title{
ANALYSIS OF FRESH FUEL CRITICAL EXPERIMENTS APPROPRIATE FOR BURNUP CREDIT VALIDATION
}

M. D. DeHart and S. M. Bowman

Manuscript Completed: March 1994

Date Published: October 1995

Prepared for

Sandia National Laboratories

under subcontract $\mathrm{AD}-4072$ with Oak Ridge National Laboratory

Prepared by the

OAK RIDGE NATIONAL LABORATORY

managed by

LOCKHEED MARTIN ENERGY SYSTEMS, INC.

for the

U.S. DEPARTMENT OF ENERGY

under contract DE-AC05-84OR21400 


\section{DISCLAMMER}

Portions of this document may be illegible in electronic image products. Images are produced from the best available original document. 


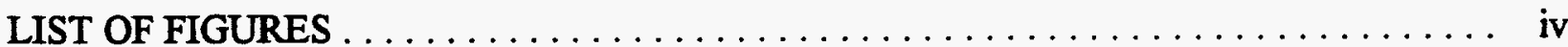

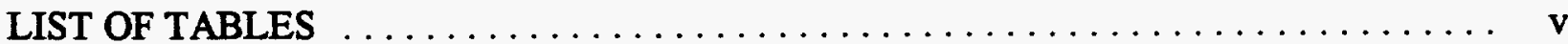

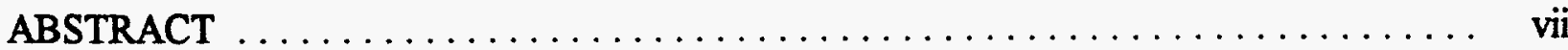

ACKNOWLEDGMENTS $\ldots \ldots \ldots \ldots \ldots \ldots \ldots \ldots \ldots \ldots \ldots \ldots \ldots \ldots \ldots \ldots \ldots$ ix

1. INTRODUCTION $\ldots \ldots \ldots \ldots \ldots \ldots \ldots \ldots \ldots \ldots \ldots \ldots \ldots \ldots \ldots \ldots \ldots \ldots \ldots$

2. DESCRIPTION OF FRESH FUEL CRITICAL EXPERIMENTS $\ldots \ldots \ldots \ldots \ldots \ldots$

$2.1 \mathrm{UO}_{2}$ CRITICAL EXPERIMENTS FOR LWR FUEL IN

CASK GEOMETRIES $\ldots \ldots \ldots \ldots \ldots \ldots \ldots \ldots \ldots \ldots \ldots \ldots \ldots, \quad 3$

2.2 GADOLINIUM CRITICAL EXPERIMENTS $\ldots \ldots \ldots \ldots \ldots \ldots \ldots \ldots, 4$

2.3 LWR MOX FUEL CRITICAL EXPERIMENTS $\ldots \ldots \ldots \ldots \ldots \ldots \ldots$

3. CRITICALITY CALCULATIONS BASED ON FRESH FUEL EXPERIMENTS $\ldots \ldots$. 8

3.1 CRITICALITY SEQUENCES OF THE SCALE-4 CODE SYSTEM . . . . . . . 8

3.2 RESULTS OF CRITICALITY CALCULATIONS USING SCALE- $4 \ldots \ldots \ldots 9$

3.2.1 Criticality Calculations Based on LWR-Type $\mathrm{UO}_{2}$ Experiments . . . . . . 9

3.2.2 Criticality Calculations Based on LWR-Type $\mathrm{UO}_{2}$ Experiments

Containing Gadolinium $\ldots \ldots \ldots \ldots \ldots \ldots \ldots \ldots \ldots$

3.2.3 Criticality Calculations Based on LWR-Type

Mixed-Oxide Experiments ..................... 12

3.2.4 Combined Results for all Critical Experiments . . . . . . . . . 15

4 BIAS AND UNCERTAINTY FROM CRITICAL EXPERIMENTS $\ldots \ldots \ldots \ldots \ldots \ldots$

4.1 ESTABLISHMENT OF AN UPPER SAFETY LIMIT

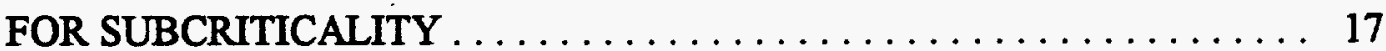

4.2 METHODS FOR DETERMINATION OF AN UPPER SAFETY LIMIT . . . . 19

4.2.1 USL Method 1: Confidence Band with Administrative Margin . . . . . . 19

4.2.2 USL Method 2: Single-Sided Uniform Width Closed

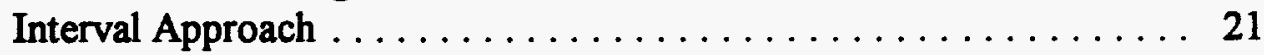

4.2.3 USL Method 3: Worst Case with Administrative Margin $\ldots \ldots \ldots 22$

4.2.4 Application of Upper Safety Limit Methods $\ldots \ldots \ldots \ldots \ldots \ldots 23$

4.3 CALCULATION OF UPPER SAFETY LIMITS $\ldots \ldots \ldots \ldots \ldots \ldots \ldots$

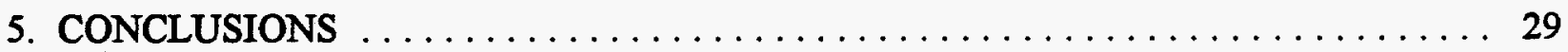

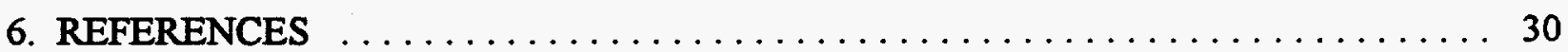

APPENDIX A. PHYSICAL DESCRIPTION OF CRITICAL EXPERIMENTS . . . . . . 33

APPENDIX B. SCALE-4 INPUT LISTINGS FOR THE 34 FRESH FUEL CRITICALS . . 79

APPENDIX C. RESULTS OF ADDITIONAL CRITICAL CALCULATIONS . . . . . . . 159 


\section{LIST OF FIGURES}

Figure

Page

$1 \quad k_{\text {eff }}$ vs AEG for MOX critical experiments $\ldots \ldots \ldots \ldots \ldots \ldots \ldots \ldots \ldots$

$2 \quad k_{\text {eff }}$ vs AEG for combined fresh fuel criticals $\ldots \ldots \ldots \ldots \ldots \ldots \ldots \ldots$

3 Confidence band and safety margin applied to a set of criticality calculations . . . . . 20

4 USLs computed by Methods 1, 2, and 3 for the 34 fresh fuel criticals . . . . . . . 25

5 Method 1 USL as a function of combinations of critical calculations . . . . . . . 28

A.1 Description of $4.31 \mathrm{wt} \%{ }^{235} \mathrm{U}$ enriched $\mathrm{UO}_{2}$ fuel rods used in experiments ft214r $\ldots 34$

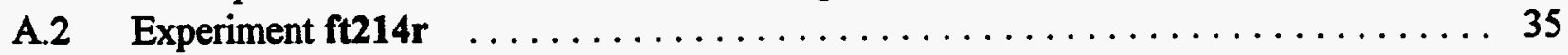

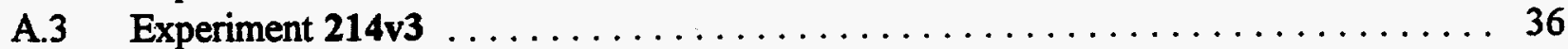

A.4 Experimental assembly elevations for $\mathbf{f t 2 1 4 r}$ and $\mathbf{f t 2 1 4} \mathbf{v 3} \ldots \ldots \ldots \ldots \ldots \ldots$

A.5 Description of 2.35 wt $\%{ }^{235} \mathrm{U}$ enriched $\mathrm{UO}_{2}$ fuel rods used in absorber plate experiments . . . . . . . . . . . . . . . . . . . . . . 39

A.6 Experimental setup of the absorber plate experiments and the shielding wall experiments $\ldots \ldots \ldots \ldots \ldots \ldots \ldots \ldots \ldots \ldots \ldots \ldots \ldots \ldots$

A.7 Assembled depleted uranium wall for depleted uranium shielding wall experiment . . 42

A.8 Assembled lead wall for lead shielding wall experiment $\ldots \ldots \ldots \ldots \ldots \ldots \ldots$

A.9 Assembled steel wall for steel shielding wall experiment $\ldots \ldots \ldots \ldots \ldots \ldots \ldots \ldots$

A.10 Experimental setup for soluble boron experiments $\ldots \ldots \ldots \ldots \ldots \ldots \ldots \ldots$

A.11 Dimensions of $2.46 \%$ enriched $\mathrm{UO}_{2}$ fuel rod in experiment baw1484a $\ldots \ldots \ldots 48$

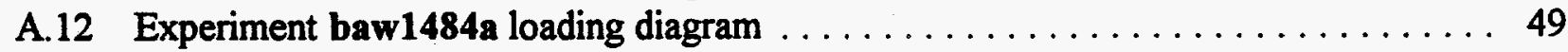

A.13 Experiment baw1484a vertical dimensions $\ldots \ldots \ldots \ldots \ldots \ldots \ldots \ldots \ldots$

A.14 Experiment bnw1810a core loading diagram $\ldots \ldots \ldots \ldots \ldots \ldots \ldots \ldots \ldots \ldots$

A.15 Axial core structure dimensions for EPRI-196 $\mathrm{UO}_{2}$ experiments $\ldots \ldots \ldots \ldots \ldots$

A.16 Dimensions of "eggcrate" lattice grids for EPRI-196 $\mathrm{UO}_{2}$ and $\mathrm{MOX}$ experiments . . . 55

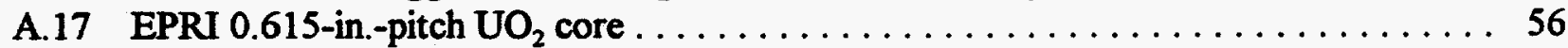

A.18 EPRI 0.870 -in.-pitch $\mathrm{UO}_{2}$ core $\ldots \ldots \ldots \ldots \ldots \ldots \ldots \ldots \ldots \ldots \ldots \ldots \ldots$

A.19 Axial view of Saxton experimental setup $\ldots \ldots \ldots \ldots \ldots \ldots \ldots \ldots \ldots \ldots \ldots$

A.20 Gadolinium experiment bnw1810b quarter-core (symmetric) loading diagram . . . . 62

A.21 Gadolinium experiment bnw1810c quarter-core (symmetric) loading diagram ..... 63

A.22 Description of MOX fuel rods for EPRI experiments $\ldots \ldots \ldots \ldots \ldots \ldots \ldots \ldots$

A.23 $\mathrm{UO}_{2}-2$ wt $\% \mathrm{PuO}_{2}$ "eggcrate" core structure dimensions for EPRI experiments . . . 67

A.24 Unborated EPRI 0.70 -in. $\mathrm{UO}_{2}-2$ wt $\% \mathrm{PuO}_{2}$ core $\ldots \ldots \ldots \ldots \ldots \ldots \ldots \ldots$

A.25 Borated EPRI 0.70 -in. $\mathrm{UO}_{2}-2$ wt $\% \mathrm{PuO}_{2}$ core $\ldots \ldots \ldots \ldots \ldots \ldots \ldots \ldots \ldots$

A.26 Unborated EPRI 0.87-in. $\mathrm{UO}_{2}-2$ wt $\% \mathrm{PuO}_{2}$ core $\ldots \ldots \ldots \ldots \ldots \ldots \ldots \ldots$

A.27 Borated EPRI 0.87-in. $\mathrm{UO}_{2}-2$ wt $\% \mathrm{PuO}_{2}$ core $\ldots \ldots \ldots \ldots \ldots \ldots \ldots \ldots \ldots$

A.28 Unborated EPRI 0.99 -in. $\mathrm{UO}_{2}-2$ wt $\% \mathrm{PuO}_{2}$ core $\ldots \ldots \ldots \ldots \ldots \ldots \ldots \ldots \ldots$

A.29 Borated EPRI 0.99-in. $\mathrm{UO}_{2}-2$ wt $\% \mathrm{PuO}_{2}$ core $\ldots \ldots \ldots \ldots \ldots \ldots \ldots \ldots$

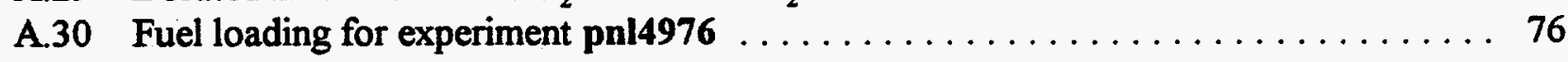

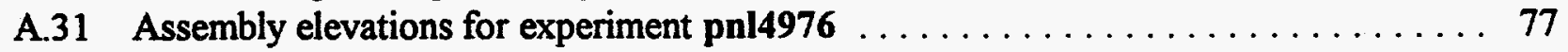




\section{LIST OF TABLES}

Table

Page

$1 \quad \mathrm{UO}_{2}$ critical experiments for $\mathrm{LWR}$ fuel in cask geometries $\ldots \ldots \ldots \ldots \ldots \ldots$

2 Critical experiments with $\mathrm{UO}_{2}$ and gadolinium $\ldots \ldots \ldots \ldots \ldots \ldots \ldots \ldots \ldots \ldots \ldots \ldots$

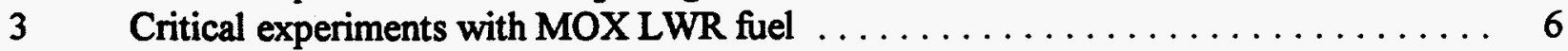

$4 \quad$ Criticality calculations for validation of $\mathrm{UO}_{2}$ in $\mathrm{LWR}$ fuel cask geometries . . . . . . 10

5 Thermal range energy structure for the SCALE-4 27-group burnup library ........ 11

6 Criticality calculations for $\mathrm{B} \& W-1810$ gadolinium experiments $\ldots \ldots \ldots \ldots \ldots 11$

7 Criticality calculations for validation of LWR-type MOX experiments $\ldots \ldots \ldots \ldots 13$

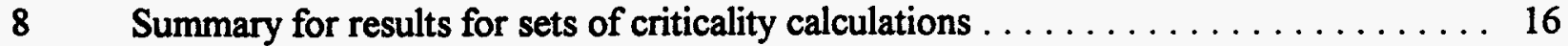

9 Parameters used in USL calculation for fresh fuel criticals $\ldots \ldots \ldots \ldots \ldots \ldots \ldots 24$

10 Summary of USL calculations for various sets of data $\ldots \ldots \ldots \ldots \ldots \ldots 27$

A.1 Description of neutron flux trap plates in experiments ft214r and $\mathbf{f t 2 1 4 v 3} \ldots \ldots \ldots 33$

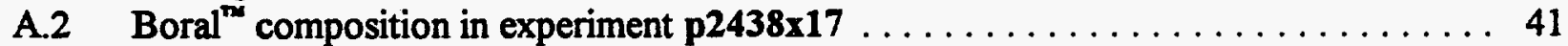

A.3 Critical separation between assemblies for shielding wall experiments .......... 45

A.4 Critical array dimensions of soluble boron experiments . . . . . . . . . . . 47

A.5 Properties of $2.46 \%$ enriched $\mathrm{UO}_{2}$ fuel rods in experiment baw1484a $\ldots \ldots \ldots \ldots 47$

A.6 Certified chemical analysis of $\mathrm{B}_{4} \mathrm{C}$ for experiment baw14894a $\ldots \ldots \ldots \ldots \ldots 49$

A.7 Physical properties of $4.02 \mathrm{wt} \%$ enriched $\mathrm{UO}_{2}$ fuel rods in $\mathrm{B} \& \mathrm{~W}-1810$ experiments . 53

A.8 Experiment description for bnw $\mathbf{1 8 1 0 a} \ldots \ldots \ldots \ldots \ldots \ldots \ldots \ldots \ldots \ldots \ldots \ldots \ldots$

A.9 EPRI-196 $\mathrm{UO}_{2}$ critical experiment descriptions $\ldots \ldots \ldots \ldots \ldots \ldots \ldots \ldots \ldots \ldots$

A.10 Saxton $\mathrm{UO}_{2}$ fuel rod specifications $\ldots \ldots \ldots \ldots \ldots \ldots \ldots \ldots \ldots \ldots \ldots \ldots \ldots \ldots$

A.11 Saxton $\mathrm{UO}_{2}$ critical experiment descriptions $\ldots \ldots \ldots \ldots \ldots \ldots \ldots \ldots \ldots \ldots$

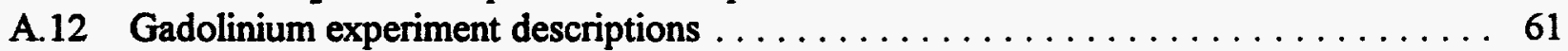

A.13 Physical properties of $1.944 \mathrm{wt} \%$ enriched $\mathrm{UO}_{2}-\mathrm{Gd}_{2} \mathrm{O}_{3}$ fuel rods for

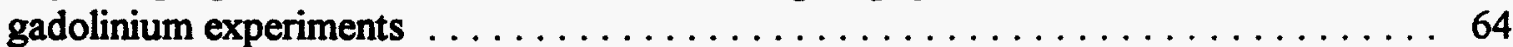

A.14 MOX fuel compositions in EPRI experiments $\ldots \ldots \ldots \ldots \ldots \ldots \ldots \ldots \ldots \ldots \ldots \ldots$

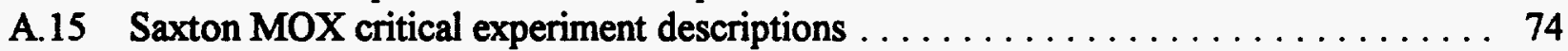

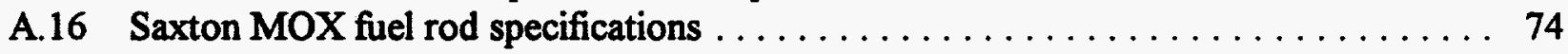

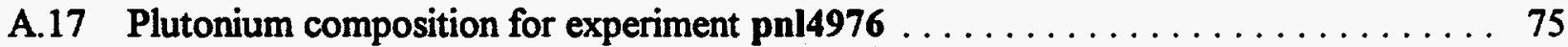

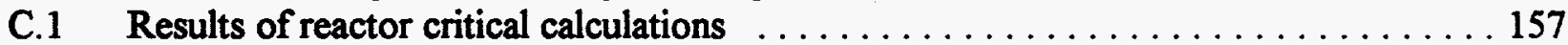

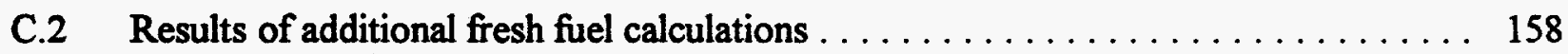




\section{ACKNOWLEDGMENTS}

The authors wish to express their appreciation to several individuals who contributed their ideas and efforts in the analyses described herein. Particular thanks go to M. C. Brady of Sandia National Laboratories, who participated in the early selection of fresh fuel experiments and who provided technical oversight for most of the duration of this work; C. V. Parks of Oak Ridge National Laboratory, who provided guidance and reviewed and commented on the draft report; $\mathrm{H}$. Taniuchi of Kobe Steel, Ltd., Kobe, Japan, and S. K. Martin of Oak Ridge National Laboratory, who helped perform many of the calculations; and S. R. Bierman of Pacific Northwest Laboratories, who suggested many of the fresh fuel critical experiments that were analyzed. The authors also wish to acknowledge L. F. Norris for her continuing efforts in the text editing, formatting, and release of this report.

This work was sponsored as part of the Cask System Development Program within the U.S. Department of Energy's Office of Civilian Radioactive Waste Management.

This report was prepared by the Oak Ridge National Laboratory for Sandia National Laboratories in accordance with the technical and quality assurance requirements specified in Sandia subcontract $\mathrm{AD}-4072$. All work described in the subcontract Statement of Work was conducted under the Sandia Burnup Credit QA Program and implementing procedures. 



\begin{abstract}
The ANS/ANS-8.1 standard requires that calculational methods used in determining criticality safety limits for applications outside reactors be validated by comparison with appropriate critical experiments. This report provides a detailed description of 34 fresh fuel critical experiments and their analyses using the SCALE-4.2 code system and the 27-group ENDF/B-IV cross-section library. The 34 critical experiments were selected based on geometry, material, and neutron interaction characteristics that are applicable to a transportation cask loaded with pressurized-water-reactor spent fuel. These 34 experiments are a representative subset of a much larger data base of low-enriched uranium and mixed-oxide critical experiments. A statistical approach is described and used to obtain an estimate of the bias and uncertainty in the calculational methods and to predict a confidence limit for a calculated neutron multiplication factor. The SCALE- 4.2 results for a superset of approximately 100 criticals are included in uncertainty analyses, but descriptions of the individual criticals are not included.
\end{abstract}




\section{INTRODUCTION}

The ANSI/ANS-8.1 standard, "Nuclear Criticality Safety in Operations with Fissionable Materials Outside Reactors,"1 requires that a calculational method used in determining criticality safety limits for a system be validated by comparison with critical experiments that are applicable to the system. The Standard does not define nor discuss what constitutes an "area of applicability," but it does provide for extension beyond the area of applicability if trends in the bias are considered. In identifying the area of applicability for a validation, the following issues should be addressed:

Code Similarity - The computer codes selected, the modeling options employed in the codes, and the cross-section data and processing techniques that are used must be consistent in both the validation analyses and the problem analyses.

Physical System Similarity - The fissile material, the geometry, the moderator, the material compositions, and the neutron absorbers in the critical experiments used for the validation determine the area of applicability for other physical systems to be analyzed.

Similar Particle Interaction Characteristics - Justification that the particle interaction characteristics are similar between the validation analyses and the problem of interest can be difficult to demonstrate. The average energy causing fission, the ratio of thermal fissions and absorptions to total fissions and absorptions, and the ratio of moderator to fissile material (i.e., $\mathrm{H} / \mathrm{X}$ ) are examples of quantities used to establish similarity and justify inclusion in the area of applicability.

The purpose of this report is to describe and analyze a set of 34 fresh fuel critical experiments that represent geometry, material, and neutron interaction characteristics applicable to a transportation cask loaded with pressurized-water-reactor (PWR) spent fuel. These 34 experiments are only a representative subset of a much larger data base of low-enriched uranium and mixed-oxide (MOX) critical experiments. The $19 \mathrm{UO}_{2}$ critical experiments included in the set of 34 were selected to span the range of enrichment, materials, and geometry typical of transport configurations. Thirteen MOX critical experiments were selected to provide a basis for demonstrating that the calculational method is capable of analyzing pin-lattice configurations with mixtures of uranium and plutonium oxide. Because gadolinium is an important fission product in spent fuel after several years of cooling, two experiments with gadolinium included in the pin-lattice were selected to demonstrate adequate cross-section data.

The 34 criticals were analyzed using the SCALE-4.2 code system ${ }^{2}$ and the 27-group ENDF/B-IV cross-section library. SCALE is a well-established code system that is widely used in away-from-reactor (AFR) applications and has served as the primary computational tool used by the U.S. Department of Energy (DOE) in technical studies related to burnup credit. ${ }^{3}$ Although the SCALE models and results for the 34 critical experiments are emphasized in the report, the description of the 34 criticals should be sufficient for analysis by any computational tool that is appropriate for criticality safety analyses.

Another purpose of this report is to describe and to demonstrate the application of a statistical approach to obtain an estimate of the bias and uncertainty in the calculational method based on the performance of the computational tool in predicting the neutron multiplication factor, $\mathrm{k}_{\mathrm{eff}}$. A method that uses the bias and uncertainty information to estimate a confidence limit for subsequent calculations of $k_{\text {eff }}$ is also described. Trends in $k_{\text {eff }}$ and an estimation of the bias, uncertainty, and confidence limit are done with the subset of 34 critical experiments and a much larger set of 100 fresh 
Note that even with the 100 fresh fuel criticals, the fission products typically present in spent fuel are not included in any measured critical analyzed in this report. Thus in terms of its applicability to burnup credit, validation results with fresh fuel critical experiments must be used in conjunction with other work that will account for aspects of spent fuel criticality analysis not specifically addressed here.

Section 2 of this report describes the 34 fresh fuel critical experiments used in the validation process. Section 3 describes the SCALE system used in the analyses of these experiments and the results obtained based on the SCALE-4.2 models. Trends in the calculated results and correlations between key parameters are also discussed. In Sect. 4, a statistical approach is described for the determination of bias and uncertainty, and for the combination of these parameters for the determination of an upper safety limit that ensures subcriticality with a given confidence level for future calculations. 


\section{DESCRIPTION OF FRESH FUEL CRITICAL EXPERIMENTS}

This section provides a description of a select set of 34 water-moderated, lattice-type critical experiments performed with low-enriched uranium and MOX fuel rods. This set of fresh fuel critical experiments was selected from a literature survey that sought to identify a representative sampling of experiments that represent the material, geometric, and neutronic characteristics in spent fuel casks. ${ }^{4}$ The presence of plutonium and gadolinium (as a fission product) in spent fuel led to the decision to add criticals with gadolinium in the fuel and criticals with $\mathrm{MOX}\left(\mathrm{UO}_{2}-\mathrm{PuO}_{2}\right)$ fuel rods. The following subsections describe these critical experiments, grouped in terms of the following sets:

1. $\mathrm{UO}_{2}$ critical experiments with geometric features of spent fuel transportation and storage casks (19);

2. $\mathrm{UO}_{2}$ critical experiments with gadolinium in the fuel (2); and

3. MOX critical experiments containing low-enriched $\mathrm{UO}_{2}-\mathrm{PuO}_{2}$ fuel rods (13).

Section 3 will describe the assumptions made and the results obtained for calculational models based on these experiments

\section{1 $\mathrm{UO}_{2}$ CRITICAL EXPERIMENTS FOR LWR FUEL IN CASK GEOMETRIES}

Nineteen LWR-type fuel lattice experiments ${ }^{5-13}$ were selected as the most representative of typical low-enrichment $\mathrm{UO}_{2} \mathrm{LWR}$ assemblies. These experiments cover a wide range of conditions and allow for the study of six different aspects of criticality related to fuel storage in transportation and storage casks and the application of burnup credit:

1. neutron interaction among LWR-type fuel assemblies;

2. effect of neutron absorber materials between fuel assemblies;

3. effect of commonly used cask shielding materials;

4. neutron spectra shift or relative neutron moderation caused by dissolved boron;

5. effect of neutron flux traps between fuel assemblies; and

6. effect of voiding on the performance of neutron flux traps.

(Although currently no burnup credit cask designs use flux traps, such experiments provide relevant information on neutron interaction among fuel assemblies separated by water.) These experiments contain enrichments ranging from 2.35 to $5.74 \mathrm{wt} \%{ }^{235} \mathrm{U}$; absorbers such as boron, Boral, and stainless steel; and reflectors of uranium, lead, and steel. Fuel pin pitches ranging from 1.42 to 2.21 $\mathrm{cm}$ are represented, with moderator-to-fuel volume ratios ranging from 1.09 to 5.067. Table 1 provides a summary of the key aspects of each experiment. The case designation is the name assigned to the criticality model for each experiment, and is used as a convenient reference name for each experiment. The specific designs of the experiments are described in detail in Appendix A. 


\section{4}

Table 1. $\mathrm{UO}_{2}$ critical experiments for LWR fuel in cask geometries

\begin{tabular}{|c|c|c|c|c|c|c|}
\hline $\begin{array}{l}\text { Case } \\
\text { No. }\end{array}$ & $\begin{array}{l}\text { Case } \\
\text { designation }\end{array}$ & $\begin{array}{l}\text { Enrichment } \\
\text { (wt \% }{ }^{235} \mathrm{U} \text { ) }\end{array}$ & Description & $\begin{array}{l}\text { Lattice } \\
\text { pitch } \\
\text { (cm) }\end{array}$ & $\begin{array}{l}\text { Lattice } \\
\text { waterffuel } \\
\text { volume ratio }\end{array}$ & Ref. \\
\hline 1 & $\mathrm{ft214r}$ & 4.31 & Flux traps, no voids & 1.89 & 1.60 & 5 \\
\hline 2 & $\mathrm{f} 214 \mathrm{v} 3$ & 4.31 & Flux traps with voids & 1.89 & 1.60 & 5 \\
\hline 3 & p2438x05 & 2.35 & No absorber plates & 2.03 & 2.92 & 6 \\
\hline 4 & $\mathrm{p} 2438 \times 17$ & 2.35 & Boral absorber plates & 2.03 & 2.92 & 6 \\
\hline 5 & p2438x24 & 2.35 & Aluminum absorber plates & 2.03 & 2.92 & 6 \\
\hline 6 & $\mathrm{p} 2438 \times 28$ & 2.35 & Stainless steel absorber plates & 2.03 & 2.92 & 6 \\
\hline 7 & p392614a & 4.31 & Lead reflector & 1.89 & 1.60 & 7 \\
\hline 8 & p3926u4a & 4.31 & Uranium reflector & 1.89 & 1.60 & 7 \\
\hline 9 & p3602s4 & 4.31 & $\begin{array}{l}\text { Steel reflector, borated steel absorber } \\
\text { plates }\end{array}$ & 1.89 & 1.60 & 8 \\
\hline 10 & $\mathrm{p} 4267 \mathrm{a}$ & 4.31 & No soluble boron & 1.89 & 1.59 & 9 \\
\hline 11 & $\mathrm{p} 4267 \mathrm{~b}$ & 4.31 & $2550 \mathrm{ppm}$ soluble boron & 1.89 & 1.59 & 9 \\
\hline 12 & $\mathrm{p} 4267 \mathrm{c}$ & 4.31 & No soluble boron & 1.72 & 1.09 & 9 \\
\hline 13 & p4267d & 4.31 & $2550 \mathrm{ppm}$ soluble boron & 1.72 & 1.09 & 9 \\
\hline 14 & baw1484a & 2.46 & Core IV - 84 B4C pins & 1.64 & 1.84 & 10 \\
\hline 15 & bnw1810a & $4.02,2.46$ & $\begin{array}{l}\mathrm{UO}_{2} \text { exp. for comparison with } \mathrm{UO}_{2}+\mathrm{Gd} \\
\text { exps. }\end{array}$ & 1.64 & 1.62 & 11 \\
\hline 16 & e196u6n & 2.35 & $\begin{array}{l}\mathrm{UO}_{2} \text { exp. for comparison with EPRI } \\
\text { MOX exps. }\end{array}$ & 1.56 & 1.20 & 12 \\
\hline 17 & el96u87c & 2.35 & $\begin{array}{l}\mathrm{UO}_{2} \text { exp. for comparison with EPRI } \\
\text { MOX exps. }\end{array}$ & 2.21 & 3.69 & 12 \\
\hline 18 & $\operatorname{saxu56}$ & 5.74 & $\begin{array}{l}\mathrm{UO}_{2} \text { exp. for comparison with Saxton } \\
\text { MOX exps. }\end{array}$ & 1.42 & 1.93 & 13 \\
\hline 19 & $\operatorname{saxu} 792$ & 5.74 & $\begin{array}{l}\mathrm{UO}_{2} \text { exp. for comparison with Saxton } \\
\text { MOX exps. }\end{array}$ & 2.01 & 5.07 & 13 \\
\hline
\end{tabular}




\subsection{GADOLINIUM CRITICAL EXPERIMENTS}

Gadolinium is a strong neutron absorber and a significant isotope with respect to reactivity in spent LWR fuel that has undergone several years of cooling; it is produced by the radioactive decay of fission product ${ }^{135} \mathrm{Eu}$, which has a 4.7 -year half-life. Two $\mathrm{UO}_{2}-\mathrm{Gd}_{2} \mathrm{O}_{3}$ experiments ${ }^{11}$ were modeled to examine the ability of SCALE-4 and the 27-group ENDF/B-IV burnup library to represent gadolinium absorption in LWR fuel. In addition, bnw1810a (case No. 15), which was based on the same lattice configuration but contained no gadolinium, was used as a reference for comparison with the remaining gadolinium-bearing experiments; this experiment is included in the set of fresh fuel $\mathrm{UO}_{2}$ experiments (see Table 1). The two gadolinium-bearing experiments included a small number of $\mathrm{UO}_{2}-\mathrm{Gd}_{2} \mathrm{O}_{3}$ fuel rods in selected patterns among fresh $\mathrm{UO}_{2}$ fuel rods. Criticality was achieved by adjusting the soluble boron concentration. Table 2 provides a summary of the key aspects of each $\mathrm{UO}_{2}-\mathrm{Gd}_{2} \mathrm{O}_{3}$ experiment. As with the $\mathrm{UO}_{2}$-only experiments, the specific designs of the gadolinium experiments are described in Appendix A.

\subsection{LWR MOX FUEL CRITICAL EXPERIMENTS}

Spent fuel contains many actinides and fission products not present in fresh fuel. From a criticality safety perspective, the most significant actinide other than uranium present in spent fuel is plutonium, which has fissile isotopes $\left({ }^{29} \mathrm{Pu}\right.$ and $\left.{ }^{241} \mathrm{Pu}\right)$ as well as one major neutron-absorbing isotope $\left.{ }^{210} \mathrm{Pu}\right)$. Therefore, $13 \mathrm{MOX}$ critical experiments ${ }^{12-14}$ were selected for validating a methodology for spent fuel containing $\mathrm{PuO}_{2}$ and $\mathrm{UO}_{2}$. These $\mathrm{LWR}$-type $\mathrm{MOX}$ fuel lattice experiments, summarized in Table 3, were included to demonstrate the capability of the SCALE-4 27-group burnup library to treat the mixture of uranium and plutonium isotopes in a fuel lattice, as would be found in spent fuel assemblies. The experiments contained varying amounts of soluble boron, triangular and squarelattice arrangements, with varying pitches. One experiment had a lattice comprised of a pattern of alternating $\mathrm{UO}_{2}$ and $\mathrm{MOX}$ rods, in an attempt to simulate the overall plutonium content of a highly burned LWR reactor core (as opposed to a highly burned assembly, which would possess a higher relative plutonium content). All MOX rods consisted of natural uranium in oxide form, mixed with $\sim 90 \%{ }^{239} \mathrm{Pu}$-enriched plutonium oxide, in $\mathrm{PuO}_{2}$ fractions of 2 or $6.6 \mathrm{wt} \%$. Four $\mathrm{UO}_{2}$ experiments listed in Table 1 (cases 16-19) were performed in conjunction with corresponding sets of MOX experiments to provide similar geometric configurations for better resolution of plutonium effects. Table 3 provides a summary of the key aspects of each MOX experiment. The specific designs of the MOX experiments are described in Appendix A.

\subsection{QUALIFICATION OF CRITICAL EXPERIMENTS}

The 34 critical experiments described in this report are recognized benchmark standard experiments performed specifically for calculational benchmarking purposes. Each experiment has been formally documented in reports issued by the organizations conducting each experiment. These reports were reviewed prior to publication and have subsequently been reviewed by a large number of benchmark analysts. The number of calculations performed at the time of the experiments and in benchmark calculations serve as a confirmation of the accuracy of the experimental measurements. 
Table 2. Critical experiments with $\mathrm{UO}_{2}$ and gadolinium

\begin{tabular}{lllclll}
\hline $\begin{array}{l}\text { Case } \\
\text { No. }\end{array}$ & $\begin{array}{l}\text { Case } \\
\text { designation }\end{array}$ & $\begin{array}{l}\text { Enrichment } \\
\left(\mathrm{wt} \%{ }^{25} \mathrm{U}\right)\end{array}$ & Description & $\begin{array}{l}\text { Lattice } \\
\text { pitch } \\
(\mathrm{cm})\end{array}$ & $\begin{array}{l}\text { Lattice } \\
\text { water/fuel } \\
\text { volume ratio }\end{array}$ & Ref. \\
\hline 20 & bnw1810b & $4.02,2.46$ & 12 Gd fuel rods in inner zone & 1.64 & 1.62 & 11 \\
21 & bnw1810c & $4.02,2.46$ & 16 Gd fuel rods in inner zone & 1.64 & 1.62 & 11 \\
\hline
\end{tabular}

Table 3. Critical experiments with MOX LWR fuel

\begin{tabular}{|c|c|c|c|c|c|c|}
\hline $\begin{array}{l}\text { Case } \\
\text { No. } \\
\end{array}$ & $\begin{array}{l}\text { Case } \\
\text { designation }\end{array}$ & $\begin{array}{l}\text { Enrichment } \\
\left(w t \%{ }^{233} \mathrm{U} /\right. \\
\left.w t \%{ }^{239} \mathrm{Pu}\right) \\
\end{array}$ & Description & $\begin{array}{l}\text { Lattice } \\
\text { pitch } \\
\text { (cm) } \\
\end{array}$ & $\begin{array}{l}\text { Lattice } \\
\text { water/fuel } \\
\text { volume ratio } \\
\end{array}$ & Ref. \\
\hline 22 & epri70un & $0.72 / 91.8$ & $0 \mathrm{ppm}$ soluble boron, $2 \mathrm{wt} \% \mathrm{PuO}_{2}$ & 1.78 & 1.20 & 12 \\
\hline 23 & epri70b & $0.72 / 91.8$ & $681 \mathrm{ppm}$ soluble boron, $2 \mathrm{wt} \% \mathrm{PuO}_{2}$ & 1.78 & 1.20 & 12 \\
\hline 24 & epri87un & $0.72 / 91.8$ & $0 \mathrm{ppm}$ soluble boron, $2 \mathrm{wt} \% \mathrm{PuO}_{2}$ & 2.21 & 1.53 & 12 \\
\hline 25 & epri87b & $0.72 / 91.8$ & $1090 \mathrm{ppm}$ soluble boron, $2 \mathrm{wt} \% \mathrm{PuO}_{2}$ & 2.21 & 1.53 & 12 \\
\hline 26 & epri99un & $0.72 / 91.8$ & 0 ppm soluble boron, $2 \mathrm{wt} \% \mathrm{PuO}_{2}$ & 2.51 & 3.64 & 12 \\
\hline 27 & epri99b & $0.72 / 91.8$ & $767 \mathrm{ppm}$ soluble boron, $2 \mathrm{wt} \% \mathrm{PuO}_{2}$ & 2.51 & 3.64 & 12 \\
\hline 28 & saxton 52 & $0.72 / 90.5$ & $\begin{array}{l}\text { Unborated, } 22 \times 23 \text { lattice, } 6.6 \text { wt \% } \\
\mathrm{PuO}_{2}\end{array}$ & 1.32 & 1.68 & 13 \\
\hline 29 & $\operatorname{saxton} 56$ & $0.72 / 90.5$ & $\begin{array}{l}\text { Unborated, } 19 \times 19 \text { lattice, } 6.6 \text { wt \% } \\
\mathrm{PuO}_{2}\end{array}$ & 1.42 & 2.17 & 13 \\
\hline 30 & saxton $56 \mathrm{~b}$ & $0.72 / 90.5$ & $\begin{array}{l}337 \mathrm{ppm} \text { boron, } 21 \times 21 \text { lattice, } 6.6 \mathrm{wt} \\
\% \mathrm{PuO}_{2}\end{array}$ & 1.42 & 2.17 & 13 \\
\hline 31 & $\operatorname{saxtn} 735$ & $0.72 / 90.5$ & $\begin{array}{l}\text { Unborated, } 13 \times 13 \text { lattice, } 6.6 \text { wt \% } \\
\mathrm{PuO}_{2}\end{array}$ & 1.87 & 4.70 & 13 \\
\hline 32 & $\operatorname{saxtn} 792$ & $0.72 / 90.5$ & $\begin{array}{l}\text { Unborated, } 12 \times 12 \text { lattice, } 6.6 \text { wt \% } \\
\mathrm{PuO}_{2}\end{array}$ & 2.01 & 5.67 & 13 \\
\hline 33 & $\operatorname{saxtn104}$ & $0.72 / 90.5$ & $\begin{array}{l}\text { Unborated, } 11 \times 11 \text { lattice, } 6.6 \mathrm{wt} \% \\
\mathrm{PuO}_{2}\end{array}$ & 2.64 & 10.75 & 13 \\
\hline 34 & pnl4976 & $\begin{array}{l}\mathrm{MOX}: \\
0.72 / 91.8 \\
\mathrm{UO}_{2}: \\
4.31 / 0.0\end{array}$ & $\begin{array}{l}\mathrm{MOX} \text { and } \mathrm{UO}_{2} \text { rods in uniform pattern, } \\
\text { triangular lattice, } 2 \mathrm{wt} \% \mathrm{PuO}_{2} \text { in } \mathrm{MOX} \\
\text { pins }\end{array}$ & 1.60 & 0.49 & 14 \\
\hline
\end{tabular}


Many of these experiments have been accepted for benchmarking purposes in numerous fresh-fuel storage and transportation package design and licensing applications. In addition, the use of a comprehensive set of experimental data from a number of independent facilities provides a high degree of confidence that potential inaccuracies, errors, or omissions in any experiment will be accounted for in the determination of calculational bias described later in this report. 


\section{CRITICALITY CALCULATIONS BASED ON FRESH FUEL EXPERIMENTS}

In order to demonstrate the applicability of the SCALE-4.2 system for the range of conditions spanned by the fresh fuel experiments described in the previous section, computational models have been developed based on each experimental configuration. In all the models, approximations were applied where appropriate. Polypropylene or acrylic-base plates and lattice plates were not modeled because their neutronic characteristics are similar to water. Likewise, other structural components such as control and safety rod guides, support angles and channels, and tanks were neglected because the material (e.g., aluminum) was virtually invisible to neutrons or the component was positioned near the periphery of the experiment and had no significant impact on the system $\mathrm{k}_{\text {eff. }}$. Chemical elements that appeared in materials in trace amounts were also considered negligible in the models. For reference, the SCALE-4.2 input files for these experiments are included in Appendix B.

The following subsection describes the sequences and modules of the SCALE-4.2 system used in the analysis of these computational models. This description is followed by a discussion of the results of calculations performed using these models, in terms of the three classes of experiments described in Sect. 2.

\subsection{CRITICALITY SEQUENCES OF THE SCALE-4 CODE SYSTEM}

SCALE is a well-established code system that has been widely used in AFR applications for criticality safety analyses via its CSAS analysis sequences. ${ }^{15}$ In this work, CSAS sequences CSASN, CSAS25, and CSAS2X are used in the criticality models. All of the sequences invoke a standardized procedure to provide appropriate cross sections for use in calculations. Each procedure begins with the SCALE Material Information Processor, ${ }^{16}$ which generates material number densities and related information, prepares geometry data for resonance self-shielding and flux-weighting cell calculations and creates data input files for the cross-section processing codes. The BONAMI ${ }^{17}$ and NITAWL- ${ }^{18}$ codes are then used to perform problem-specific (resonance-corrected) cross-section processing. BONAMI applies the Bondarenko method of resonance self-shielding for nuclides that have Bondarenko data included in the cross-section library and creates a formatted library for use by subsequent modules. (Note: The 27-group burnup library does not contain unresolved resonance data; hence BONAMI performs only cross-section formatting procedures with this library.) NITAWL-II performs Nordheim resonance self-shielding corrections for nuclides that have resonance parameters included with their cross-section data. The CSASN sequence terminates at this point; the cross-section library produced from this calculation can be used as is or combined with other crosssection libraries and used in a subsequent standalone criticality calculation. Criticality $\left(k_{e f f}\right)$ calculations are performed via three-dimensional (3-D) Monte Carlo calculations using KENO V.a. ${ }^{19}$ All KENO V.a calculations were performed with at least 600 neutrons per generation and a minimum of 240,000 histories. The CSAS25 sequence automatically invokes KENO V.a after resonance processing is completed. If necessary, the CSAS2X sequence is used in which the 1-D discreteordinates code XSDRNPM ${ }^{20}$ is invoked to perform cell-weighting of cross sections prior to the criticality calculation. Cross sections used in all calculations were obtained from the SCALE 27group burnup library, a hybrid library originally developed for depletion analyses. This cross-section library contains ENDF/B-IV (actinide) and ENDF/B-V (fission product) data for isotopes important 
in spent fuel from commercial reactor fuel designs. SCALE calculations described in this report were performed using SCALE-4.2 on an IBM RS/6000 workstation.

\subsection{RESULTS OF CRITICALITY CALCULATIONS USING SCALE-4}

The following subsections describe the results for SCALE-4 models based on each of the three sets of critical experiments discussed earlier. Each criticality model is identified by a name corresponding to the case designations given earlier in Tables 1 through 3 for the fresh fuel experiments.

\subsubsection{Criticality Calculations Based on LWR-Type $\mathrm{UO}_{2}$ Experiments}

Results of the criticality calculations for the $19 \mathrm{UO}_{2}$-only critical experiments are given in Table 4. In addition to the calculated values of effective multiplication factors and their associated standard deviations, this table includes the average energy group in which fission occurs, which can be used to assess the amount of neutron thermalization associated with a given configuration. Table 5 provides a listing of the energy boundaries, energy range, and average energy for each of the thermal $(23.05 \mathrm{eV})$ energy groups in the 27-group burnup library, so that one can determine the energy range represented by each average energy group (AEG) value. Note that the AEG is a simple spectrum indicator, as it characterizes the average energy group, and therefore the average neutron energy at which fission occurs. A smaller AEG value represents a higher energy system than a larger AEG (lower energy) value.

The calculational results for this set of criticals are within $1.4 \%$ of the known critical condition, with the nominal computed value of $k_{\text {eff }}$ ranging from 0.9861 to 1.0000 , and a mean value for $k_{\text {eff }}$ of $0.9941 \pm 0.0036$. These values indicate an average bias of roughly $-0.6 \%$ in the calculation of $\mathrm{k}_{\mathrm{eff}}$ over all $\mathrm{UO}_{2}$ cases. Statistical analyses of $\mathrm{k}_{\mathrm{eff}} \mathrm{vs}$ various independent variables [i.e., enrichment, moderator/ fuel ratios, AEG in which fission occurs, boron concentration, and reference number (see last column of Tables 1 through 3)] indicate a strong correlation between the AEG and the moderator/fuel ratio, and to a lesser extent between AEG and pitch. This correlation is not unexpected, since increased pitch results in an increased moderator/fuel ratio, which in turn would result in a better-moderated and therefore more thermal system. In addition, cases p392614a, p3926u4a, and p3602s4, which all utilized reflecting walls, trended toward a higher value of $k_{\text {eff }}$ than other cases with no reflection. No other significant correlations were noted.

In general, the 27-group burnup library shows a trend for increasing $\mathrm{k}_{\text {eff }}$ with increasing AEG. This trend is not observed here, probably due to the relatively small range of AEGs spanned by these experiments. As will be shown later, addition of more $\mathrm{UO}_{2}$-only criticals does illustrate this trend.

\subsubsection{Criticality Calculations Based on LWR-Type $\mathrm{UO}_{2}$ Experiments Containing Gadolinium}

The bnw1810 series of experiments used multiple fuel rod types in a single core. Because the SCALE CSAS25 sequence only allows cross-section processing for only one fuel rod cell type per problem, Dancoff factors and resonance data were calculated using CSASN and explicitly specified in the CSAS25 calculation for the two fuel mixtures that were not specified as the fuel 
Table 4. Criticality calculations for validation of $\mathrm{UO}_{2}$ in $\mathrm{LWR}$ fuel cask geometries

\begin{tabular}{|c|c|c|c|c|}
\hline $\begin{array}{l}\text { Case } \\
\text { No. }\end{array}$ & $\begin{array}{c}\text { Case } \\
\text { designation }\end{array}$ & $k_{\text {eff }}$ & $\pm \sigma$ & $\begin{array}{l}\text { AEG in which } \\
\text { fission occurs }\end{array}$ \\
\hline 1 & $\mathrm{ft} 214 \mathrm{r}$ & 0.9971 & 0.0016 & 21.66 \\
\hline 2 & $\mathrm{ft} 214 \mathrm{v} 3$ & 0.9924 & 0.0011 & 21.64 \\
\hline 3 & p2438x05 & 0.9912 & 0.0014 & 23.58 \\
\hline 4 & $\mathrm{p} 2438 \times 17$ & 0.9927 & 0.0010 & 23.55 \\
\hline 5 & p $2438 \times 24$ & 0.9924 & 0.0013 & 23.58 \\
\hline 6 & p $2438 \times 28$ & 0.9921 & 0.0014 & 23.56 \\
\hline 7 & p392614a & 1.0000 & 0.0015 & 21.96 \\
\hline 8 & p3926u4a & 0.9994 & 0.0014 & 21.31 \\
\hline 9 & p3602s4 & 0.9970 & 0.0016 & 21.93 \\
\hline 10 & $\mathrm{p} 4267 \mathrm{a}$ & 0.9952 & 0.0011 & 22.05 \\
\hline 11 & $\mathrm{p} 4267 \mathrm{~b}$ & 0.9991 & 0.0012 & 20.91 \\
\hline 12 & $\mathrm{p} 4267 \mathrm{c}$ & 0.9940 & 0.0011 & 21.15 \\
\hline 13 & p4267d & 0.9904 & 0.0013 & 19.98 \\
\hline 14 & baw1484a & 0.9912 & 0.0010 & 22.63 \\
\hline 15 & bnw1810a & 0.9953 & 0.0011 & 21.68 \\
\hline 16 & e196u6n & 0.9904 & 0.0014 & 22.21 \\
\hline 17 & e196u87c & 0.9946 & 0.0013 & 23.77 \\
\hline 18 & saxu56 & 0.9861 & 0.0016 & 21.90 \\
\hline 19 & saxu792 & 0.9972 & 0.0011 & 23.42 \\
\hline
\end{tabular}


Table 5. Thermal range energy structure for the SCALE-4 27-group burnup library ${ }^{a}$

\begin{tabular}{ccccc}
\hline $\begin{array}{c}\text { 27BURNUPLIB } \\
\text { thermal group No. }\end{array}$ & $\begin{array}{c}\text { Upper energy } \\
\text { boundary (eV) }\end{array}$ & $\begin{array}{c}\text { Lower energy } \\
\text { boundary (eV) }\end{array}$ & $\begin{array}{l}\text { Group average } \\
\text { energy (eV) }\end{array}$ & $\begin{array}{l}\text { Group energy } \\
\text { width (eV) }\end{array}$ \\
\hline 15 & 3.05 & 1.77 & 2.41 & 1.28 \\
16 & 1.77 & 1.30 & 1.54 & 1.64 \\
17 & 1.30 & 1.13 & 1.22 & 0.17 \\
18 & 1.13 & 1.00 & 1.07 & 0.13 \\
19 & 1.00 & 0.800 & 0.90 & 0.20 \\
20 & 0.800 & 0.400 & 0.600 & 0.400 \\
21 & 0.400 & 0.325 & 0.363 & 0.075 \\
22 & 0.325 & 0.225 & 0.275 & 0.100 \\
23 & 0.225 & 0.100 & 0.163 & 0.125 \\
24 & 0.100 & 0.0500 & 0.075 & 0.0500 \\
25 & 0.0500 & 0.0300 & 0.0400 & 0.0200 \\
26 & 0.0300 & 0.0100 & 0.0200 & 0.0200 \\
27 & 0.0100 & 0.0000100 & 0.00501 & 0.00999 \\
\hline
\end{tabular}

${ }^{a}$ See ref. 2.

mixture on the lattice cell description card. The $4.02 \mathrm{wt} \% \mathrm{UO}_{2}$ fuel in the inner zone was specified as the fuel mixture on the lattice cell card for each of these calculations.

The SCALE-4 results for the two gadolinium criticals are presented in Table 6. The first row of the table, in italics, contains the results from case bnw1810a for the purposes of comparison. This case was based on the same experimental configuration but contained no gadolinium. Results show that cases both with and without gadolinium are statistically consistent (i.e., grouped within $2 \sigma$ of

Table 6. Criticality calculations for $B \& W-1810$ gadolinium experiments

\begin{tabular}{llllc}
\hline $\begin{array}{c}\text { Case } \\
\text { No. }\end{array}$ & $\begin{array}{c}\text { Case } \\
\text { designation }\end{array}$ & $\mathrm{k}_{\text {off }}$ & \pm 0 & $\begin{array}{c}\text { Average energy group (AEG) } \\
\text { in which fission occurs }\end{array}$ \\
\hline $15^{a}$ & bnw1810a & 0.9953 & 0.0010 & 21.68 \\
20 & bnw1810b & 0.9919 & 0.0010 & 21.77 \\
21 & bnw1810c & 0.9949 & 0.0010 & 21.82 \\
\hline
\end{tabular}

$\mathrm{UO}_{2}$-only experiment, included for comparison purposes. 
their average). For cases 20 and 21 , the average value of $k_{\text {eff }}$ is $0.9934 \pm 0.0021$, which is consistent with the average result for the $19 \mathrm{UO}_{2}$-only cases. These calculations indicate that SCALE-4 can accurately predict the reactivity effect of gadolinium absorption in LWR fuel.

\subsubsection{Criticality Calculations Based on LWR-Type MOX Experiments}

Results of the criticality calculations for the 13 MOX critical experiments (cases 22-34) are given in Table 7, along with the results of similar configuration experiments (cases 16-19, in italics). Nominal $k_{\text {eff }}$ values for the 13 MOX experiments range from 0.9869 to 1.0077 and have a mean value of $1.0017 \pm 0.0059$. The EPRI MOX criticals have an average value of $k_{\text {eff }}$ of $1.0028 \pm 0.0058$, compared with $0.9925 \pm 0.0030$ for the corresponding $\mathrm{UO}_{2}$-only experiments. Similarly, the Saxton MOX criticals have an average value of $k_{\text {eff }}$ of $1.0031 \pm 0.0016$, compared with $0.9917 \pm 0.0078$ for the corresponding $\mathrm{UO}_{2}$-only experiments. Therefore, $\mathrm{k}_{\mathrm{eff}}$ values for the plutonium-bearing $\mathrm{MOX}$ experiments are approximately $1 \%$ greater than the results for $\mathrm{UO}_{2}$ cases.

Statistical analyses were performed for relationships between $\mathrm{k}_{\mathrm{eff}}$ and other independent parameters. As with the $\mathrm{UO}_{2} \mathrm{LWR}$ criticals, a positive correlation is seen between the AEG and the moderator/fuel ratio, and between AEG and pitch, reflecting the effect of enhanced moderation in the larger lattice spacings. In addition, a strong correlation is observed between the AEG and $k_{\text {effs }}$ as illustrated in Fig. 1; no such trend was observed in the $\mathrm{UO}_{2}$ critical experiments. Note that a bias observed for plutonium-bearing criticals is not limited to the SCALE 27-group burnup library. Similar trends have been identified in other work using other cross-section libraries; hence the bias appears to be inherent in current plutonium cross-section data. ${ }^{21,22}$

The calculated $\mathrm{k}_{\text {eff }}$ value for the simulated burnup experiment, case pnl4976, is nearly $1 \%$ lower than any other MOX case. This difference has two possible explanations: First, the water/fuel volume ratio (and hence the AEG) is much smaller than the other MOX experiments, which is consistent with the trend observed previously. Second, the alternating lattice of $\mathrm{PuO}_{2}-\mathrm{UO}_{2}$ and $\mathrm{UO}_{2}$ fuel rods was difficult to model in the SCALE cross-section resonance processing code NITAWL-II, and may have introduced errors in resonance-region cross sections. To compound this error, this critical was undermoderated and therefore operated in the upper thermal energies, which gave increased weight to resonance energies.

Because NITAWL-II does not consider 2-D effects in the processing of the overlapping resonances of $\mathrm{Pu}$ and $\mathrm{U}$, three separate cases were required to generate the problem-dependent cross sections:

1. A CSASN case modeled an infinite array of the MOX rods at the experimental triangular pitch of $1.598 \mathrm{~cm}$. The cross sections for the natural $\mathrm{UO}_{2}$ and the Zircaloy clad of the MOX rods were obtained from this case. 
Table 7. Criticality calculations for validation of LWR-type MOX experiments

\begin{tabular}{|c|c|c|c|c|}
\hline $\begin{array}{l}\text { Case } \\
\text { No. }\end{array}$ & $\begin{array}{c}\text { Case } \\
\text { designation }\end{array}$ & $k_{\text {eff }}$ & $\pm \sigma$ & $\begin{array}{l}\text { AEG in which } \\
\text { fission occurs }\end{array}$ \\
\hline 16 & $e 196 u 6 n^{a}$ & 0.9904 & 0.0014 & 22.21 \\
\hline 17 & $e 196 u 87 c^{a}$ & 0.9946 & 0.0013 & 23.77 \\
\hline 22 & epri70un & 0.9956 & 0.0013 & 21.10 \\
\hline 23 & epri70b & 0.9955 & 0.0014 & 20.66 \\
\hline 24 & epri87un & 1.0037 & 0.0010 & 22.62 \\
\hline 25 & epri87b & 1.0071 & 0.0012 & 22.07 \\
\hline 26 & epri99un & 1.0077 & 0.0015 & 23.09 \\
\hline 27 & epri99b & 1.0072 & 0.0009 & 22.67 \\
\hline 18 & $\operatorname{scos} u 56^{a}$ & 0.9861 & 0.0016 & 21.90 \\
\hline 19 & saxu $792^{a}$ & 0.9972 & 0.0011 & 23.42 \\
\hline 28 & saxton 52 & 1.0015 & 0.0012 & 20.34 \\
\hline 29 & saxton56 & 1.0014 & 0.0018 & 21.04 \\
\hline 30 & saxton $56 \mathrm{~b}$ & 1.0027 & 0.0015 & 20.79 \\
\hline 31 & $\operatorname{saxtn} 735$ & 1.0031 & 0.0017 & 22.56 \\
\hline 32 & $\operatorname{saxtn} 792$ & 1.0040 & 0.0018 & 22.85 \\
\hline 33 & saxtn104 & 1.0057 & 0.0022 & 23.46 \\
\hline 34 & pnl4976 & 0.9869 & 0.0012 & 18.21 \\
\hline
\end{tabular}

${ }^{0} \mathrm{UO}_{2}$-only experiment, included for comparison purposes. 


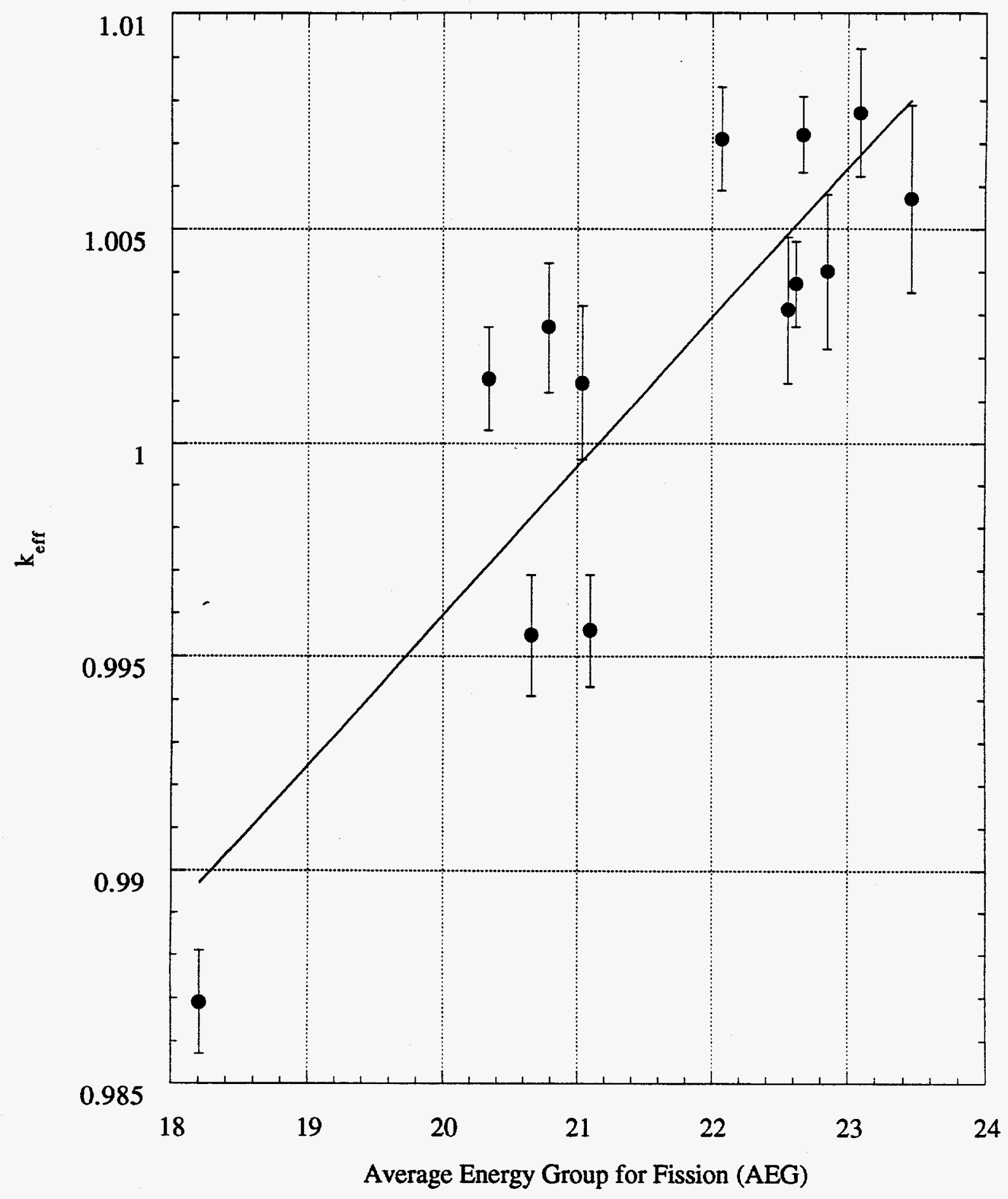

Fig. 1. $k_{\text {eff }}$ vs AEG for MOX critical experiments. 
2. The cross sections for the $\mathrm{PuO}_{2}$ in the MOX rods were obtained from a second case; this case did not consider the presence of the surrounding $\mathrm{UO}_{2}$ rods because a resonance material in the moderator cannot be treated by NITAWL-II (NITAWL-II assumes a 1/E flux in the moderator region). In this case, an infinite array of the $\mathrm{PuO}_{2-}$ $\mathrm{UO}_{2}$ rods was modeled with a triangular pitch of $2.768 \mathrm{~cm}$, the spacing between the MOX rods. The density of the moderator was multiplied by 0.379 , the volume fraction of water in the moderator region of this larger lattice cell. The remainder of the moderator region was occupied by the $\mathrm{UO}_{2}$ rods and was omitted because of the limitations in NITAWL-II discussed earlier.

3. The third CSASN case modeled an infinite lattice of the $4.31 \mathrm{wt} \% \mathrm{UO}_{2}$ rods at the experimental pitch of $1.598 \mathrm{~cm}$. The cross sections for the $4.31 \mathrm{wt} \% \mathrm{UO}_{2}$ fuel and clad and all the nonfuel materials were taken from this case.

The results of the MOX calculations demonstrate that SCALE-4 does accurately calculate the effective multiplication factor for MOX LWR-type fuel. However, a bias in plutonium cross sections results in an overprediction of $\mathrm{k}_{\text {eff }}$ for more thermal (lower energy or higher AEG value) systems, and can underpredict $k_{\text {eff }}$ for higher energy (smaller AEG) configurations.

\subsubsection{Combined Results for all Critical Experiments}

Results for each of the three sets of experiments are summarized in Table 8. This summary shows the range of calculated results for each set of experiments and highlights differences and similarities between the sets. Specifically, the $\mathrm{UO}_{2}+\mathrm{Gd}$ criticals are consistent with the $\mathrm{UO}_{2}$-only criticals, while the MOX criticals show a more broad variation in $k_{\text {eff }}$ over the range of AEGs. These differences and similarities are illustrated in Fig. 2, which shows the calculated value of $k_{\text {eff }}$ as a function of AEG for all experiments. Error bars represent the stochastic standard deviation calculated by KENO V.a for each value of $k_{\text {eff }}$. Each set of experiments is illustrated by a different marker so as to distinguish between the results of each set. A linear regression fit is drawn for each set of data, with the exception of the two $\mathrm{UO}_{2}+\mathrm{Gd}$ cases, which do not present sufficient data points for a meaningful fit. It is worth noting, however, that the two $\mathrm{UO}_{2}+\mathrm{Gd}$ results are consistent with the general trend of the $\mathrm{UO}_{2}$-only results, suggesting little if any bias due to the presence of gadolinium. The fit for the $\mathrm{UO}_{2}$ criticals shows a downward trend with increasing AEG; however, this trend is probably due to the wide spread in the data and a relatively narrow range of AEGs, rather than a correlation with AEG. As discussed earlier, statistical analyses showed essentially no correlation between $\mathrm{k}_{\text {eff }}$ and AEG for the $\mathrm{UO}_{2}$ fresh fuel criticals for these 34 experiments (although this correlation is observed for an increased number of experiments with a more broad range of AEGs). The solid line in the figure represents the regression fit to all data points, to illustrate the general trend for all fresh fuel critical results; the bias in this fit is due to the plutonium bias in the MOX criticals. These results indicate that the SCALE criticality sequences used in this work together with the hybrid 27BURNUPLIB cross-section library provide an acceptable estimate of criticality for $\mathrm{UO}_{2}$-only, $\mathrm{UO}_{2}+\mathrm{Gd}$, and $\mathrm{UO}_{2}+\mathrm{PuO}_{2}$ systems in LWR-type cask geometry configurations. 
Table 8. Summary for results for sets of criticality calculations

\begin{tabular}{lllcc}
\hline Experiment subset & Mean $\mathrm{k}_{\text {eff }}$ & $\sigma\left(\overline{\mathrm{k}_{\text {eff }}}\right)$ & Maximum & Minimum \\
\hline $\mathrm{UO}_{2}$ only & 0.9941 & 0.0036 & 1.0000 & 0.9861 \\
$\mathrm{UO}_{2}+\mathrm{Gd}$ fuel & 0.9934 & 0.0021 & 0.9949 & 0.9919 \\
$\mathrm{UO}_{2}+\mathrm{PuO}_{2}$ & 1.0017 & 0.0059 & 1.0077 & 0.9869 \\
All critical experiments & 0.9970 & 0.0058 & 1.0077 & 0.9861 \\
\hline
\end{tabular}

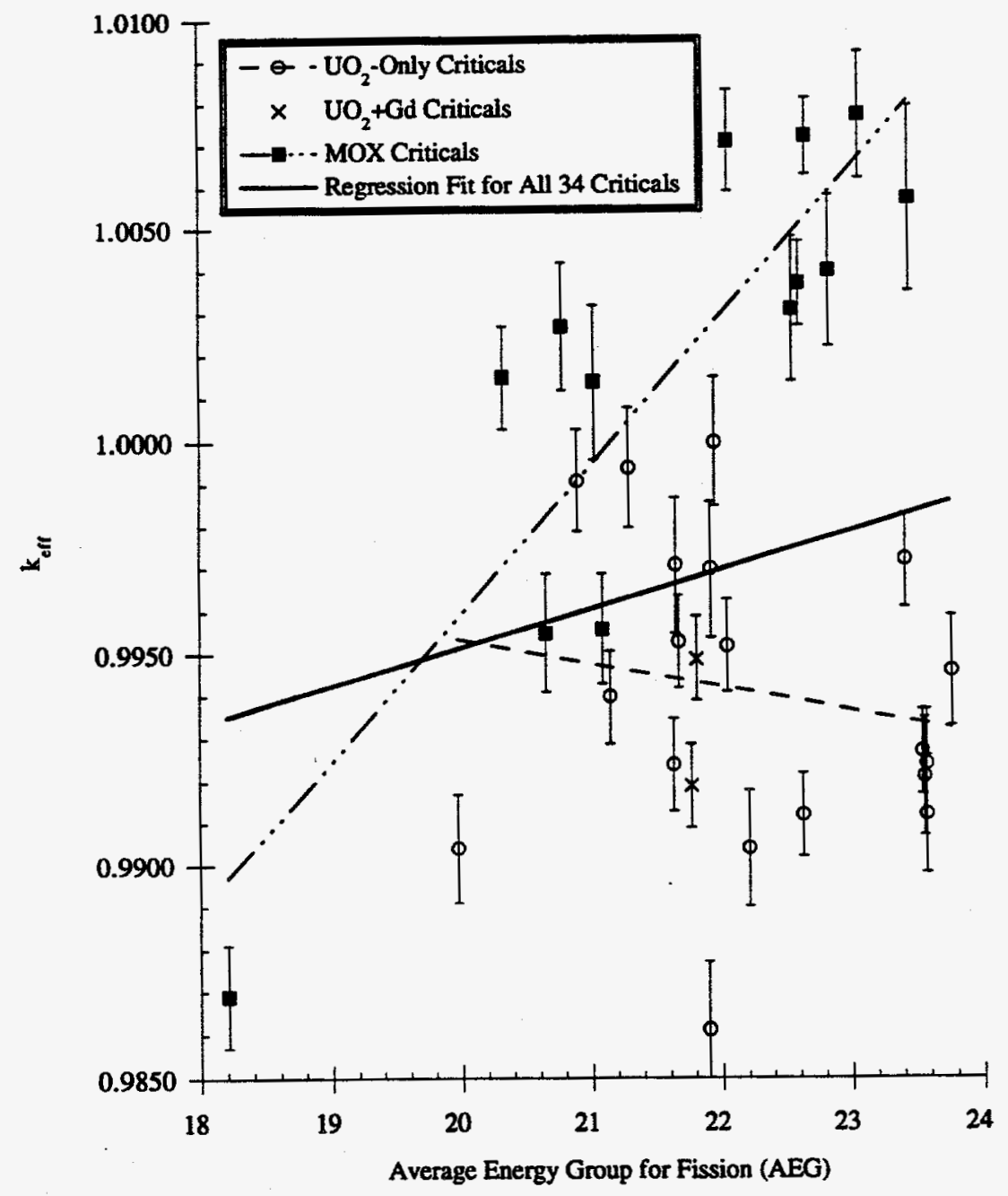

Fig. 2. $k_{\text {eff }}$ vS AEG for combined fresh fuel criticals. 


\section{BIAS AND UNCERTAINTY FROM CRITICAL EXPERIMENTS}

For a subcritical configuration, it is desirable to possess a confidence that the calculation of $k_{\text {eff }}$ for a system guarantees sufficient subcriticality; this is especially true in the absence of direct experimental measurements. This ensurance of subcriticality requires the determination of an acceptable margin between a calculated value of $k_{\text {eff }}$ and a maximum acceptable subcritical value, based on known biases and uncertainties associated with the codes and data used to calculate $k_{\text {eff }}$. This section describes three methods for the determination of an upper safety limit (USL) from the bias and uncertainty terms associated with the calculation of criticality. ANSI standards serve as a basis for these approaches and are used in defining uncertainty and bias terms as they relate to criticality experiments and calculations. Descriptions are provided for each of three methods, followed by examples that demonstrate the use of these methods based on calculated results given in the previous section of this report. These examples are used not only to illustrate the application of the various methods, but also to demonstrate the magnitude of the margin associated with each approach when applied to SCALE-4 analyses. USLs are provided for various combinations of results from the 34 fresh fuel criticals; results from a number of additional similar critical experiments are also included in the USL determinations to demonstrate the effect of additional data on each USL method.

\subsection{ESTABLISHMENT OF AN UPPER SAFETY LIMIT FOR SUBCRITICALTTY}

The recommended approach for establishing subcriticality based on the numerical calculation of the neutron multiplication factor is prescribed in Sect. 5.1 of ANSI/ANS-8.17. ${ }^{23}$ The following paragraphs describe the recommended approach as set forth in the Standard, with interpretations in terms of application for burnup credit methodologies.

The criteria to establish subcriticality requires that the calculated multiplication factor for a subcritical system, $k_{z}$ be less than or equal to an established maximum allowable multiplication factor based on benchmark calculations and uncertainty terms, that is,

$$
\mathrm{k}_{\mathrm{z}} \leq \mathrm{k}_{\mathrm{c}}-\Delta \mathrm{k}_{\mathrm{i}}-\Delta \mathrm{k}_{\mathrm{c}}-\Delta \mathrm{k}_{\mathrm{m}},
$$

where

$k_{c}=$ mean value of $k_{\text {eff }}$ resulting from the calculation of benchmark criticality experiments using a specific calculational method and data,

$\Delta \mathrm{k}_{\mathbf{s}}=$ uncertainty in the value of $\mathrm{k}_{\mathrm{v}}$,

$\Delta \mathrm{k}_{\mathrm{c}}=$ uncertainty in the value of $\mathrm{k}_{\mathrm{c}}$,

$\Delta \mathrm{k}_{\mathrm{m}}=$ additional margin to ensure subcriticality.

Often, $\Delta k_{m}$ is assigned an administrative limit of 0.05 ; however, a value for this margin can also be estimated statistically.

If the calculational bias $(\beta)$ is defined as $\beta=1-k_{c}$, then the uncertainty in the bias is identical to the uncertainty in $k_{c}$ (i.e., $\Delta k_{c}=\Delta \beta$ ). Thus the subcriticality condition may be rewritten as:

$$
\mathrm{k}_{\mathrm{g}}+\Delta \mathrm{k}_{\mathrm{s}}+\Delta \mathrm{k}_{\mathrm{m}}+\beta+\Delta \beta \leq 1 .
$$


The value $k_{c}$ and thus the bias $\beta$ are not necessarily a constant over the range of a parameter of interest. If trends exist which cause the benchmark values of $k_{\text {ff }}$ to vary with one or more parameters (e.g., enrichment, burnup, etc.), then $\beta$ can be determined from a best fit for the calculated $k_{\text {eff }}$ values as a function of each of the parameters upon which it is dependent.

The set of critical experiments used as benchmarks in the computation of $\beta$ should be representative of the composition, configuration, and nuclear characteristics of the system for which $\mathrm{k}_{\mathrm{z}}$ is to be determined. However, ANSI/ANS-8.1 allows that the range of applicability may be extended beyond the range of conditions represented by the benchmark experiments by extrapolating the trends established for the bias. When the extrapolation is large relative to the range of data ("large" is undefined by the ANSI standard), the calculational method applied should be supplemented by other methods in order to better estimate the extrapolated bias.

In addition to the bias $\beta$ determined based on a given computational method, data, and a suite of benchmarks, there is an uncertainty, $\Delta \beta$. This uncertainty may include uncertainties in the critical experiments, statistical and/or convergence uncertainties in the benchmark calculations, uncertainties due to extrapolation beyond the range of experimental data, and uncertainties due to limitations or weaknesses in the geometrical or nuclear modeling of the critical experiments. Similarly, for a given subcritical system, there is an uncertainty $\Delta \mathrm{k}_{\mathrm{z}}$ associated with the calculated $\mathrm{k}_{\text {eff }}$ value for the system, $\mathbf{k}_{\mathbf{r}}$. This uncertainty includes statistical/convergence and modeling uncertainties, as well as uncertainties in the material, fabrication, and exposure history (not addressed by fresh fuel criticals) of the system components.

Based on the criteria for subcriticality set forth in ANSI/ANS-8.17 (ref. 23) and described above, a USL may be determined based on the analysis of a number of critical systems. The USL is determined such that there is a high degree of confidence that a calculated result is subcritical; a system is considered acceptably subcritical if a calculated $k_{\text {eff }}$ plus calculational uncertainties lies at or below this limit (i.e., $k_{r}+\Delta k_{z} \leq$ USL). Thus based on Eq. (2), the USL is the magnitude of the sum of the biases, uncertainties, and administrative and/or statistical margins applied to a set of critical benchmarks, such that with a high degree of confidence,

$$
\mathrm{USL}=1-\Delta \mathrm{k}_{\mathrm{m}}-\beta-\Delta \beta
$$

Based on a given set of critical experiments, USLs are determined as a function of key system parameters, such as the AEG causing fission (AEG), fuel enrichment, or fuel/moderator ratio. Because both $\beta$ and $\Delta \beta$ can vary with a given parameter, the USL is typically expressed as a function of the parameter, within an appropriate range of applicability derived from the parameter bounds.

Three approaches that can be used in calculating a USL are discussed in the following subsection. This discussion is followed by a comparison of USLs calculated by each method for various sets of critical calculations. 


\subsection{METHODS FOR DETERMINATION OF AN UPPER SAFETY LIMIT}

In this subsection, three different methods for determining the USL of a subcritical configuration are presented and discussed. USLs calculated based on each of these methods and selected sets of critical calculations are presented in Sect. 4.3.

\subsubsection{USL Method 1: Confidence Band with Administrative Margin}

References 24 and 25 discuss a statistical approach in which a USL is determined as the lower bound of a set of two margins applied to a linear fit to a set of experimental data. This approach is illustrated in Fig. 3. In this figure, the upper line (solid) represents a linear regression fit to a set of calculations based on critical experiments, $k_{c}(x)$. As indicated in the figure, $\beta(x)$ is given as $1-k_{c}$. The middle line (long dashes) represents the lower confidence band for a single additional calculation. The width of this band is determined statistically based on the existing data and a specified level of confidence; the greater the standard deviation in the data or the larger the confidence desired, the larger the band width will be. This confidence band, $W$, accounts for uncertainties in the experiments, the calculational approach, and in calculational data (e.g., cross sections), and is therefore a statistical basis for $\Delta \beta$, the uncertainty in the value of $\beta$. W is defined for a confidence level of $\left(1-\gamma_{1}\right)$ using the relationship

$$
W=\max \left\{\left.w(x)\right|_{x_{\min } x_{\max }}\right\}
$$

where

$$
w(x)=t_{\gamma_{1}} s_{p}\left[1+\frac{1}{n}+\frac{(x-\bar{x})^{2}}{\sum_{i=1, n}\left(x_{i}-\bar{x}\right)^{2}}\right]^{\frac{1}{2}}
$$

and

$$
\begin{aligned}
& n=\text { the number of critical calculations used in establishing } k_{c}(x), \\
& t_{\gamma_{1}}=\text { the Student-t distribution statistic for } \gamma_{1} \text { and } n-2 \text { degrees of freedom, } \\
& \bar{x} \quad=\text { the mean value of parameter } x \text { in the set of calculations, } \\
& \mathbf{s}_{\mathrm{p}}=\text { the pooled standard deviation for the set of criticality calculations. }
\end{aligned}
$$

The function $w(\mathrm{x})$ is a curvilinear function. For simplicity, it is desirable to obtain a constant width margin. Hence, for conservatism, the confidence band width $\mathrm{W}$ is defined as the maximum of $\left(w\left(x_{\min }\right), w\left(x_{\max }\right)\right)$, where $x_{\min }$ and $x_{\max }$ are the minimum and maximum values of the independent parameter $\mathrm{x}$, respectively. Typically, $\mathrm{W}$ is determined at a $95 \%$ confidence level. 


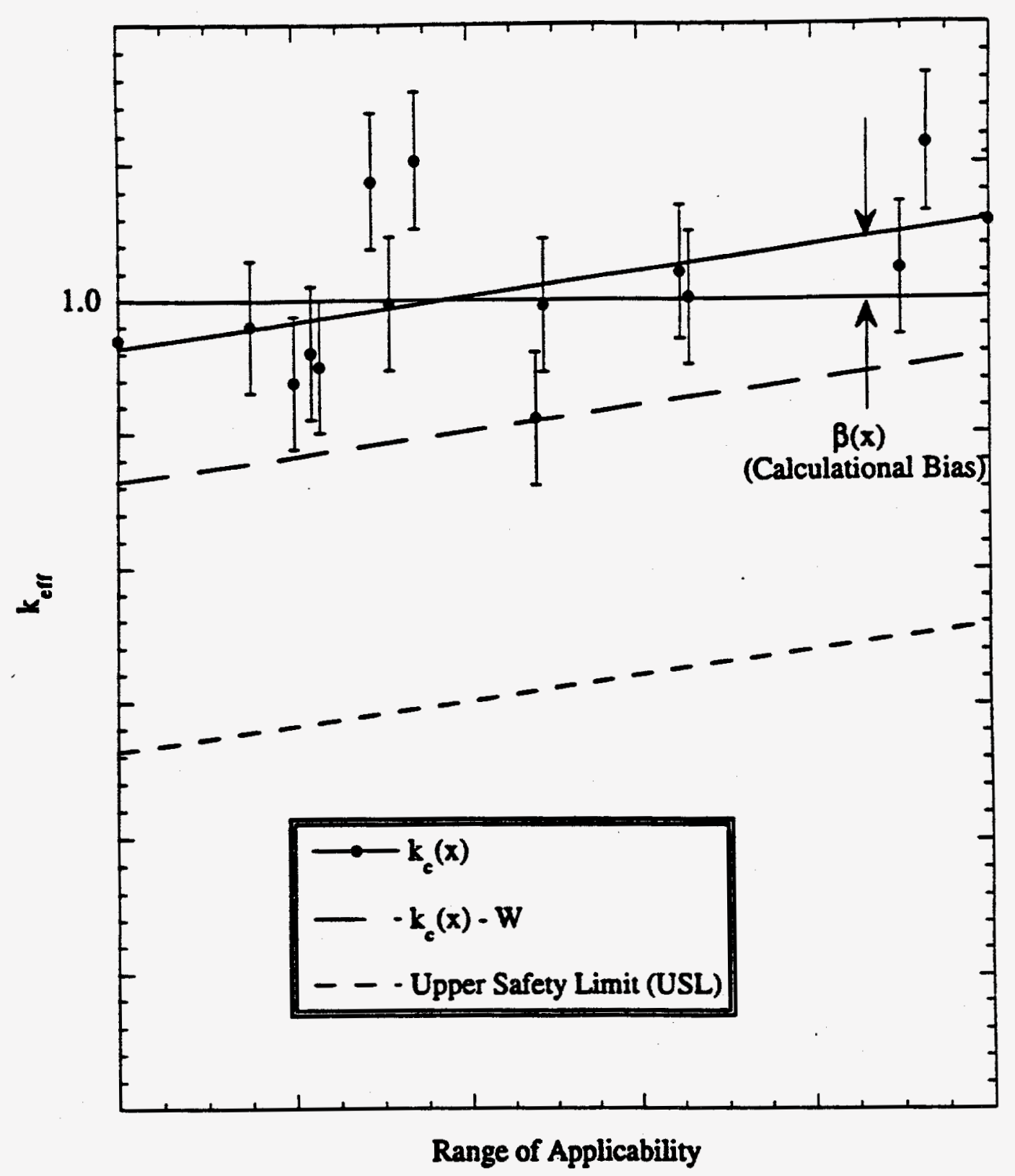

Fig. 3. Confidence band and safety margin applied to a set of criticality calculations. 
The pooled standard deviation is obtained from the pooled variance $\left(s_{p}=\sqrt{s_{p}^{2}}\right)$, where $s_{p}^{2}$ is given as

$$
s_{p}^{2}=s_{k(x)}^{2}+s_{w}^{2},
$$

where $s_{k(x)}^{2}$ is the variance (or mean-square error) of the regression fit, and is given by:

$$
s_{k(x)}^{2}=\frac{1}{(n-2)}\left[\sum_{i=1, n}\left(k_{i}-\bar{k}\right)^{2}-\frac{\left\{\sum_{i=1, n}\left(x_{i}-\bar{x}\right)\left(k_{i}-\bar{k}\right)\right\}^{2}}{\sum_{i=1, n}\left(x_{i}-\bar{x}\right)^{2}}\right],
$$

and $s_{w}^{2}$ is the within-variance of the data:

$$
s_{w}^{2}=\frac{1}{n} \sum_{i=1, n} \sigma_{i}^{2},
$$

where $\sigma_{i}$ is the standard deviation associated with $k_{i}$ for a Monte Carlo calculation. For deterministic codes that do not have a standard deviation associated with a computed value of $k$, the standard deviation is zero.

The bottom line (short dashes) in the figure represents the USL, based on an additional margin of subcriticality. This safety margin provides further assurance of subcriticality, and represents the quantity $\Delta \mathrm{k}_{\mathrm{m}}$ defined earlier. In USL Method $1, \Delta \mathrm{k}_{\mathrm{m}}$ is given an arbitrary administrative value; as mentioned earlier, a value of 0.05 is typically assigned. Using these formulations, the USL Method 1 is defined as:

$$
\mathrm{USL}_{1}(\mathrm{x})=1.0-\Delta \mathrm{k}_{\mathrm{m}}-\mathrm{W}-\beta(\mathrm{x}) \text {. }
$$

\subsubsection{USL Method 2: Single-Sided Uniform Width Closed Interval Approach}

In this method, sometimes also referred to as a lower tolerance band (LTB) approach, statistical techniques with a more rigorous basi ${ }^{2427}$ are applied in order to determine a combined lower confidence band plus safety margin. In other words, in the administrative margin approach of Sect. 4.2.1, $\Delta \beta$ and $\Delta \mathrm{k}_{\mathrm{m}}$ are determined independently, while in the LTB method, a combined statistical lower bound is determined in terms of the product $C_{\alpha / p} \cdot s_{p}$, where $s_{p}$ is the pooled variance 
of $\mathrm{k}_{\mathrm{c}}$ described earlier, and $\mathrm{C}_{\alpha / \mathrm{p}}$ is a statistically determined multiplier. Thus the USL Method 2 is given as

$$
\mathrm{USL}_{2}(x)=1.0-\left(C_{\alpha / p} \cdot S_{p}\right)-\beta(x)
$$

The term $\mathrm{C}_{\alpha / \mathrm{p}} \cdot \mathrm{s}_{\mathrm{p}}$ provides a band for which there is a probability $\rho$ that with an $\alpha$ confidence an additional calculation of $\mathrm{k}_{\mathrm{eff}}$ for a critical system will lie within the band. For example, a $\mathrm{C}_{95 / 99.5}$ multiplier produces a USL for which there is a $95 \%$ confidence that 995 out of 1000 future calculations of critical systems will yield a value of $k_{\text {eff }}$ above the USL. Calculation of the multiplier $\mathrm{C}_{\alpha / p}$ is somewhat complicated and beyond the scope of this report; reference 28 provides a more detailed discussion of this statistical technique and the determination of $C_{\alpha / p}$. In essence, this approach provides a more statistically based safety margin, $\Delta \mathrm{k}_{\mathrm{m}}$, which can be determined as the difference $\left(C_{\alpha / p} \cdot s_{p}\right)-W$. In criticality safety applications, such a statistically determined approach generally yields a margin of much less than 0.05 , which serves to illustrate the conservatism that may be associated with an administrative margin. Often in the use of Method 1 in the determination of a USL, it is advantageous to apply Method 2 in tandem to demonstrate that the $5 \%$ margin is conservative relative to a purely statistical basis; this concurrent application of Method 2 is especially important when a limited number of data points are used in determination of $k_{c}(x)$, or when the calculated values have a large standard deviation.

\subsubsection{USL Method 3: Worse Case with Administrative Margin}

In this approach, the bias and associated uncertainty are combined, and are estimated by assuming that $\beta(x)+\Delta \beta=1-k_{\min }=\beta_{\max }$, where $k_{\min }$ is the minimum value of $k_{\text {eff }}$ is taken from a set of critical calculations. In other words, the confidence band associated with a set of calculations is assumed to be bounded by the "worst case" calculation (i.e., the case that results in the lowest calculated value of $k_{\text {eff }}$ ). For additional conservatism, $\beta_{\max }$ is required to be equal to or greater than zero. Extra safety margin is allowed by including an arbitrary administrative margin, as applied in Method 1, such that the USL Method 3 is defined as

$$
\mathrm{USL}_{3}(\mathrm{x})=1-\Delta \mathrm{k}_{\mathrm{m}}-\beta_{\max }
$$

Although this approach provides a straightforward and simple method for setting a USL, it has no mathematical basis from which one may derive a level of confidence. Thus there is no basis for confidence that future calculations will be bounded by the assumed bias. If the minimum value of $k_{\text {eff }}$ results from a single poor measurement or poor calculational model, a USL based on this value is likely to be overly conservative; on the other hand, however, if the low point is one of several lowlying points, the statistical probability of a single future calculation being lower is increased, and the approach may be nonconservative relative to other methods. Furthermore, because such an approach does not treat the effect of variation in calculational bias with other parameters (e.g., AEG), it may be conservative only in the range of this parameter near the worst-case calculation, and nonconservative in other ranges. In addition, the lower bound cannot be increased by any number of additional calculations, but can be reduced if a lower value of $\mathrm{k}_{\text {eff }}$ is found in subsequent calculations. 


\subsubsection{Application of Upper Safety Limit Methods}

For a given parameter, any of these three methods is generally considered applicable over the range of that parameter in the set of calculations used to determine the USL. However, as discussed earlier, ANSI/ANS-8.1 allows the range of applicability to be extended beyond this range by extrapolating the trends established for the bias. No precise guidelines are specified for the limits of extrapolation. Thus engineering judgment and additional uncertainty should be applied when extrapolating more than a few percent beyond the range of the parameter bounds.

Based on the fresh fuel criticals described earlier in this report, it is possible to determine a set of USLs based on any of the various parameters studied (e.g., AEG, pitch, moderator/fuel ratio, etc.). However, for these results the AEG is the only parameter for which a correlation with $k_{\text {eff }}$ is noted. The following section demonstrates the calculation of the USL as a function of AEG, using each of the three methods described above. These examples will demonstrate the conservatism associated with each method and may be used for guidance in applying each of the methods for any appropriate set of benchmarks, any given criticality code or code system, or for a different crosssection library.

\subsection{CALCULATION OF UPPER SAFETY LIMITS}

In this section, each of the three methods described in the previous section is applied to KENO V.a results for the set of 34 fresh fuel critical calculations. In addition, results based on subsets of these data and supersets including the results of additional critical calculations are analyzed in order to demonstrate the effect of changes in data on each of the methods. The USLs are determined as a function of the AEG as calculated by KENO V.a. These calculations are presented to serve as an example of the use of these methods and to provide a means for an analyst to confirm his interpretation of the approach.

Tables 4, 6, and 7 of Sect. 3 provide the results calculated for each of the fresh fuel criticals. In addition to the calculated value of $k_{\text {eff }}$ and its stochastic uncertainty for each case, these tables provide the average energy group for fission, as computed by KENO V.a using the SCALE 27BURNUPLIB cross-section library. Using the approaches described earlier, the various terms required to determine the USL by each method are computed. Table 9 summarizes the intermediate results and the three USL values computed for the combined criticals.

Figure 4 shows the $k_{\text {eff }}$ results for all 34 fresh fuel criticals, together with lines representing the regression fit $\left[k_{c}(x)\right]$, the $95 \%$ confidence band for a single calculation $\left[k_{c}(x)-W\right]$, the USL based on Method 1 [USL ${ }_{1}=k_{c}(x)-W-0.05$ ], the USL based on Method 2 [USL $L_{2}=k_{c}(x)-$ $\left.\left(C_{95 p 9.5} \mathrm{~s}_{\mathrm{p}}\right)\right]$, and the USL based on Method $3\left[\mathrm{USL}_{3}=1.0-0.05-\beta_{\max }\right]$. Note the substantial conservatism of Method 1 relative to Method 2. The deviation of the individual values with respect to $k_{c}(x)$ is not especially large, indicating that the SCALE-4 results have a relatively small uncertainty in the bias, which gives a reasonably high lower tolerance band (USL $)_{2}$. This results in a value for $\Delta \mathrm{k}_{\mathrm{m}}$ of roughly 0.016 , compared with the assumed administrative margin of 0.05 used in the determination of $\mathrm{USL}_{1}$ based on a $95 \% / 99.5 \%$ confidence level in the calculation of $\mathrm{C}_{\alpha / \beta}$; at a $99 \% / 99.9 \%$ confidence level (calculation not shown), $C \cdot \mathrm{s}_{\mathrm{p}}$ is 0.03613 , which translates to $\Delta \mathrm{k}_{\mathrm{m}} \sim$ 0.025 , or about half of the assumed 0.05 margin. Note also that for this set of critical calculations 
Table 9. Parameters used in USL calculation for fresh fuel criticals

\begin{tabular}{|c|c|}
\hline Parameter & Value \\
\hline $\mathbf{n}$ & 34 \\
\hline Linear regression fit, $\mathrm{k}$ (AEG) & $0.9769+\left(\right.$ AEG $\left.\times 9.1152 \times 10^{-4}\right)$ \\
\hline Bias $[\beta(\mathrm{AEG})]$ & $0.0231-\left(\right.$ AEG $\left.\times 9.1152 \times 10^{-4}\right)$ \\
\hline Minimum AEG $\left(x_{\min }\right)$ & 18.21 \\
\hline Maximum AEG $\left(\mathrm{x}_{\max }\right)$ & 23.77 \\
\hline Bias at minimum AEG $\left[\beta\left(\mathrm{x}_{\min }\right)\right]$ & 0.006501 \\
\hline Bias at maximum AEG $\left[\beta\left(\mathrm{x}_{\operatorname{mux}}\right)\right]$ & 0.001433 \\
\hline Minimum $\mathrm{k}_{\text {eff }}$ & 0.9861 \\
\hline$\beta_{\max }$ (bias at minimum $k_{\text {eff }}$ ) & 0.0139 \\
\hline Average AEG $(\overline{\mathbf{x}})$ & 21.99 \\
\hline Average $k_{\text {eff }}(\overline{\mathbf{k}})$ & 0.9970 \\
\hline Variance of fit, $s_{k(x)}^{2}$ & $3.4152 \times 10^{-5}$ \\
\hline Within-data variance, $s_{w}^{2}$ & $1.8477 \times 10^{-6}$ \\
\hline Pooled variance, $s_{p}^{2}$ & $3.6000 \times 10^{-5}$ \\
\hline Pooled standard deviation, $s_{p}$ & $6.0000 \times 10^{-3}$ \\
\hline Student-t @ (n-2) deg. of freedom, $\gamma_{1}$ & 1.694 \\
\hline $\mathrm{W}_{95 x}\left[\max\right.$ of $\left.w\left(x_{\min }\right), w\left(x_{\max }\right)\right]$ & 0.01167 \\
\hline $\mathrm{C}_{95 / 199.5}$ & 4.554 \\
\hline $\mathrm{C}_{95 / 199.5} \cdot \mathrm{S}_{\mathrm{p}}$ & 0.02733 \\
\hline$C \cdot s_{p}-W$ & 0.01566 \\
\hline $\begin{array}{l}\mathrm{USL}_{1} \text { (confidence band with administrative } \\
\text { margin) }\end{array}$ & $0.9152+\left(\right.$ AEG $\left.\times 9.1152 \times 10^{-4}\right)$ \\
\hline $\begin{array}{l}\text { USL }_{2} \text { (single-sided uniform width closed } \\
\text { interval) }\end{array}$ & $0.9496+\left(\right.$ AEG $\left.\times 9.1152 \times 10^{-4}\right)$ \\
\hline USL $_{3}$ (worst case with administrative margin) & 0.9361 \\
\hline
\end{tabular}




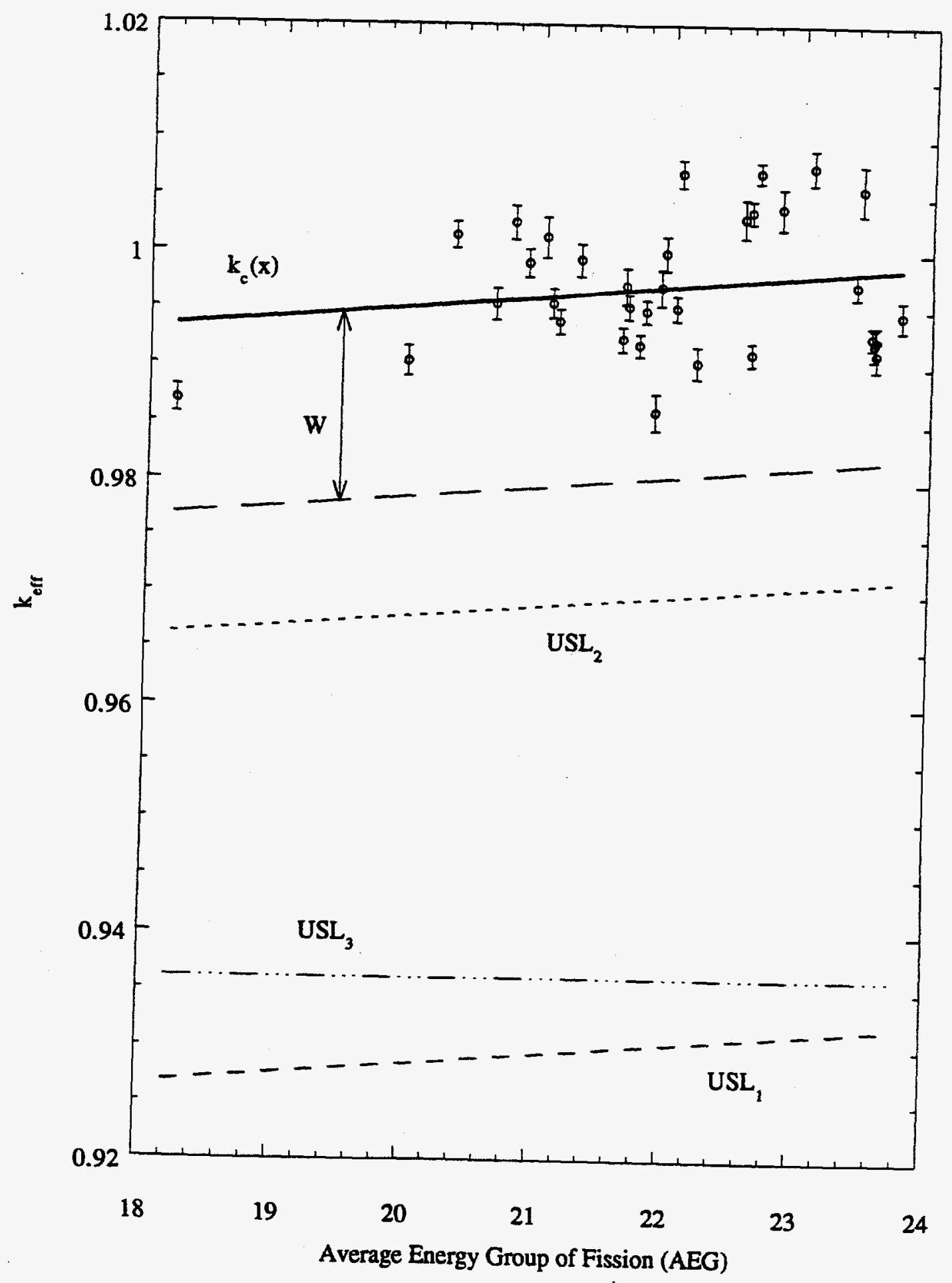

Fig. 4. USLs computed by Methods 1, 2, and 3 for the 34 fresh fuel criticals. 
USL $_{1}$ is more conservative than USL $_{3}$ over the full range of the validation. This is because there were multiple low-lying values of $k_{\text {eff }}$ resulting in a larger confidence band for a single future calculation than the assumed bounding maximum bias (i.e., $W>\beta_{\max }$ ).

Although these results demonstrate the relative differences between the three methods for determining a USL, the relative behaviors of Methods 1 and 2 are statistical in nature and are coupled to the distribution of the critical experiments themselves. Thus it would be of interest to determine the relative USLs for various different sets of calculations. To facilitate this comparison, subsets of the combined 34 cases can be studied to assess the effects of smaller groups of criticals. Additionally, results for other relevant critical experiments can be included to demonstrate the effect of larger collections. Specifically, a collection of seven critical calculations based on the burned fuel analyses of reactor restart criticals, described in detail in ref. 29 , can be used to expand the data base to include phenomena similar to spent fuel conditions. The set can be further augmented by a set of 59 recently developed fresh fuel critical models developed in addition to the 34 cases included in this report for a more broad-based validation effort, ${ }^{21,30} 39$ of these additional criticals are $\mathrm{UO}_{2}$-only cases. Results $\left(k_{e, j} \sigma\right.$, and AEG) for the members of each of these two sets of additional criticality calculations are included in Appendix $\mathrm{C}$; the specific details of each configuration are available in the original references. ${ }^{20,30}$ Table 10 summarizes the results of USL calculations for each combination of criticality calculations.

Table 10 gives the linear equations for the USL as a function of AEG for Methods 1 and 2; since Method 3 does not account for trends in the bias, this USL is assumed constant over the full range of AEGs. Because the y-intercept term of this equation can be misleading, especially when the slope is large, USLs are also reported as evaluated at a value of 22, near the mean AEG value for 34 fresh fuel criticals. In general, USL ${ }_{1}$ and USL $_{2}$ tend to increase with an increasing number of criticals, due to better statistical bases, as illustrated in Fig. 5 . The cases with $19 \mathrm{UO}_{2}$-only and $13 \mathrm{MOX}$-only experiments are exceptions to this trend; this is probably caused by a reduced deviation in $\mathrm{k}_{\mathrm{eff}}$ values due to a similarity in physical configurations and material composition. With the exception of the MOX-only set, the Method 3 USL does not change for any combination; in fact, the USL computed by Method 3 can only remain constant or decrease with added numbers of critical calculations.

In order to apply a USL for burnup credit in a spent fuel cask design, it is necessary to determine that the AEG expected for such a design lies in the range of roughly 18.0 to 24.0 when computed using KENO V.a and the 27BURNUPLIB cross-section library. The exact AEG will be strongly tied to the specifics of the cask design and loading. However, an estimate of the approximate AEG which might be observed in such a design can be determined from existing models. Related and ongoing work studying the sensitivity of $k_{\text {eff }}$ to various parameters in a conceptual cask design $^{31}$ for a range of enrichments, burnup, and cooling times gives a range of computed AEGs from 21.7 to 22.2. This range is well within the range of AEGs spanned by the 34 critical experiments detailed in this document and is located in the range of the highest density of critical calculation results. Hence in terms of AEG, a USL determined over the range of fresh fuel appears to be appropriate for spent fuel cask analyses.

Note that the combined set of $58 \mathrm{UO}_{2}$-only criticals shows a positive trend with AEG. As was noted earlier, this correlation with AEG is a known bias in the SCALE ENDF/B-IV 27-group libraries. This trend is not observed for the $19 \mathrm{UO}_{2}$-only criticals subset of the 34 critical experiments described in this report. This lack of a trend is probably due to the limited number of experiments and the fact that these experiments do not extend into the upper thermal energy regions where the bias is most pronounced. 
Table 10. Summary of USL calculations for various sets of data

\begin{tabular}{|c|c|c|c|c|c|c|}
\hline Description & $\begin{array}{l}\text { No. of } \\
\text { exp. }\end{array}$ & $\mathbf{W}$ & $\beta_{\text {mx }}$ & $\begin{array}{c}\mathrm{USL}_{1} \\
\left.\text { (USL }{ }_{1} @ \mathrm{AEG}=22\right)\end{array}$ & $\begin{array}{c}\mathrm{USL}_{2} \\
(\mathrm{USL} \\
\end{array}$ & $\begin{array}{c}\mathrm{USL}_{3} \\
\left.\text { (USL }_{3} @ \mathrm{AEG}=22\right)\end{array}$ \\
\hline \multirow[t]{2}{*}{$\begin{array}{l}\mathrm{UO}_{2} \text {-only cases } \\
\text { (from Table 4) }\end{array}$} & 19 & 0.00774 & 0.0139 & $\begin{array}{l}0.9487-\text { AEG } x \\
5.5429 \times 10^{-4}\end{array}$ & $\begin{array}{l}0.9867-\text { AEG } \\
5.5429 \times 10^{-4}\end{array}$ & 0.9361 \\
\hline & & & & $(0.9365)$ & $(0.9745)$ & $(0.9361)$ \\
\hline \multirow[t]{2}{*}{$\begin{array}{l}\text { MOX-only cases } \\
\text { (from Table 6) }\end{array}$} & 13 & 0.00764 & 0.0131 & $\begin{array}{l}0.8685+\text { AEG } \times \\
3.4872 \times 10^{-3}\end{array}$ & $\begin{array}{l}0.9056+\text { AEG } x \\
3.4872 \times 10^{-3}\end{array}$ & 0.9369 \\
\hline & & & & $(0.9452)$ & $(0.9823)$ & $(0.9369)$ \\
\hline \multirow[t]{2}{*}{$\begin{array}{l}\mathrm{UO}_{2}+\mathrm{MOX} \\
\text { (Table 4 + } \\
\text { Table 6) }\end{array}$} & 32 & 0.01192 & 0.0139 & $\begin{array}{l}0.9159+\text { AEGX } \\
8.8254 \times 10^{-1}\end{array}$ & $\begin{array}{l}0.9497+\text { AEG } x \\
8.8254 \times 10^{-4}\end{array}$ & 0.9361 \\
\hline & & & & $(0.9353)$ & $(0.9691)$ & $(0.9361)$ \\
\hline \multirow[t]{2}{*}{$\begin{array}{l}\mathrm{UO}_{2}+\mathrm{MOX}+ \\
\text { Gd (Tables 4-6) }\end{array}$} & 34 & 0.01167 & 0.0139 & $\begin{array}{l}0.9152+\text { AEG } x \\
9.1152 \times 10^{-4}\end{array}$ & $\begin{array}{l}0.9486+\text { AEGx } \\
9.1152 \times 10^{-4}\end{array}$ & 0.9361 \\
\hline & & & & $(0.9353)$ & $(0.9697)$ & $(0.9361)$ \\
\hline \multirow[t]{2}{*}{$\begin{array}{l}\text { Original } 34+7 \\
\text { reactor criticals }\end{array}$} & 41 & 0.01201 & 0.0139 & $\begin{array}{l}0.9405-\text { AEG } x \\
1.9729 \times 10^{-4}\end{array}$ & $\begin{array}{l}0.9750-\mathrm{AEG} \times \\
1.9729 \times 10^{-4}\end{array}$ & 0.9361 \\
\hline & & & & $(0.9362)$ & $(0.9707)$ & $(0.0961)$ \\
\hline \multirow[t]{2}{*}{$\begin{array}{l}\text { Original } 34+59 \\
\text { additional fresh } \\
\text { fuel criticals }\end{array}$} & 93 & 0.01267 & 0.0139 & $\begin{array}{l}0.9257+\text { AEG } \times \\
4.3915 \times 10^{-4}\end{array}$ & $\begin{array}{l}0.9619+\text { AEGX } \\
4.3915 \times 10^{-4}\end{array}$ & 0.9361 \\
\hline & & & & $(0.9354)$ & $(0.9716)$ & $(0.0961)$ \\
\hline \multirow{2}{*}{$\begin{array}{l}\text { Original } 34+59 \\
\text { additional + } 7 \\
\text { reactor criticals }\end{array}$} & 100 & 0.01261 & 0.0139 & $\begin{array}{l}0.9342+\text { AEG } x \\
7.0783 \times 10^{-5}\end{array}$ & $\begin{array}{l}0.9706+\text { AEG } x \\
7.0783 \times 10^{-5}\end{array}$ & 0.9361 \\
\hline & & & & $(0.9358)$ & $(0.9721)$ & $(0.0961)$ \\
\hline $\begin{array}{l}19 \mathrm{UO}_{2} \text {-only } \\
\text { cases }+39 \\
\text { additional } \mathrm{UO}_{2}- \\
\text { only cases }\end{array}$ & 58 & 0.00857 & 0.0139 & $\begin{array}{l}0.92130+\text { AEG } \times \\
6.7077 \times 10^{-4} \\
(0.9361)\end{array}$ & $\begin{array}{l}0.96095+\text { AEG } \times \\
6.7077 \times 10^{-4} \\
(0.9757)\end{array}$ & $(0.9361)$ \\
\hline
\end{tabular}




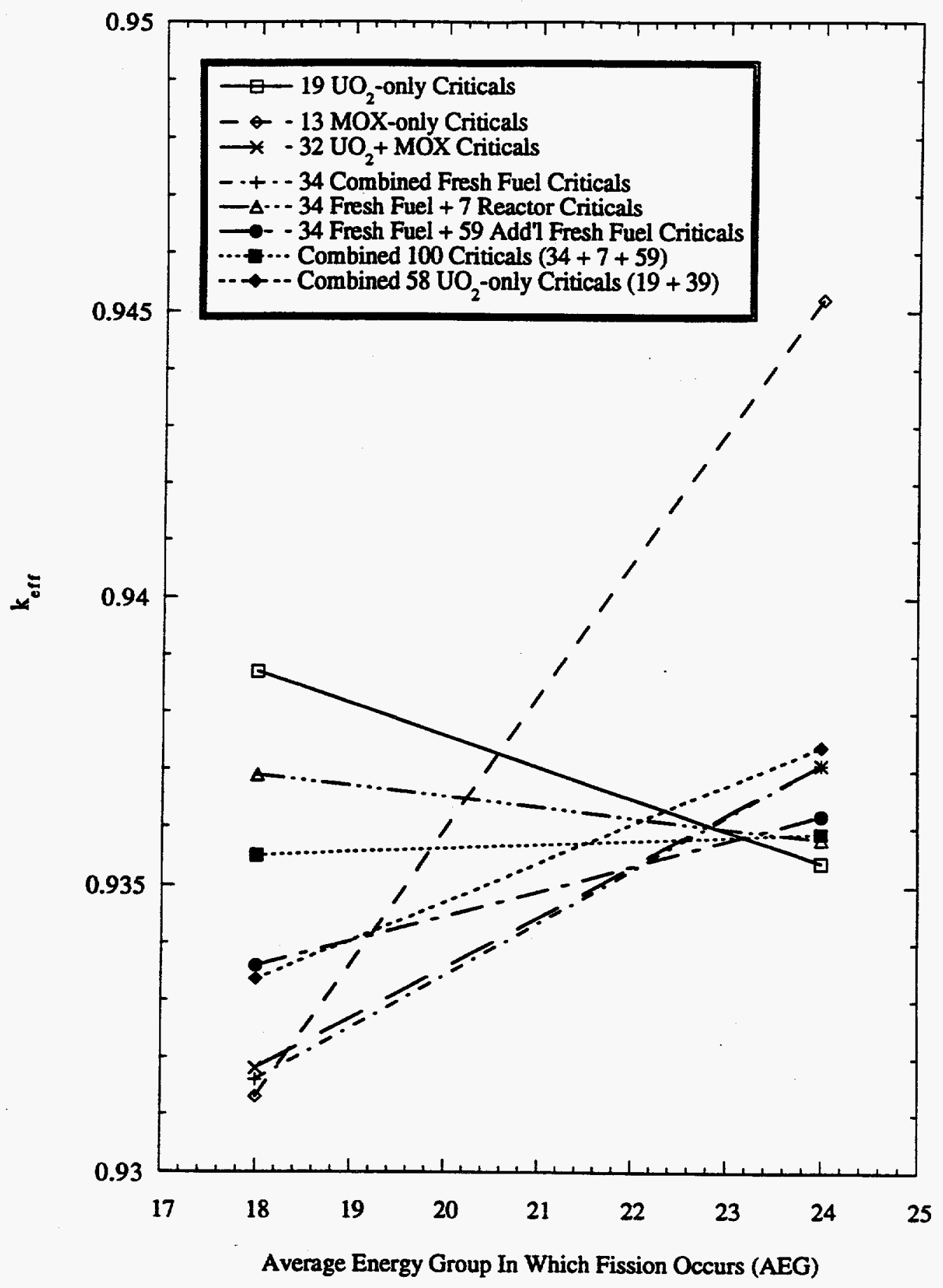

Fig. 5. Method 1 USL as a function of combinations of critical calculations. 


\section{CONCLUSIONS}

Any methodology used in the safety evaluation of a spent fuel cask must be validated in accordance with the ANSI/ANS-8.1 Standard. Current methodologies applied in spent fuel transportation and storage applications are based on the assumption that fuel is in its most reactive state (i.e., unburned). Hence such approaches, while overly conservative, are relatively easy to validate. Because of the complex physical processes involved in the production, depletion, and decay of isotopes during one or more fuel cycles, burnup credit methods require substantially more effort to validate. Burnup credit methods that take credit for fission-product poisoning will require additional effort in order to validate the effect of fission products on bias and uncertainty terms; however, the criticals described here are appropriate for burnup credit methods which take credit only for reactivity effects due to actinide depletion and activation.

Fresh fuel experiments may be applied as a portion of the validation process for criticality methods for burnup credit applications. Included in this report were fresh fuel critical experiments having geometric, material, and nuclear characteristics similar to PWR spent fuel cask environments. These problems included $19 \mathrm{UO}_{2}$ critical experiments with geometries related to various aspects of fuel loading in transportation and storage casks. In addition, there were two experiments that included gadolinium in the fuel, and $13 \mathrm{MOX}$ critical experiments. Criticality calculations based on these experiments demonstrate the ability of the SCALE-4 methodology developed at ORNL to predict a value of $k_{\text {eff }}$ very close to the known value of 1.0 (within $1.4 \%$ ) for the fresh fuel criticals. The calculated $k_{\text {eff }}$ values of the fresh fuel critical experiments ranged from 0.9861 to 1.0077 .

Three approaches were presented for the determination of a USL that will ensure an adequate margin of subcriticality for a given code system, data, and a set of critical calculations. Based on the results of criticality calculations performed for the above critical experiments using the SCALE-4 code and the SCALE 27-group burnup library (27BURNUPLIB), the calculation of USLs was demonstrated for three methods. Results indicate that the first method, referred to as the "confidence band with administrative margin" method, or simply Method 1 , generally gives a generous margin for uncertainty over the more statistical rigor of Method 2, and is more reasonable and often more conservative than that of Method 3.

Further work to expand the data base of critical experiments is desirable. Fresh fuel criticals are valuable in assessing the effect of geometry on calculational methods; many such experiments have been performed based on cask-like configurations. However, these experiments lack many of the isotopes present in spent fuel (i.e., fission products and some actinides) and cannot represent operating history effects Thus experiments using spent fuel or simulated spent fuel, with axially varying burnup, are desirable to provide added confidence in the capability of computer codes to represent and predict the behavior of such systems under design basis conditions.

The 34 criticals described in this report were originally selected as generally representative of LWR configurations, and as such were not selected to characterize or to represent any specific configuration. Additional fresh fuel criticals may be required to validate methods for a specific spent fuel design. Nevertheless, the results presented in this paper indicate that fresh fuel critical experiments with characteristics applicable to spent fuel transportation and storage casks can be accurately modeled with current analysis methods such as those provided in SCALE-4. 


\section{REFERENCES}

1. American National Standard for Nuclear Criticality Safety in Operations with Fissionable Materials Outside Reactors, ANSI/ANS-8.1-1983. (Reaffirmed November 1988)

2. SCALE: A Modular Code System for Performing Standardized Computer Analyses for Licensing Evaluation, NUREG/CR-0200, Rev. 4 (ORNL/NUREG/CSD-2/R4), Vols. I, II, and III (February 1995). Available from Radiation Shielding Information Center as CCC-545.

3. M. C. Brady and T. L. Sanders, "A Validated Methodology for Evaluating Burnup Credit in Spent Fuel Casks," Proc. International Conference on Nuclear Criticality Safety, Christ Church, Oxford, United Kingdom, September 9-13, 1991.

4. S. M. Bowman et al., "Validation of SCALE-4 for LWR Fuel in Transportation and Storage Cask Conditions," Trans. Am. Nucl. Soc. 62, 338-340 (1990).

5. S. R. Bierman, Criticality Experiments With Neutron Flux Traps Containing Voids, PNL7167, Battelle Pacific Northwest Laboratory, 1990.

6. S. R. Bierman et al., Critical Separation Between Subcritical Clusters of $2.35 \mathrm{Wi} \%$ wU Enriched UO, Rods in Water with Fixed Neutron Poisons, PNL-2438, Battelle Pacific Northwest Laboratory, 1977.

7. S. R. Bierman et al., Criticality Experiments with Subcritical Clusters of $2.35 \mathrm{Wt} \%$ and 4.31 Wt\% 20 Un Eniched UO, Rods in Water with Uranium or Lead Reflecting Walls, PNL-3926, Battelle Pacific Northwest Laboratory, 1981.

8. S. R. Bierman and E. D. Clayton, Criticality Experiments with Subcritical Clusters of 2.35 wt $\%$ and 4.31 wt $\%$ w Enriched UO, Rods in Water with Steel Reflecting Walls, PNL3602, Battelle Pacific Northwest Laboratory, 1981.

9. B. M. Durst et al., Critical Experiments with 4.31 wt $\%$ wU Enriched UO, Rods in Highly Borated Water Lattices, PNL-4267, Battelle Pacific Northwest Laboratory, 1982.

10. M. N. Baldwin et al., Critical Experiments Supporting Close Proximity Water Storage of Power Reactor Fuel, BAW-1484-7, Babcock and Wilcox Company, 1979.

11. L. W. Newman et al., Urania Gadolinia: Nuclear Model Development and Critical Experiment Benchmark, BAW-1810, Babcock and Wilcox Company, 1984.

12. R. I. Smith and G. J. Konzek, Clean Critical Experiment Benchmarks for Plutonium Recycle in LWRs, EPRI NP-196, Vols. I and II, Electric Power Research Institute, 1976 and 1978. 
13. E. G. Taylor et al., Saxton Plutonium Program Critical Experiments for the Saxton Partial Plutonium Core, WCAP-3385-54, Westinghouse Electric Corp., Atomic Power Division, 1965.

14. S. R. Bierman et al., Criticality Experiments with Low Enriched UO2 Rods in Water Containing Dissolved Gadolinium, PNL-4976, Battelle Pacific Northwest Laboratory, February 1984.

15. N. F. Landers and L. M. Petrie, "CSAS4: An Enhanced Criticality Safety Analysis Module with Search Options," Sect. C4 of SCALE: A Modular Code System for Performing Standardized Computer Analyses for Licensing Evaluation, NUREG/CR-0200, Rev. 4 (ORNL/NUREG/CSD-2/R4), Vols. I, II, and III (February 1995). Available from Radiation Shielding Information Center as CCC-545.

16. N. F. Landers, L. M. Petrie, and J. A. Bucholz, "The Material Information Processor for SCALE," Sect. M7 of SCALE: A Modular Code System for Performing Standardized Computer Analyses for Licensing Evaluation, NUREG/CR-0200, Rev. 4 (ORNL/NUREG/CSD-2/R4), Vols. I II, and III (February 1995). Available from Radiation Shielding Information Center as CCC-545.

17. N. M. Greene, "BONAMI-S: Resonance Self-Shielding by the Bondarenko Method," Sect. F1 of SCALE: A Modular Code System for Performing Standardized Computer Analyses for Licensing Evaluation, NUREG/CR-0200, Rev. 4 (ORNL/NUREG/CSD-2/R4), Vols. I, II, and III (February 1995). Available from Radiation Shielding Information Center as CCC545.

18. N. M. Greene, L. M. Petrie, and R. M. Westfall, "NITAWL-II: SCALE System Module for Performing Resonance Shielding and Working Library Production," Sect. F2 of SCALE: $A$ Modular Code System for Performing Standardized Computer Analyses for Licensing Evaluation, NUREG/CR-0200, Rev. 4 (ORNL/NUREG/CSD-2/R4), Vols. I, II, and III (February 1995). Available from Radiation Shielding Information Center as CCC-545.

19. L. M. Petrie and N. F. Landers, "KENO V.a: An Improved Monte Carlo Criticality Program with Supergrouping," Sect. F11 of SCALE: A Modular Code System for Performing Standardized Computer Analyses for Licensing Evaluation, NUREG/CR-0200, Rev. 4 (ORNL/NUREG/CSD-2/R4), Vols. I II, and III (February 1995). Available from Radiation Shielding Information Center as CCC-545.

20. N. M. Greene and L. M. Petrie, "XSDRNPM-S: A One-Dimensional Discrete-Ordinates Code for Transport Analysis," Sect. F3 of SCALE: A Modular Code System for Performing Standardized Computer Analyses for Licensing Evaluation, NUREG/CR-0200, Rev. 4 (ORNL/NUREG/CSD-2/R4), Vols. I, II, and III (February 1995). Available from Radiation Shielding Information Center as CCC-545. 
21. M. D. DeHart and S. M. Bowman, Validation of the SCALE Broad Structure 44-Group ENDF/B-V Crass-Section Library for Use in Criticality Safety Analyses, NUREG/CR-6102 (ORNL/TM-12460), U.S. Nuclear Regulatory Commission, September 1994.

22. R. J. Brissenden, "Increasing the Physical Realism of the MONK Criticality Code," in Proc. of the Topical Meeting on Physics and Methods in Criticality Safety, September 19-23, 1993, Nashville, Tenn., 1994.

23. American National Standard for Nuclear Criticality Safety Criteria for the Handling, Storage, and Transportation of LWR Fuel Outside Reactors, ANSI/ANS-8.17-1984. (Reaffirmed August 1989).

24. H. R. Dyer, W. C. Jordan, and V. R. Cain, "A Technique for Code Validation for Criticality Safety Calculations," Trans. Am. Nucl. Soc. 63, 238 (June 1991).

25. M. E. Easter, Validation of KENO V.a and Two Cross-Section Libraries for Criticality Calculations of Low-Enriched Uranium Systems, ORNL/CSD/TM-223, Martin Marietta Energy Systems, Inc., Oak Ridge Natl. Lab., July 1985.

26. D. C. Bowden and F. A . Graybill, "Confidence Bands of Uniform and Proportional Width for Linear Models," Am. Stat. Assoc. J. 61, 182 (March 1966).

27. N. L. Johnson, Ed., “Query,” Technometrics, 10207 (February 1968).

28. V. R Cain, A Computer Code to Perform Analyses of Criticality Validation Results, Y/DD574, Martin Marietta Energy Systems, Inc., Oak Ridge Y-12 Plant, September 1992.

29. M. D. DeHart et al., SCALE-4 Analysis of Pressurized Water Reactor Critical Configurations, ORNL/TM-12294, Volumes 1-5, Martin Marietta Energy Systems, Inc., Oak Ridge Natl. Lab., 1995.

30. S. M. Bowman et al., "Validation of SCALE-4 for Burnup Credit Applications," Nucl. Tech. 110, 53 (April 1995).

31. M. D. DeHart, Sensitivity and Parametric Evaluations of Significant Aspects of Burmup Credit for PWR Spent Fuel Packages, ORNL/TM-12973, Martin Marietta Energy Systems, Inc., Oak Ridge Natl. Lab. (in press). 


\section{APPENDIX A}

\section{PHYSICAL DESCRIPTION OF CRITICAL EXPERIMENTS}

The following sections provide descriptions of the physical layout and material specifications provided in refs. 5 through 14 for the critical experiments included in this report. These descriptions were used as a basis for the KENO V.a models described in Appendix B. Experiment numbers (1 through 34) and designations (e.g., ft214r) correspond to those assigned in Tables 1 through 3 of the main body of the report.

\section{FLUX TRAP EXPERIMENTS (CASES 1 AND 2)}

The first set of experiments ${ }^{5}$ listed in Table 1, designated as ft214r and $\mathrm{ft}^{214 \mathrm{v} 3}$, consisted of four fuel assemblies of 4.31 weight percent (wt \%) $\mathrm{UO}_{2}$ rods in a $1.891-\mathrm{cm}$-square lattice pitch, arranged in a $2 \times 2$ array. Details of the fuel rod design are given in Fig. A.1. The assemblies were separated by a $3.73-\mathrm{cm}$-wide neutron flux trap created by $0.673-\mathrm{cm}$-thick Boral ${ }^{\mathrm{Tm}}$ plates. The flux trap plates are described in Table A.1. Voids were created in the flux trap region of the second experiment by inserting three 0.63 -cm-thick aluminum plates. This step resulted in voiding of $51 \%$ and decreased the critical size of the experiment by approximately $9.5 \%$. These experiments test the capability of the methodology to model neutron flux traps effectively.

In the first experiment, ft214r, three of the fuel assemblies were $16 \times 16$ arrays of fuel rods, and the fourth fuel assembly was a $15 \times 15$ fuel rod array with seven additional fuel rods in the 16th row (Fig. A.2). The experimenter's advice in ref. 5 is to treat the seven additional rods estimated to achieve criticality as a full row of partial fuel-water cells. However, calculations have been performed with SCALE-4 that demonstrated that explicit representation of the additional fuel rods needed to achieve criticality yields virtually identical results. Experiment ft214v3 had three fuel assemblies that were $14 \times 15$ fuel rod arrays and one assembly consisting of a $15 \times 15$ fuel rod array (Fig. A.3). The additional seven rods estimated to achieve criticality should be added in a fifteenth row to one of the $14 \times 15$ fuel assemblies. The axial view for both flux trap experiments is illustrated in Fig. A.4.

Table A.1. Description of neutron flux trap plates in experiments ft214r and $\mathrm{ft214v3}$

\begin{tabular}{lc}
\hline \multicolumn{1}{c}{ Element } & wt \% \\
\hline $\mathrm{Al}$ & 62.54 \\
$\mathrm{~B}$ & 29.22 \\
$\mathrm{C}$ & 8.16 \\
$\mathrm{O}$ & 0.06 \\
$\mathrm{Fe}$ & 0.02 \\
Core density, $\mathrm{g} / \mathrm{cm}^{3}$ & 2.64 \\
Core thickness, $\mathrm{cm}^{3}$ & 0.470 \\
Length, cm & 96 \\
Width, cm & 45 \\
\hline
\end{tabular}

Source: ref. 5. 


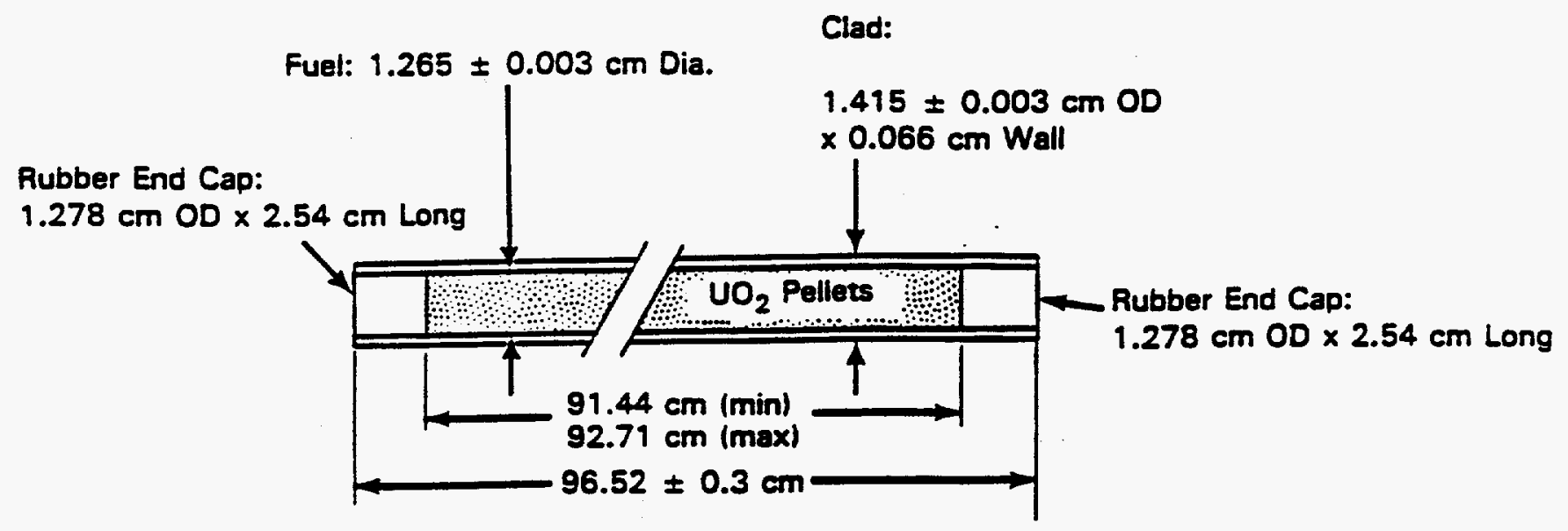

Cladding: 6061 Aluminum Tubing

Loading

$$
\begin{aligned}
& \text { Enrichment }-4.306 \pm 0.013 \text { w\%\% }{ }^{225} \mathrm{U} \\
& \text { Oxide Density }-10.40 \pm 0.06 \mathrm{~g} / \mathrm{cm}^{3} \\
& U O_{2}-1203.38 \pm 4.12 \mathrm{~g} / \mathrm{Rod} \\
& U-1059.64 \pm 4.80 \mathrm{~g} / \mathrm{Rod}
\end{aligned}
$$

Uranium Composition:

$$
\begin{aligned}
& { }^{224} U-0.022 \pm 0.002 w \% \\
& { }^{225} U-4.306 \pm 0.013 w \% \\
& { }^{236} U-0.022 \pm 0.002 w \% \\
& { }^{238} U-95.650 \pm 0.017 w 1 \%
\end{aligned}
$$

End Cap:

$$
\begin{array}{ll}
C-58 \pm 1 w t \% & 5-1.7 \pm 0.2 w t \% \\
H-6.5 \pm 0.3 w t \% & 0-22.1 w t \% \text { (Balence) } \\
\text { Ca-11.4 } \pm 1.8 w t \% & \text { Si-0.3 } \pm 0.1 \text { wt\% }
\end{array}
$$

Notes:

1. Error limits are one standard deviation

2. End Cap Density is $1.321 \mathrm{~g} / \mathrm{cm}^{3}$

Fig. A.1. Description of 4.31 wt $\%{ }^{233} \mathrm{U}$-enriched $\mathrm{UO}_{2}$ fuel rods used in experiments ft214r. 

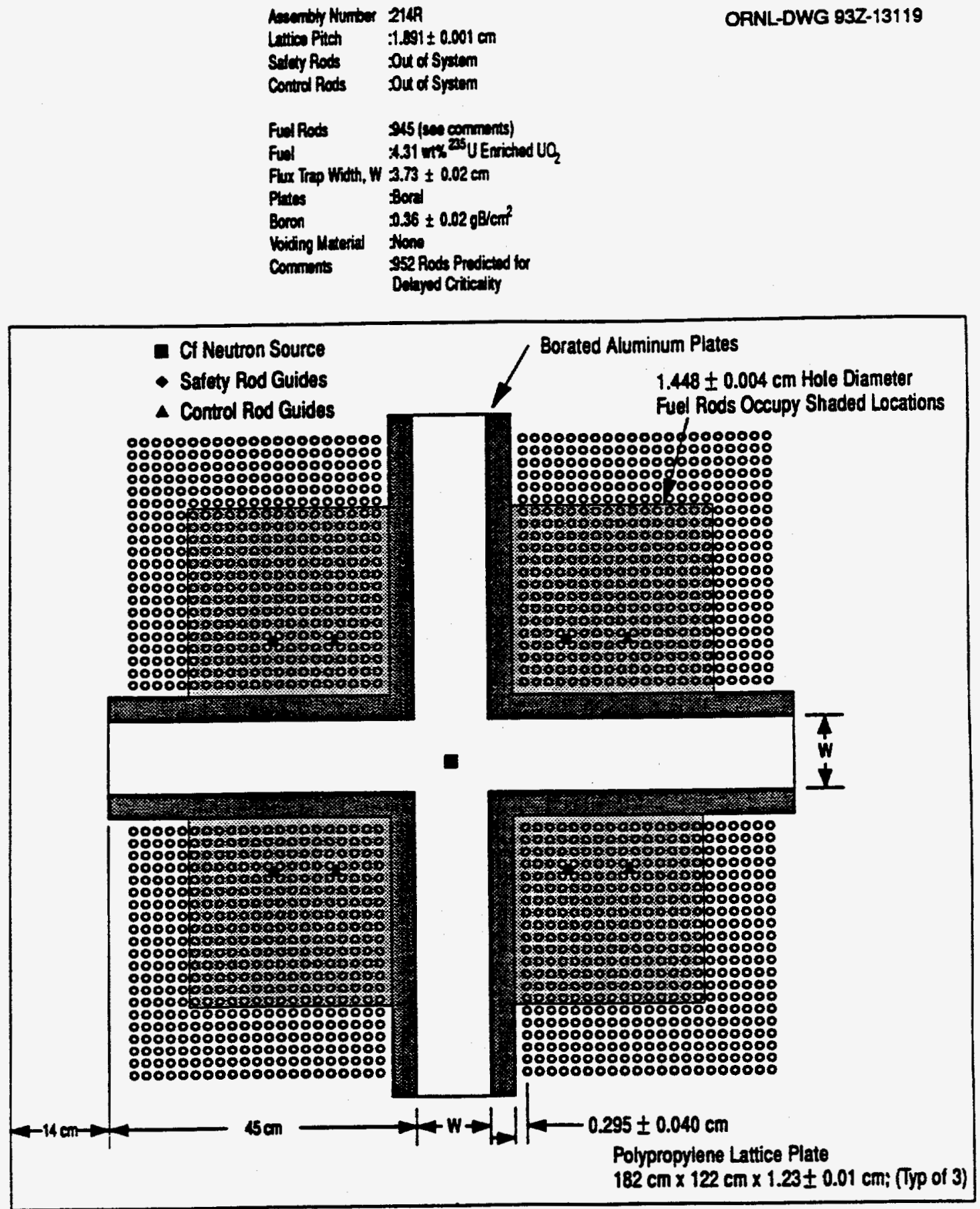

Fig. A.2. Experiment ft214r. Source: ref. 5. 


\begin{tabular}{|c|c|}
\hline $\begin{array}{l}\text { Aseombly Number } \\
\text { Lattice Pheh } \\
\text { Salety Rods } \\
\text { Control Rods }\end{array}$ & $\begin{array}{l}\text { : 214vs } \\
\text { : 1.807 } 10.001 \mathrm{~cm} \\
\text { : Out of Syatem } \\
\text { :Out of Syatem }\end{array}$ \\
\hline $\begin{array}{l}\text { Fual Rods } \\
\text { Fual } \\
\text { Flux Trap With, } w \\
\text { Plates } \\
\text { goron } \\
\text { Volding Watertal } \\
\text { Commints }\end{array}$ & 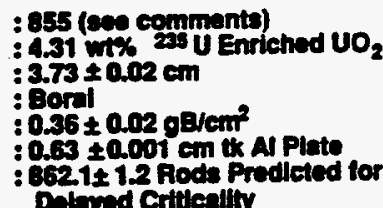 \\
\hline
\end{tabular}

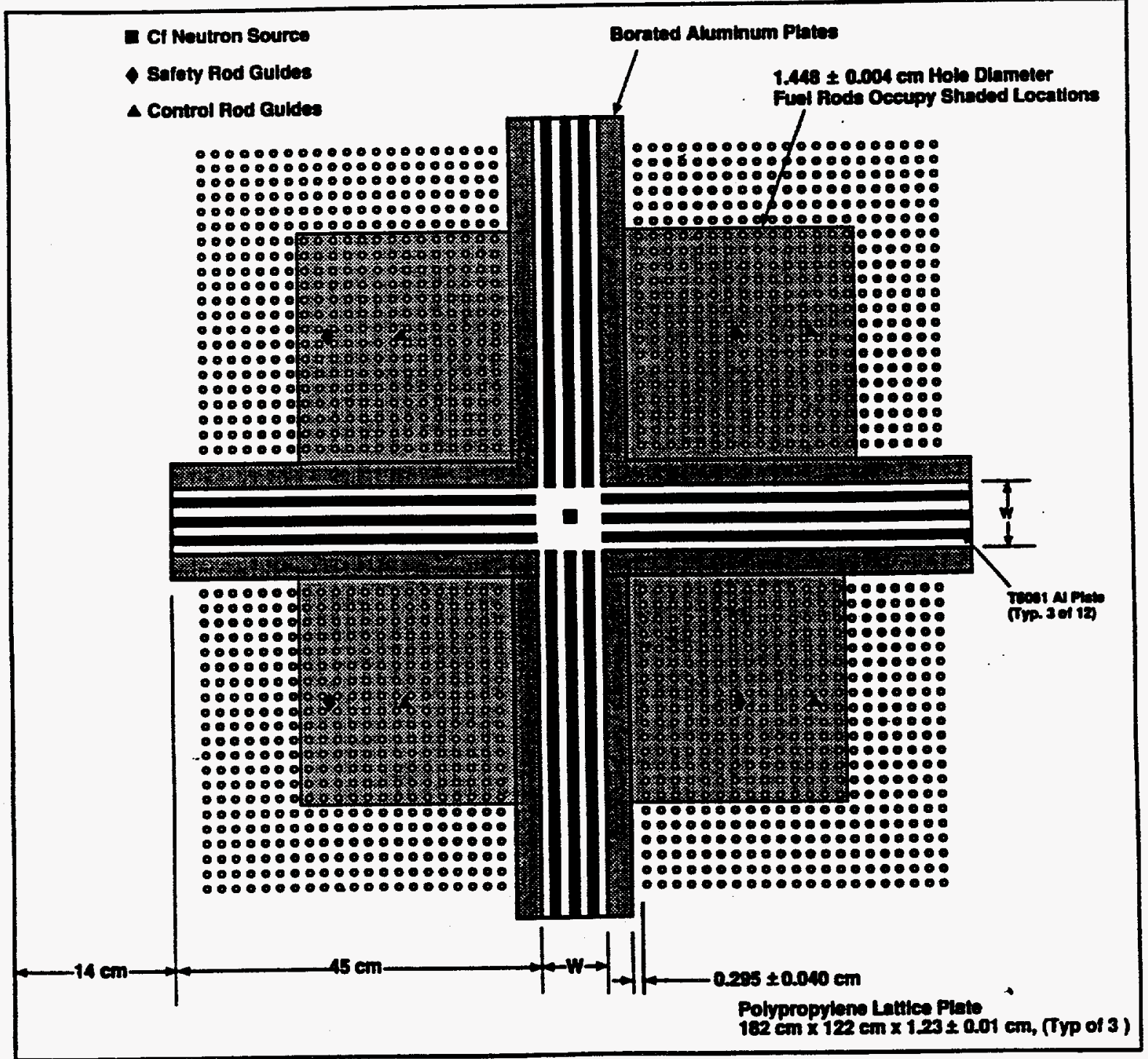

Fig. A.3. Experiment 214v3. Source: ref. 5. 


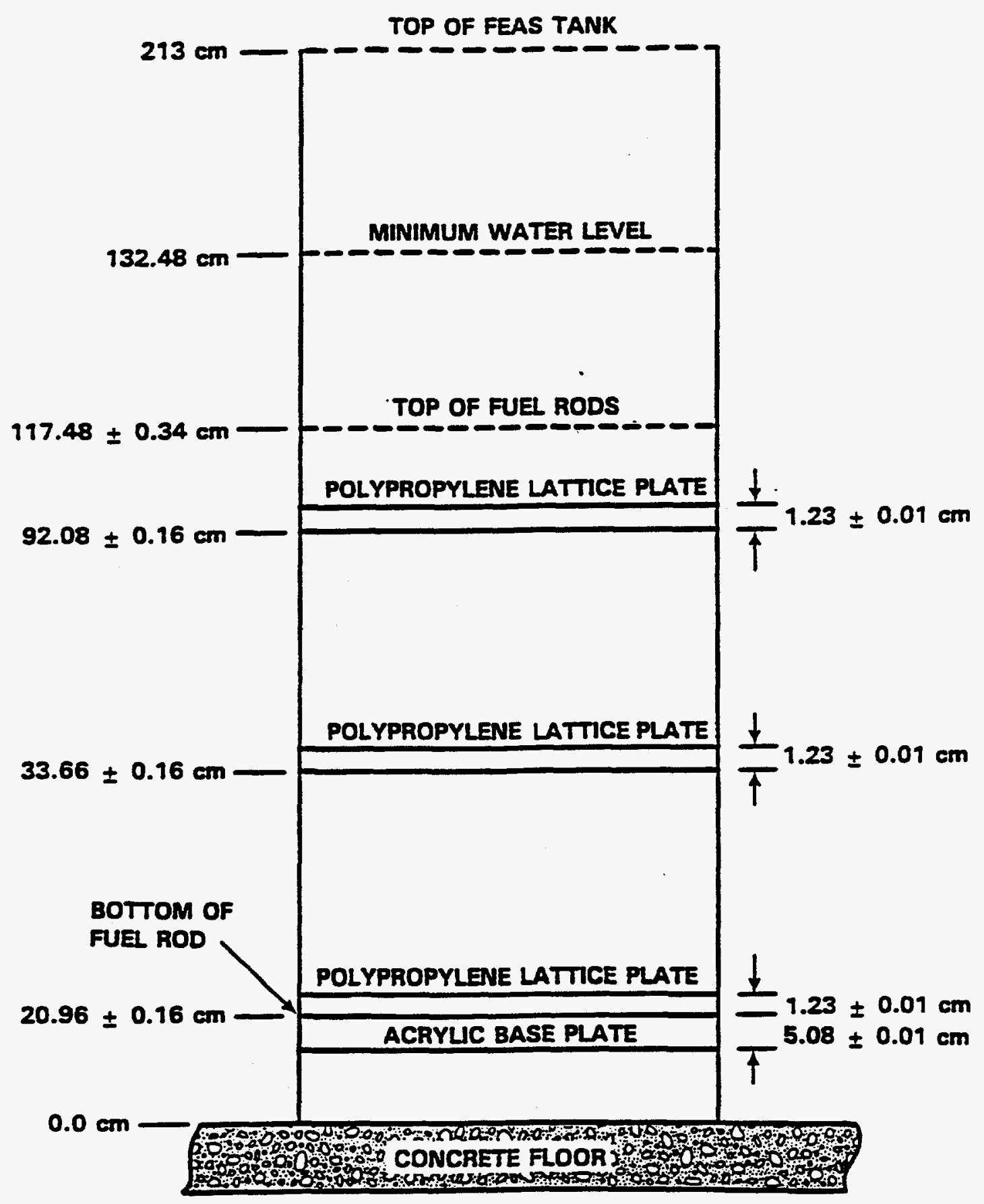

Fig. A.4. Experimental assembly elevations for $f t 214 r$ and $f(214 v 3$. Source: ref. 5. 


\section{PNL-2438 ABSORBER PLATE EXPERIMENTS (CASES 3, 4, 5, AND 6)}

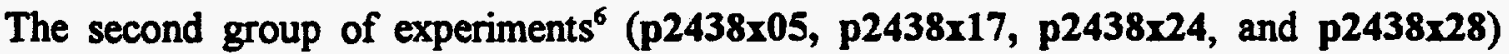
consisted of three fuel assemblies of $2.35 \mathrm{wt} \% \mathrm{UO}_{2}$ rods in a 2.032-cm-square lattice pitch arranged in a row. Absorber plates of Boral ${ }^{\text {me }}$, aluminum, or stainless steel were inserted between the fuel assemblies $(0.645 \mathrm{~cm}$ from the cell boundary of the center assembly) to determine the effect on the critical separation between the fuel assemblies. Modeling these experiments demonstrates the ability of the calculational techniques to predict the effect of absorber plates between fuel assemblies. A description of the $2.35 \mathrm{wt} \% \mathrm{UO}_{2}$ fuel rods is provided in Fig. A.5. Planar and axial views of the experiments are shown in Fig. A.6.

Experiment p2438x05 contained no plates between the fuel assemblies. All three fuel assemblies were $20 \times 16$ fuel rod arrays with a critical spacing of $8.39 \mathrm{~cm}$ between assemblies (measured from outer edge of fuel rod). Experiment p2438x17 contained Boral ${ }^{m}$ plates. The chemical composition of the Boral ${ }^{\text {Ts }}$ is listed in Table A.2. The Boral ${ }^{\text {Ts }}$ plates were $36.5 \mathrm{~cm}$ wide by $91.5 \mathrm{~cm}$ long and $0.713 \mathrm{~cm}$ thick (including 0.102 -cm-thick aluminum cladding on both sides of the $\mathrm{B}_{4} \mathrm{C}-\mathrm{Al}$ absorber). The center fuel assembly was a $20 \times 16$ array, and the two outer assemblies were $22 \times 16$ arrays. The critical separation distance between assemblies was $5.05 \mathrm{~cm}$. Experiment p2438 24 used aluminum plates between three $20 \times 16$ fuel assemblies. Although aluminum is not generally considered a neutron absorber, it is a common material in fuel baskets and acts as a voiding material in flooded conditions. The plates were $35.6 \mathrm{~cm}$ wide by $91.5 \mathrm{~cm}$ long and $0.625 \mathrm{~cm}$ thick. The critical spacing between fuel assemblies was $8.67 \mathrm{~cm}$. Lastly, experiment p2438 28 contained stainless-steel-304 plates between three $20 \times 16$ fuel assemblies. The plates were $35.6 \mathrm{~cm}$ wide by $91.5 \mathrm{~cm}$ long and $0.485 \mathrm{~cm}$ thick. The critical spacing was $6.88 \mathrm{~cm}$ between assemblies. 
DESCRIPTION OF 2.35 wt\% ${ }^{235}$ U ENRICHED $\cup_{2}$ RODS

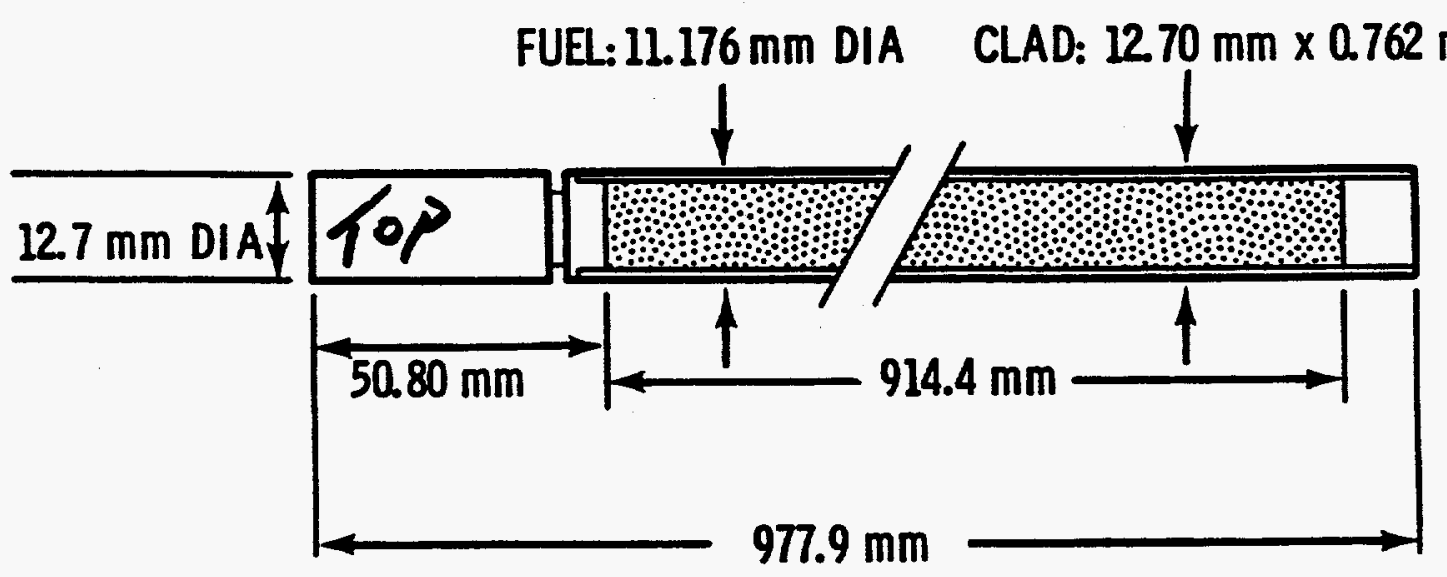

CLADDING: 6061 ALUMINUM TUBING SEAL WELDED WITH A LOWER END PLUG OF 5052 H32 ALUMINUM AND A TOP PLUG OF 1100 ALUMINUM

TOTAL WEIGHT OF LOADED FUEL RODS: $917 \mathrm{gm}$ (AVERAGE)

LOADING:

$825 \mathrm{gm}$ OF $\mathrm{UO}_{2}$ POWDER/ROD, $726 \mathrm{gm}$ OF U/ROD, $17.08 \mathrm{gm}$ OF U-235/ROD ENRICHMENT $-2.35 \pm 0.05$ W/O U-235

FUEL DENSITY $-9.20 \mathrm{mg} / \mathrm{mm}^{3}$ (84\% THEORETICAL DENSITY)

Fig. A.5. Description of $2.35 \mathrm{wt} \%{ }^{235} \mathrm{U}$-enriched $\mathrm{UO}_{2}$ fuel rods used in absorber plate experiments. Source: ref. 6. 


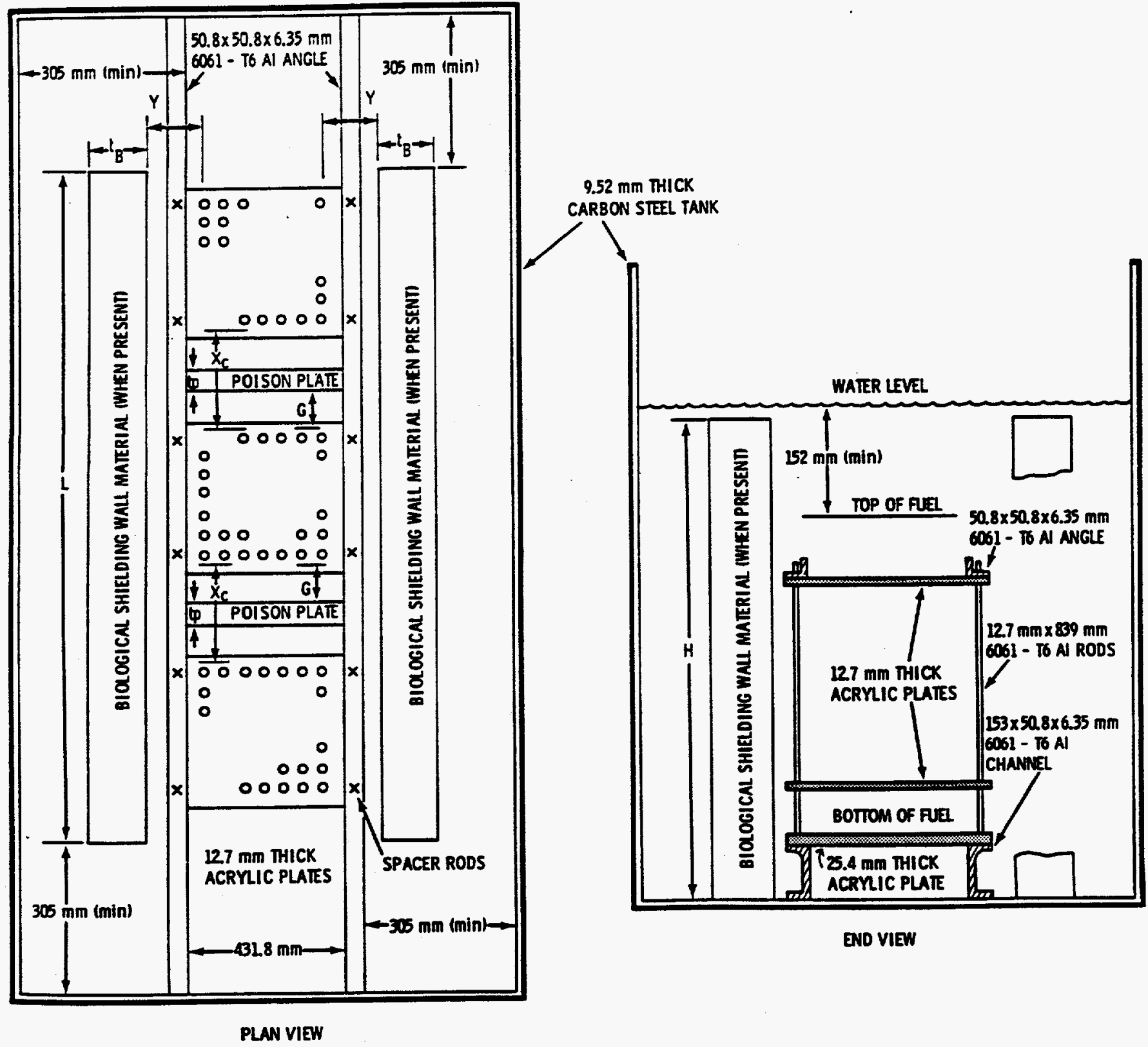

Fig. A.6. Experimental setup of the absorber plate experiments and the shielding wall experiments. Source: ref. 6. 
Table A.2. Boral ${ }^{\text {TM }}$ composition in experiment $\mathbf{p 2 4 3 8 \times 1 7}$

\begin{tabular}{lc} 
Element & $\begin{array}{c}\text { Boral } \\
\text { wt }(2.49 \\
\text { wt } \%\end{array}$ \\
\hline $\mathrm{Al}$ & 62.39 \\
$\mathrm{~B}$ & 28.70 \\
$\mathrm{C}$ & 7.97 \\
$\mathrm{Cr}$ & 0.05 \\
$\mathrm{Cu}$ & 0.09 \\
$\mathrm{Fe}$ & 0.33 \\
$\mathrm{Mg}$ & 0.05 \\
$\mathrm{Mn}$ & 0.05 \\
$\mathrm{Na}$ & 0.02 \\
$\mathrm{Ni}$ & 0.02 \\
$\mathrm{Si}$ & 0.20 \\
$\mathrm{~S}$ & 0.03 \\
$\mathrm{Zn}$ & 0.10 \\
\hline
\end{tabular}

Source: ref. 6.

PNL-3926/3602 SHIELDING WALL EXPERIMENTS (CASES 7, 8, AND 9)

The third set of experiments ${ }^{7.8}$ (p392614a, p3926u49, and p3602s4) consisted of three fuel assemblies of $4.31 \mathrm{wt} \% \mathrm{UO}_{2}$ rods in a 1.892 -cm-square lattice pitch arranged in a row, similar to the setup of the PNL-2438 absorber plate experiments . Shielding walls of depleted uranium, lead, or steel were positioned on both sides of the fuel assemblies, $1.956 \mathrm{~cm}$ from the cell boundary of the assemblies. These experiments simulate the effect of the cask shielding materials on $\mathrm{k}_{\text {eff }}$.

The fuel in these experiments is identical to that used in the flux trap experiments, as described in Fig. A.1; the experimental setup is identical to that used in the absorber plate experiments, as illustrated in Fig. A.6. The three wall types are shown in Figs. A.7 through A.9. Each experiment utilized three $12 \times 16$ fuel assemblies. Criticality was controlled by the separation distance between assemblies. The separation distances were measured from rod surface to rod surface in these experiments and are listed in Table A.3.

\section{PNL-4267 SOLUBLE BORON EXPERIMENTS (CASES 10, 11, 12, AND 13)}

The fourth set of experiments ${ }^{9}$ was selected to examine the effects of adding soluble boron to the water moderator. These experiments used a single array of $4.31 \mathrm{wt} \% \mathrm{UO}_{2}$ rods at two different lattice pitches, $1.890 \mathrm{~cm}$ and $1.715 \mathrm{~cm}$, in order to study the effect of water-to-fuel volume ratios on highly borated systems. Although the wide-pitched assembly ( 357 rods) required fewer rods to achieve criticality than the narrow-pitched assembly ( 509 rods) with no boron in the system, the 


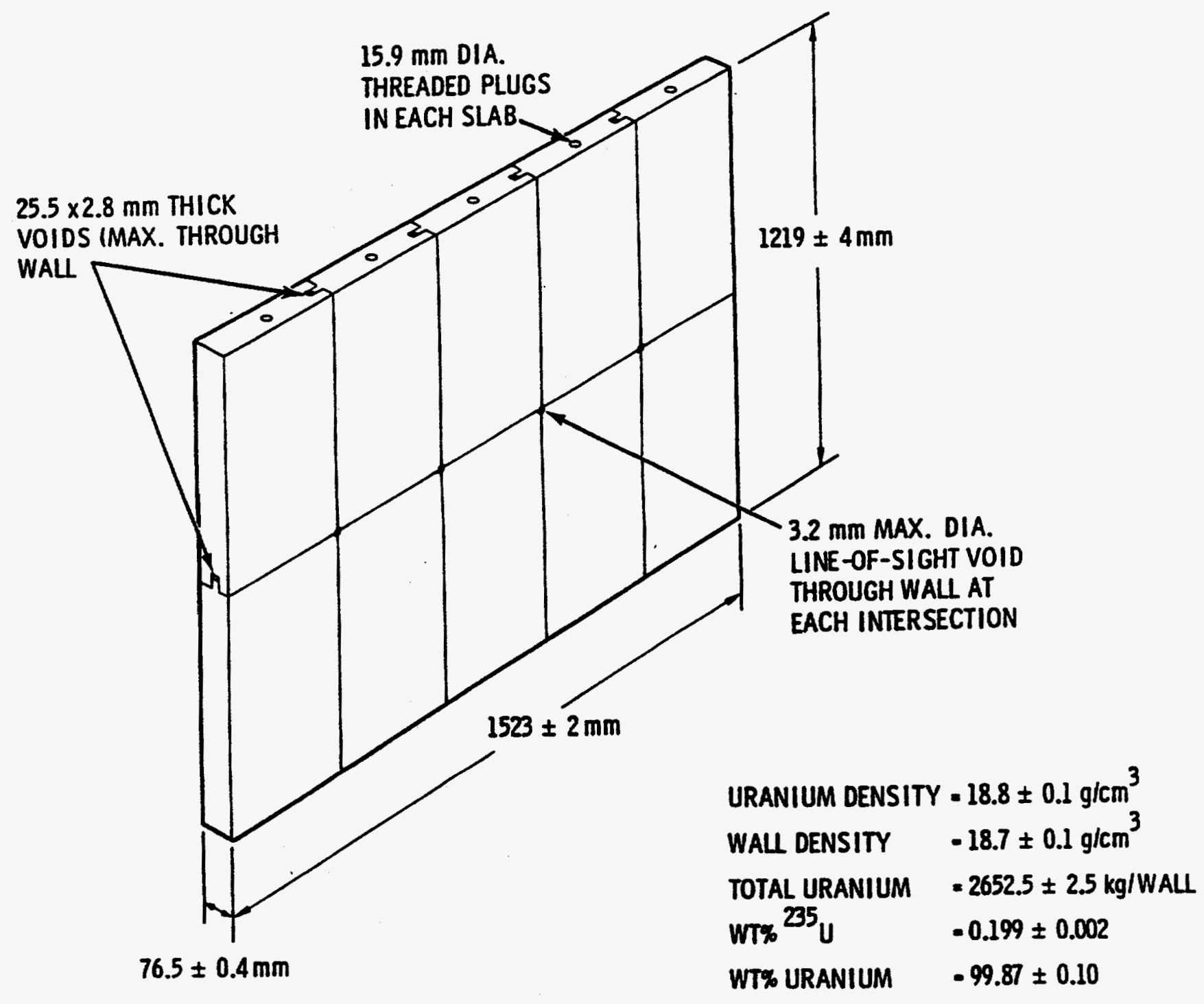

$8100234-4$

Fig. A.7. Assembled depleted uranium wall for depleted uranium shielding wall experiment. Source: ref. 7. 


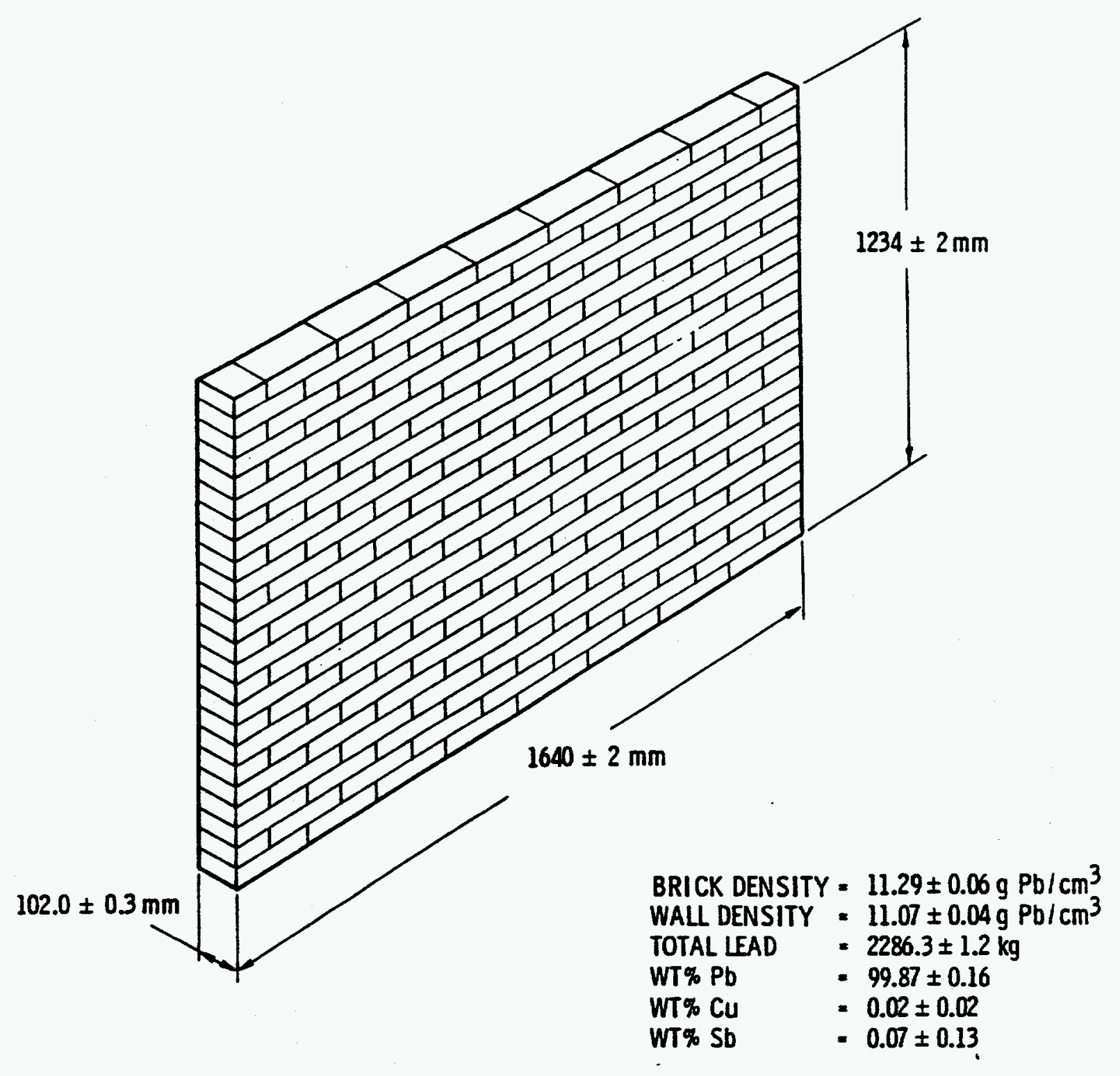

$8106234-3$

Fig. A.8. Assembled lead wall for lead shielding wall experiment. Source: ref. 7. 


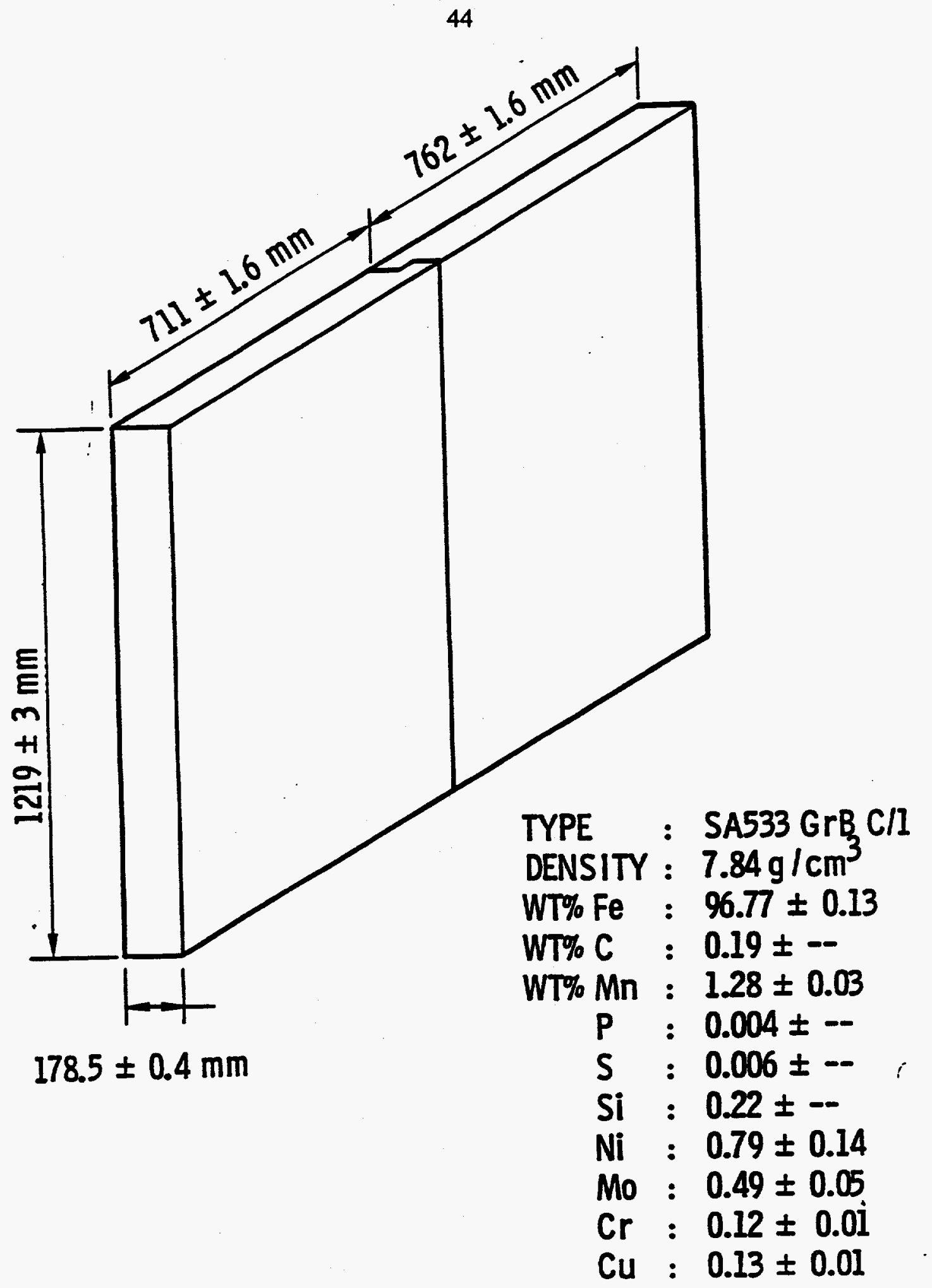

Fig. A.9. Assembled steel wall for steel shielding wall experiment. Source: ref. 8. 
Table A.3. Critical separation between assemblies for shielding wall experiments

\begin{tabular}{lc}
\hline Wall type. & Critical separation (cm) \\
\hline Uranium & 19.24 (ref. 7) \\
Lead & 17.43 (ref. 7) \\
Steel & 15.84 (ref. 8) \\
\hline
\end{tabular}

Measured from rod surface to rod surface of adjacent assemblies.

opposite was true for the borated cases ( 1237 vs 1192 rods, respectively). With no boron, the widepitched assembly has greater moderation and is more reactive than the narrow-pitched assembly, and therefore requires fewer fuel rods. For the borated cases, the greater moderation of the wide-pitched assembly results in greater boron worth and lower reactivity (requiring more fuel rods) compared with the narrow-pitched experiment.

The specifications for the $4.31 \mathrm{wt} \% \mathrm{UO}_{2}$ fuel rods are identical to those given previously in Fig. A.1. The experimental setup is illustrated in Fig. A.10. The container was surrounded by a unborated water reflector on all four sides. The boron concentration and array size for each experiment are given in Table A.4.

\section{BAW-1484 ABSORBER ROD EXPERIMENT (CASE 14)}

The next experiment, ${ }^{10}$ experiment baw1484a, consisted of nine fuel assemblies of $2.46 \mathrm{wt}$ $\% \mathrm{UO}_{2}$ arranged in a $3 \times 3$ array. Each assembly was a $14 \times 14$ array of fuel rods with a $1.636-\mathrm{cm}$ lattice pitch. The assemblies were separated by a water gap containing 84 equally spaced $\mathrm{B}_{4} \mathrm{C}$ neutron absorber rods. The width of the water gap was equal to the fuel rod lattice pitch. Criticality was controlled by varying the water level. The aluminum-clad fuel rods are described in Table A.5 and Fig. A.11. The $B_{4} C$ pins were aluminum tubes filled with natural $B_{4} C$ powder. The aluminum tubes had a $1.113-\mathrm{cm}$ outer diameter and a wall thickness of $0.089 \mathrm{~cm}$. The bottom ends were sealed with aluminum plugs, $0.952 \mathrm{~cm}$ long, and the tops were sealed with removable cork plugs. Each pin contained $156 \mathrm{~g}$ of $\mathrm{B}_{4} \mathrm{C}$, which constituted a column that extended about $30 \mathrm{~cm}$ above the water level. The $B_{4} C$ is compacted to a linear density of $0.879 \mathrm{~g} / \mathrm{cm}$, which is a density of $1.28 \mathrm{~g} / \mathrm{cm}^{3}$. The certified chemical analysis of the $B_{4} C$ powder is given in Table A.6. The experimental setup is illustrated in Figs. A.12 and A.13. The critical moderator level was $145.68 \mathrm{~cm}$ for this experiment.

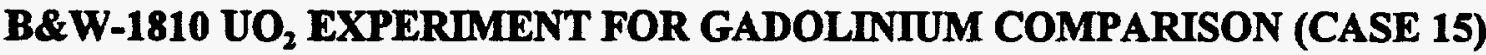

A set of three $\mathrm{UO}_{2}-\mathrm{Gd}_{2} \mathrm{O}_{3}$ experiments ${ }^{11}$ was perfomed by $\mathrm{B} \& W$ with various configurations. A baseline case using $\mathrm{UO}_{2}$ only was performed, designated here as bnw1810a, using a combination of $4.02 \mathrm{wt} \%$ and $2.46 \mathrm{wt} \% \mathrm{UO}_{2}$ rods. Criticality was achieved by varying the soluble boron concentration in the moderator. The core configuration is illustrated in Fig. A.14, which gives a 

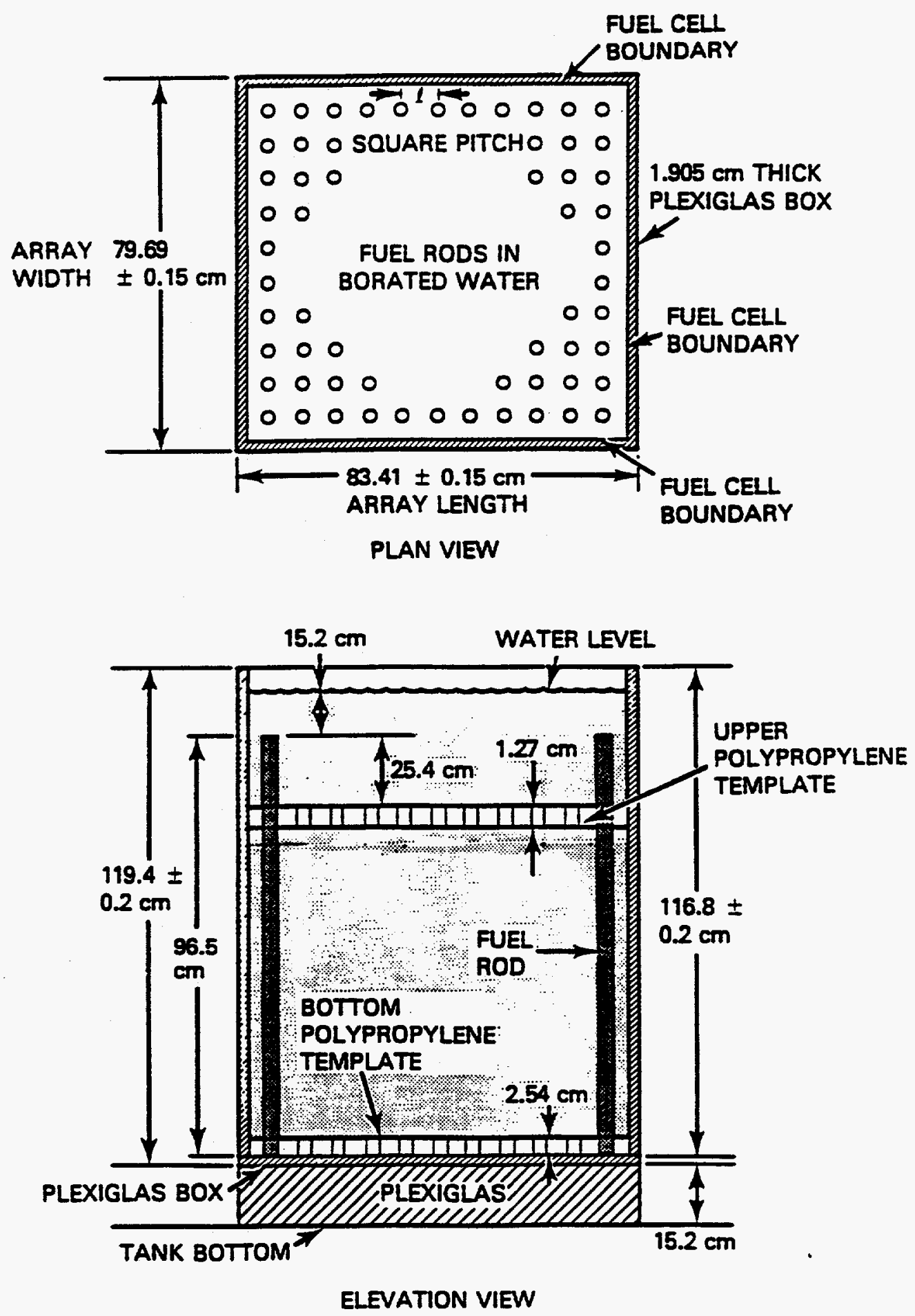

Fig. A.10. Experimental setup for soluble boron experiments. Source: ref. 9. 
Table A.4. Critical array dimensions of soluble boron experiments

\begin{tabular}{ccccc}
$\begin{array}{c}\text { Experiment } \\
\text { No. }\end{array}$ & $\begin{array}{c}\text { Square } \\
\text { pitch } \\
(\mathrm{cm})\end{array}$ & $\begin{array}{c}\text { Boron }^{a} \\
\text { concentration } \text { g/l }\end{array}$ & $\begin{array}{c}\text { Critical } \\
\text { array width } \\
\text { No. of rods }\end{array}$ & $\begin{array}{c}\text { Total rods }^{b} \\
\text { for } \\
\text { criticality }\end{array}$ \\
\hline 173 & 1.890 & 0.0 & 40 & 357 \\
177 & 1.890 & 2.55 & 40 & 1237 \\
178 & 1.715 & 0.0 & 44 & 509 \\
181 & 1.715 & 2.55 & 44 & 1192 \\
\hline
\end{tabular}

Boron added in the form of $\mathrm{H}_{3} \mathrm{BO}_{3}$.

'The error in critical rod number is $<0.5 \%$.'

Source: ref. 9.

Table A.5. Properties of $2.46 \%$ enriched $\mathrm{UO}_{2}$ fuel rods in experiment bawl484a

\begin{tabular}{|c|c|}
\hline Parameter & Value \\
\hline Outside diameter, $\mathrm{cm}$ & 1.206 \\
\hline Wall thickness, cm & 0.081 \\
\hline Wall material & Aluminum \\
\hline Pellet diameter, $\mathrm{cm}$ & 1.030 \\
\hline Total length, cm & 156.44 \\
\hline Active fuel length, cm & 153.34 \\
\hline Pellet length, cm & 1.914 \\
\hline $\mathrm{Wt}$ of $\mathrm{UO}_{2}, \mathrm{~g} / \mathrm{rod}$ & 1305.5 \\
\hline Wt U/wt $\mathrm{UO}_{2}, \%$ & 88.13 \\
\hline Wt of U, g/rod & 1150.5 \\
\hline Wt of ${ }^{235} \mathrm{U}, \mathrm{g} / \mathrm{rod}$ & 28.29 \\
\hline Enrichment, ${ }^{235} \mathrm{U} / \mathrm{U}$ wt $\%$ & 2.459 \\
\hline Pellet density, $\mathrm{g} / \mathrm{cm}^{3}$ & 10.29 \\
\hline Bulk density, $\mathrm{g} / \mathrm{cm}^{3}$ & 10.22 \\
\hline
\end{tabular}

Source: ref. 10. 


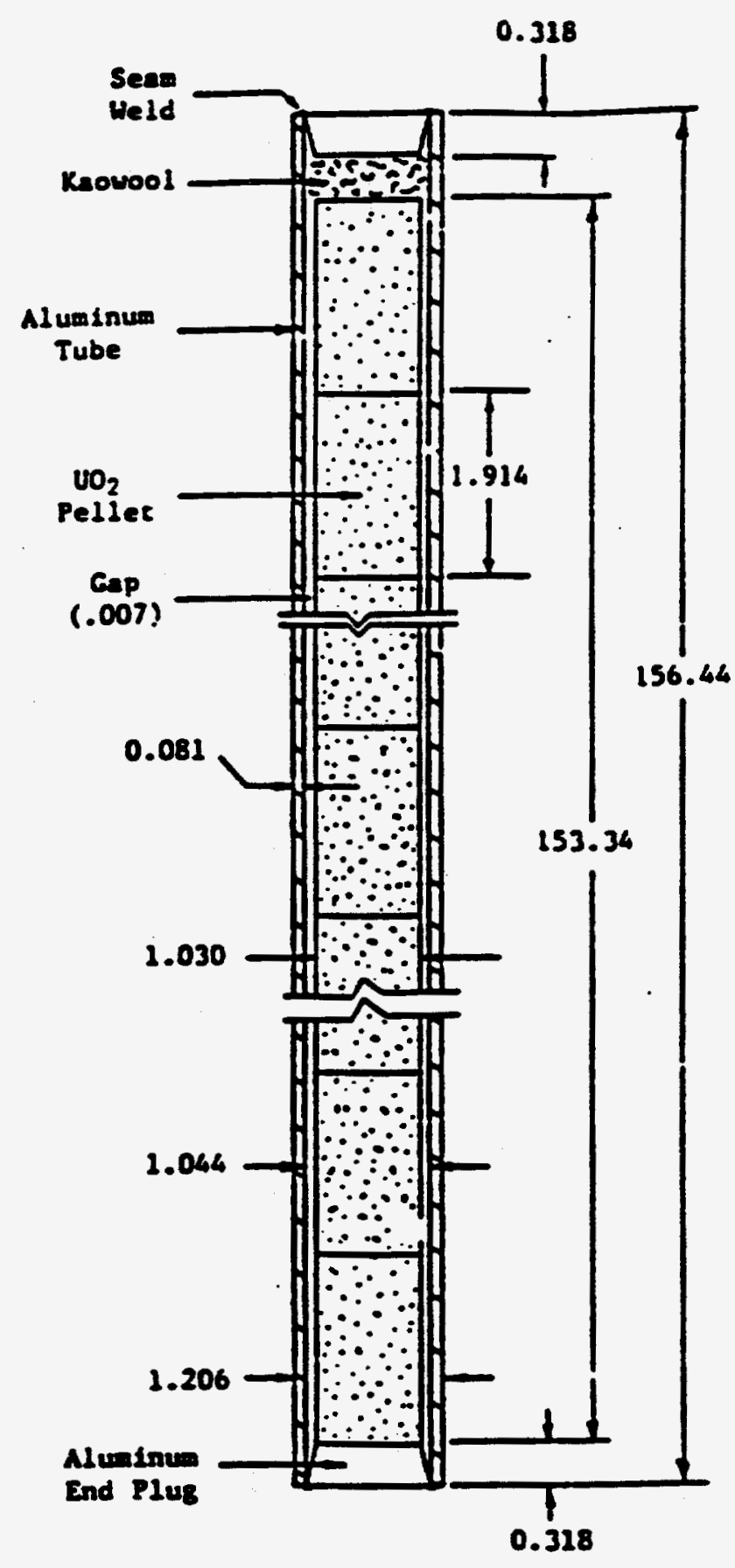

Note: All dimensions in cencimerers.

Fig. A.11. Dimensions of $2.46 \%$ enriched $\mathrm{UO}_{2}$ fuel rod in experiment bawl484a. Source: ref. 10. 
Table A.6. Certified chemical analysis of $\mathrm{B}_{4} \mathrm{C}$ for experiment bawl484a

Total boron

Total carbon

Anhydrous $\mathrm{B}_{2} \mathrm{O}_{3}$

Boron plus carbon

Source: ref. 10.
$77.8 \mathrm{wt} \%$

$20.8 w t \%$

$0.10 \mathrm{wt} \%$

$98.6 \mathrm{wt} \%$

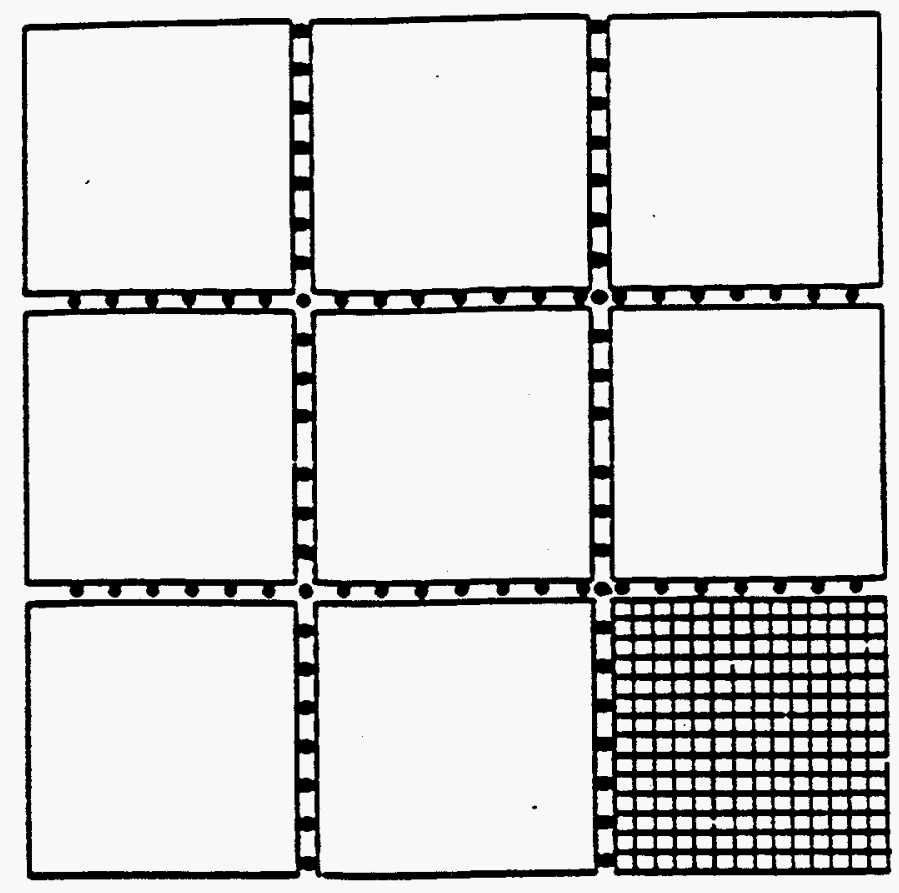

- Fucl Rod Position

- s. $_{4}$ PIn

Note: The large squares represent $14 \times 14$ fuel assemblies as shown in the lower righthand corner.

Fig. A.12. Experiment bawl484a loading diagram. Source: ref. 10. 


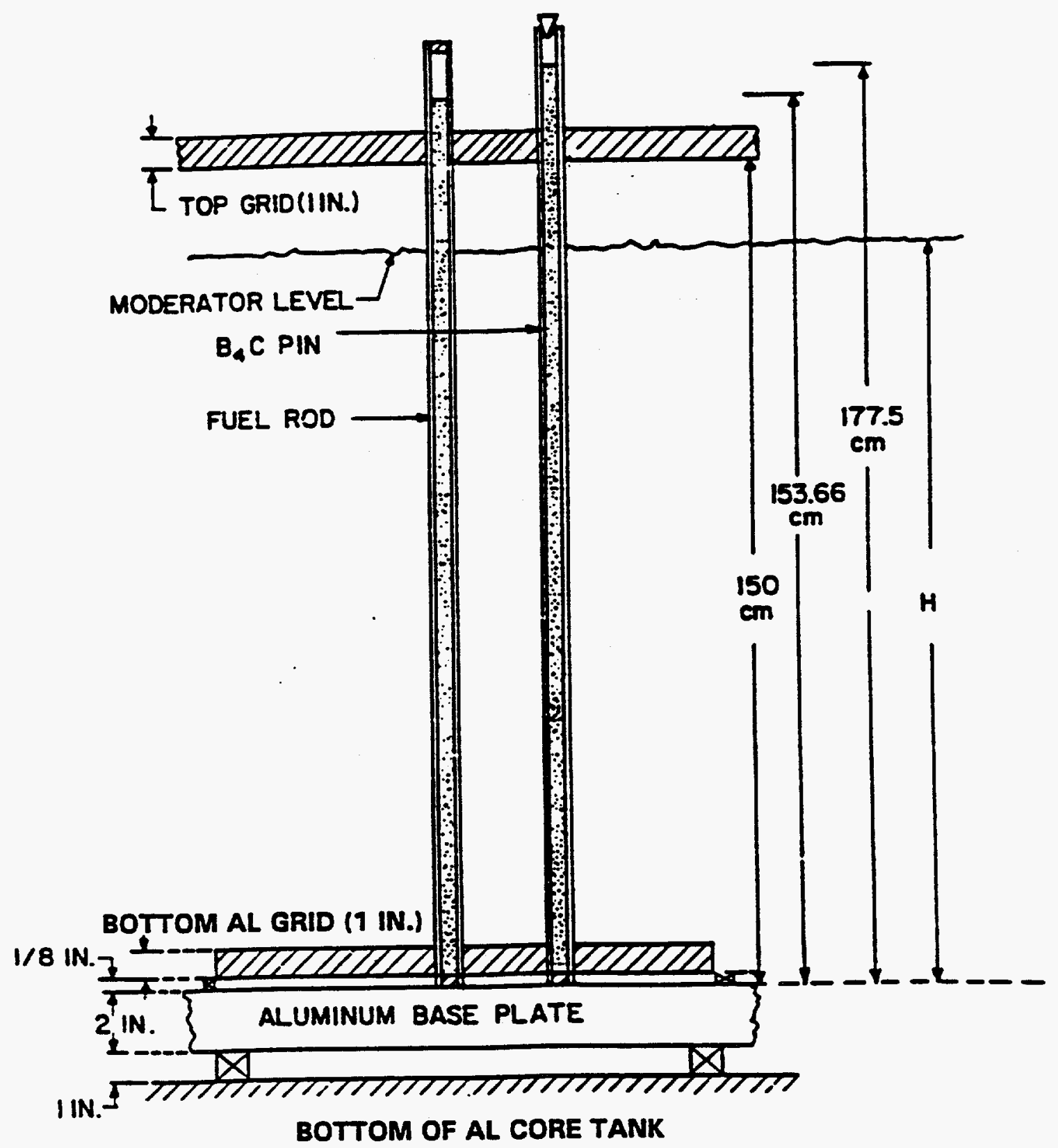

Fig. A.13. Experiment bawl484a vertical dimensions. Source: ref. 10. 
ORNL-DWG 93Z-15101

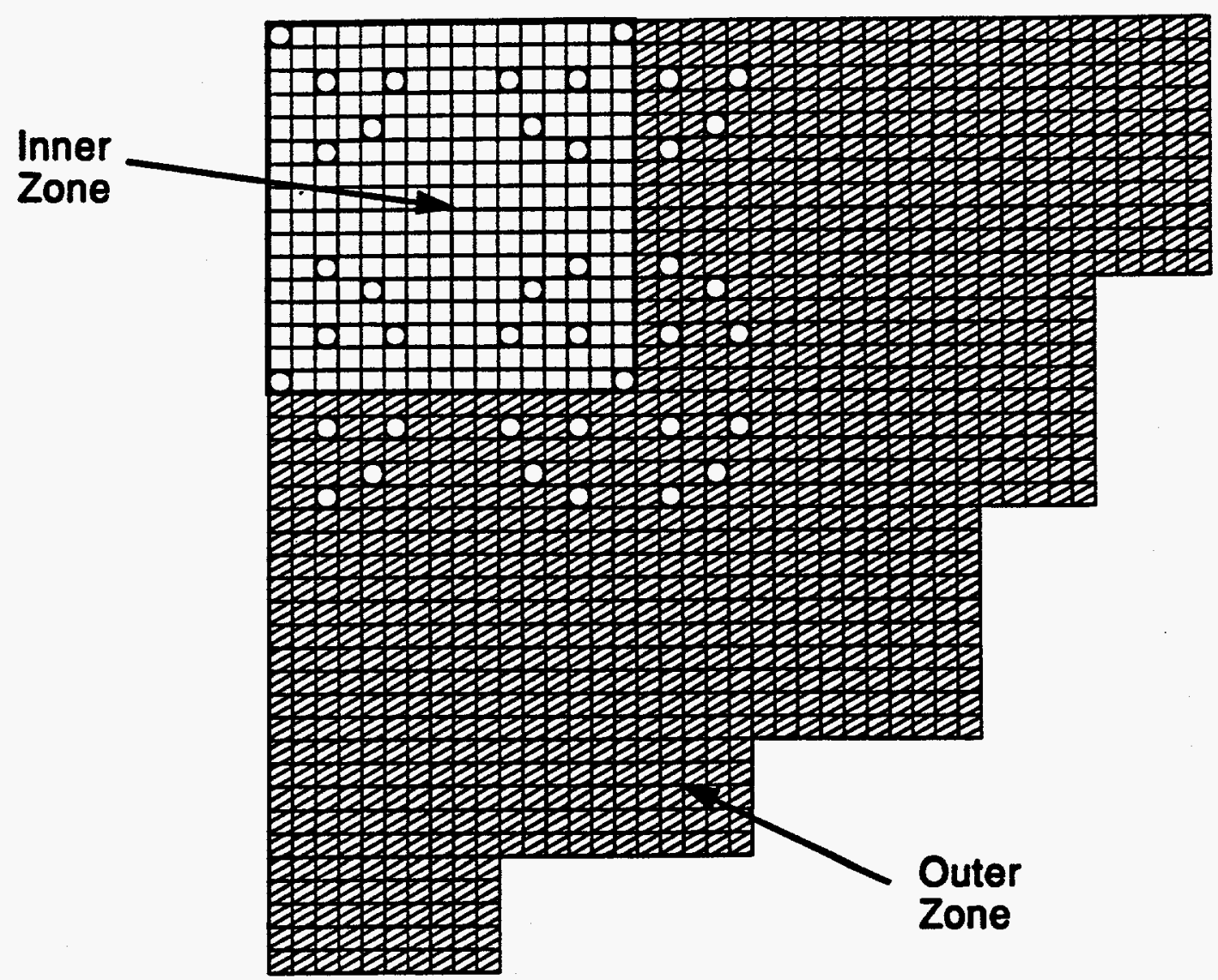

a VACANT WATER-FILLED POSITION

2.46 wt \% U-235 ENRICHED FUEL: OUTER ZONE $\square 4.02$ wt \% U-235 ENRICHED FUEL: INNER ZONE

Fig. A.14. Experiment bnw1810a quarter-core (symmetric) loading diagram. Source: ref. 10. 
quarter-core representation of the entire core. As shown in the figure, the core was divided into two fuel zones. The inner zone of the core $(31 \times 31$ lattice cells) was comprised of the $4.02 \mathrm{wt} \%$ fuel; the physical properties of this fuel are given in Table A.7. The outer zone of the core was comprised of $2.46 \mathrm{wt} \%$ fuel, identical to that used in the absorber rod experiment of case 14, as described in Table A.5 and Fig. A.11. The core critical conditions are described in Table A.8.

\section{EPRI-196 UO, EXPERIMENTS FOR MOX COMPARISON (CASES 16 AND 17)}

Several experiments were performed at Pacific Northwest Laboratory (PNL) for the Electric Power Research Institute (EPRI) to study the effect of the presence of plutonium isotopes in LWRtype fuel. ${ }^{12}$ In these experiments, MOX fuel rods were used, composed primarily of $\mathrm{UO}_{2}(98 \mathrm{wt} \%$ ), with the balance being $\mathrm{PuO}_{2}$. To provide a baseline for assessing the effect of the $\mathrm{Pu}$ isotopes, two experiments (e196u6n and e196u87c) were performed using fuel rods comprised only of $2.35 \mathrm{wt} \%$ enriched $\mathrm{UO}_{2}$. The fuel rods used in these experiments were identical to those used in the earlier absorber plate experiments, as illustrated in Fig. A.5. The axial arrangement of the experiments is illustrated in Fig. A.15. At least 12 in. of water was located below the lower solid aluminum plate. The specifications for the aluminum "eggcrate" grids are given in Fig. A.16. This figure shows dimensions for both the $\mathrm{UO}_{2}$ and MOX lattices; the details of the MOX experiments will be discussed later in this Appendix. Note that a single grid spacer was used for both the 0.615-in. (1.562-cm) and 0.870-in. (2.210-cm)-pitch experiments, e196u6n and e196u87c, respectively. This was accomplished by loading every other lattice location in the wider lattice spacing experiment for each

grid. This alternative arrangement increased the lattice spacing by a factor of $\sqrt{2}$. The core layouts for the experiments are shown in Figs. A.17 and A.18 A water reflector of at least 12 in. was located on all sides of each experiment. The number of rods and boron concentrations at critical are given in Table A.9.

\section{SAXTON UO, EXPERIMENTS FOR MOX COMPARISON (CASES 18 AND 19)}

A series of $\mathrm{MOX}$ and $\mathrm{UO}_{2}$ critical experiments was also performed at the Westinghouse Reactor Evaluation Center (WREC) as part of the Saxton Plutonium Program. ${ }^{13}$ Like the EPRI-196 experiments, two $\mathrm{UO}_{2}$-only experiments (saxu56 and saxu792) were performed to provide a nonplutonium basis for comparison with plutonium-bearing experiments. However, the $\mathrm{UO}_{2}$ fuel was a relatively highly enriched $5.74 \mathrm{wt} \%{ }^{23} \mathrm{U}$, compared with $2.35 \mathrm{wt} \%$ in the EPRI set. Each of these experiments consisted of a single array of fuel rods in a square-lattice arrangement, at different pitches. The fuel rod specifications are provided in Table A.10. The fuel rods were loaded in single rectangular arrays as specified in Table A.11. An axial view of the experimental setup is shown in Fig. A 19. Three grid plates were used to support the fuel rods. The fuel rod holes in the aluminum grid plates were $1.008 \mathrm{~cm}$ in diameter. The grid plates were supported at each corner with $1.111-\mathrm{cm}$ (7/16-in.) stainless steel support rods covered with $1.588-\mathrm{cm}$ (5/8-in.) aluminum pipe. 
Table A.7. Physical properties of 4.02 wt \% enriched $\mathrm{UO}_{2}$ fuel rods in B\&W-1810 experiments

\begin{tabular}{ll}
\hline \multicolumn{1}{c}{ Parameter } & \multicolumn{1}{c}{ Value } \\
\hline Outside diameter, cm (in.) & $1.2078(0.4755)$ \\
Wall material & Type 304 stainless steel \\
Fuel diameter, cm (in.) & $1.1278(0.444)$ \\
Total length, cm (in.) & $181.6(71.5)$ \\
Active fuel length, cm (in.) & $169.4(66.7)$ \\
Weight of fuel, g/rod & 1600 \\
Weight of uranium, g/rod & 1408 \\
Weight of ${ }^{235} \mathrm{U}, \mathrm{g} / \mathrm{rod}$ & 56.61 \\
Enrichment, ${ }^{235} \mathrm{U} / \mathrm{U}, \mathrm{wt} \%$ & 4.020 \\
Fuel density, g/cm & 9.46 \\
\hline
\end{tabular}

Source: ref. 11.

Table A.8. Experiment description for bnw1810a

\begin{tabular}{ll}
\hline \multicolumn{1}{c}{ Parameter } & Value \\
\hline Number of 2.46 wt $\%{ }^{235} \mathrm{U}$ fuel pins & 3920 \\
Number of 4.02 wt $\%{ }^{235} \mathrm{U}$ fuel pins & 888 \\
Number of gadolinium fuel pins & 0 \\
Number of water holes & 153 \\
Critical boron concentration (ppm) & $1899.3 \pm 0.9$ \\
\hline
\end{tabular}

Source: ref. 11. 
FUL:Y REPLCOTED

IVODERATOR HEIGHT

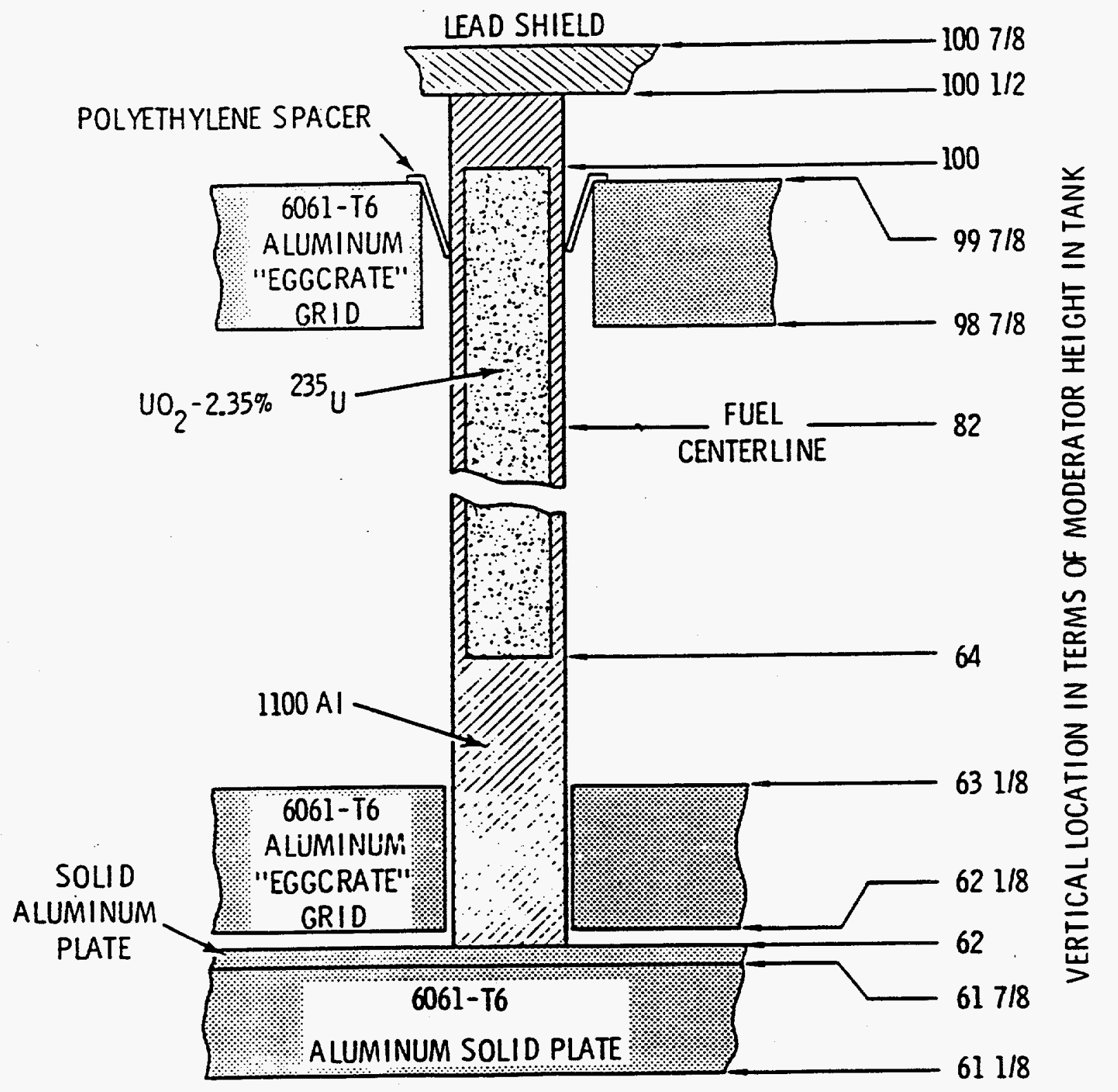

Fig. A.15. Axial core structure dimensions for EPRI-196 UO Un $_{2}$ experiments. Source: ref. 12. 


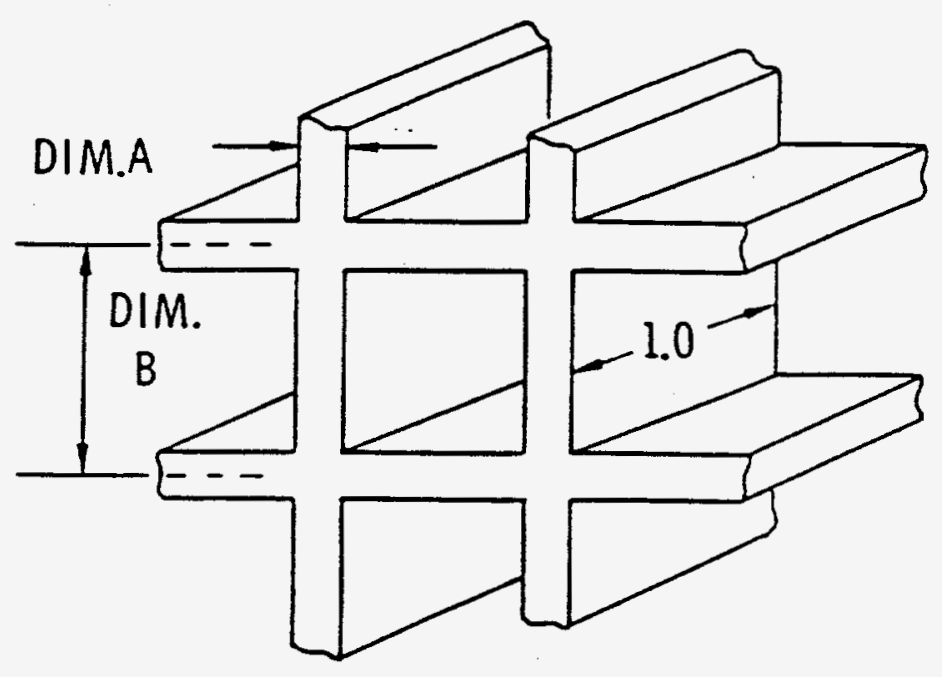

\begin{tabular}{c|l|l|l|l|} 
FUEL TYPE & \multicolumn{1}{c}{ PITCH } & \multicolumn{1}{c}{ GRID } & \multicolumn{1}{c}{ DIM.A } & \multicolumn{1}{c}{ DIM B } \\
\hline $\mathrm{UO}_{2}-2.35 \% 235 \mathrm{U}$ & $\begin{array}{l}0.615 \\
0.87\end{array}$ & $\begin{array}{l}\text { UPPER } \\
\text { LOWER }\end{array}$ & $\begin{array}{l}0.032 \\
0.090\end{array}$ & 0.615 \\
\hline $\mathrm{UO}_{2}-2{\mathrm{WT} \% \mathrm{PUO}_{2}(8 \% 240 \mathrm{PU})}^{2}$ & 0.87 & $\begin{array}{l}\text { UPPER } \\
\text { LOWER }\end{array}$ & $\begin{array}{l}0.032 \\
0.032\end{array}$ & 0.615 \\
\hline $\mathrm{UO}_{2}-2 \mathrm{WT}_{2} \mathrm{PUO}_{2}(8 \% 240 \mathrm{PU})$ & 0.70 & UPPER & 0.125 & 0.70 \\
\hline
\end{tabular}

Fig. A. 16. Dimensions of "eggcrate" lattice grids for EPRI-196 $\mathrm{UO}_{2}$ and MOX experiments. Source: ref. 12. 
ORNL-DWG 93Z-13103

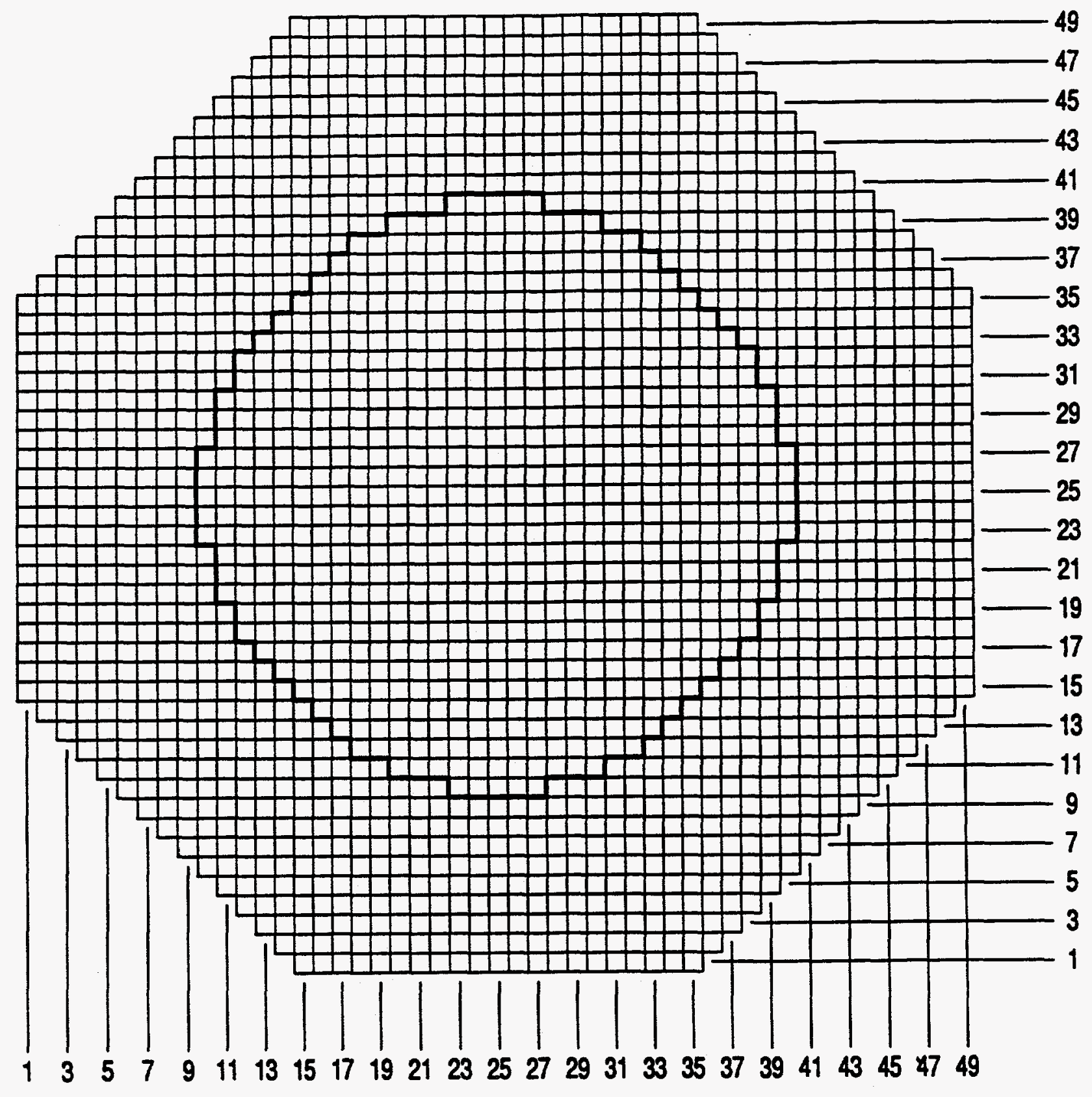

Fig. A.17. EPRI 0.615-in.-pitch $\mathrm{UO}_{2}$ core. Source: ref. 12. 
ORNL-DWG 93Z-13094

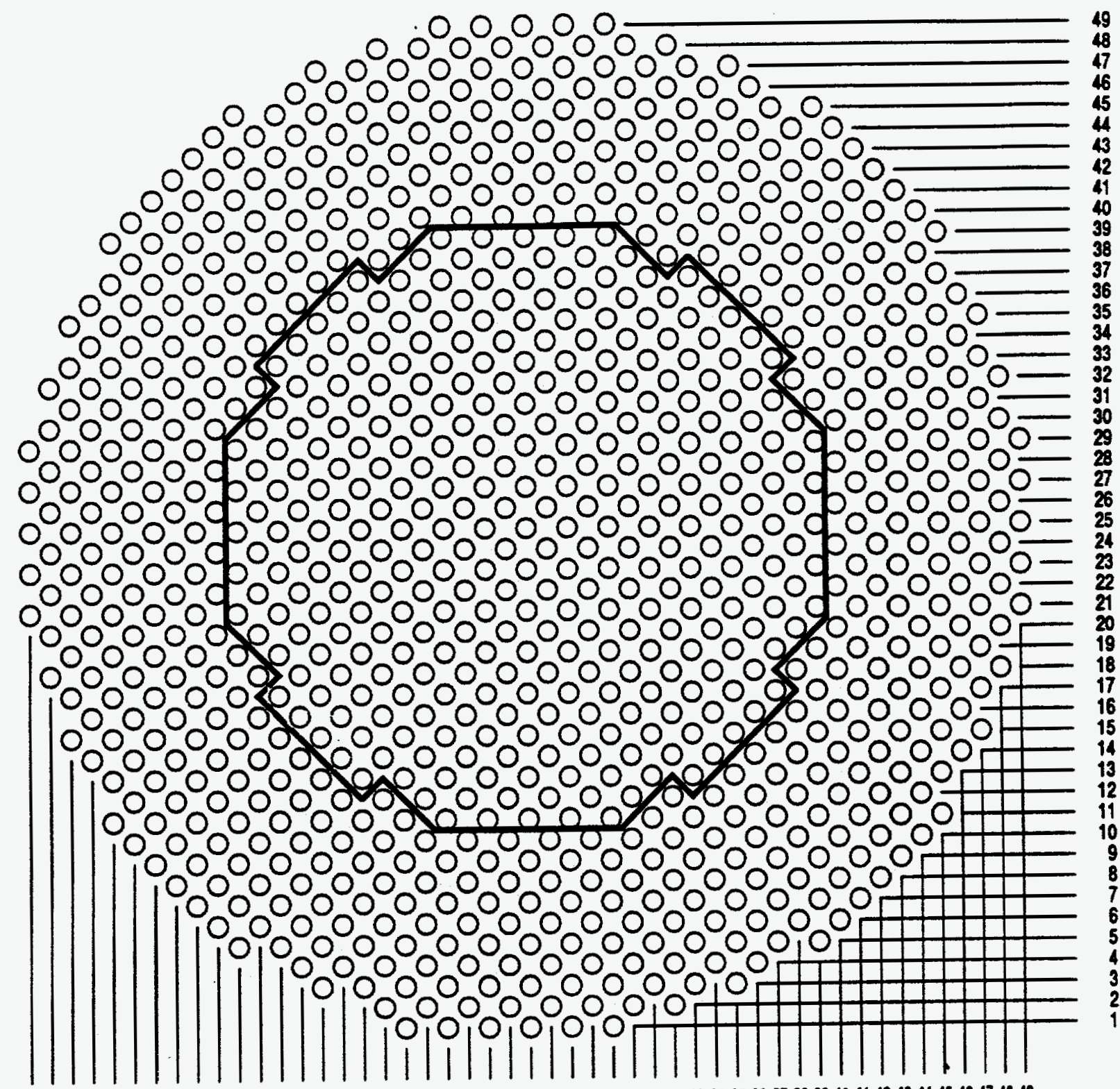

123456789101112131415161718192021222324252527282930313233343537383940414243444464849

Fig. A.18. EPRI 0.870-in.-pitch $\mathrm{UO}_{2}$ core. Source: ref. 12. 


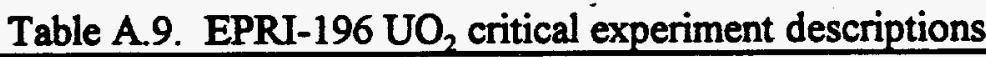

\begin{tabular}{lcccc}
\hline Fuel type & $\begin{array}{c}\text { Pitch } \\
\text { (in./cm) }\end{array}$ & $\begin{array}{c}\text { Water/fuel } \\
\text { volume ratio }\end{array}$ & $\begin{array}{c}\text { Critical } \\
\text { No. of rods }\end{array}$ & $\begin{array}{c}\text { Boron } \\
\text { concentration } \\
\text { (ppm) }\end{array}$ \\
\hline $\mathrm{UO}_{2}$ & $0.615 / 1.562$ & 1.196 & 708 & 0.9 \\
$\mathrm{UO}_{2}$ & $0.870 / 2.210$ & 3.687 & 342 & 0.9 \\
\hline
\end{tabular}

Source: ref. 12.

Table A.10. Saxton $\mathrm{UO}_{2}$ fuel rod specifications

\begin{tabular}{ll}
\hline Pellet diameter, cm (in.) & $0.907(0.357)$ \\
Clad OD, cm (in.) & $0.993(0.391)$ \\
Clad ID, cm (in.) & $0.917(0.361)$ \\
Clad material & $304 \mathrm{SS}$ \\
\% theoretical density & 93 \\
Fuel length, cm (in.) & $92.96(36.6)$ \\
Enrichment & $5.74 \mathrm{wt} \%{ }^{235} \mathrm{U}$ \\
Theoretical density (g/cc) & $10.96\left(\mathrm{UO}_{2}\right)$ \\
Weight percent of ${ }^{239} \mathrm{Pu}$ & $\mathrm{N} / \mathrm{A}$ \\
Weight percent of ${ }^{240} \mathrm{Pu}$ & $\mathrm{N} / \mathrm{A}$ \\
Weight percent of ${ }^{241} \mathrm{Pu}$ & N/A \\
Weight percent of ${ }^{242} \mathrm{Pu}$ & N/A \\
\hline Source: ref. 13. &
\end{tabular}

Table A.11. Saxton $\mathrm{UO}_{2}$ critical experiment descriptions

\begin{tabular}{ccccc}
\hline $\begin{array}{c}\text { Pitch } \\
\text { (in./cm) }\end{array}$ & $\begin{array}{c}\text { Water/fuel } \\
\text { volume ratio }\end{array}$ & $\begin{array}{c}\text { Critical } \mathrm{H}_{2} \mathrm{O} \\
\text { height }(\mathrm{cm})\end{array}$ & $\begin{array}{c}\text { Critical } \\
\text { no. of rods }\end{array}$ & $\begin{array}{c}\text { Boron } \\
\text { concentration } \\
\text { (ppm) }\end{array}$ \\
\hline $0.56 / 1.422$ & 1.933 & 83.71 & $361(19 \times 19)$ & 0 \\
$0.792 / 2.012$ & 5.067 & 90.60 & $182(13 \times 14)$ & 0 \\
\hline
\end{tabular}

Source: ref. 13. 


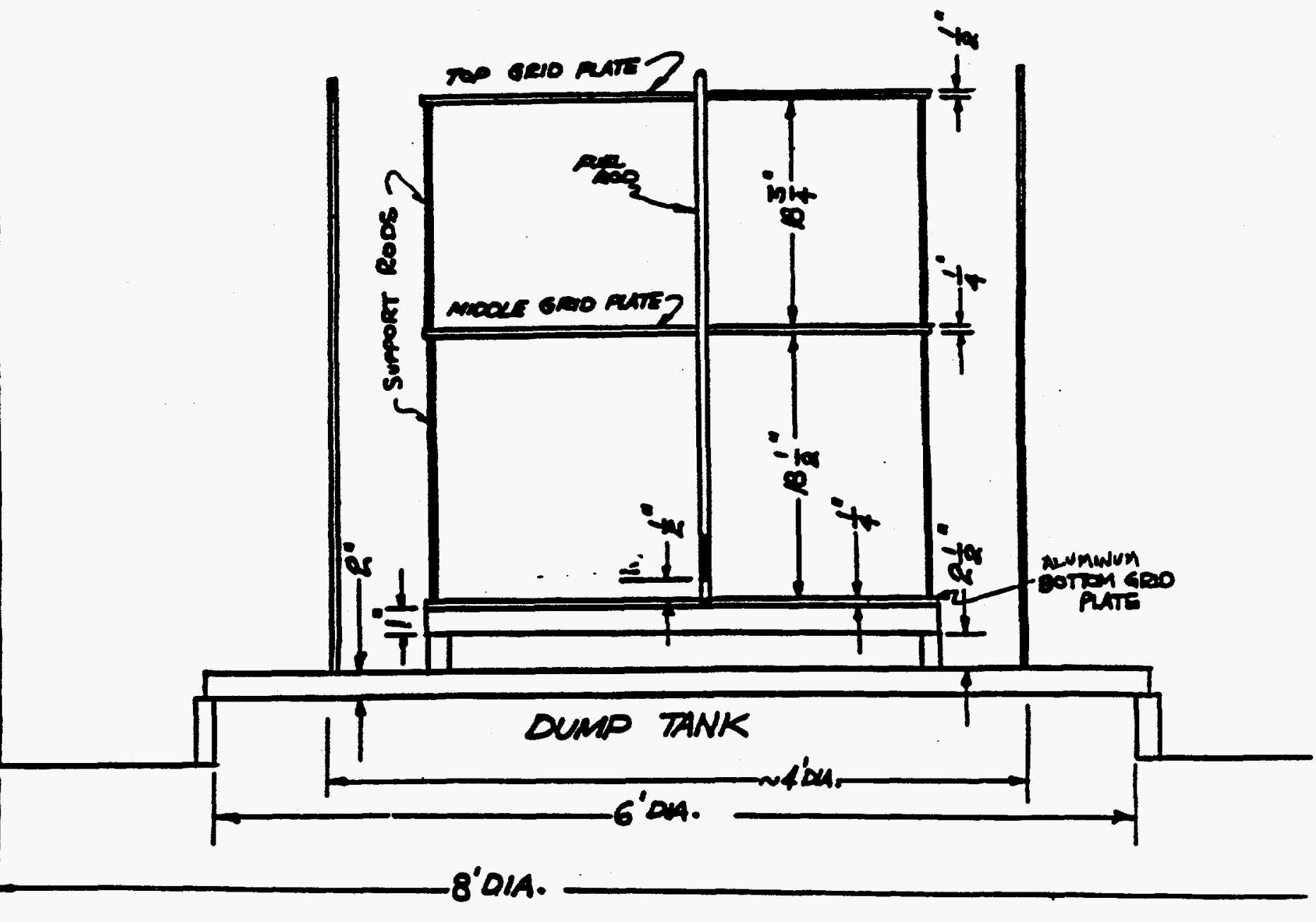

Fig. A.19. Axial view of Saxton experimental setup. Source: ref. 13. 


\section{UO $_{2}$ GADOLINIUM EXPERIMENTS (CASES 20 AND 21)}

These two experiments (bnw1810b and bnw1810c) ${ }^{11}$ were based on the $\mathrm{UO}_{2}$-only configuration of case 15 (bnw1810a), with the addition of $\mathrm{UO}_{2}-\mathrm{Gd}_{2} \mathrm{O}_{3}$ rods in place of selected 4.02 wt $\% \mathrm{UO}_{2}$-only rods. The $\mathrm{UO}_{2}-\mathrm{Gd}_{2} \mathrm{O}_{3}$ fuel rods contained $4 \mathrm{wt} \% \mathrm{Gd} \mathrm{O}_{3}$ and $96 \mathrm{wt} \% \mathrm{UQ}$ $\left(1.944 \mathrm{wt} \%{ }^{23} \mathrm{U}\right.$ ). The cores simulated a $15 \times 15$ lattice PWR checkerboard loading of assemblies containing the gadolinium fuel rods. The center $45 \times 45$ lattice cells of each core can be divided by imaginary lines into nine "fuel assemblies." Five of these assemblies contain varying numbers of $\mathrm{UO}_{2}-\mathrm{Gd}_{2} \mathrm{O}_{3}$ fuel rods. The inner zone $\left(31 \times 31\right.$ lattice cells) contained $4.02 \mathrm{wt} \% \mathrm{UO}_{2}$ fuel rods, and the outer zone contained $2.46 \mathrm{wt} \% \mathrm{UO}_{2}$ fuel rods. The fuel loadings for the two experiments are described in Table A.12 and illustrated in quarter core representations in Figs. A.20 and A.21. The $2.46 \mathrm{wt} \% \mathrm{UO}_{2}$ fuel rods were described previously in Table A.5 and Fig. A.11; the $4.02 \mathrm{wt} \% \mathrm{UO}_{2}$ were described earlier in Table A.7. The $\mathrm{UO}_{2}-\mathrm{Gd}_{2} \mathrm{O}_{3}$ rods are described below in Table A.13.

\section{EPRI-196 MOX EXPERIMENTS (CASES 22-27)}

Eight LWR fuel critical experiments conducted at PNL for EPRI included two $\mathrm{UO}_{2}$-only ( $2.35 \mathrm{wt} \%{ }^{235} \mathrm{U}$ ) and $6 \mathrm{MOX}\left(98 \mathrm{wt} \% \mathrm{UO}_{2}\right.$ and $2 \mathrm{wt} \% \mathrm{PuQ}$ ) water-moderated experiments (epri70b, epri70un, epri87b, epri87un, epri99b, and epri99un). ${ }^{12}$ The $\mathrm{UO}_{2}$-only experiments were described earlier (cases 16 and 17). The $\mathrm{PuO}_{2}$ in the $\mathrm{MOX}$ fuel contained $8 \mathrm{wt} \%{ }^{240} \mathrm{Pu}$. Although the relative distribution of the plutonium isotopes differs from that found in burned LWR fuel, the ratio of $\mathrm{Pu} /{ }^{23} \mathrm{U}$ (2.79) bounds that calculated for such fuel (approximately 1.01). MOX fuel rods were loaded in three different lattice pitches, both with and without boron. A description of the MOX rods is given in Fig. A.22. These experiments were performed from December 1975 to March 1976. The plutonium isotopic distribution and calculated atom densities based on an analysis performed in August 1976 are presented in Table A.14. As noted in the table, the ${ }^{241} \mathrm{Pu}$ and ${ }^{241} \mathrm{Am}$ number densities were then adjusted to February 1976 based on a half-life of 14.5 years for ${ }^{211} \mathrm{Pu}$. The axial view of the experiments is illustrated in Figs. A.23. There was at least 12 in. of water below the lower solid aluminum plate. The specifications for the aluminum "eggcrate" grids are given earlier in Fig. A.16. Note that the 0.87-in.-pitch experiments used a 0.615-in.-lattice-pitch grid and both the 0.70-in.- and 0.99-in.-pitch experiments used the 0.70-in. grids. This arrangement was accomplished by loading every other lattice location in the wider lattice spacing experiment for each grid. This increased the lattice spacing by a factor of $\sqrt{2}$. The core layouts for the experiments are shown in Figs. A.24 through A.29. A water reflector of at least 12 in. was positioned on all sides of each experiment.

\section{SAXTON MOX EXPERIMENTS (CASES 28-33)}

A series of $\mathrm{MOX}$ and $\mathrm{UO}_{2}$ critical experiments were also performed at the Westinghouse Reactor Evaluation Center (WREC) as part of the Saxton Plutonium Program. ${ }^{13}$ The MOX fuel in these experiments was $6.6 \mathrm{wt} \% \mathrm{PuO}_{2}\left(9 \mathrm{wt} \%{ }^{200} \mathrm{Pu}\right)$ compared with $2 \mathrm{wt} \%$ in the PNL experiments. The $\mathrm{Pu} /{ }^{235} \mathrm{U}$ ratio was 10.02, compared with 2.79 in the other set. Each of these experiments also consisted of a single large array of fuel rods in a square lattice arrangement. Six MOX experiments at five different pitches were chosen (saxton52, saxton52b, saxtn735, saxtn792, and saxtn104). 
Table A.12. Gadolinium experiment descriptions

\begin{tabular}{|c|c|c|c|c|c|c|}
\hline Core & Core description & $\begin{array}{l}\text { No. of } \\
2.46 \text { wt } \%{ }^{235} \mathrm{U} \\
\text { fuel pins }\end{array}$ & $\begin{array}{l}\text { No. of } \\
4.02 \mathrm{wt} \%{ }^{23 s} \mathrm{U} \\
\text { fuel pins }\end{array}$ & $\begin{array}{l}\text { No. of Gd } \\
\text { fuel } \\
\text { pins }\end{array}$ & $\begin{array}{l}\text { No. of } \\
\text { water } \\
\text { holes }\end{array}$ & $\begin{array}{l}\text { Moderator } \\
\text { boron } \\
\text { concentration } \\
\text { (ppm) }\end{array}$ \\
\hline bnwl810b & $\begin{array}{l}15 \times 15,12 \mathrm{Gd} \text { pin configuration, } \\
\text { checkerboard, } 1 / 4 \mathrm{Gd} \text { loading } \\
\text { in diagonals }\end{array}$ & 3920 & 860 & 28 & 153 & $1653.8 \pm 0.7$ \\
\hline
\end{tabular}

Source: ref. 11. 


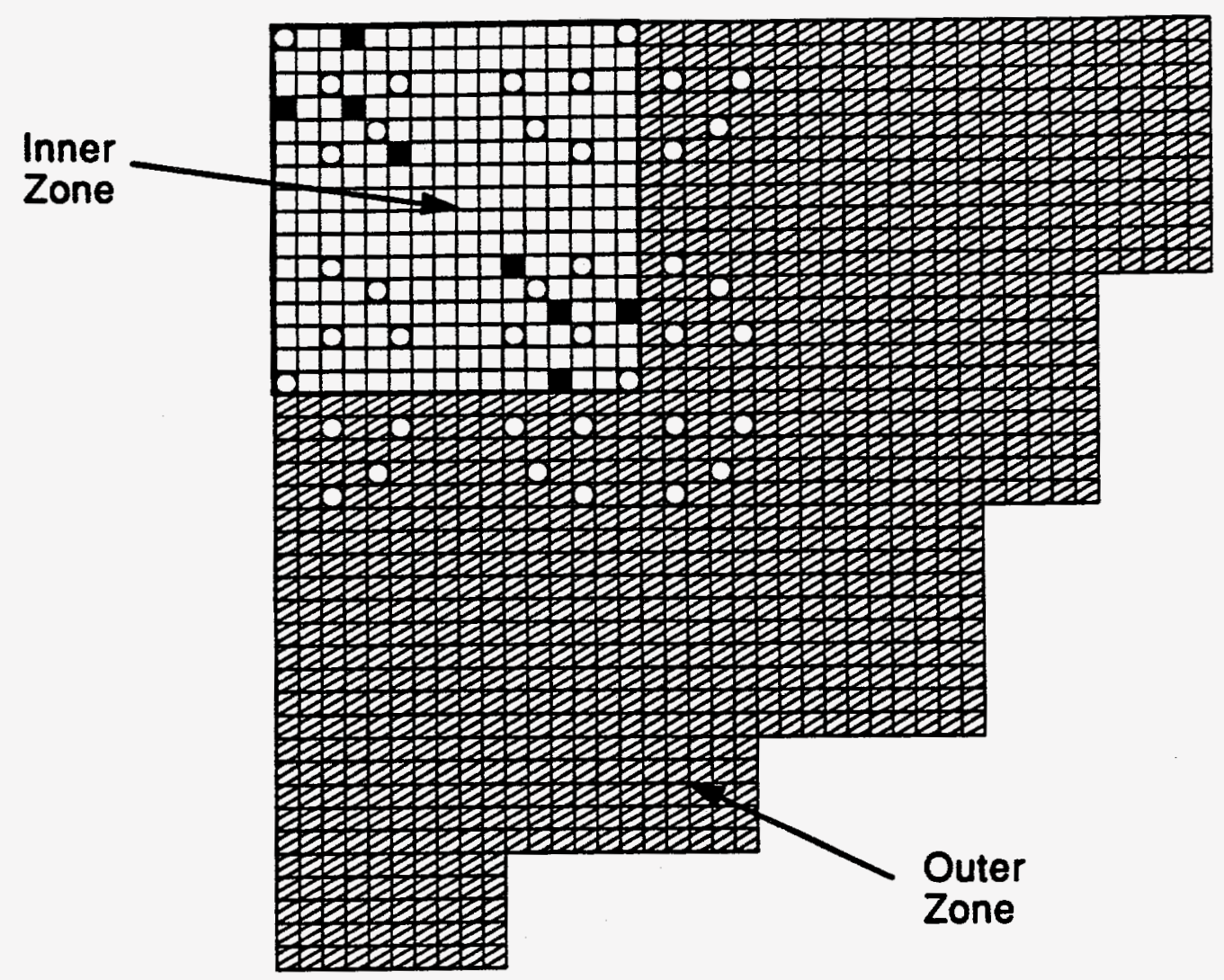

口 VACANT WATER-FILLED POSITION

$\square 2.46 w t \%$ U-235 ENRICHED FUEL: OUTER ZONE

$\square 4.02$ wt \% U-235 ENRICHED FUEL: INNER ZONE

$4.00 \mathrm{wt} \% \mathrm{Gd}_{2} \mathrm{O}_{3} / 1.94 \mathrm{wt} \%$ U-235 ENRICHED FUEL

Fig. A.20. Gadolinium experiment bnw1810b quarter-core (symmetric) loading diagram. Source: ref. 11. 
OANL-DWG 93Z-13100

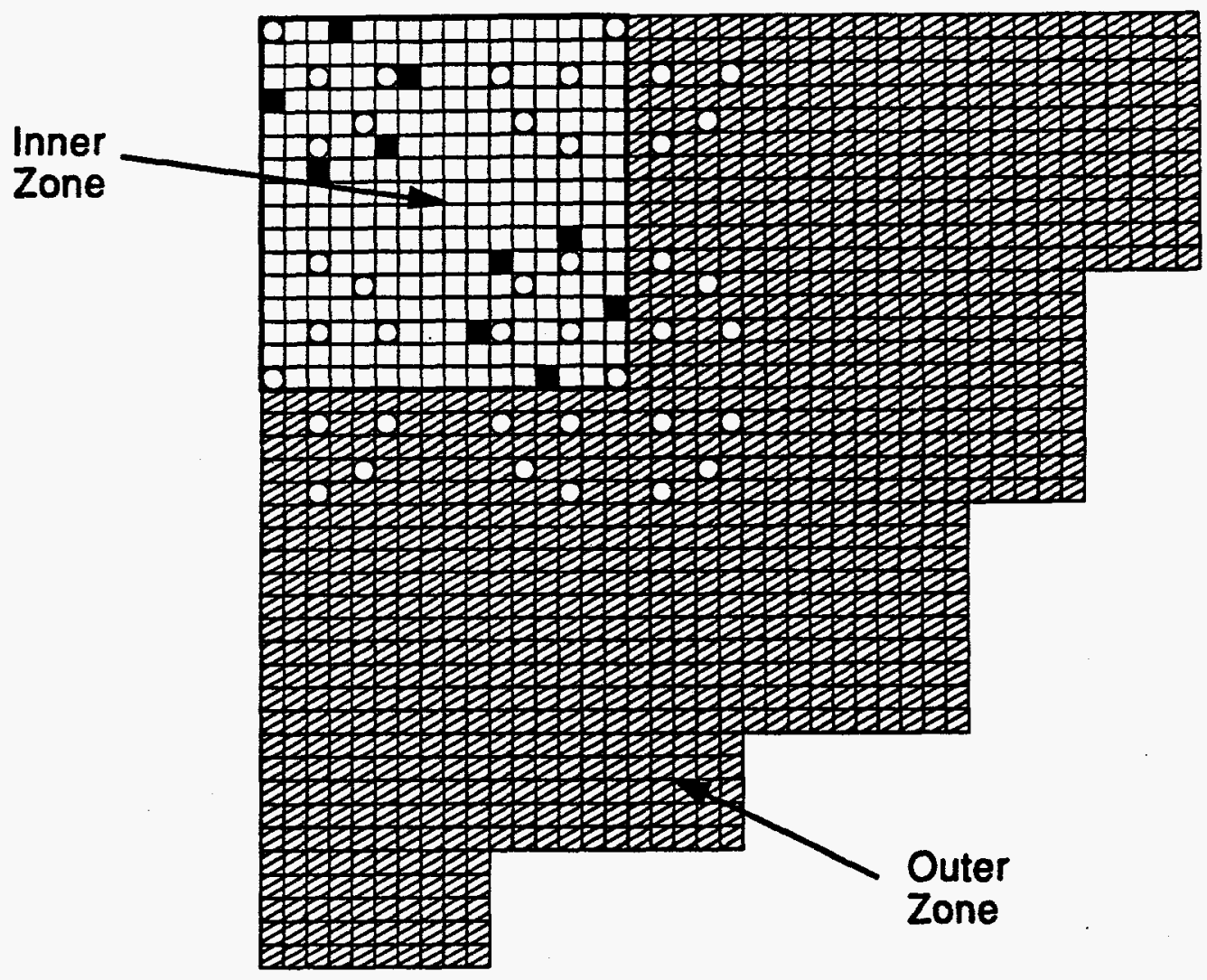

口 VACANT WATER-FILLED POSITION

曰 $2.46 w t \%$ U-235 ENRICHED FUEL: OUTER ZONE 4.02 wt \% U-235 ENRICHED FUEL: INNER ZONE - $4.00 \mathrm{wt} \% \mathrm{Gd}_{2} \mathrm{O}_{3} / 1.94 \mathrm{wt} \%$ U-235 ENRICHED FUEL

Fig. A.21. Gadolinium experiment bnw1810c quarter-core (symmetric) loading diagram. Source: ref. 11. 
Table A-13. Physical properties of 1.944 wt \% enriched

$\mathrm{UO}_{2}-\mathrm{Gd}_{2} \mathrm{O}_{3}$ fuel rods for gadolinium experiments

\begin{tabular}{ll}
\hline \multicolumn{1}{c}{ Parameter } & \multicolumn{1}{c}{ Value } \\
\hline Outside diameter, cm (in.) & $1.0973(0.432)$ \\
Wall thickness, cm (in.) & $0.0813(0.032)$ \\
Wall material & Type 6063 aluminum \\
Fuel diameter, cm (in.) & $1.030(0.4055)$ \\
Total length, cm (in.) & $160.0(63.0)^{\circ}$ \\
Active fuel length, cm (in.) & $153.4(60.4)$ \\
Wt \% UO ${ }_{2}$ & 96 \\
Wt \% Gd ${ }_{3}$ & 4 \\
Enrichment, ${ }^{25} \mathrm{U} / \mathrm{U}$, wt \% & 1.944 \\
Fuel density, g/cm & $10.22^{b}$ \\
\hline
\end{tabular}

Includes 0.125-in.-thick Al plug at top and bottom.

Assumed to be identical to that of the $2.46 \mathrm{wt} \% \mathrm{UO}_{2}$ Al clad rods (see Table A-5).

Source: ref. 29. 
CLAD: $1.435 \pm 0.003 \mathrm{~cm}$ OD $x 0.076 \mathrm{~cm}$ WALL

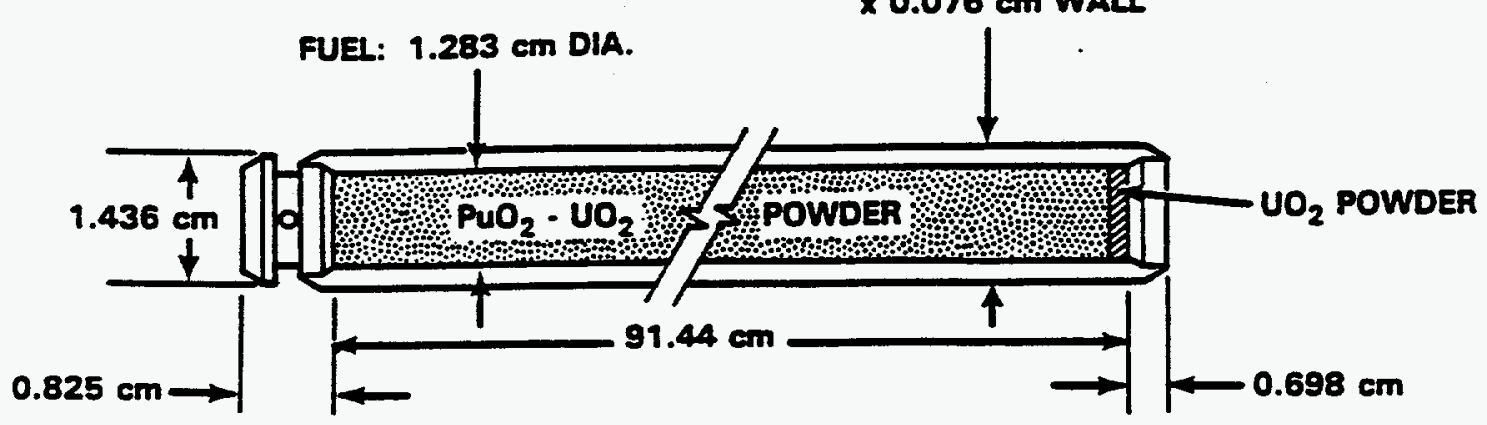

CLADDING: ZIRCALOY-2 TUBING WITH PLUGS SEAL WELDED AT BOTH ENDS

LOADING:

ENRICHMENT - 2.00 WT\% $\mathrm{PUO}_{2}$ IN NATURAL $\mathrm{UO}_{2}$ OXIDE DENSITY $-9.54 \mathrm{~g} / \mathrm{cm}^{3}$

$\mathrm{PuO}_{2}+\mathrm{UO}_{2}-1128 \mathrm{~g} / \mathrm{ROD}$

$\mathrm{Pu}-20.169 \pm 0.004 \mathrm{~g} / \mathrm{ROD}$

$U \cdot 970.306 \pm 0.225 g / R O D$

$\mathrm{UO}_{2}$ POWDER - NATURAL URANIUM ABOUT $0.2 \mathrm{~cm}$ THICK

Fig. A.22. Description of MOX fuel rods for EPRI experiments. Source: ref. 12. 
Table A.14. MOX fuel compositions in EPRI experiments

\begin{tabular}{|c|c|}
\hline \multicolumn{2}{|c|}{ Measured data } \\
\hline Isotopic wt $\%{ }^{238} \mathrm{Pu}^{a}$ & $0.009 \pm 0.002$ \\
\hline Isotopic wt \% ${ }^{239} \mathrm{Pu}^{a}$ & $91.835 \pm 0.018$ \\
\hline Isotopic wt $\%^{210} \mathrm{Pu} u^{a}$ & $7.760 \pm 0.018$ \\
\hline Isotopic wt $\%{ }^{211} \mathrm{Pu}^{a}$ & $0.367 \pm 0.004$ \\
\hline Isotopic wt \% ${ }^{212} \mathrm{Pu}^{a}$ & $0.028 \pm 0.002$ \\
\hline Concentration (ppm) ${ }^{241} \mathrm{Am}^{6}$ & $64.6 \pm 0.3$ \\
\hline $\mathrm{Wt} \% \mathrm{U}^{b}$ & $86.02 \pm 0.06$ \\
\hline $\mathrm{Wt} \% \mathbf{P u}^{b}$ & $1.788 \pm 0.001$ \\
\hline
\end{tabular}

Calculated atom densities of fuel constituents

\begin{tabular}{|c|c|c|}
\hline \multirow[t]{2}{*}{ Isotope } & \multicolumn{2}{|c|}{ Atom density (atoms $/ \mathrm{b}-\mathrm{cm}$ ) } \\
\hline & February 1976 & August 1976 \\
\hline${ }^{238} \mathrm{Pu}$ & & $3.8850 \times 10^{-8}$ \\
\hline${ }^{239} \mathrm{Pu}$ & & $3.9477 \times 10^{-4}$ \\
\hline${ }^{200} \mathrm{Pu}$ & & $3.3218 \times 10^{-5}$ \\
\hline${ }^{241} \mathrm{Pu}^{\mathrm{c}}$ & $1.6023 \times 10^{-6}$ & $1.5645 \times 10^{-6}$ \\
\hline${ }^{242} \mathrm{Pu}$ & & $1.1887 \times 10^{-7}$ \\
\hline${ }^{241} \mathrm{Am}^{\circ}$ & $1.5024 \times 10^{-6}$ & $1.5402 \times 10^{-6}$ \\
\hline${ }^{234} \mathrm{U}$ & & $1.2462 \times 10^{-6}$ \\
\hline${ }^{235} \mathrm{U}$ & & $1.4891 \times 10^{-4}$ \\
\hline${ }^{236} \mathrm{U}$ & & $2.0943 \times 10^{-9}$ \\
\hline${ }^{238} \mathrm{U}$ & & $2.0619 \times 10^{-2}$ \\
\hline Oxygen & & $4.3763 \times 10^{-2}$ \\
\hline$\rho$ (oxide mixture) $=$ & & $9.54 \mathrm{~g} / \mathrm{cm}^{3}$ \\
\hline
\end{tabular}

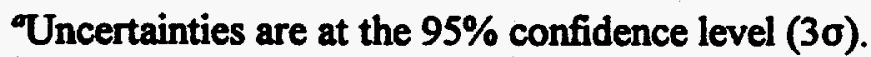

Uncertainties are at the $67 \%$ confidence level $(1 \sigma)$. (ppm) ${ }^{241} \mathrm{Am}$ concentration is given in terms of the total $\mathrm{UO}_{2}-\mathrm{PuO}_{2}$ mixture weight.

'Calculated as follows:

Half-life of ${ }^{241} \mathrm{Pu}=14.5 \mathrm{y}$

$\lambda_{241_{\mathrm{Pu}}-241_{\mathrm{Am}}}=0.047803 / \mathrm{y}$

$\mathrm{N}_{241_{\mathrm{Pu}}}$ (February 1976) $\mathrm{e}_{-\lambda t}=\mathrm{N}_{241_{\mathrm{Pu}}}$ (August 1976), where $\mathrm{t}=0.5 \mathrm{y}$

$\mathrm{N}_{241}$ Am (February 1976) $=\mathrm{N}_{241}$ Am (August 1976) $-\Delta_{241} \mathrm{Pu}$.

Source: ref. 12. 
FULLY RELLCTED

MODERATOR HEIGHT 106

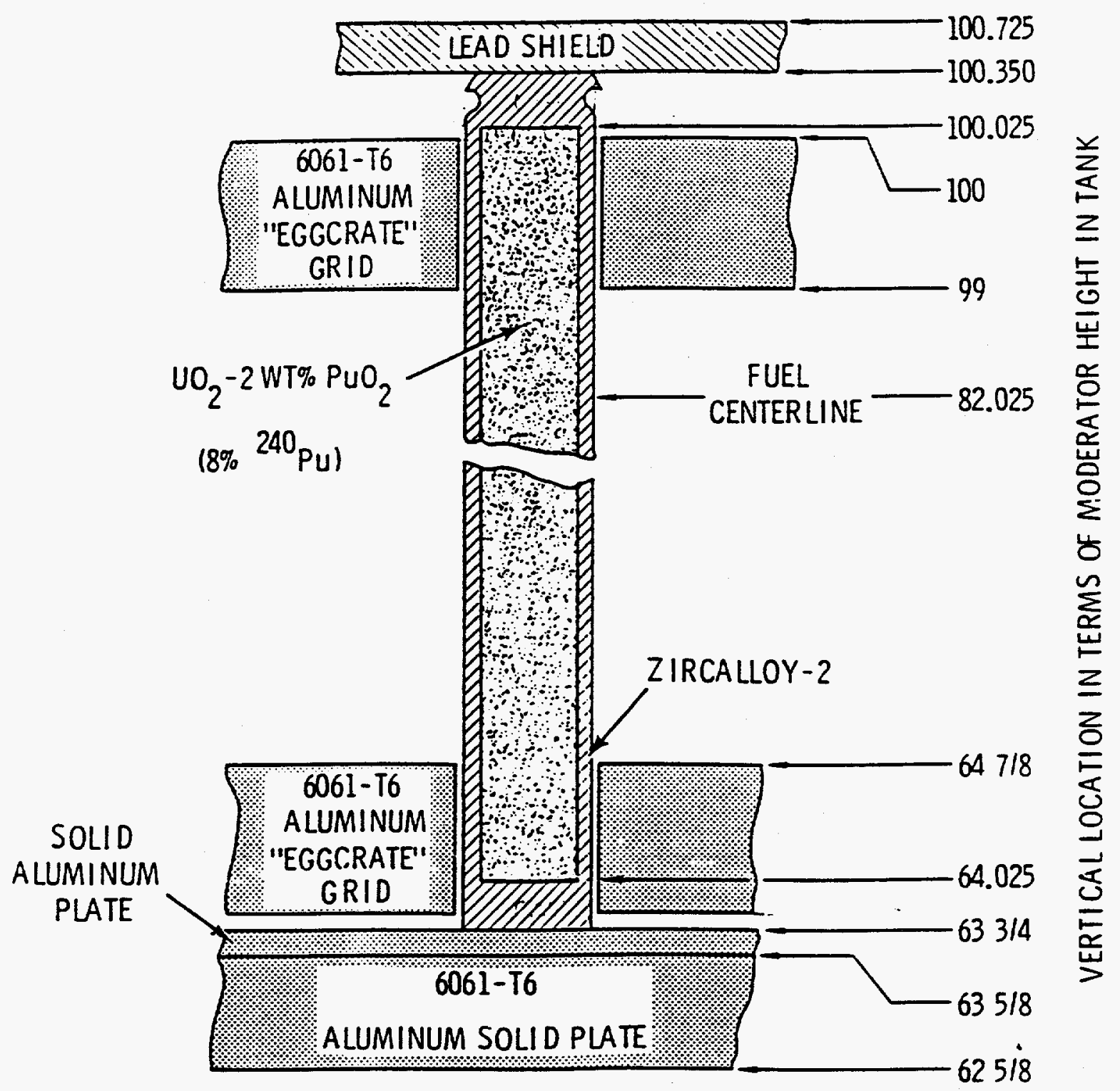

Fig. A.23. $\mathrm{UO}_{2}-2$ wt $\% \mathrm{PuO}_{2}$ "eggcrate" core structure dimensions for EPRI experiments. Source: ref. 12. 


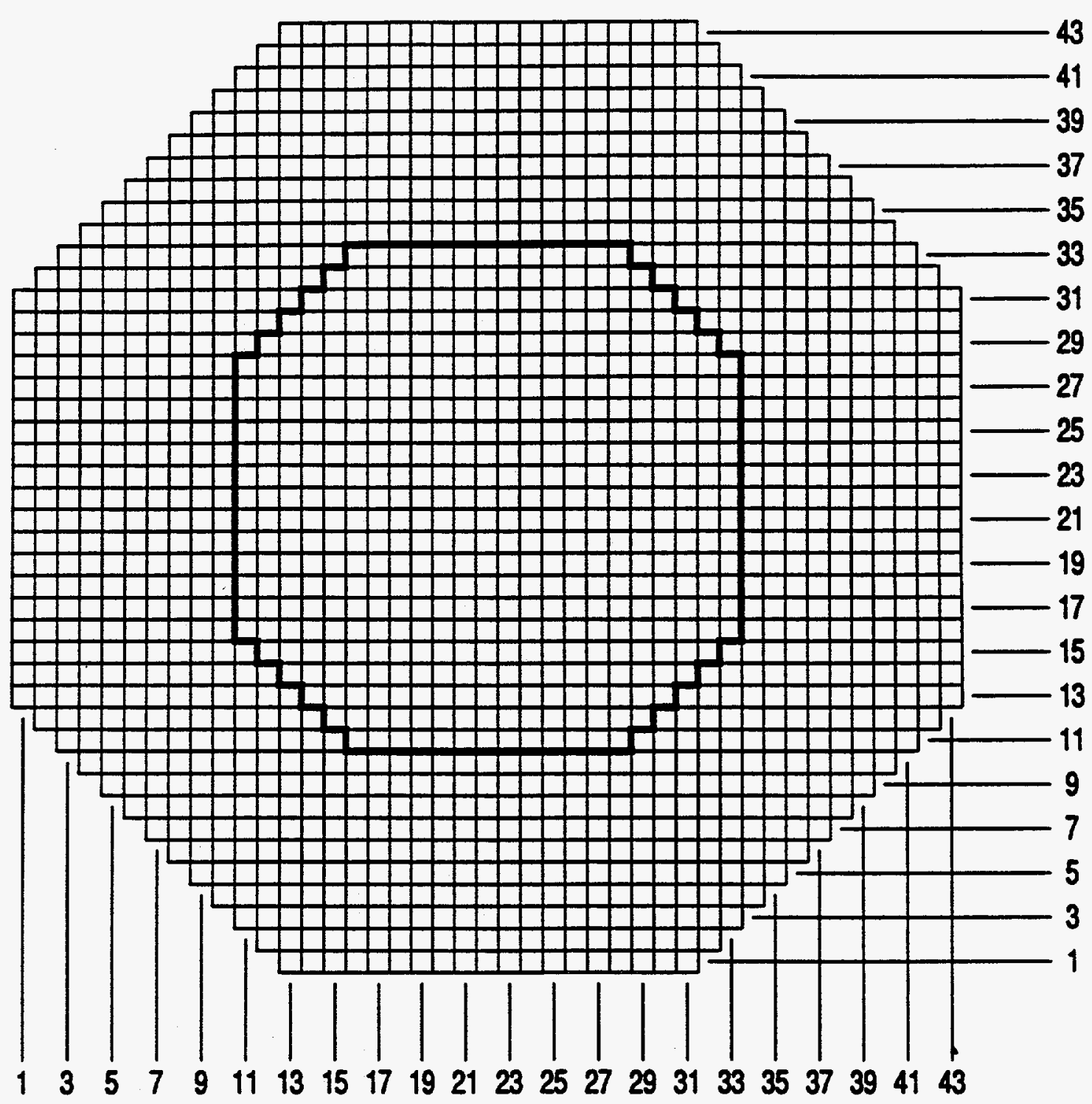

Fig. A.24. Unborated EPRI 0.70-in. $\mathrm{UO}_{2}-2 \mathrm{wt} \% \mathrm{PuO}_{2}$ core. Source: ref. 12. 
ORNL-DWG 93Z-13102

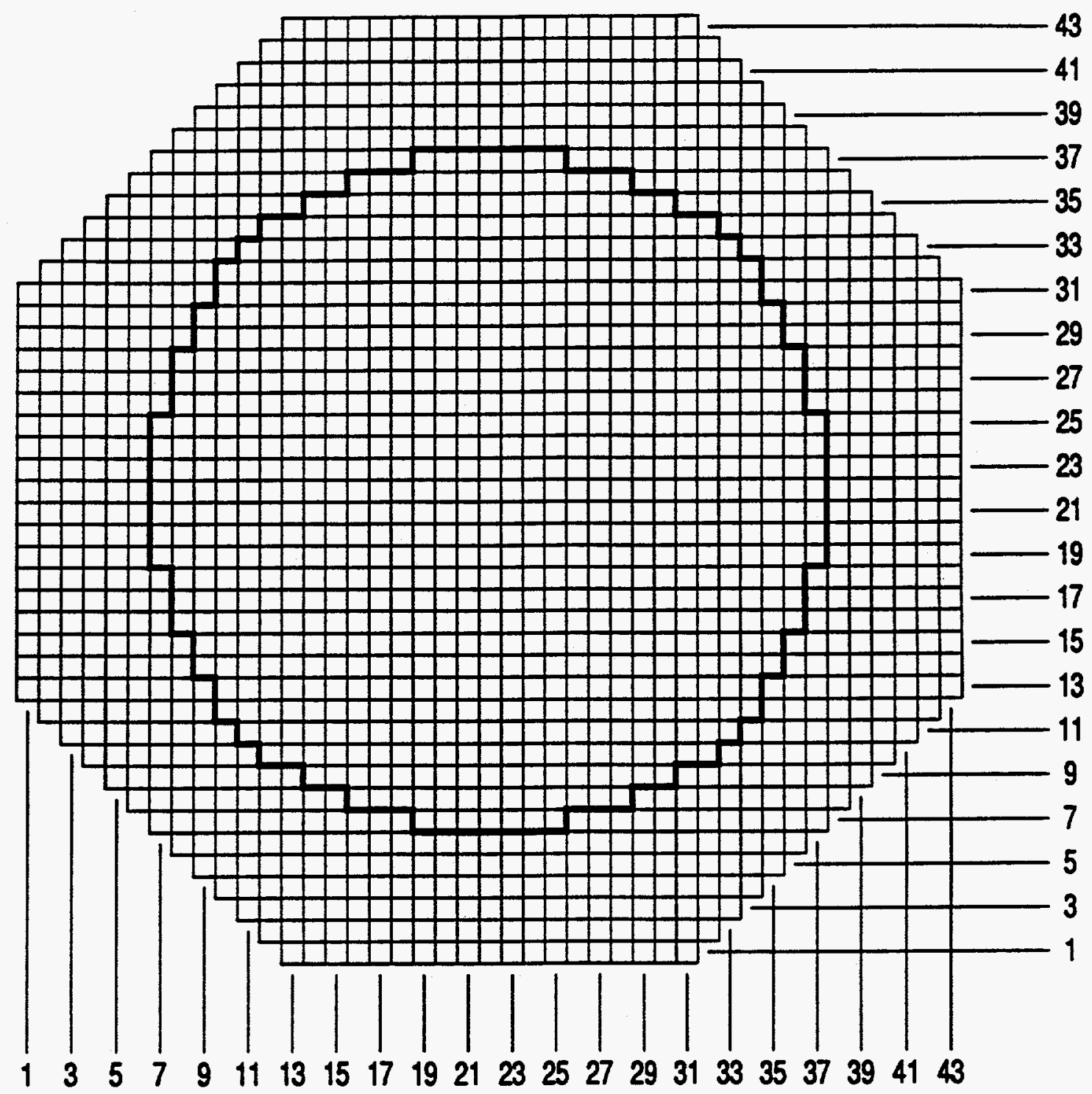

Fig. A.25. Borated EPRI 0.70-in. $\mathrm{UO}_{2}-2$ wt $\% \mathrm{PuO}_{2}$ core. Source: ref. 12. 


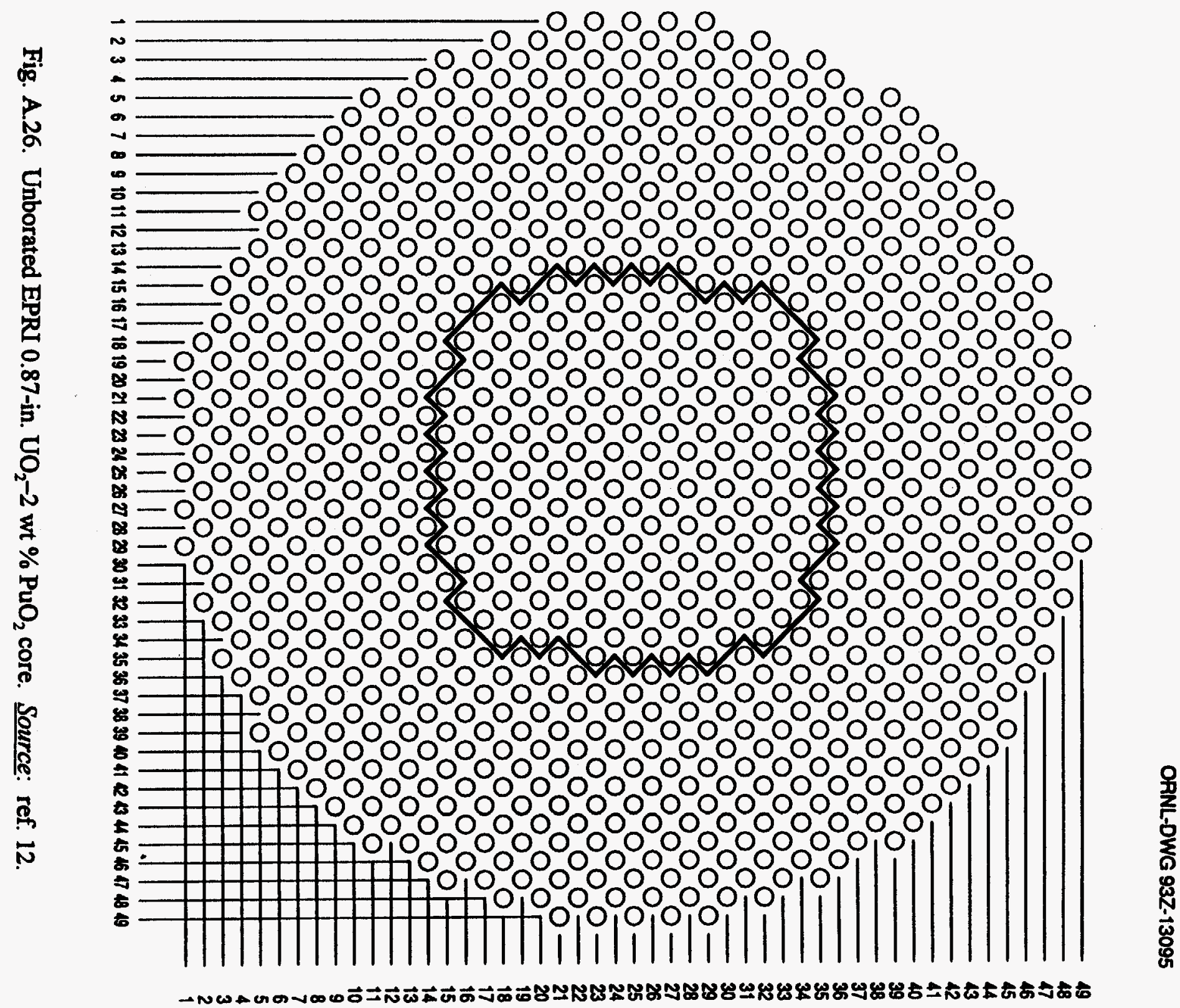


ORNL-DWG 93Z-13096

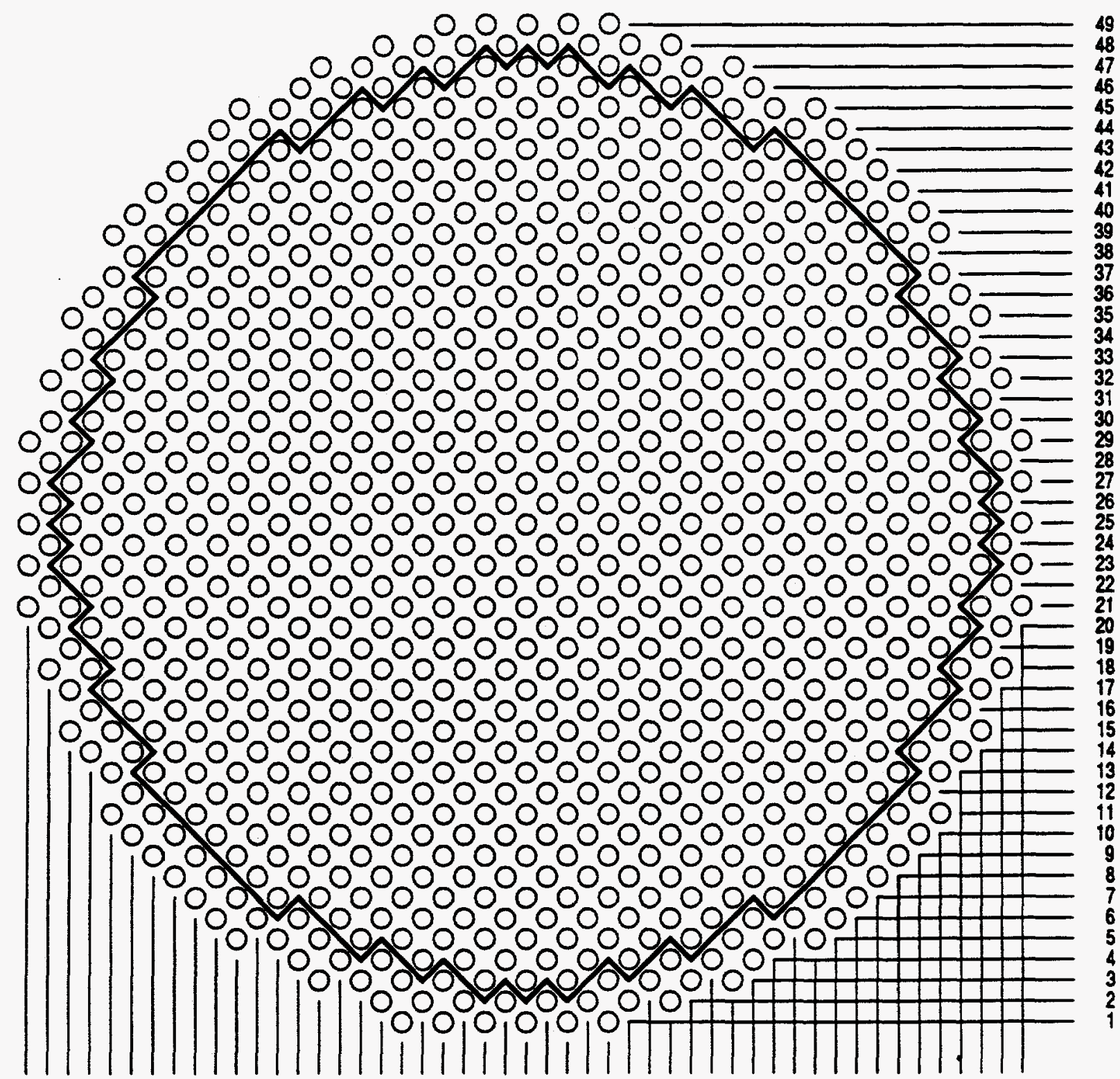

1234567891011121314151617181920212223242526272829303132333435363738394041244454748

Fig. A.27. Borated EPRI 0.87-in. $\mathrm{UO}_{2}-2 \mathrm{wt} \% \mathrm{PuO}_{2}$ core. Source: ref. 12. 


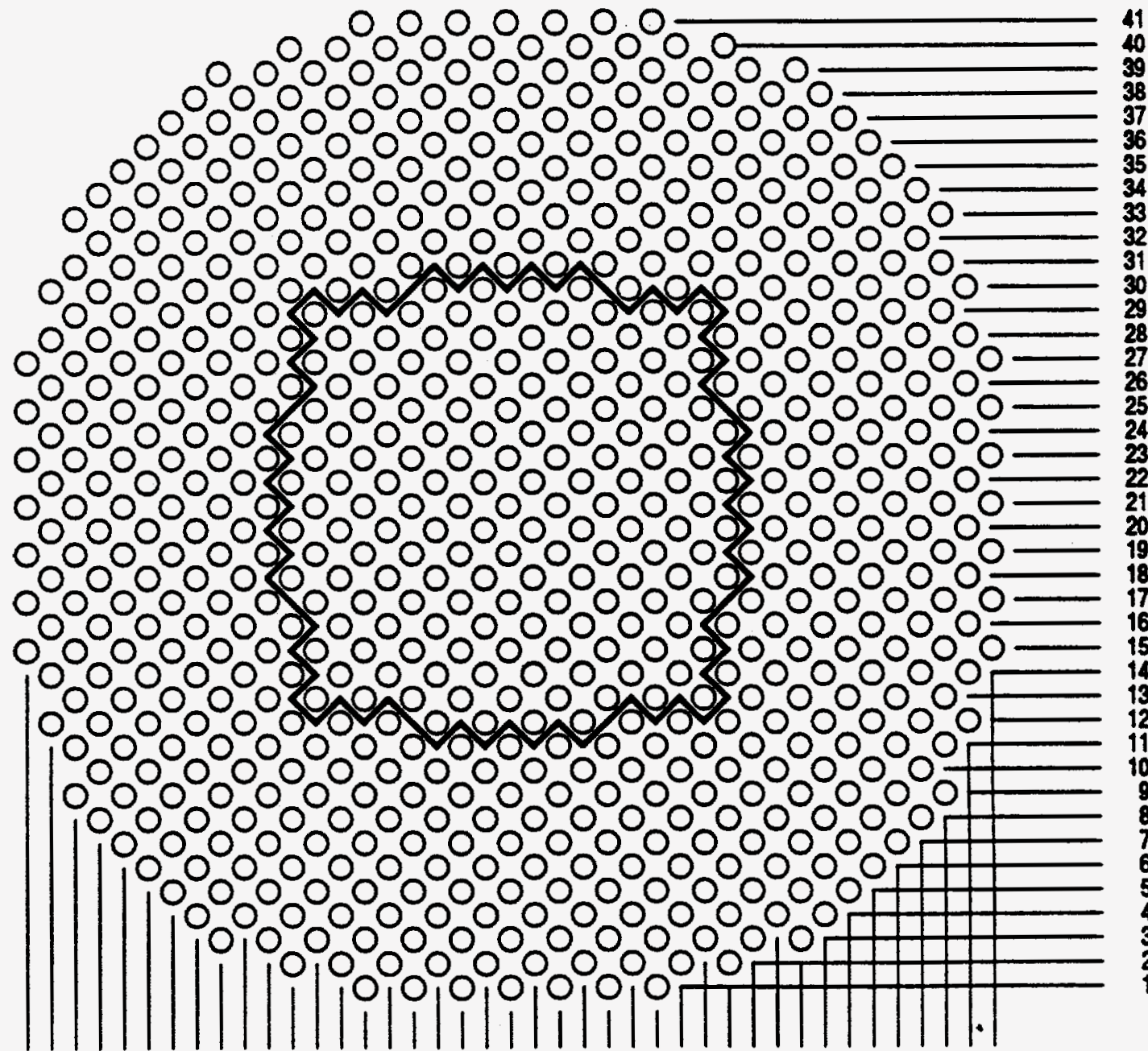

1234567891011124314151617181920212223242526272829303132333435383738394041

Fig. A.28. Unborated EPRI 0.99-in. $\mathrm{UO}_{2}-2$ wt $\% \mathrm{PuO}_{2}$ core. Source: ref. 12. 
ORNL-DWG 93Z-13098

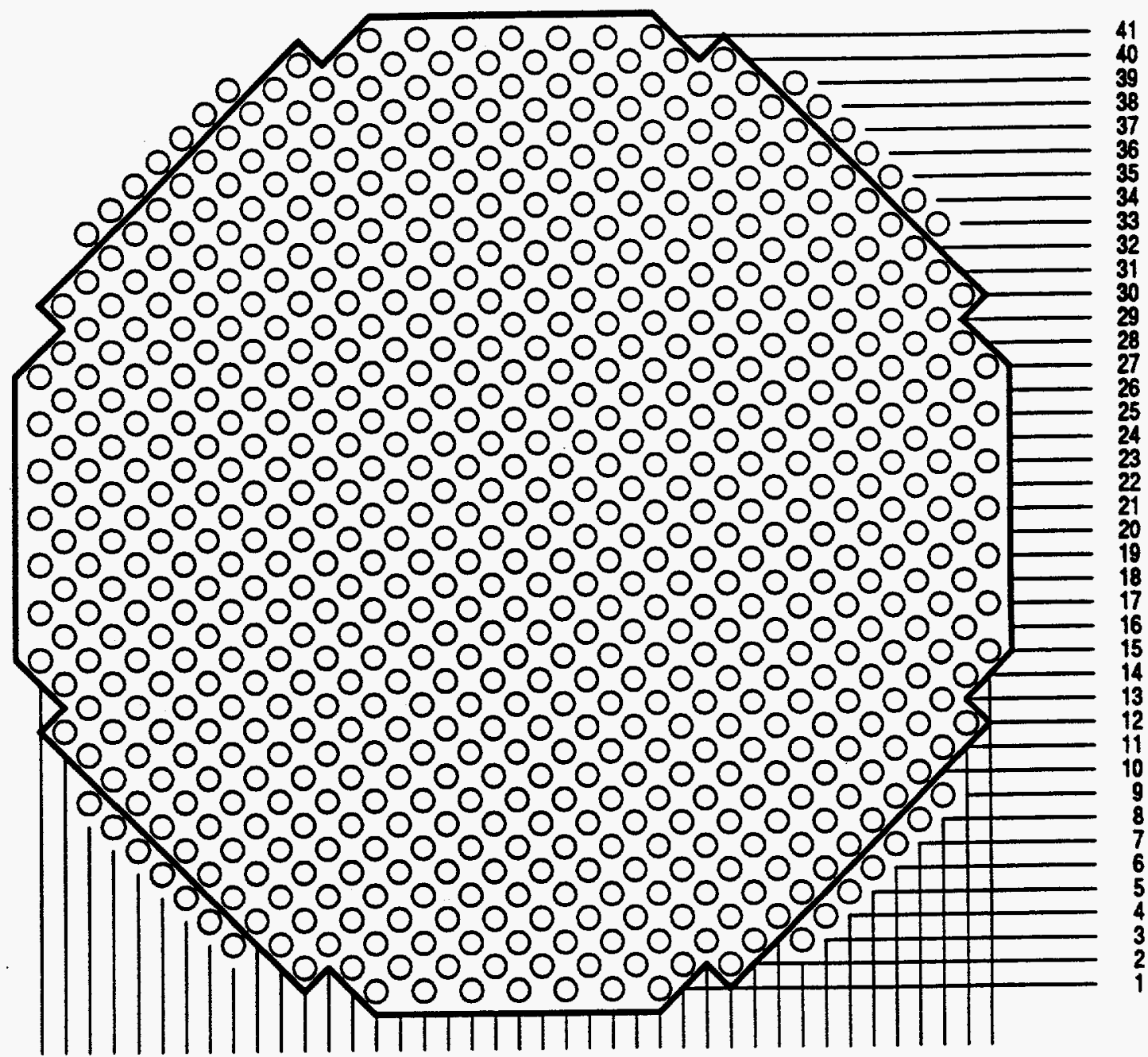

12345678910111213141516171819202122824252627282930313233343536738394041

Fig. A.29. Borated EPRI 0.99-in. $\mathrm{UO}_{2}-2$ wt $\% \mathrm{PuO}_{2}$ core. Source: ref. 12. 
The experiments are listed in Table A.15. The fuel rod specifications for both fuel types are provided in Table A.16. An axial view of the experimental setup was shown in Fig. A.19. As with the $\mathrm{UO}_{2}$-only experiments, three grid plates were used to support the fuel rods. The fuel rod holes in the aluminum grid plates were $1.008 \mathrm{~cm}$ in diameter. The grid plates were supported at each comer with $1.111-\mathrm{cm}(7 / 16-$ in.) stainless steel support rods covered with $1.588-\mathrm{cm}(5 / 8-\mathrm{in}$.) aluminum pipe.

Table A.15. Saxton MOX critical experiment descriptions

\begin{tabular}{lcccc}
\hline $\begin{array}{c}\text { Pitch } \\
\text { (in./cm) }\end{array}$ & $\begin{array}{c}\text { Water/fuel } \\
\text { volume ratio }\end{array}$ & $\begin{array}{c}\text { Critical } \mathrm{H}_{2} \mathrm{O} \\
\text { height }(\mathrm{cm})^{\mathrm{a}}\end{array}$ & $\begin{array}{c}\text { Critical } \\
\text { No. of rods }\end{array}$ & $\begin{array}{c}\text { Boron } \\
\text { concentration } \\
\text { (ppm) }\end{array}$ \\
\hline $0.52 / 1.321$ & 1.681 & 84.56 & $506(22 \times 23)$ & \\
$0.56 / 1.422$ & 2.165 & 82.96 & $361(19 \times 19)$ & 0 \\
$0.56 / 1.422$ & 2.165 & 89.70 & $441(21 \times 21)$ & 337 \\
$0.735 / 1.867$ & 4.699 & 70.11 & $169(13 \times 13)$ & 0 \\
$0.792 / 2.012$ & 5.673 & 78.43 & $144(12 \times 12)$ & 0 \\
$1.04 / 2.642$ & 10.754 & 81.17 & $121(11 \times 11)$ & 0 \\
\hline
\end{tabular}

Measured from the bottom of the fuel.

Saurce: ref. 13.

Table A.16. Saxton MOX fuel rod specifications

\begin{tabular}{ll}
\hline Pellet diameter, cm (in.) & $0.857(0.3374)$ \\
Clad O.D., cm (in.) & $0.993(0.391)$ \\
Clad I.D., cm (in.) & $0.875(0.3445)$ \\
Clad material & Zircaloy 4 \\
\% theoretical density & 94 \\
Fuel length, cm (in.) & $92.96(36.6)$ \\
Enrichment & $6.6 \mathrm{wt} \% \mathrm{PuO}_{2}$ \\
Theoretical density (g/cc) & $11.46\left(\mathrm{PuO}_{2}\right)$ \\
Weight percent of ${ }^{239} \mathrm{Pu}$ & 90.49 \\
Weight percent of ${ }^{240} \mathrm{Pu}$ & 8.57 \\
Weight percent of ${ }^{241} \mathrm{Pu}$ & 0.89 \\
Weight percent of ${ }^{242} \mathrm{Pu}$ & 0.04 \\
\hline Source: ref. 13. &
\end{tabular}


PNL-4976 MOX EXPERIMENT (CASE 34)

The final MOX experiment (pnl4976) simulated the uranium depletion and plutonium buildup of spent fuel by placing $\mathrm{MOX}$ and $\mathrm{UO}_{2}$ fuel rods in a uniform distribution to obtain a $\mathrm{Pu} /{ }^{23} \mathrm{U}$ ratio approximating that of 20,000-MWdMTU burnup. The experiment consisted of a large circular array of $583 \mathrm{PuO}_{2}-\mathrm{UO}_{2}$ rods $\left(2 \mathrm{wt} \% \mathrm{PuO}_{2}, 98 \mathrm{wt} \%\right.$ natural $\mathrm{UO}_{2}$ ) and $11744.31 \mathrm{wt} \%$ enriched $\mathrm{UO}_{2}$ rods in a triangular lattice. The specifications for the MOX rods are identical to those used in the EPRI experiments (Table A-14, Figs. A.22 and A.23), except for the plutonium composition, which is given in Table A.17. The $\mathrm{UO}_{2}$ rods are identical to those previously described in Fig. A.1. The fuel rods were placed at a triangular-lattice pitch of $1.598 \mathrm{~cm}$. Each $\mathrm{PuO}_{2}-\mathrm{UO}_{2}$ rod was surrounded by six $\mathrm{UO}_{2}$ rods (see Fig. A.30). The axial view of the experiment is illustrated in Fig. A.31.

Table A.17. Plutonium composition for experiment pnl4976

\begin{tabular}{ll}
\hline Isotopic wt $\%{ }^{238} \mathrm{Pu}$ & $0.10 \pm 0.001$ \\
Isotopic wt $\%{ }^{239} \mathrm{Pu}$ & $91.806 \pm 0.551$ \\
Isotopic wt $\%{ }^{240} \mathrm{Pu}$ & $7.876 \pm 0.394$ \\
Isotopic wt $\%{ }^{241} \mathrm{Pu}$ & $0.277 \pm 0.008$ \\
Isotopic wt $\%{ }^{242} \mathrm{Pu}$ & 0.031 \\
Concentration $(\mathrm{ppm}){ }^{241} \mathrm{Am}$ & 76 \\
\hline
\end{tabular}

Source: ref. 14. 


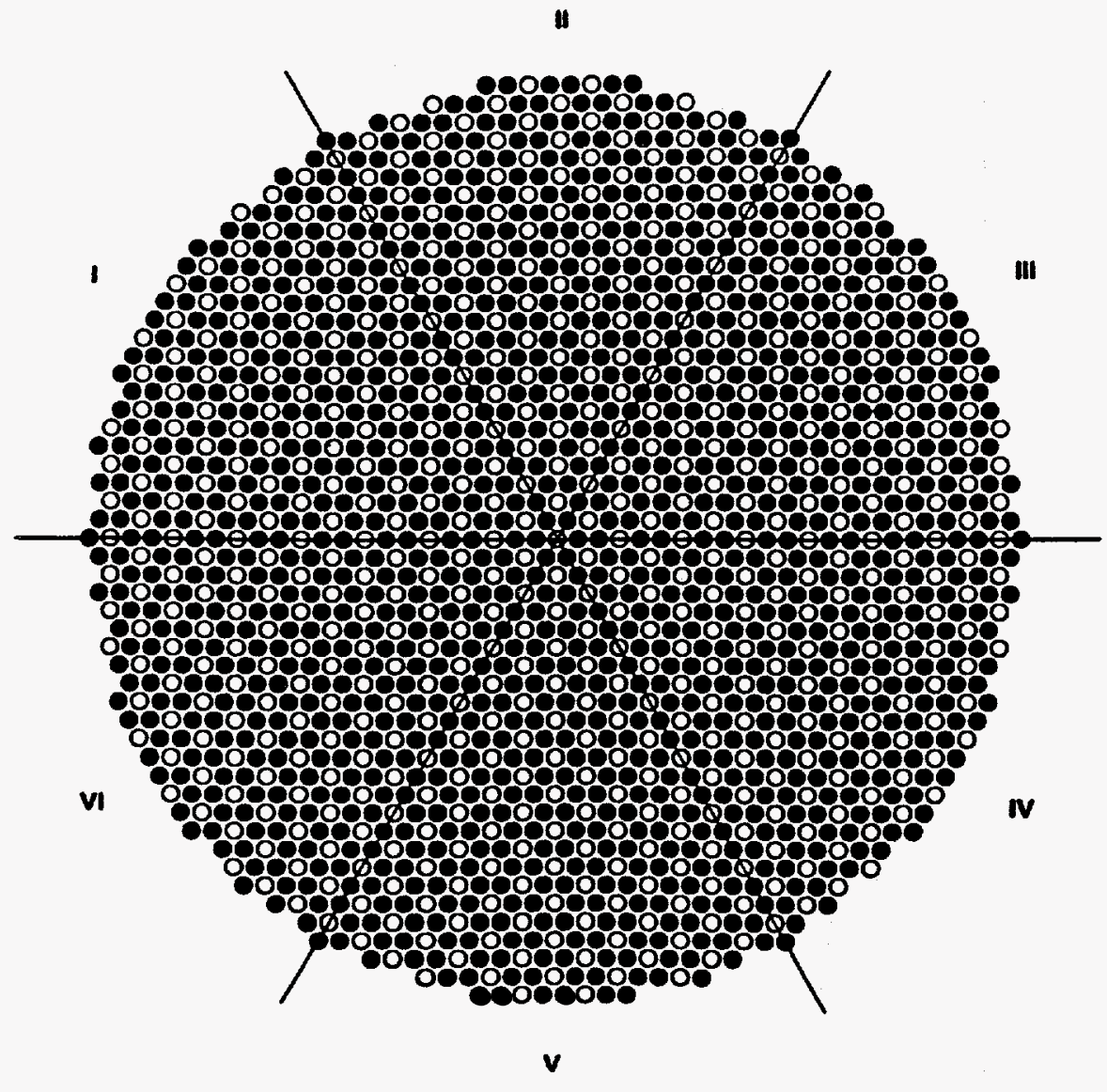

FUEL: 4.31 wI\% 235 ENAICHED UO
NATURAL UNO $\mathrm{PUO}_{2}$ CONTAINING 2.0 wt\% $\mathrm{PuO}_{2}$ EXPERIMENT: 4.3-002-196

LATTICE: 32

PITCH: $1.598 \pm 0.005 \mathrm{~cm}$

GADOLNIUM: SEE COMMENTS

CONTROL ROD: NONE

SAFETY ROD: NONE

REACTION RATES: NONE

RODS: $583 \mathrm{MO}_{2}$ RODS AT O PUUS $1174 \mathrm{UO}_{2}$ RODS AT

koff: SEE COMMENTS

COMMENTS: PERIPHERIAL UNUSED LATTICE

kaff $=1.0 \quad$ AT ZERO g Gd/liter

kaff $=0.957$ AT $0.194 \pm 0.001 \mathrm{~g}$ Gd/liter

$k_{\text {off }}=0.931$ LT $0.408 \pm 0.006 \mathrm{~g} \mathrm{Gd} /$ ilier

$k_{\text {off }}=0.914$ AT $0.626 \pm 0.008 \mathrm{~g}$ Gd/liter

$k_{\text {aff }}=0.891$ AT $0.818 \pm 0.015 \mathrm{~g} \mathrm{Gd} / \mathrm{liter}$

Fig. A.30. Fuel loading for experiment pnl4976. Source: ref. 14. 


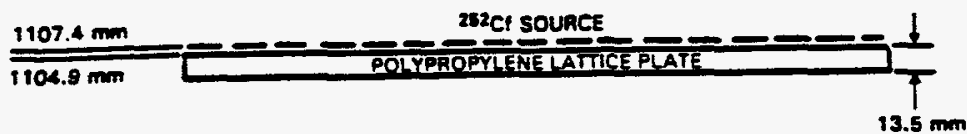

$848.49 \mathrm{~mm}$ gotTOM OF $6.35 \mathrm{~mm}$ THICX MrE gost at SPACERS

$701.68 \mathrm{~mm}$

BOTIOM OF REACTION RATE PACKETS
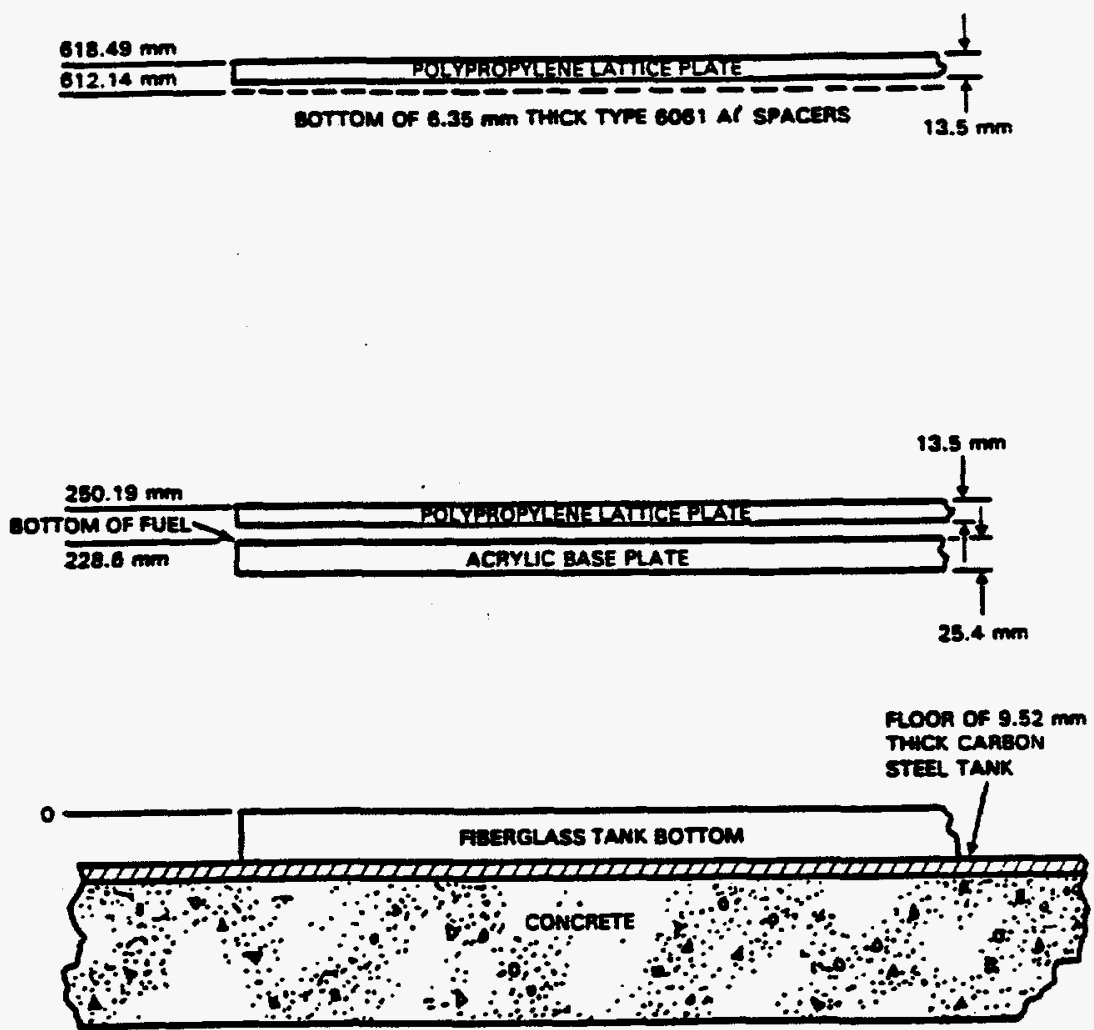

Fig. A.31. Assembly elevations for experiment pn14976. Source: ref. 14. 
.

, 


\section{APPENDIX B}

\section{SCALE-4 INPUT LISTINGS FOR THE 34 FRESH FUEL CRITICALS}

(Listed alphabetically by case designation)

\section{baw1484a}

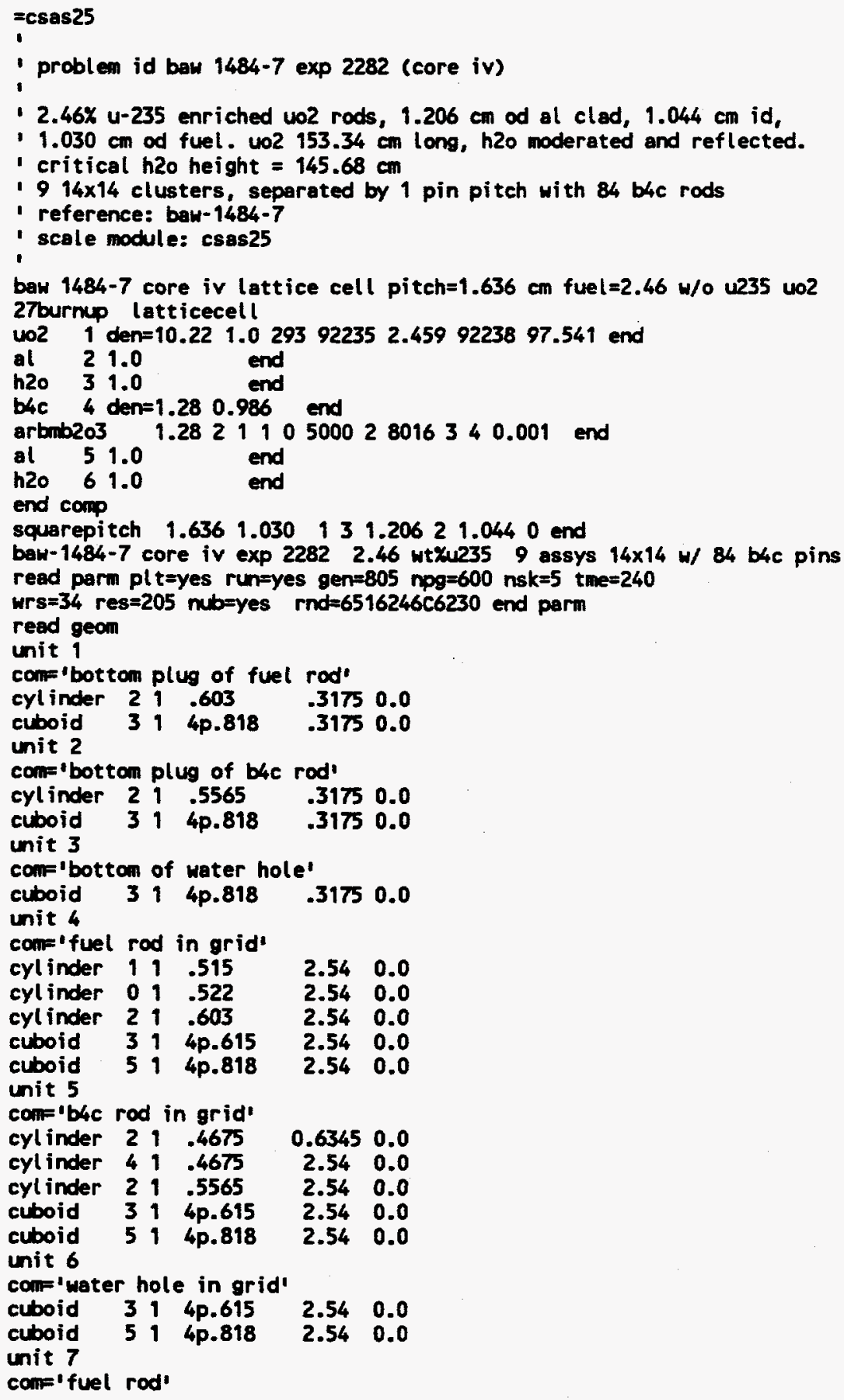


cylinder $11 \quad .515$

cylinder 011.522

cylinder 21.603

cuboid $3: 4 p .818$

unit 8

com=' b/c rod'

cyl inder 41.4675

cylinder $21 \quad .5565$

cuboid $314 \mathrm{p} .818$

unit 9

com='water hole'

$\begin{array}{lllll}\text { cuboid } & 31 & 4 p .818 & 142.8225 & 0.0\end{array}$

comp'fuel rod'

array $1 \quad 3 * 0.0$

unit 12

com='blac pin'

array $2 \quad 3 * 0.0$

unit 13

comin' water hole'

array $3 \quad 3 * 0.0$

unit 14

com='fuel assy'

array $43 * 0.0$

unit 15

conl='bottom vertical row of ble pins'

array $5 \quad 3 \star 0.0$

unit 16

com='middle vertical row of b4c pins'

array $63 \star 0.0$

unit 17

conk' top vertical row of b4c pins'

array $7 \quad 3 * 0.0$

unit 18

conflbotton row of assenblies '

array $8 \quad 3 * 0.0$

unit 19

com='middle row of assemblies'

array $9 \quad 3 * 0.0$

unit 20

conf' top row of assemblies

array $10 \quad 3 * 0.0$

unit 21

comf'horizontal row of bac pins'

array $11 \quad 3 * 0.0$

global unit 22

array $12 \quad 3 * 0.0$

cuboid $5171.984 \quad 0.071 .984 \quad 0.0 \quad 145.68 \quad-5.08$

$\begin{array}{lllllllll}\text { cuboid } 6 & 1 & 71.984 & 0.0 & 71.984 & 0.0 & 145.68 & -7.62\end{array}$

reflector $62 \quad 4 r 32$ ro 8

end geom

read bias id=500 29 end bias

read array

cons='fuel rod' are=1 mux=1 myr=1 nuz=3

complb/4c pin' are=2 nux=1 nuy=1 nuz=3

con='water hole' ara=3 nux=1 nuy=1 nuz=3

compl fuel assy' ara=4 nux=14 my $=14$ muz=1

ara=5 mux=1 nuy=14 nuz=1 fill $12 \quad 13 \quad 692$

ara $=6$ nux $=1$ nuy=14 nuz=1

ara $=7$ nux $=1$ nuy $=14$ nuz $=1$

ara $=8$ nux=5 nuy=1 nuz=1

ara $=9$ nux $=5$ nuy $=1$ nuz $=1$

13 end till

fill 147 end fill

fill 258 end fill

fill 369 and fill

and fill

ara=10 nux=5 nuy=1 nuz=1 fill $14 \quad 17 \quad 14 \quad 17 \quad 14$ end fill

ara $=11$ nux $=44$ nuy $=1$ nuz=1

$\begin{array}{llllllllll}\text { fill } & 13 & 13 & 12 & 1392 & 12 & 12 & 13 & 692 & \text { end fill }\end{array}$

ara=12 nux=1 nuy=5 nuz=i fill $1821 \quad 192120$ end fill

end array

read plot 
$t+l=1 x-y$ slice below grid plate'

xul $=-0.5 \quad$ yul $=72.5 \quad$ zul $=0.2$

$x l r=72.5 \quad y l r=-0.5 \quad z l r=0.2$

$\omega_{a x}=1$ voln=-1 nax $=260$ nch=1 12456789 ! end

$t t l=1 x-y$ slice of grid plate'

xul $=-0.5 \quad$ yul $=72.5 \quad$ zul $=2$.

$x \mid r=72.5 \quad y / r=-0.5 \quad z l r=2$.

uax $=1$ vahn=-1 nax=260 nch=1 12456789 ' end

$t t l=1 x-y$ slice above grid plate'

xul $=-0.5 \quad$ yul $=72.5 \quad z u l=50$.

$x l r=72.5 \quad y l r=-0.5 \quad z l r=50$.

uax=1 von=-1 nax=260 nch=1 12456789 1 end end plot

end date

end 


\section{bnw1810a}

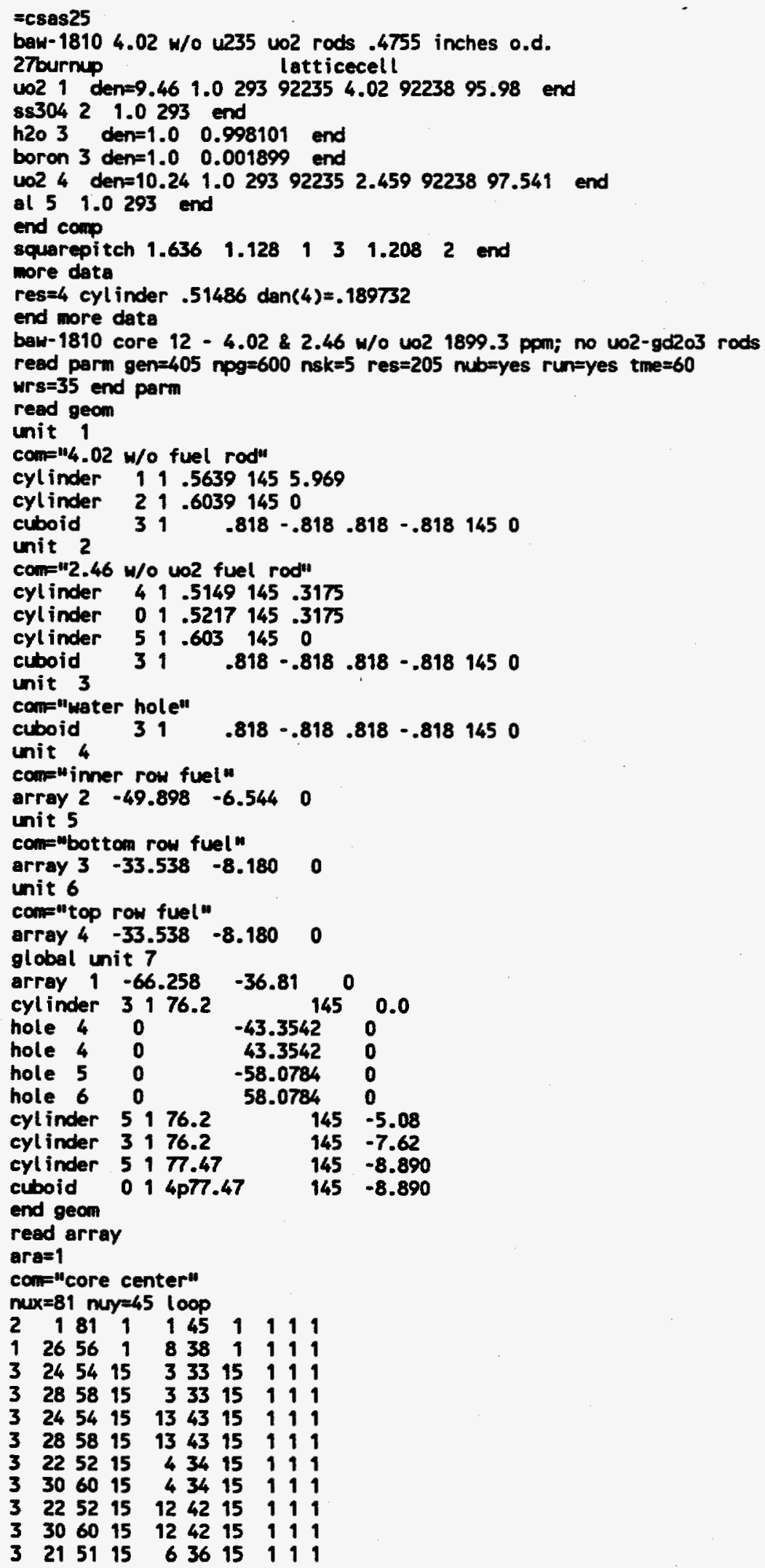




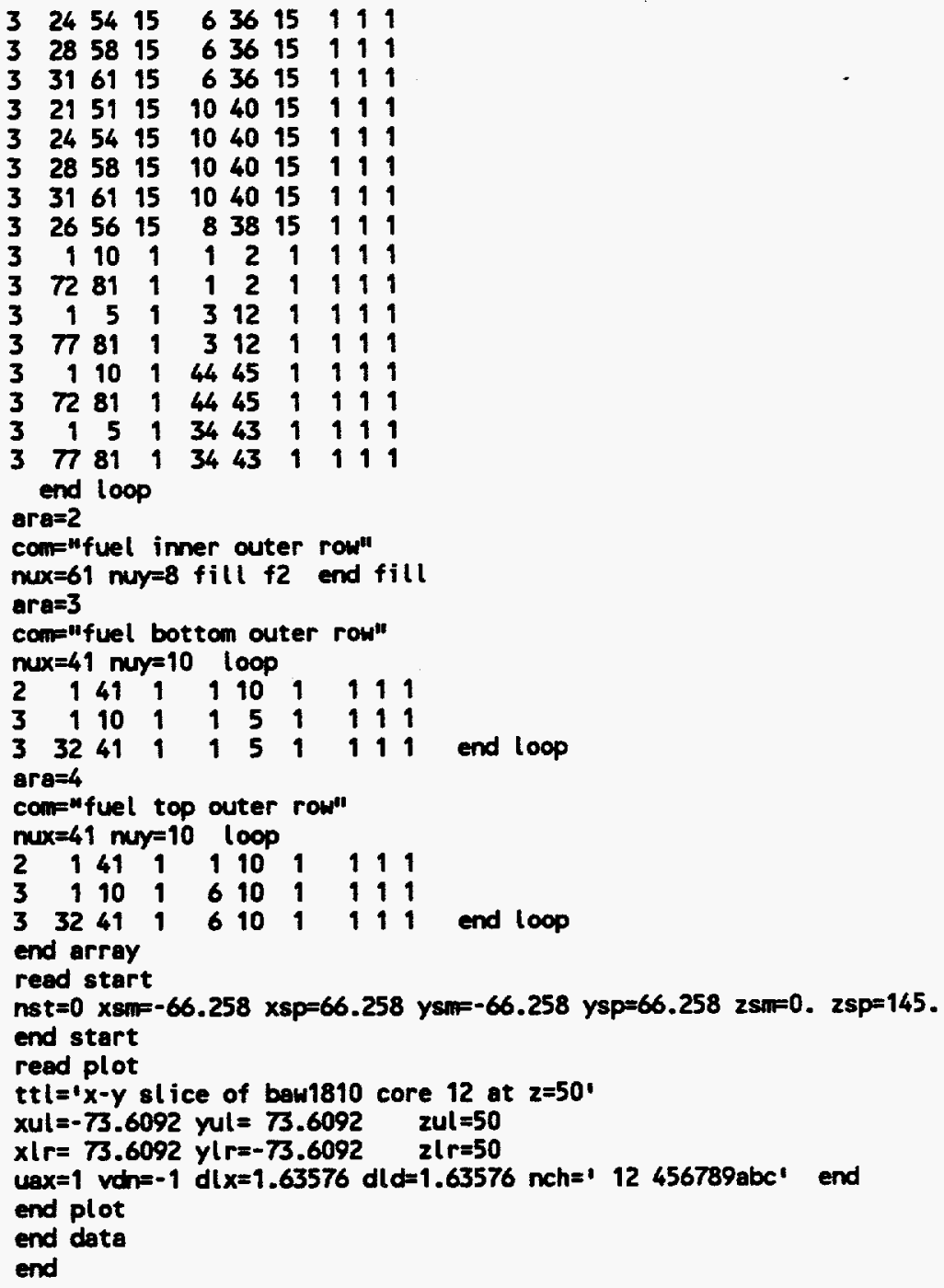




\section{bnw1810b}

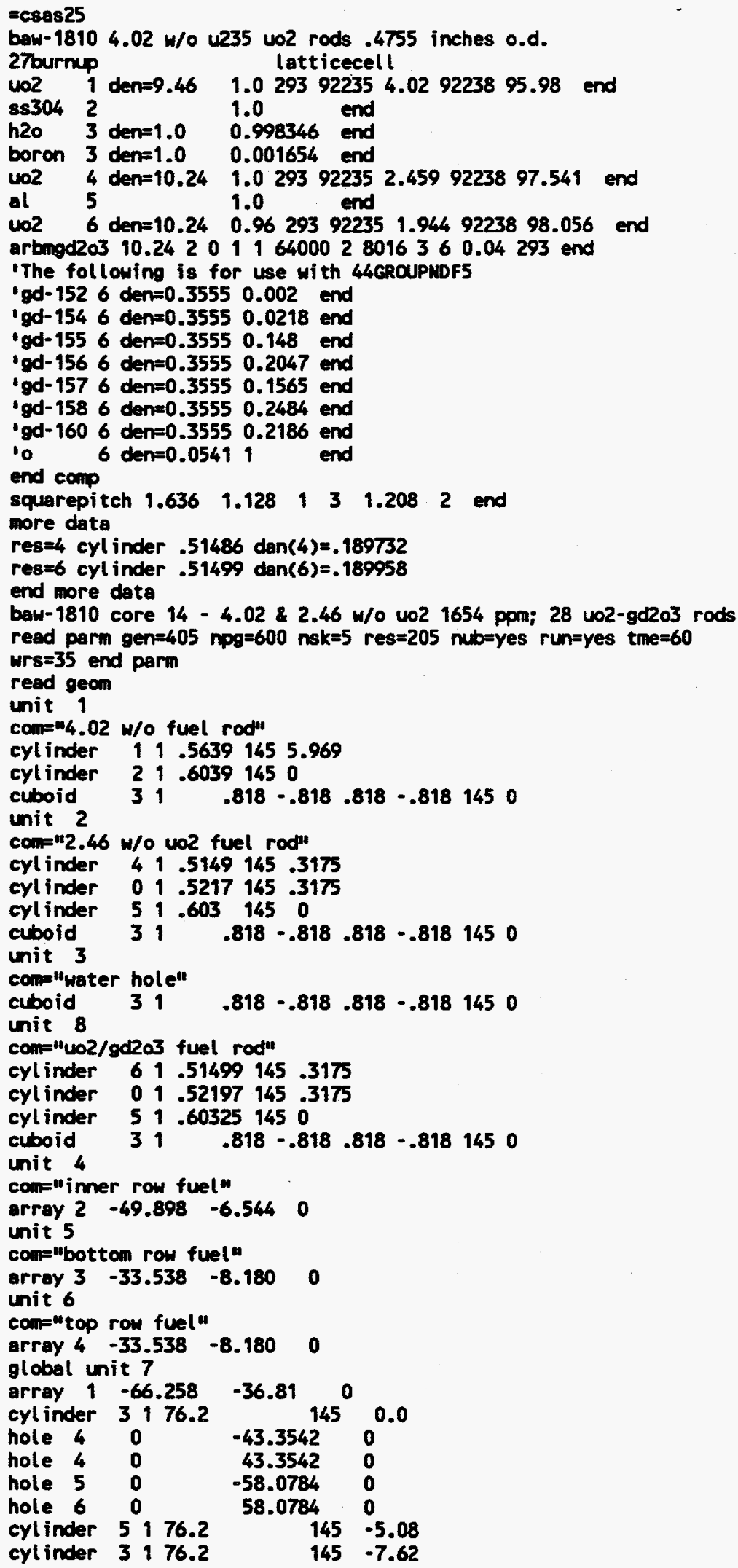




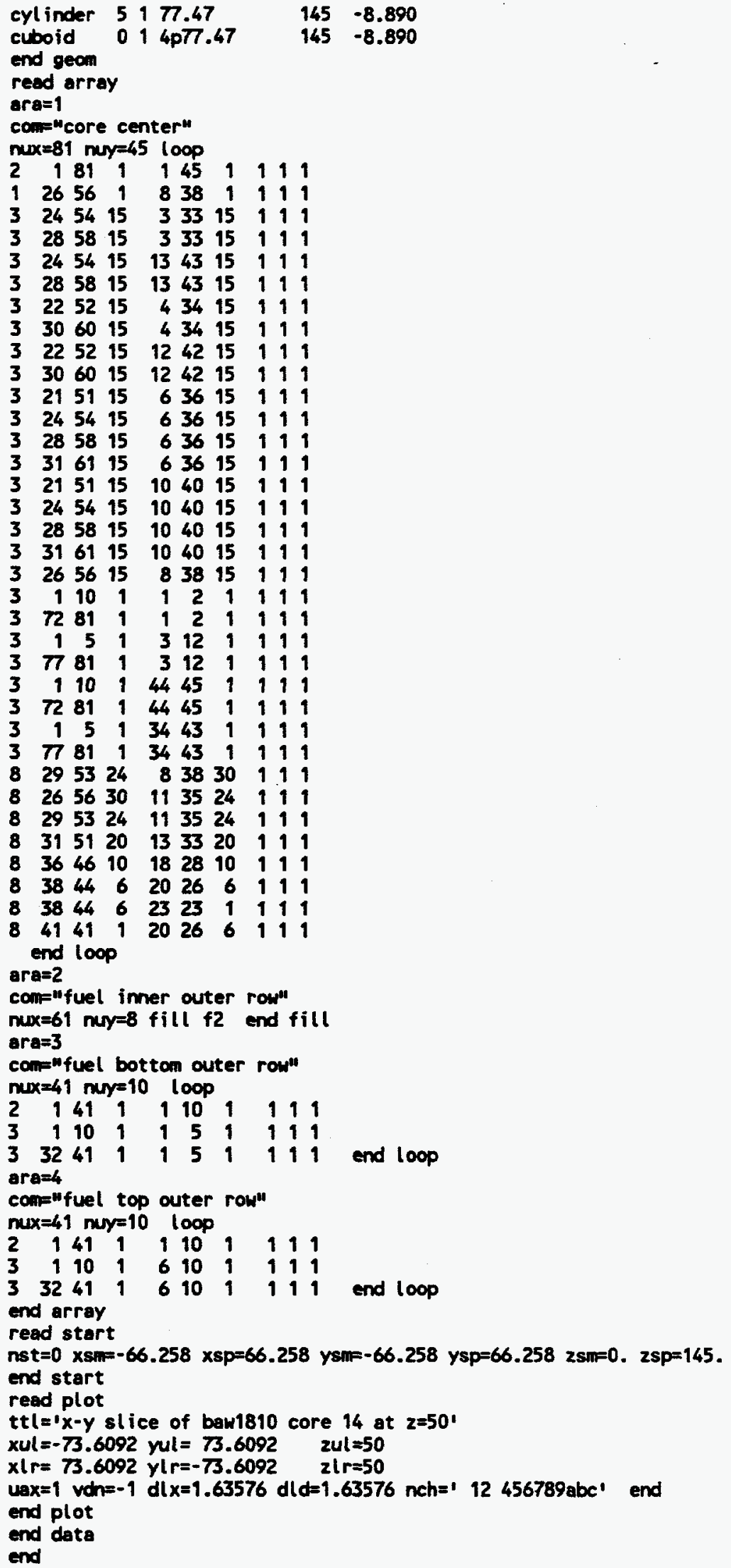




\section{bnw1810c}

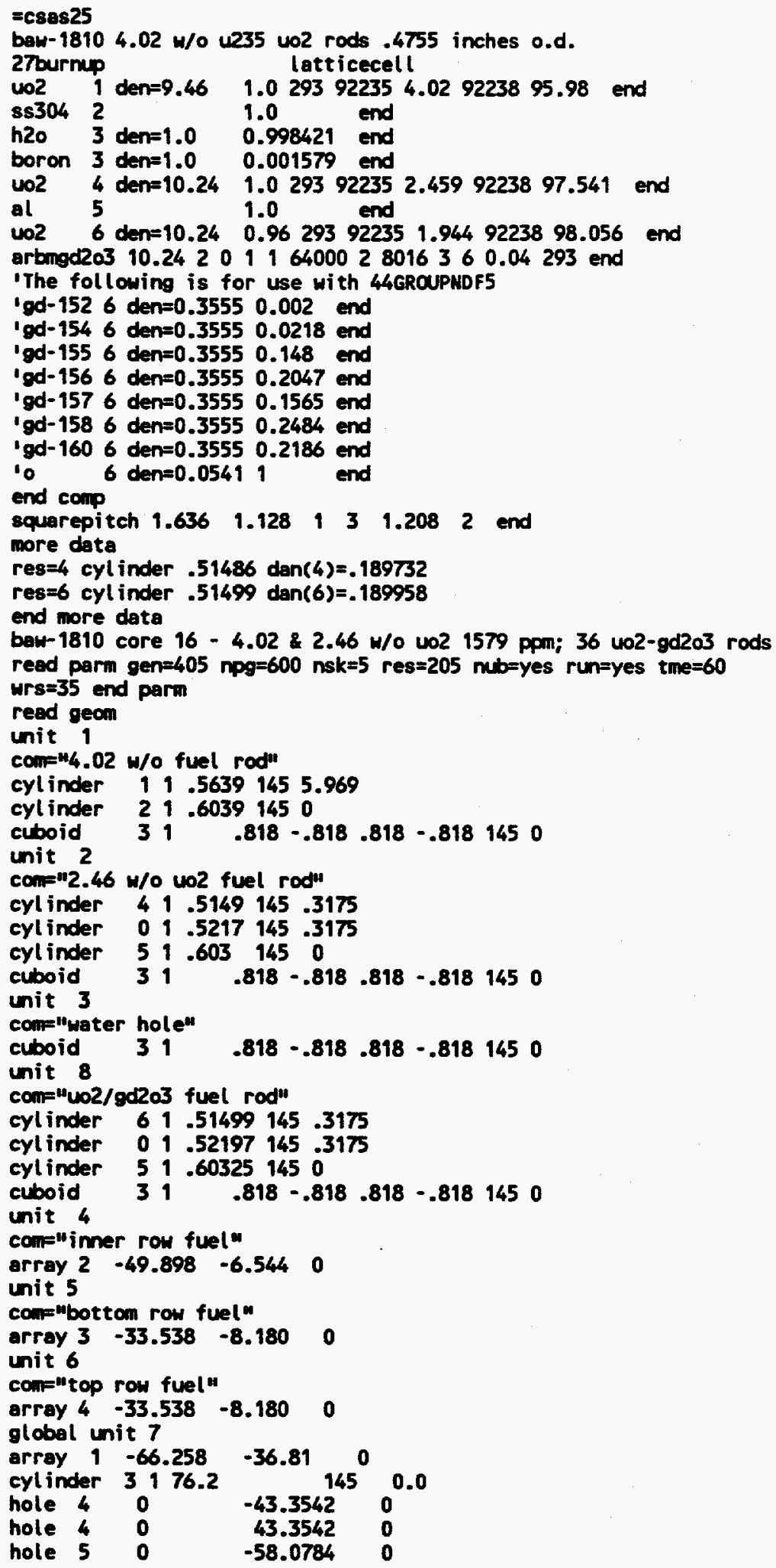




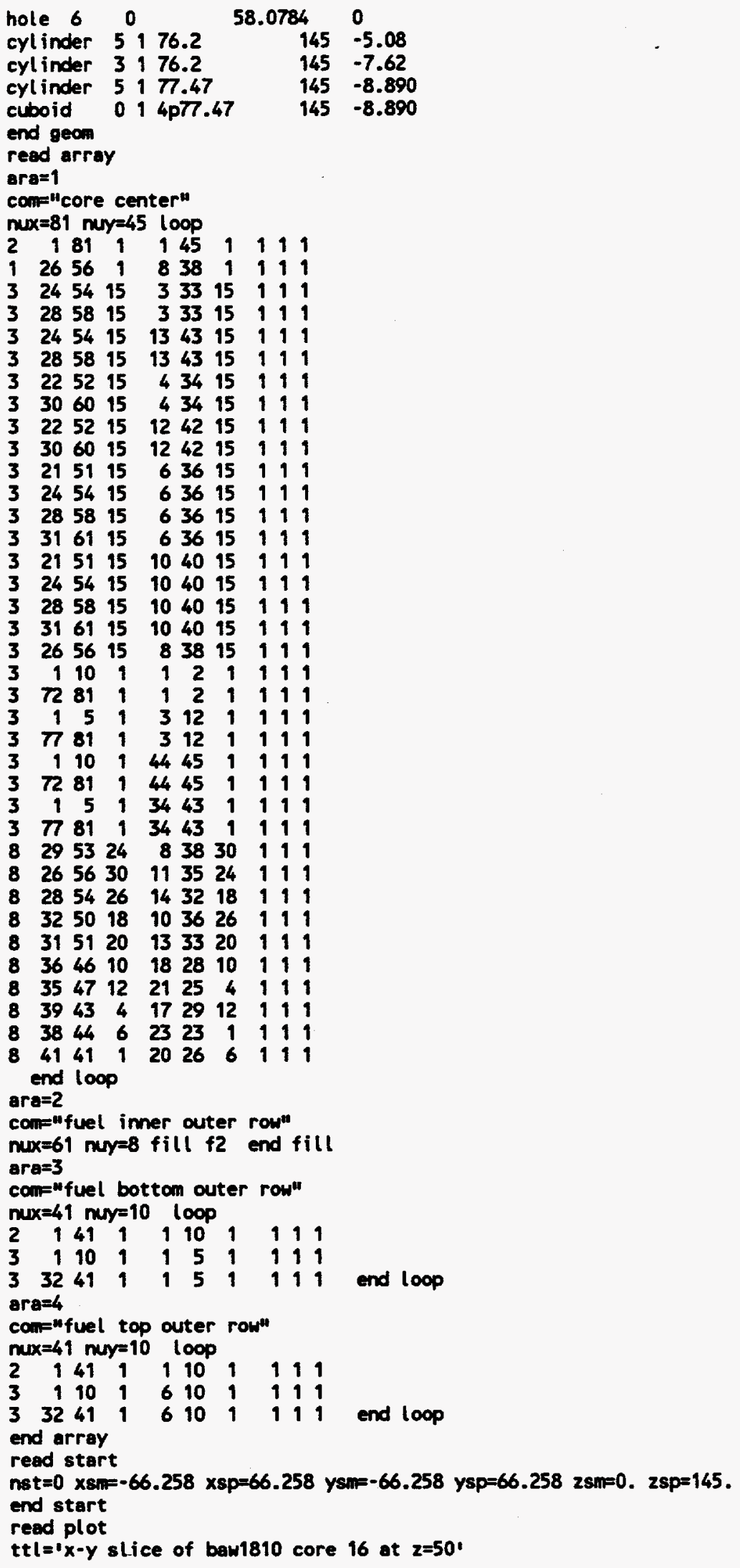


$x u l=-73.6092 \quad$ wl $=73.6092 \quad z u l=50$

$x(r=73.6092$ yl $r=-73.6092 \quad z l r=50$

uax $=1 \mathrm{vdh}=-1 \mathrm{dlx}=1.63576 \mathrm{dld}=1.63576 \mathrm{nch}=192456789 \mathrm{abcl}$ end end plot

end data

end 


\section{e196u6n}

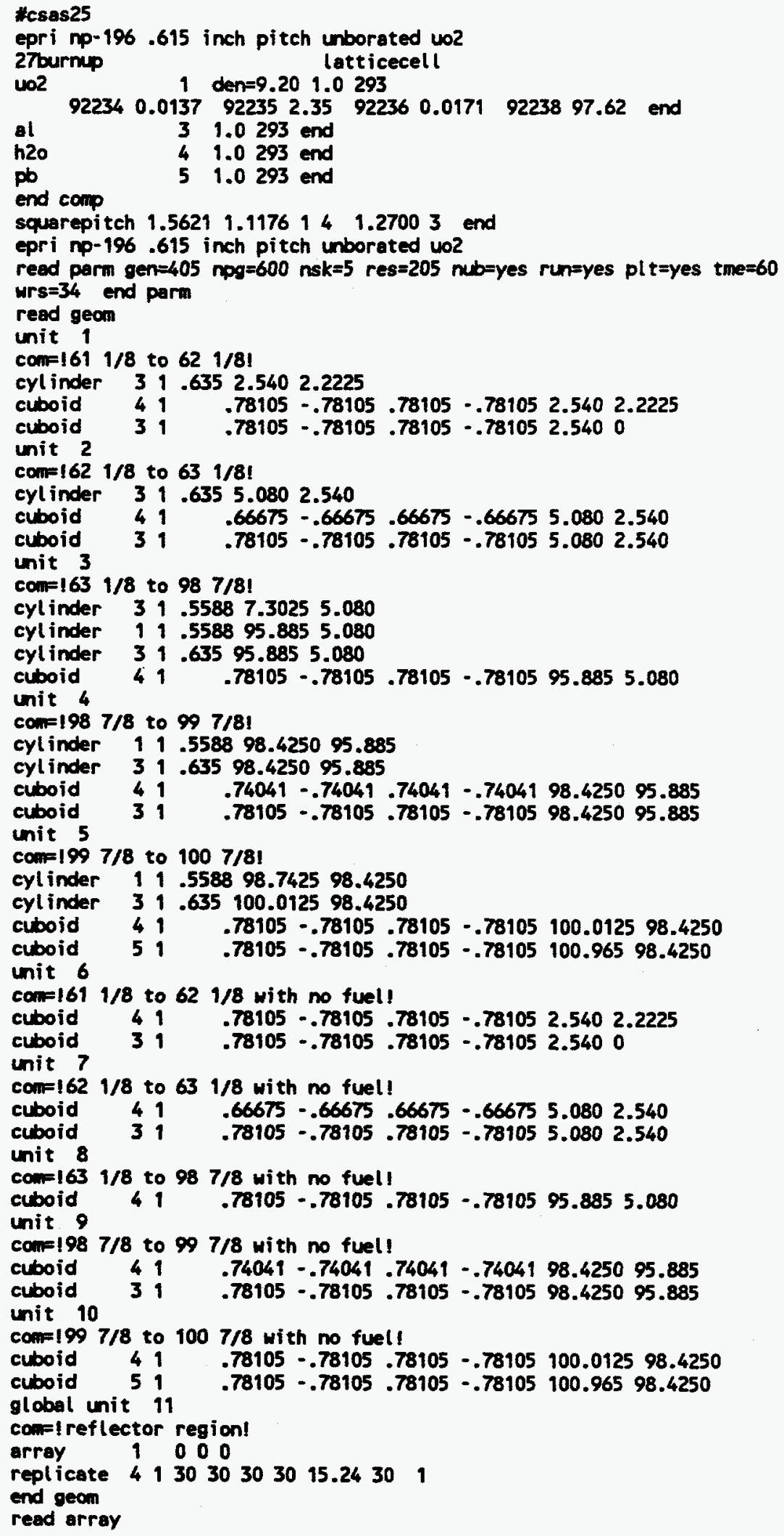


ars=1 mux=31 nuy=31 nuz=5

com=lepri np-196 .615 inch pitch unborated wo2 core - 708 rods!

fill

$13 r 6$ 5r1 23r6 11r1 18r6 15r1 15r6 17r1 13r6 19r1 11r6 21r1 9r6

$23 r 1$ 7r6 25r1 5r6 27r1 2r6 1q31 1r6 29r1 1r6 $2 q 31$

$154 r 11$ 1r6 155b403

$\begin{array}{lllllllllllllllll}13 r 7 & 5 r 2 & 23 r 7 & 11 r 2 & 18 r 7 & 15 r 2 & 15 r 7 & 17 r 2 & 13 r 7 & 19 r 2 & 11 r 7 & 21 r 2 & 9 r 7\end{array}$ $\begin{array}{lllllllllll}23 r 2 & 7 r 7 & 25 r 2 & 5 r 7 & 27 r 2 & 2 r 7 & 1931 & 1 r 7 & 29 r 2 & 1 r 7 & 2 q 31\end{array}$

$154 r 21 r 71556403$

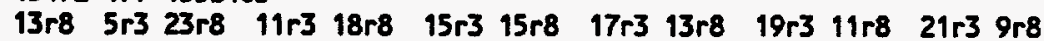
$\begin{array}{lllllllllll}23 r 3 & 7 r 8 & 25 r 3 & 5 r 8 & 27 r 3 & 2 r 8 & 1931 & 1 r 8 & 29 r 3 & 1 r 8 & 2 q 31\end{array}$

$154 r 31 r 81556403$

13r9 5r4 23rg 11r4 18r9 15r4 15r9 17r4 13rg 19r4 11rg 21r4 9r9

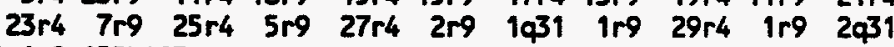

$154 r 41 r 9155 b 403$

$13 r 10$ 5r5 23r10 11r5 18r10 15r5 15r10 17r5 13r10 19r5 11r10 21r5 9r10 $23 r 5 \quad 7 r 1025 r 5 \quad 5 r 1027 r 5 \quad 2 r 10 \quad 1931$ 1r10 29r5 $1 r 102931$

$154 r 51 r 101556403$

end fill

end array

read plot

$t t l=\mid x-y$ cross-section at $z=5.0 \mathrm{~cm} \mid$

pl $t=y e s$ pic=mixture $x u l=-5$ yul=-5 zul=5 $x / r=60$ ylr=60 zlr=5 uax=1 vax=0 wax=0 uch $=0$ von=1 udn=0 nax $=130$ nch=1 $135^{\prime}$ end

end plot

end data

end 


\section{e196u87c}

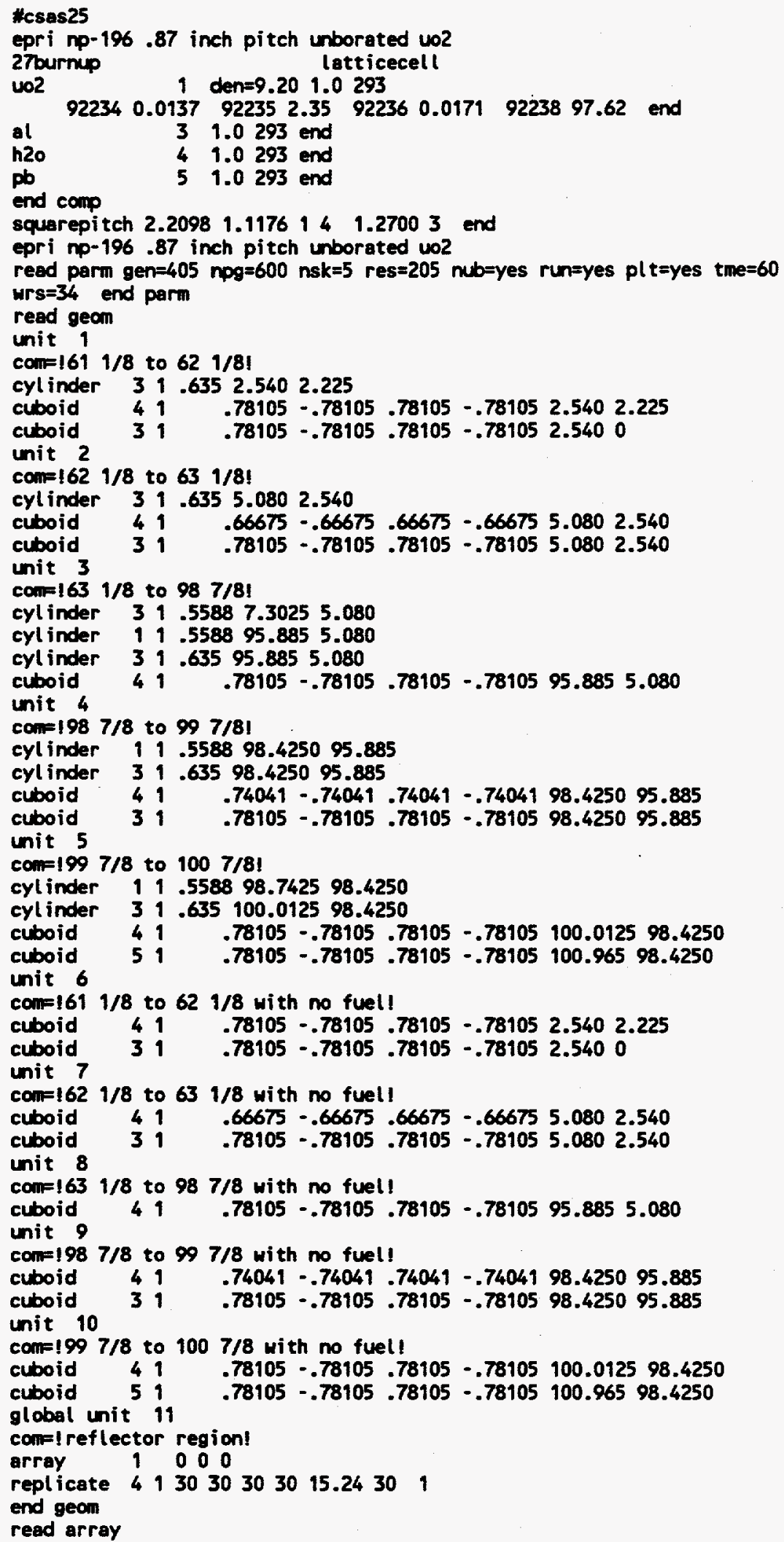




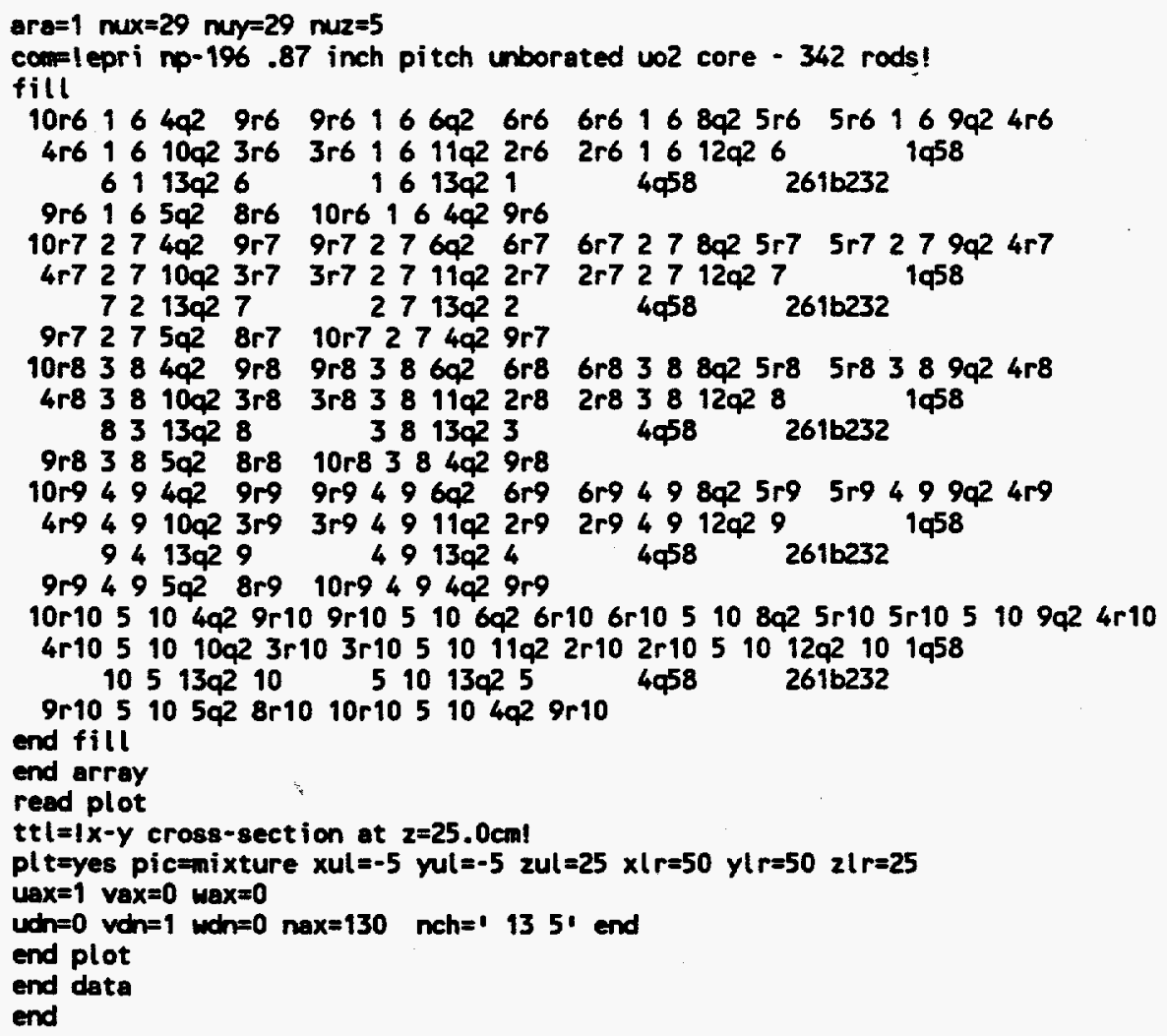




\section{epri70b}

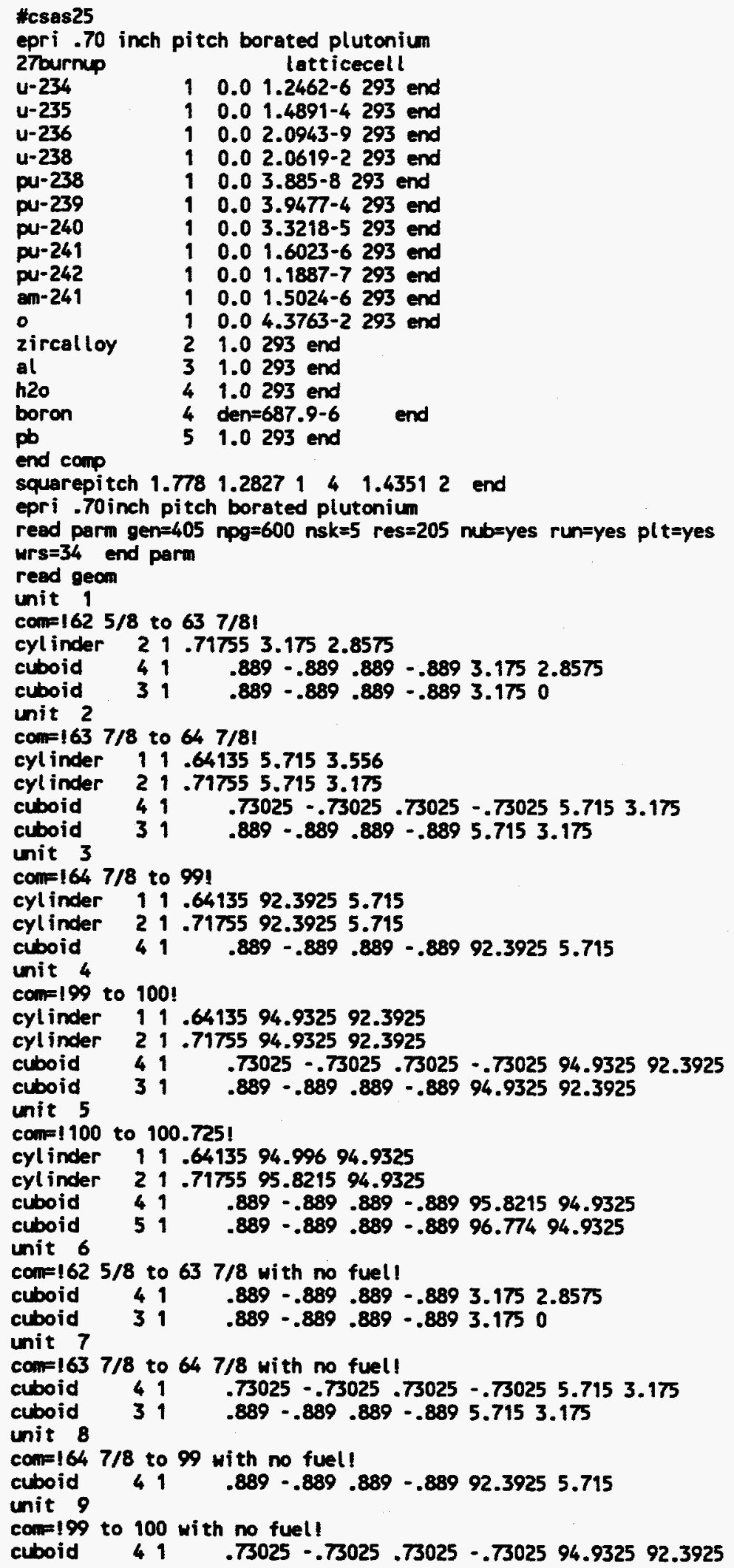




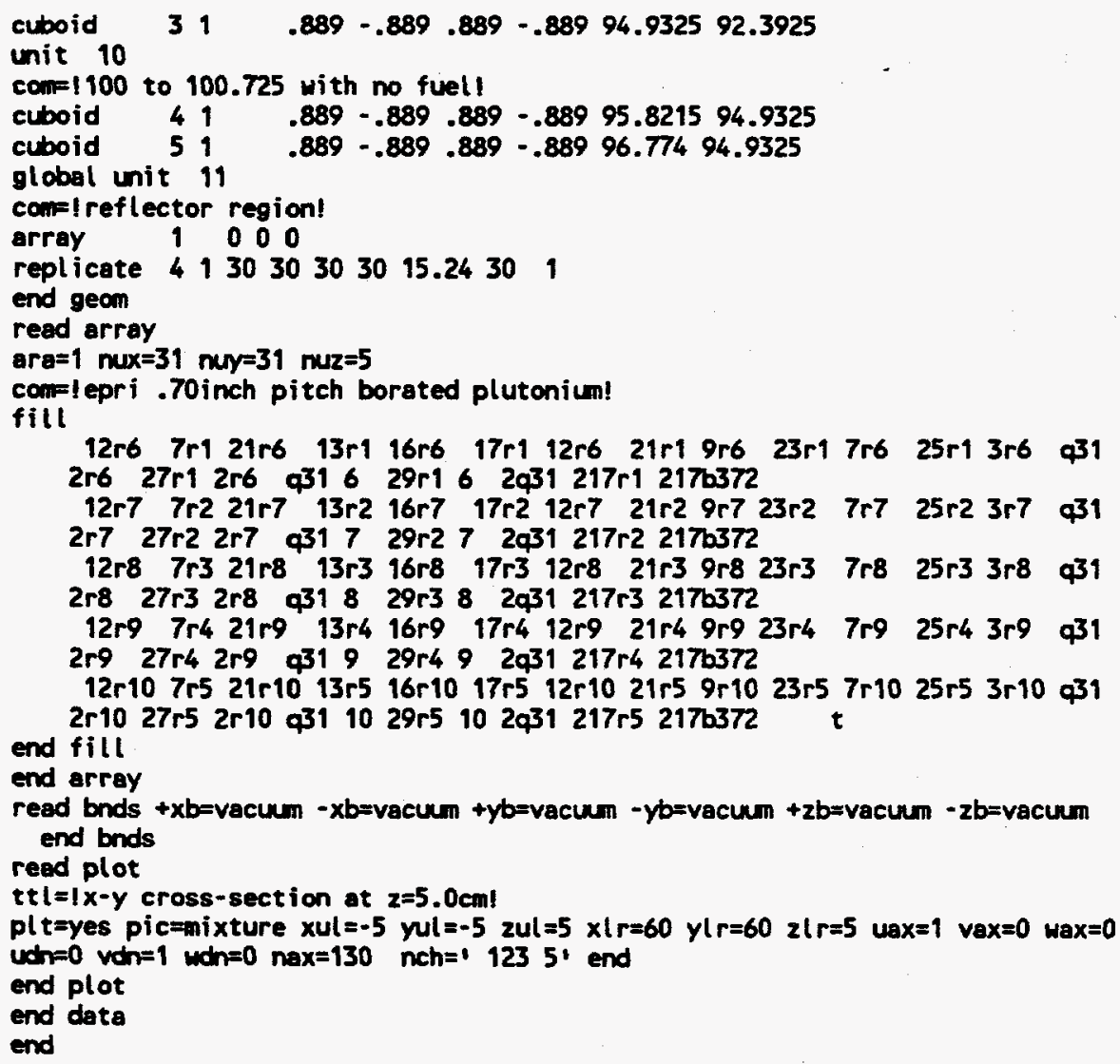


epri70un

\#csas25

epri .70 inch pitch unborated plutonium

27 burnup latticecell

$u-234 \quad 1 \quad 0.01 .2462 .6293$ end

$u-235 \quad 1 \quad 0.01 .4891-4293$ end

u-236 $10.02 .0943-9293$ end

$u-238 \quad 1 \quad 0.02 .0619-2293$ end

pu-238 $\quad 10.03 .885-8293$ end

pu-239 10.03 .9477 .4293 end

pu-240 $10.03 .3218-5293$ end

pu-241 $10.01 .6023-6293$ end

pu-242 $10.01 .1887-7293$ end

an-241 $10.01 .5024-6293$ end

$0 \quad 10.04 .3763-2293$ end

zircalloy 21.0293 end

al 31.0293 end

h20 41.0293 end

boron 4 den $=0.0$ end

pb 51.0293 end

end comp

squarepitch $1.778 \quad 1.282714 \quad 1.43512$ end

epri .70 inch pitch unborated plutonium

read perm gen=405 nog $=600$ nsk $=5$ res $=205$ nub=yes run=yes $p l t=y e s$ tme $=60$ urs $=34$ end parm

read geon

unit 1

comin=162 $5 / 8$ to $637 / 81$

cyl inder $\quad 21.717553 .175 \quad 2.8575$

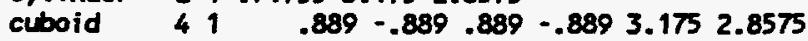

$\begin{array}{lllllllll}\text { cuboid } & 31 & .889 & -.889 & .889 & -.889 & 3.175 & 0\end{array}$

unit 2

conf $1637 / 8$ to $647 / 81$

cylinder 11.641355 .7153 .556

cylinder 21.717555 .7153 .175

cuboid $\quad 41 \quad .73025-.73025 .73025-.730255 .7153 .175$

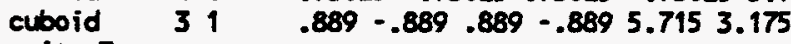

unit 3

coms $1647 / 8$ to 99 !

cylinder $11.6413592 .3925 \quad 5.715$

cylinder 21.7175592 .39255 .715

cuboid $41 \quad .889-.889 .889-.88992 .39255 .715$

unit 4

conle 199 to 100 !

cylinder $\quad 11.6413594 .932592 .3925$

cylinder 21.7175594 .932592 .3925

cuboid $\quad 41 \quad .73025-.73025 .73025 \cdot .7302594 .932592 .3925$

$\begin{array}{lllllll}\text { cuboid } & 31 & .889 & -.889 .889 & -.889 & 94.9325 & 92.3925\end{array}$

unit 5

con $=$ ! 100 to 100.725 !

cyl inder $\quad 11.6413594 .99694 .9325$

cyl inder $\quad 21.7175595 .821594 .9325$

cuboid $\quad 41 \quad .889=.889 .889 \cdot .88995 .821594 .9325$

$\begin{array}{llllll}\text { cuboid } \quad 51 & .889 & -.889 .889 & -.88996 .774 & 94.9325\end{array}$

unit 6

conif=162 $5 / 8$ to $637 / 8$ with no fuel!

cuboid $\quad 41 \quad .889 \cdot-.889 .889 \cdot-.8893 .1752 .8575$

$\begin{array}{llllllll}\text { cuboid } \quad 31 & .889 & =.889 & .889 & -.889 & 3.175 & 0\end{array}$

unit 7

com=163 $7 / 8$ to $647 / 8$ with no fuel!

cuboid $\quad 41 \quad .73025-.73025 .73025-.73025 \quad 5.7153 .175$

$\begin{array}{llllll}\text { cuboid } & 31 & .889 & -.889 .889 & -.889 & 5.7153 .175\end{array}$

unit 8

com=164 7/8 to 99 with no fuel!

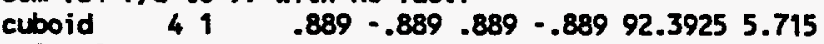

unit 9

con=! 99 to 100 with no fuel!

cuboid $\quad 41 \quad .73025-.73025 .73025-.7302594 .932592 .3925$ 


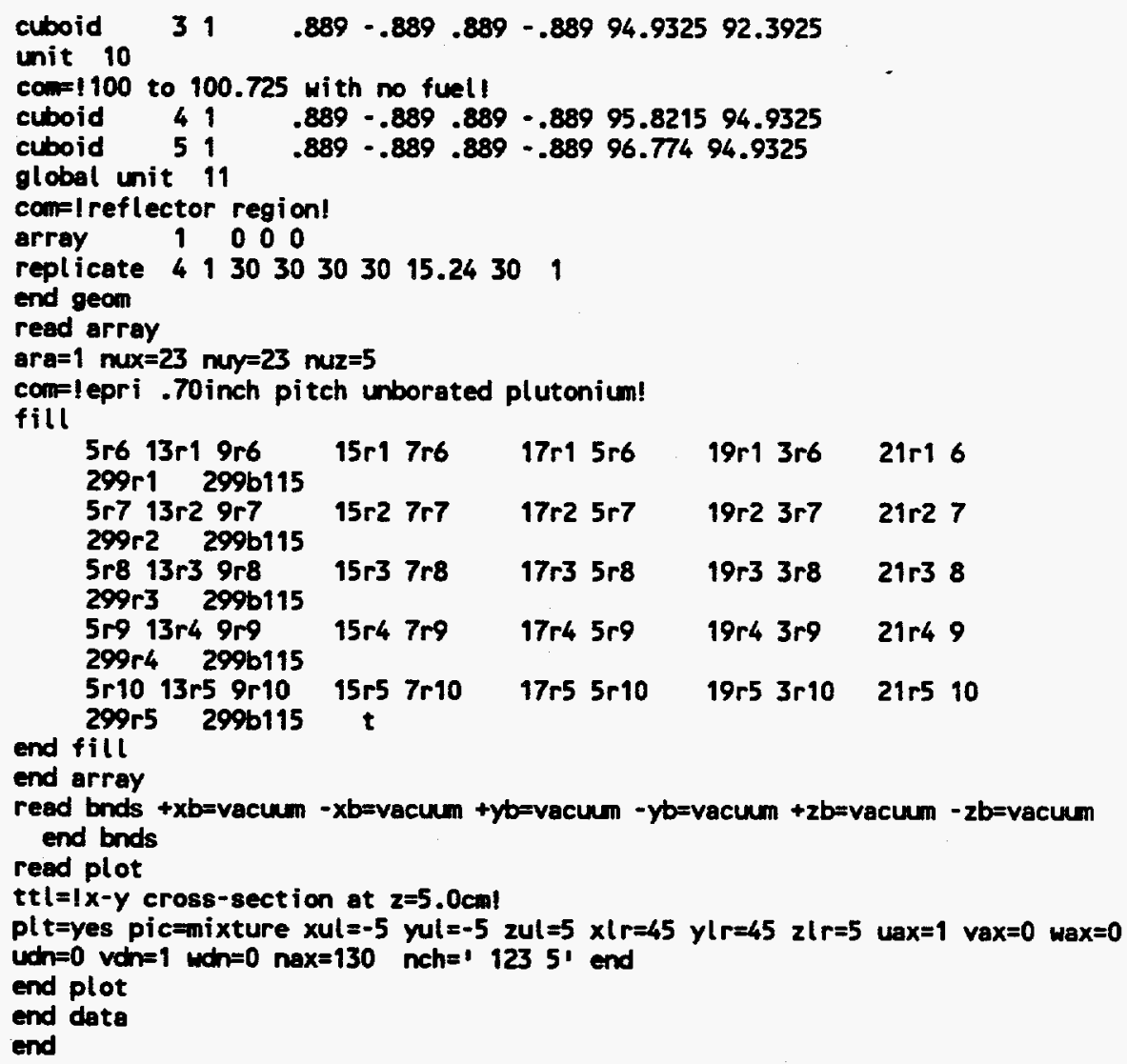




\section{epri87b}

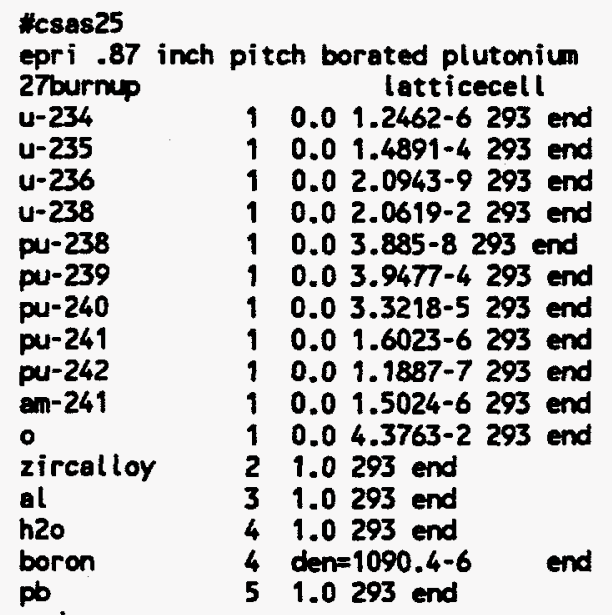

end comp

squarepitch 2.20981 .2827141 .43512 end

epri .87 inch pitch borated plutonium

read parm gen $=405$ npg=600 nsk $=5$ res=205 nub=yes run=yes $p l t=y e s$ wrs $=34$ end perm

read geom

unit 1

com=! $625 / 8$ to $637 / 8$ !

cylinder $\quad 21.717553 .1752 .8575$

cuboid $\quad 41 \quad 1.1049-1.10491 .1049-1.10493 .1752 .8575$

cuboid $\quad 31 \quad 1.1049-1.10491 .1049-1.10493 .1750$

unit 2

conis $1637 / 8$ to $647 / 8$ !

cylinder 11.641355 .7153 .556

cylinder 21.717555 .7153 .175

cuboid $\quad 41 \quad 1.06426-1.06426 \quad 1.06426-1.064265 .7153 .175$

cuboid $31 \quad 1.1049-1.10491 .1049-1.10495 .7153 .175$

unit 3

conn=164 $7 / 8$ to 991

cylinder $\quad 11$.64135 $92.3925 \quad 5.715$

cyl inder 21.7175592 .39255 .715

cuboid $41 \quad 1.1049-1.10491 .1049-1.104992 .39255 .715$

unit 4

conf 199 to 100 !

cyl inder 11.6493594 .932592 .3925

cyl inder 29.7175594 .932592 .3925

cuboid $\quad 41 \quad 1.06426-1.06426 \quad 1.06426-1.0642694 .932592 .3925$

cuboid $31 \quad 1.1049-1.10491 .1049-1.104994 .932592 .3925$

unit 5

com $=$ ! 100 to 100.725 !

cyl inder 11.6413594 .99694 .9325

cylinder $\quad 21.7175595 .821594 .9325$

cuboid $41 \quad 1.1049-1.10491 .1049-1.104995 .821594 .9325$

cuboid $51 \quad 1.1049-1.10491 .1049-1.104996 .77494 .9325$

unit 6

comil $625 / 8$ to $637 / 8$ with no fuel!

cuboid $\quad 41 \quad 1.1049-1.10491 .1049-1.10493 .1752 .8575$

cuboid $31 \quad 1.1049-1.10491 .1049-1.10493 .1750$

unit 7

com $=1637 / 8$ to $647 / 8$ with no fuel!

cuboid $41 \quad 1.06426-1.064261 .06426-1.064265 .7153 .175$

cuboid $\quad 31 \quad 1.1049-1.10491 .1049-1.10495 .7153 .175$

unit 8

com $=$ !64 $7 / 8$ to 99 with no fuel!

cuboid $\quad 41 \quad 1.1049-1.10491 .1049-1.104992 .39255 .715$

unit 9

conf 199 to 100 with no fuell

cuboid $41 \quad 1.06426-1.064261 .06426-1.0642694 .932592 .3925$ 


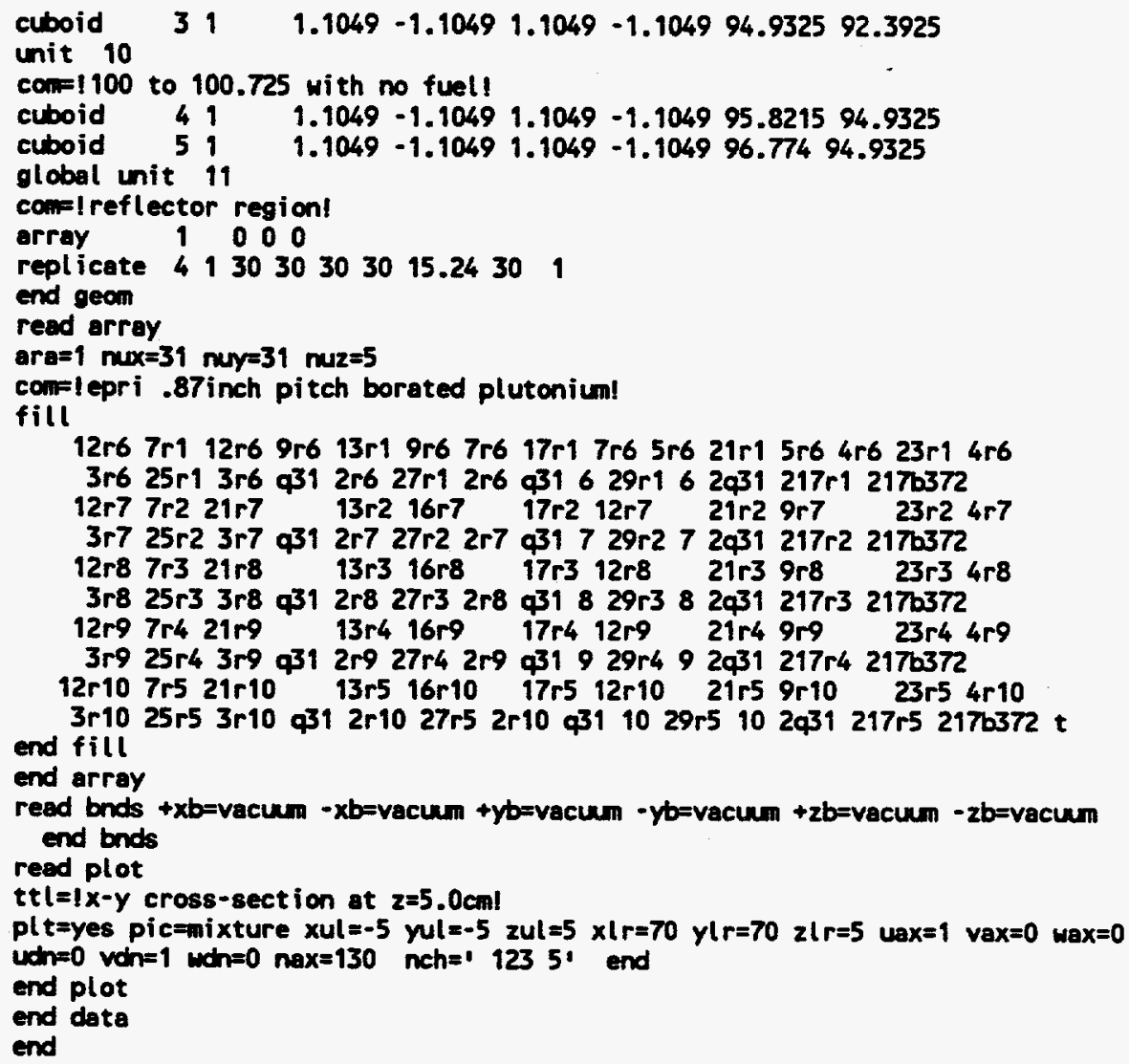


epri87un

"csas 25

epri .87 inch pitch unborated plutonium

27burnup latticecell

$\begin{array}{lllll}u-234 & 1 & 0.0 & 1.2462-6293 & \text { end }\end{array}$

$u-235 \quad 1 \quad 0.01 .4891 .4293$ end

$u-236 \quad 1 \quad 0.02 .0943-9293$ end

u-238 $\quad 10.02 .0619-2293$ end

pu-238 $10.03 .885-8293$ end

pu-239 $\quad 10.03 .9477-4293$ end

pu-240 i $0.03 .3218-5293$ end

pu-241 $10.01 .6023-6293$ end

pu-242 $10.01 .1887-7293$ end

am-241 $10.01 .5024-6293$ end

$0 \quad 10.04 .3763-2293$ end

zircalloy 21.0293 end

al 31.0293 end

h20 41.0293 end

boron 4 den=0.0 end

pb

51.0293 end

end comp

squarepitch 2.20981 .2827141 .43512 end

epri .87 inch pitch unborated plutonium

read parm gen=805 npg=600 nsk=5 res=205 nub=yes run=yes pl $t=y e s t m e=120$

urs $=34$ end parm

read gean

unit 1

confl $525 / 8$ to $637 / 81$

cylinder 21.717553 .1752 .8575

cuboid $41^{1} \quad 1.1049-1.10491 .1049-1.10493 .1752 .8575$

cuboid $31 \quad 1.1049-1.10491 .1049-1.10493 .1750$

unit 2

conf $1637 / 8$ to $647 / 8$ !

cyl inder $11.64135 \mathbf{5} .7153 .556$

cyl inder 21.717555 .7153 .175

cuboid $\quad 41 \quad 1.06426-1.064261 .06426-1.064265 .7153 .175$

cuboid $31 \quad 1.1049-1.10491 .1049-1.10495 .7153 .175$

unit 3

conn=!64 $7 / 8$ to $99 !$

cylinder $\quad 11.6413592 .39255 .715$

cylinder 21.7175592 .39255 .715

cuboid $41 \quad 1.1049-1.10491 .1049-1.104992 .39255 .715$

unit 4

conif 199 to 100 !

cylinder 11.6413594 .932592 .3925

cyl inder $2, .7175594 .932592 .3925$

cuboid $\quad 41 \quad 1.06426-1.064261 .06426-1.0642694 .932592 .3925$

cuboid $31 \quad 1.1049-1.10491 .1049-1.104994 .932592 .3925$

unit 5

com $=$ ! 100 to $100.725 !$

cylinder $\quad 11.6413594 .99694 .9325$

cylinder 21.7175595 .821594 .9325

cuboid 41 1.1049-1.1049 $1.1049-1.104995 .821594 .9325$

cuboid $\quad 51 \quad 1.1049-1.10491 .1049-1.104996 .77494 .9325$

unit 6

coni=!62 $5 / 8$ to $637 / 8$ with no fuel!

cuboid $41 \quad 1.1049-1.10491 .1049-1.10493 .1752 .8575$

cuboid $31 \quad 1.1049-1.10491 .1049-1.10493 .1750$

unit 7

confil $1637 / 8$ to $647 / 8$ with no fuel!

cuboid $\quad 41 \quad 1.06426-1.064261 .06426-1.064265 .7153 .175$

cuboid $\quad 31 \quad 1.1049-1.10491 .1049-1.10495 .7153 .175$

unit 8

conf $1647 / 8$ to 99 with no fuel!

cuboid $\quad 41 \quad 1.1049-1.10491 .1049-1.104992 .39255 .715$

unit 9

com=199 to 100 with no fuell

cuboid $\quad 41 \quad 1.06426-1.064261 .06426-1.0642694 .932592 .3925$ 


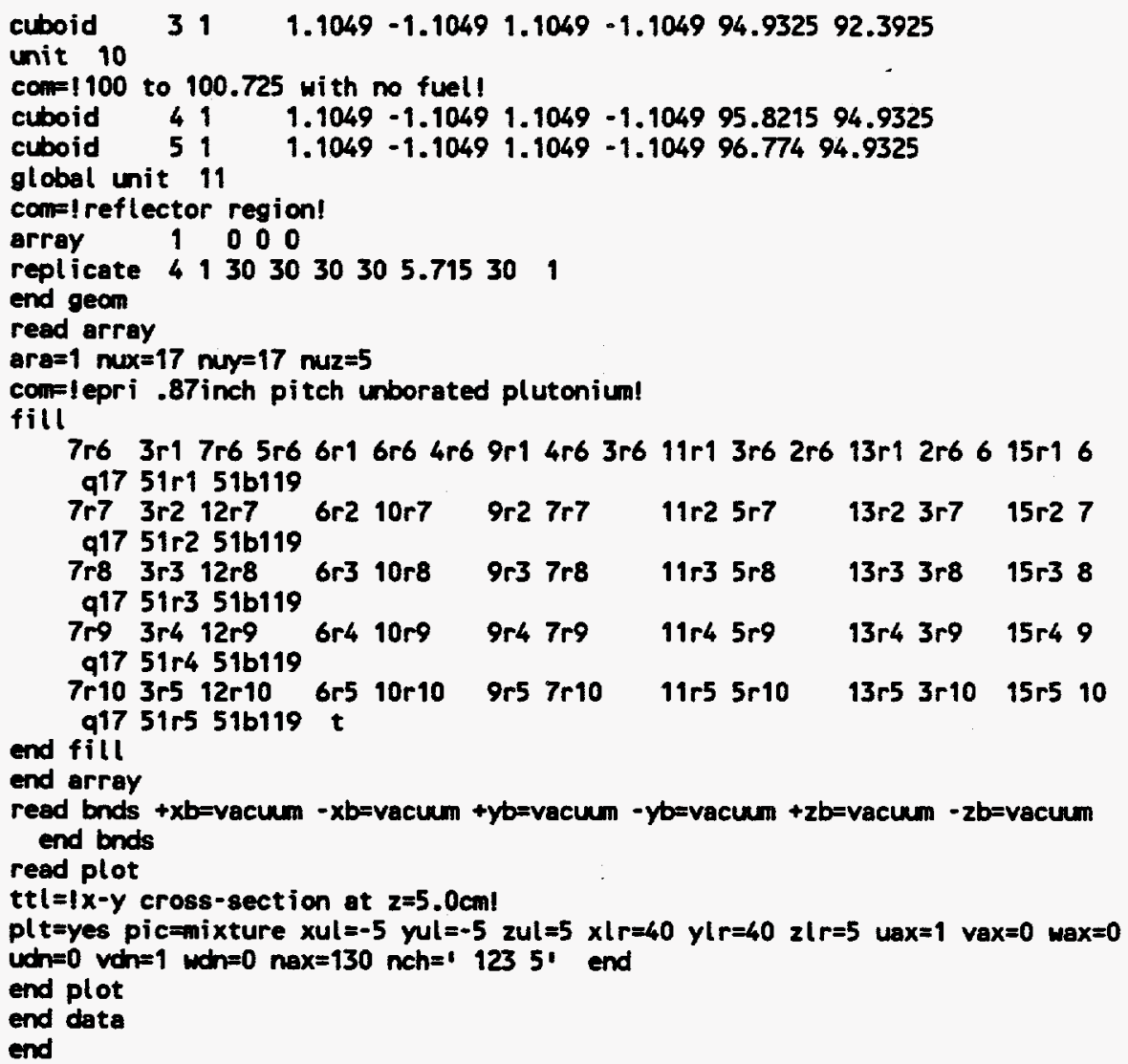


epri99b

tcsas25

epri .99 inch pitch borated plutonium

27burnup latticecell

u-234 $10.01 .2462-6293$ end

$u-235 \quad 1 \quad 0.01 .4891-4293$ end

$u-236 \quad 1 \quad 0.02 .0943-9293$ end

$u-238 \quad 1 \quad 0.02 .0619-2293$ end

pu-238 $\quad 10.03 .885-8293$ end

pu-239 $10.03 .9477-4293$ end

pu-240 $10.03 .3218-5293$ end

pu-241 $10.01 .6023-6293$ end

pu-242 $10.01 .1887-7293$ end

an-241 $10.01 .5024-6293$ end

$0 \quad 10.04 .3763-2293$ end

zircalloy 21.0293 end

al 31.0293 end

h20 41.0293 end

boron 4 den=767.25.6 end

pb 51.0293 end

end comp

squarepitch 2.51461 .2827141 .43512 end

epri .99 inch pitch borated plutonium

read parm gen=805 npg=600 nsk $=5$ res $=205$ nub=yes run=yes pl $t=y e s$

urs $=34$ tme $=60$ end parm

read geom

unit 1

conle! $625 / 8$ to $637 / 8$ !

cylinder $\quad 21.71755 \quad 3.175 \quad 2.8575$

cuboid $\quad 41 \quad 1.2573-1.2573 \quad 1.2573-1.2573 \quad 3.175 \quad 2.8573$

$\begin{array}{lllllllll}\text { cuboid } & 31 & 1.2573 & -1.2573 & 1.2573 & -1.2573 & 3.1750\end{array}$

unit 2

compl $1637 / 8$ to $647 / 8$ !

cylinder $\quad 11.641355 .7153 .556$

cylinder 21.717555 .7153 .175

cuboid $\quad 41 \quad 1.09855-1.098551 .09855-1.09855 \quad 5.7153 .175$

cuboid $\quad 31 \quad 1.2573-1.2573 \quad 1.2573-1.2573 \quad 5.7153 .175$

unit 3

com $=1647 / 8$ to 991

cylinder $11.6413592 .3925 \quad 5.715$

cylinder $\quad 21.7175592 .39255 .715$

cuboid $41 \quad 1.2573-1.2573 \quad 1.2573-1.2573 \quad 92.39255 .715$

unit 4

Cons $=$ ! 99 to $100 !$

cylinder $\quad 11.6413594 .932592 .3925$

cylinder 21.7175594 .932592 .3925

cuboid $\quad 41 \quad 1.09855-1.098551 .09855-1.0985594 .932592 .3925$

cuboid $\quad 31 \quad 1.2573-1.2573 \quad 1.2573-1.257394 .932592 .3925$

unit 5

conf 1100 to 100.725 !

cyt inder 11.6413594 .99694 .9325

cyl inder 21.7175595 .821594 .9325

cuboid $41 \quad 1.2573-1.2573 \quad 1.2573-1.257395 .821594 .9325$

$\begin{array}{lllllll}\text { cuboid } \quad 51 & 1.2573 & -1.2573 & 1.2573 & -1.2573 & 96.774 & 94.9325\end{array}$

unit 6

con=162 $5 / 8$ to $637 / 8$ with no fuel!

cuboid $\quad 41 \quad 1.2573-1.2573 \quad 1.2573-1.2573 \quad 3.175 \quad 2.8575$

cuboid $\quad 31 \quad 1.2573-1.2573 \quad 1.2573-1.2573 \quad 3.1750$

unit 7

confl63 7/8 to $647 / 8$ with no fuel!

$\begin{array}{llllllll}\text { cuboid } \quad 41 & 1.09855 & -1.09855 & 1.09855 & -1.09855 & 5.715 & 3.175\end{array}$

cuboid $31 \quad 1.2573-1.25731 .2573-1.2573 \quad 5.7153 .175$

unit 8

comfl $1647 / 8$ to 99 with no fuel!

$\begin{array}{lllllll}\text { cuboid } 41 & 1.2573 & -1.2573 & 1.2573 & -1.2573 & 92.3925 & 5.715\end{array}$

unit 9

cons= 199 to 100 with no fuel!

cuboid $\quad 41 \quad 1.09855-1.09855 \quad 1.09855-1.0985594 .932592 .3925$ 


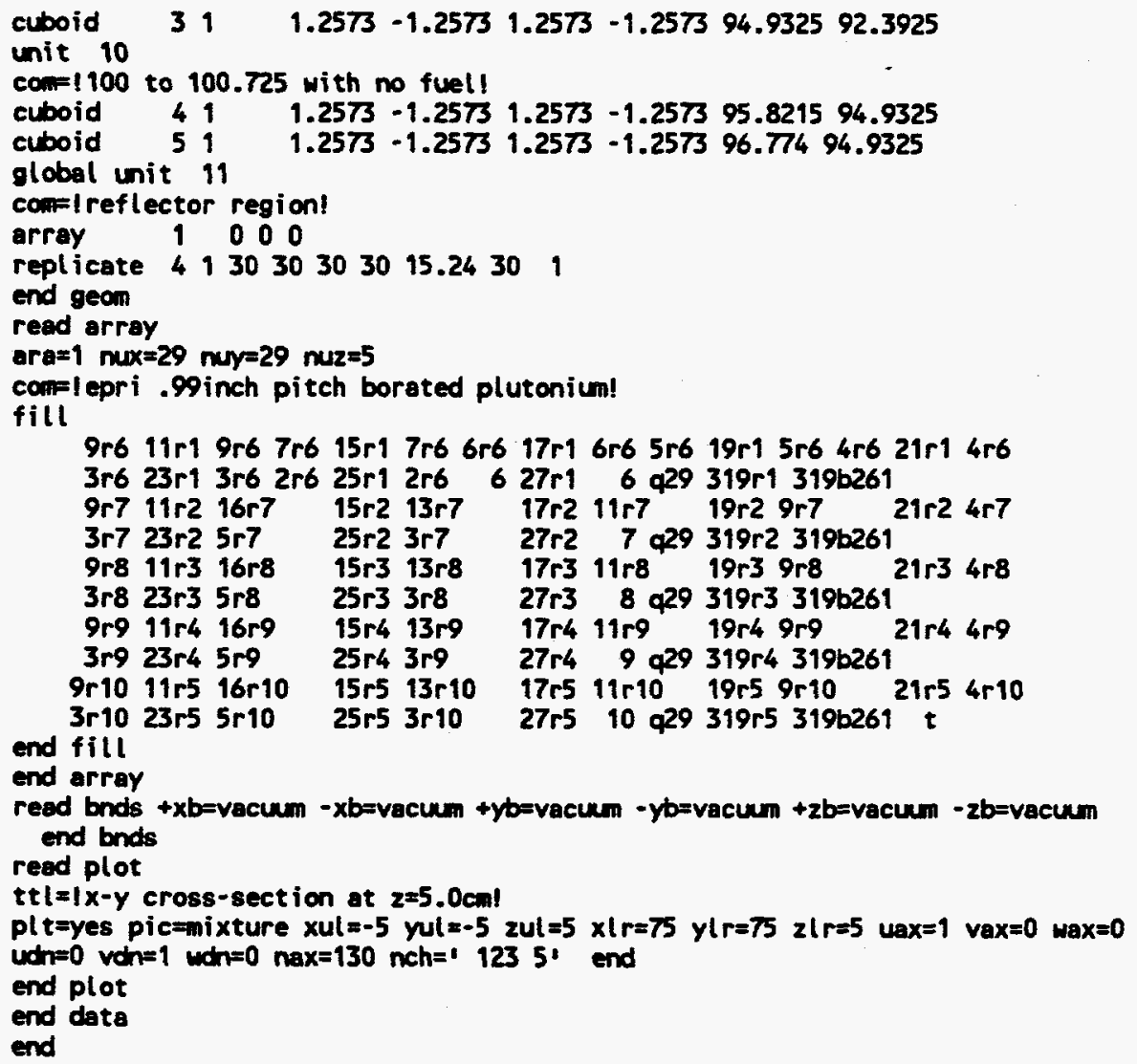




\section{epri99un}

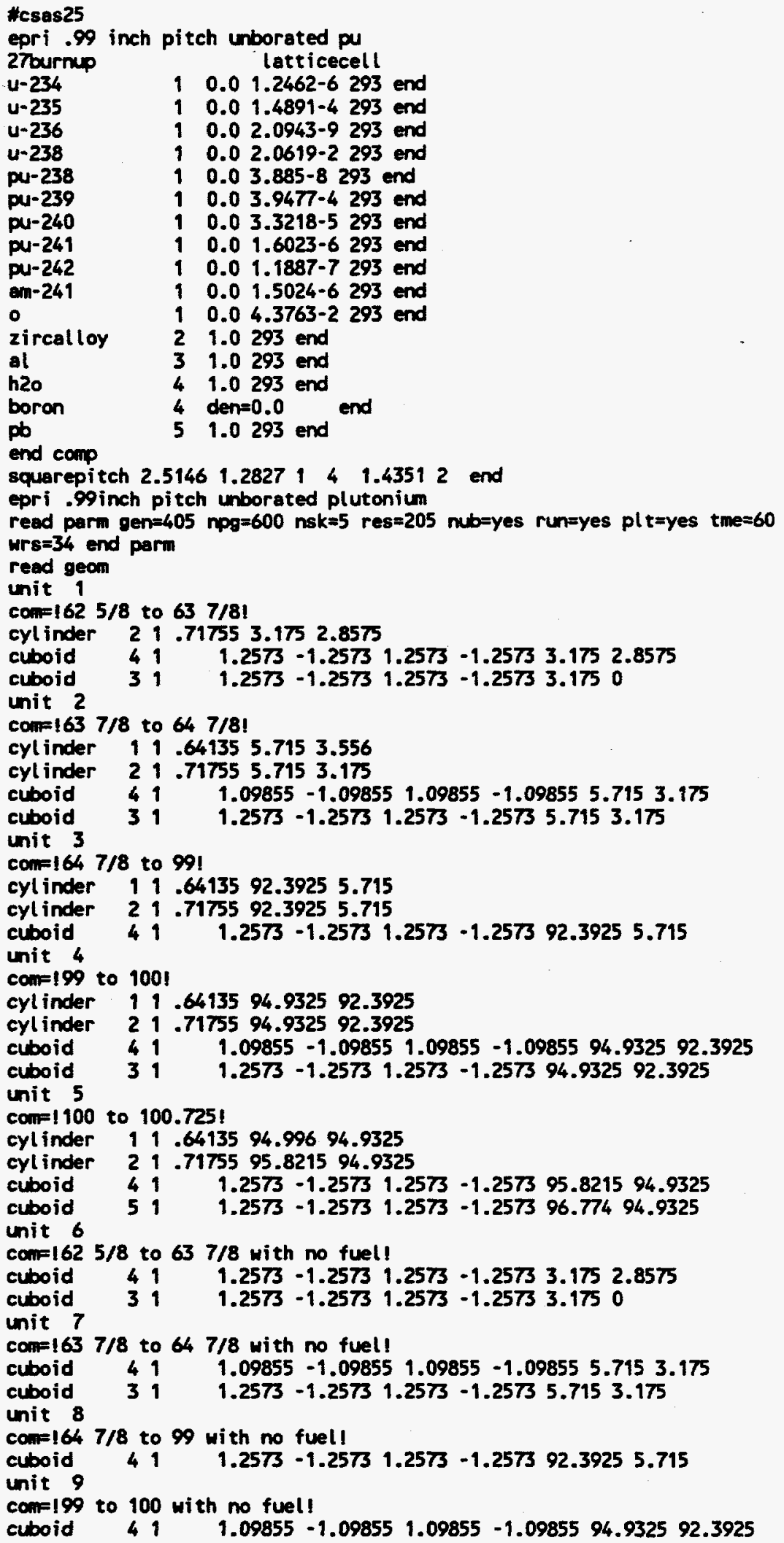


104

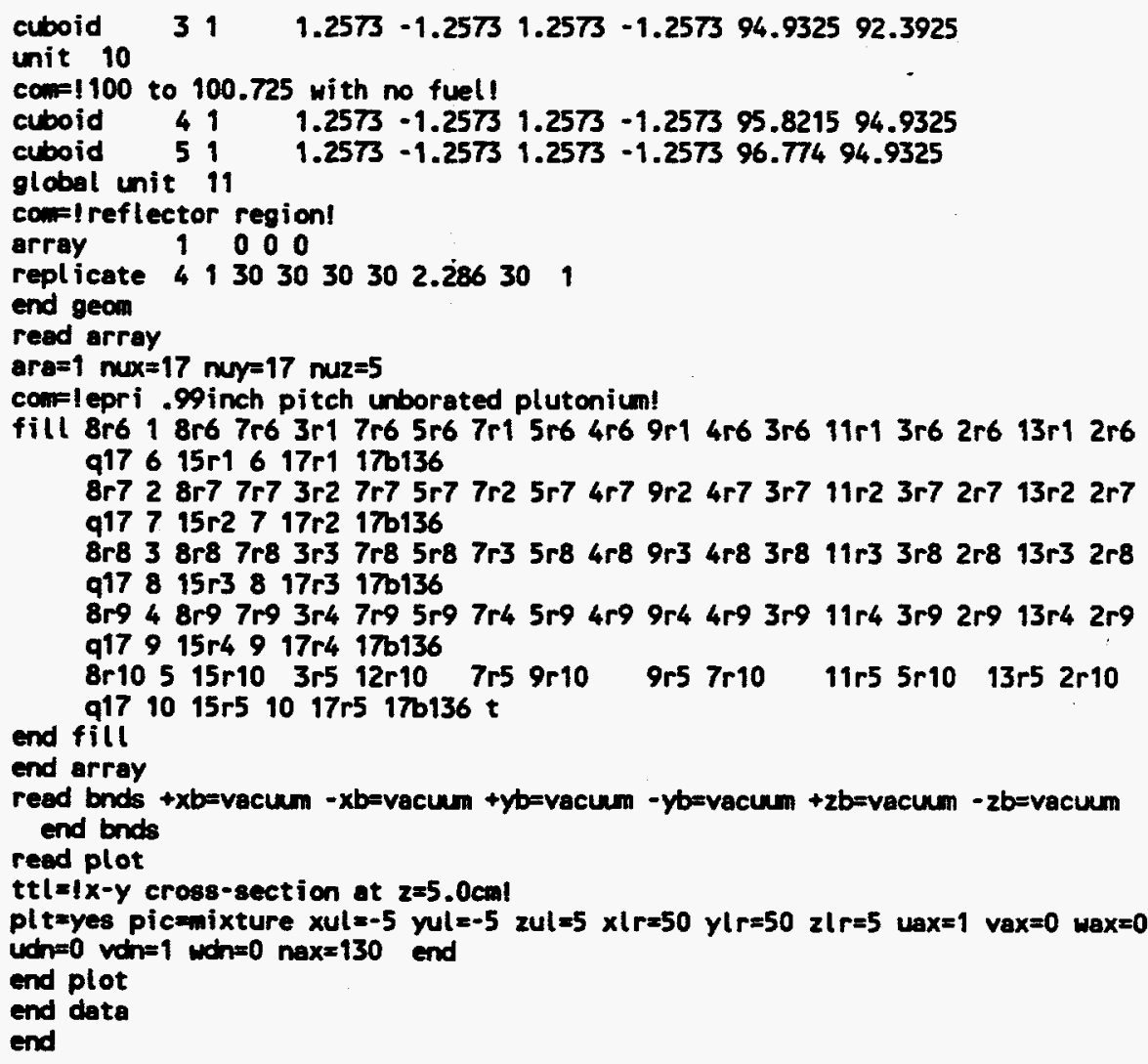




\section{ft214r}

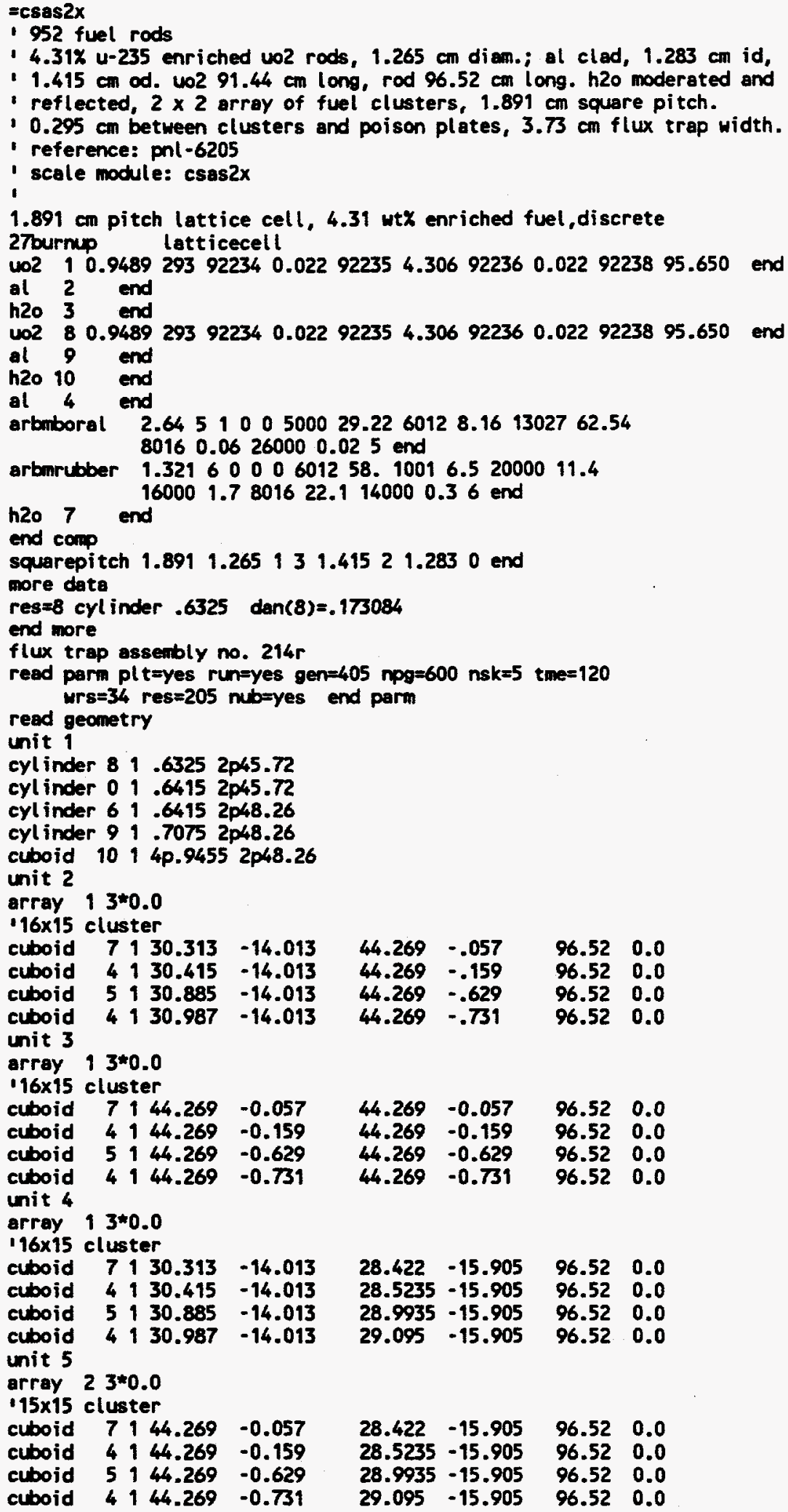




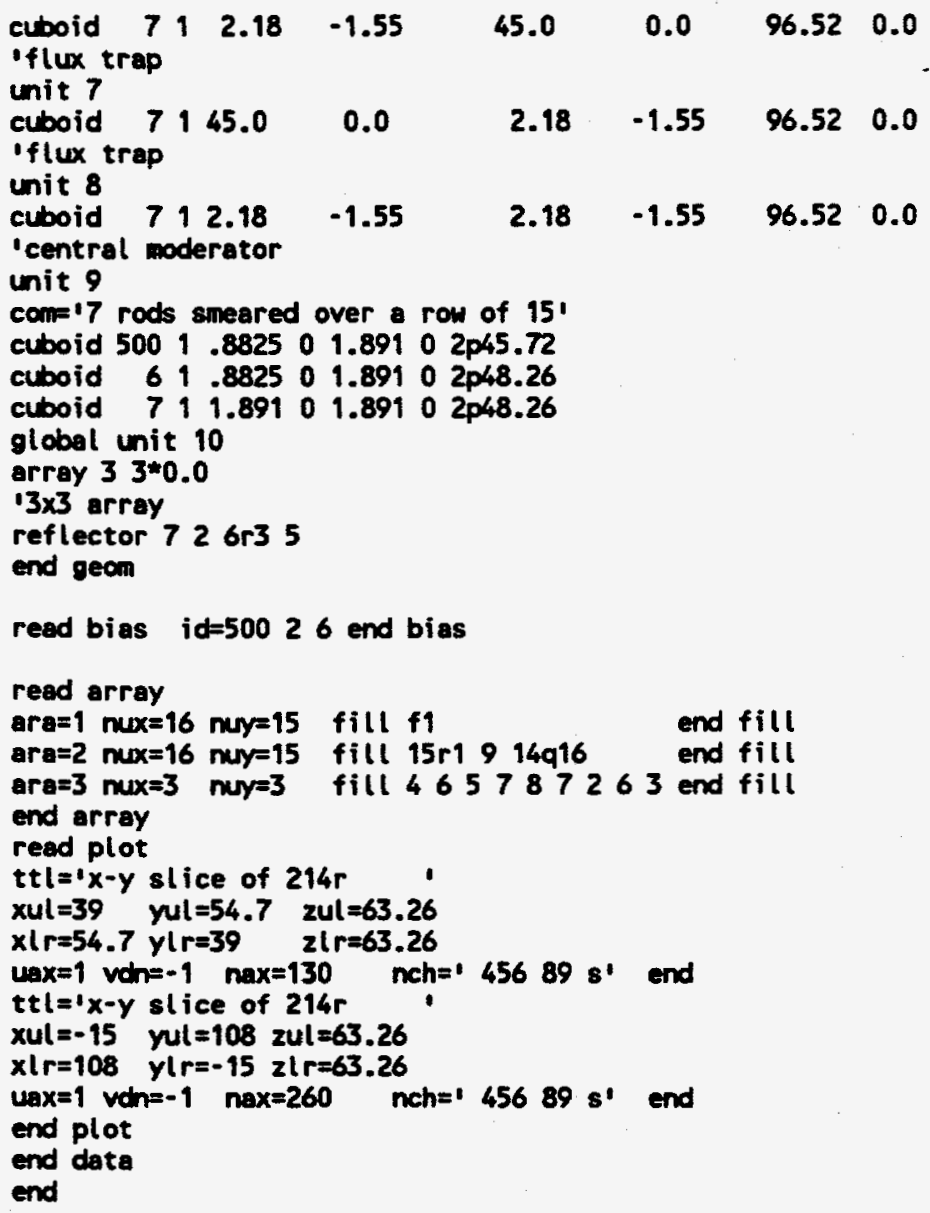




\section{ft214v3}

$=\operatorname{csas} 2 x$

- 862.1 fuel rods

- 4.31\% u-235 enriched vo2 rods, $1.265 \mathrm{~cm}$ dian.; al clad, $1.283 \mathrm{~cm}$ id,

$1.415 \mathrm{~cm}$ od. $10291.44 \mathrm{~cm}$ long, rod $96.52 \mathrm{~cm}$ long. h20 moderated and

- reflected, $2 \times 2$ array of fuel clusters, $1.891 \mathrm{~cm}$ square pitch.

- $0.295 \mathrm{~cm}$ between clusters and poison plates, $3.73 \mathrm{~cm}$ flux trap width.

- three $0.63 \mathrm{~cm} \times 45.0 \mathrm{~cm} \times 96 \mathrm{~cm}$ al plates between clusters.

- reference: pnl-6205

- scale module: $\operatorname{csas} 2 x$

1.891 cn pitch lattice cell, 4.31 wt\% enriched fuel, discrete

27burnup latticecell

vo2 10.9489293922340 .022922354 .306922360 .0229223895 .650 end

al 2 and

h20 3 end

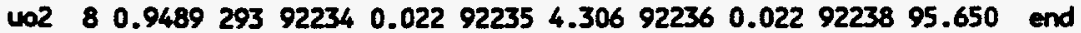

of 9 end

h2o 10 end

al 4 end

arbmboral 2.645100500029 .2260128 .161302762 .54 80160.06260000 .025 end

arbmrubber 1.3216000601258 .10016 .52000011 .4

h2o 7 160001.7801622 .1140000 .36 end

end com

squarepitch 1.8911 .265131 .41521 .2830 end

more data

res $=8$ cylinder .6325 dan $(8)=.173084$

end wore

flux trap assembly no. $214 \mathrm{v3}$

read parm plt=yes run=yes gen $=805$ npg=600 nsk $=5$ tme $=240$ wrs $=34$ res=205 mb=yes end perm

reed gecmetry

unit 1

cyl inder $81.63252 p / 45.72$

cylinder $01.64152 p 45.72$

cylinder $61.64152 p 48.26$

cylinder $91.70752 p 48.26$

cuboid 1014 p.9455 2p48.26

unit 2

array $13 * 0.0$

$114 \times 15$ cluster

cuboid $7126.531-17.795$

cuboid $4126.633-17.795$

cuboid $5127.103-17.795$

cuboid $4127.205-17.795$

96.520 .0

$.269-.159$

$44.269-.629$

$44.269-.731$

96.520 .0

96.520 .0

unit 3

array $23 * 0.0$

$115 \times 15$ cluster

cuboid $7144.269-0.057$

cuboid $4144.269-0.159$

$44.269-0.057$

$44.269-0.159$

cuboid $5144.269-0.629$

$44.269-0.629$

cuboid $4144.269 \quad-0.731$

$44.269-0.731$

96.520 .0

unit 4

array $13 * 0.0$

$14 \times 15$ cluster

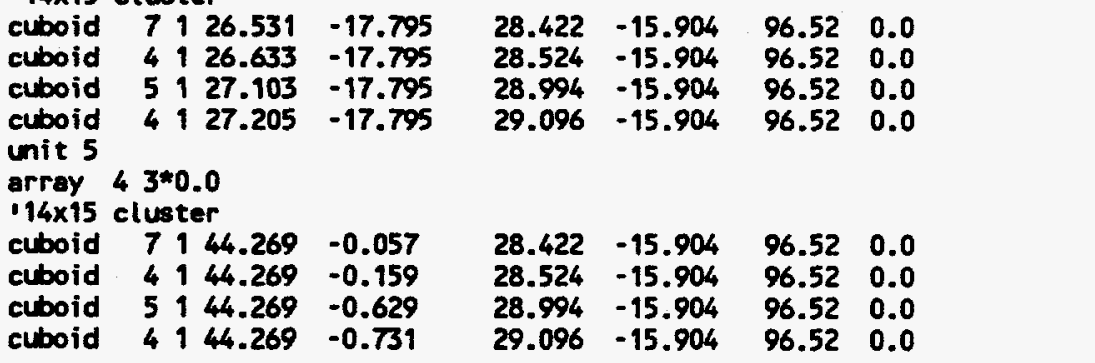

96.520 .0

96.520 .0

96.520 .0

96.520 .0 


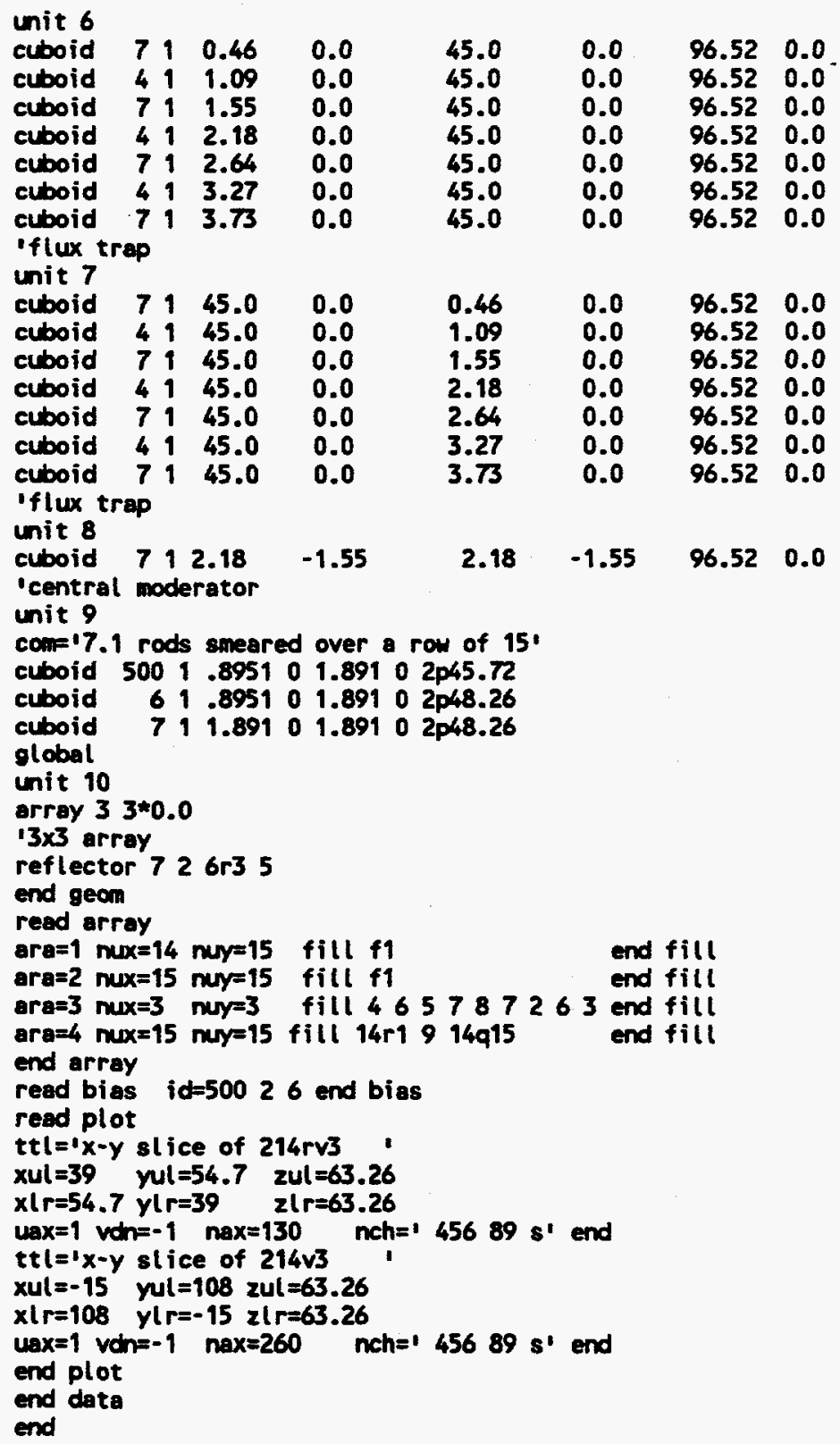




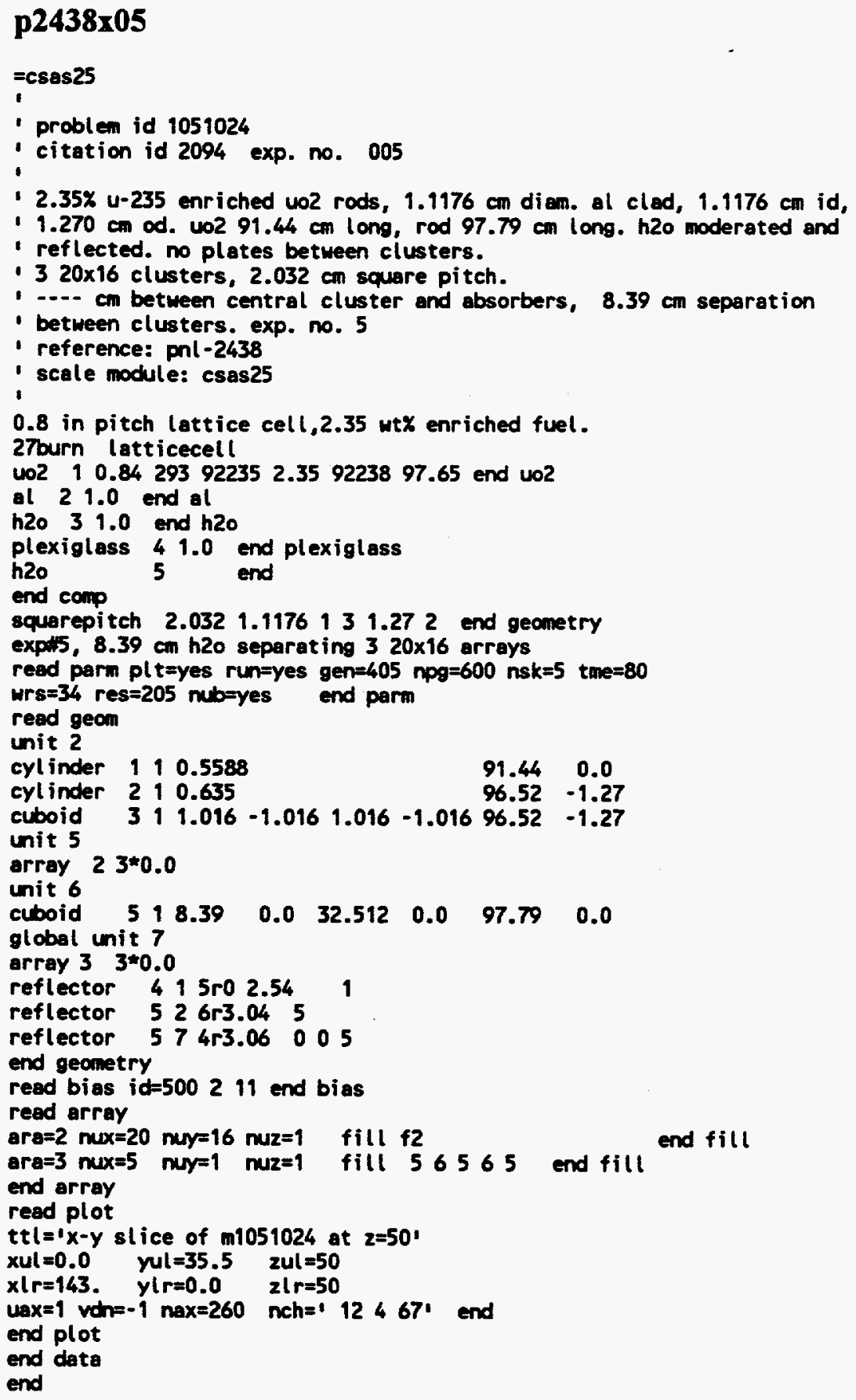




\section{p2438x17}

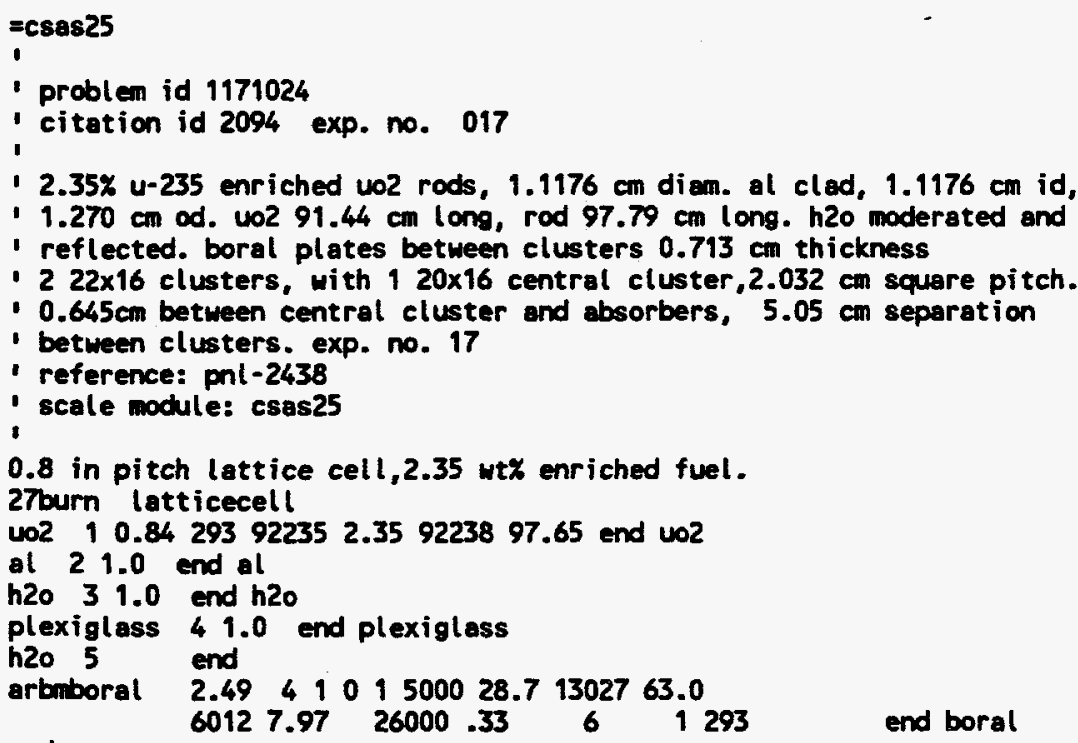

end conp

squarepitch 2.0321 .1176131 .272 end geometry

exp\$017, $5.05 \mathrm{~cm}$ h20/boral separating $222 \times 16$ arrays and $120 \times 16$ array read parm plt=yes run=yes gen $=805$ npg $=600$ nsk $=5$ tme $=240$

$u r s=34$ res=205 nub=yes end parm

reed geom

unit 2

cylinder $110.5588 \quad 91.44 \quad 0.0$

cylinder $210.635 \quad 96.52 \quad-1.27$

$\begin{array}{llllllll}\text { cuboid } 3 & 1 & 1.016 & -1.016 & 1.016 & -1.016 & 96.52 & -1.27\end{array}$

unit 6

array $23 * 0.0$

replicate 5 i 2r0.0 2r1.994 2r0.0 1

unit 7

cuboid

614.3033 .79436 .5

$\begin{array}{lll}0.0 & 91.5 & 0.0\end{array}$

cuboid

214.4053 .69236 .5

$\begin{array}{lll}0.0 & 91.5 & 0.0\end{array}$

cuboid

unit 8

cuboid

$\begin{array}{lllll}5 & 15.05 & 0.0 & 36.5\end{array}$

$0.0 \quad 97.79$

0.0

cuboid

611.2560 .74736 .5

0.091 .5

0.0

cuboid

211.3580 .64536 .5

0.091 .5

unit 9

erray $4 \quad 3 * 0.0$

repl icate 5 i 2r0.0 2r1.994 2r0.0

global

unit 10

array $5 \quad 3 \star 0.0$

reflector 415 ro $2.54 \quad 1$

reflector $526 r 3.045$

reflector $574 \mathrm{r3} .06005$

end geometry

read bias id=500 211 end bias

read array

are=2 nux=22 nuy=16 nuz=1 fill f2

er $8=4$ nux=20 nuy=16 nuz=1 fill f2

are $=5$ nux $=5$ nuy=1 nuz=1 fill

end fill

end array

read plot

$t t l=1 x-y$ slice of $m 1171024$ at $z=50$ '

xul $=0.0 \quad$ rul $=35.5 \quad$ zul $=50$

$x \mid r=145.6 \quad y / r=0.0 \quad$ zl $r=50$

uax=1 vdh=-1 nax=260 nch=1 12467 ' end

end plot

end data

end

67986 
p2438x24

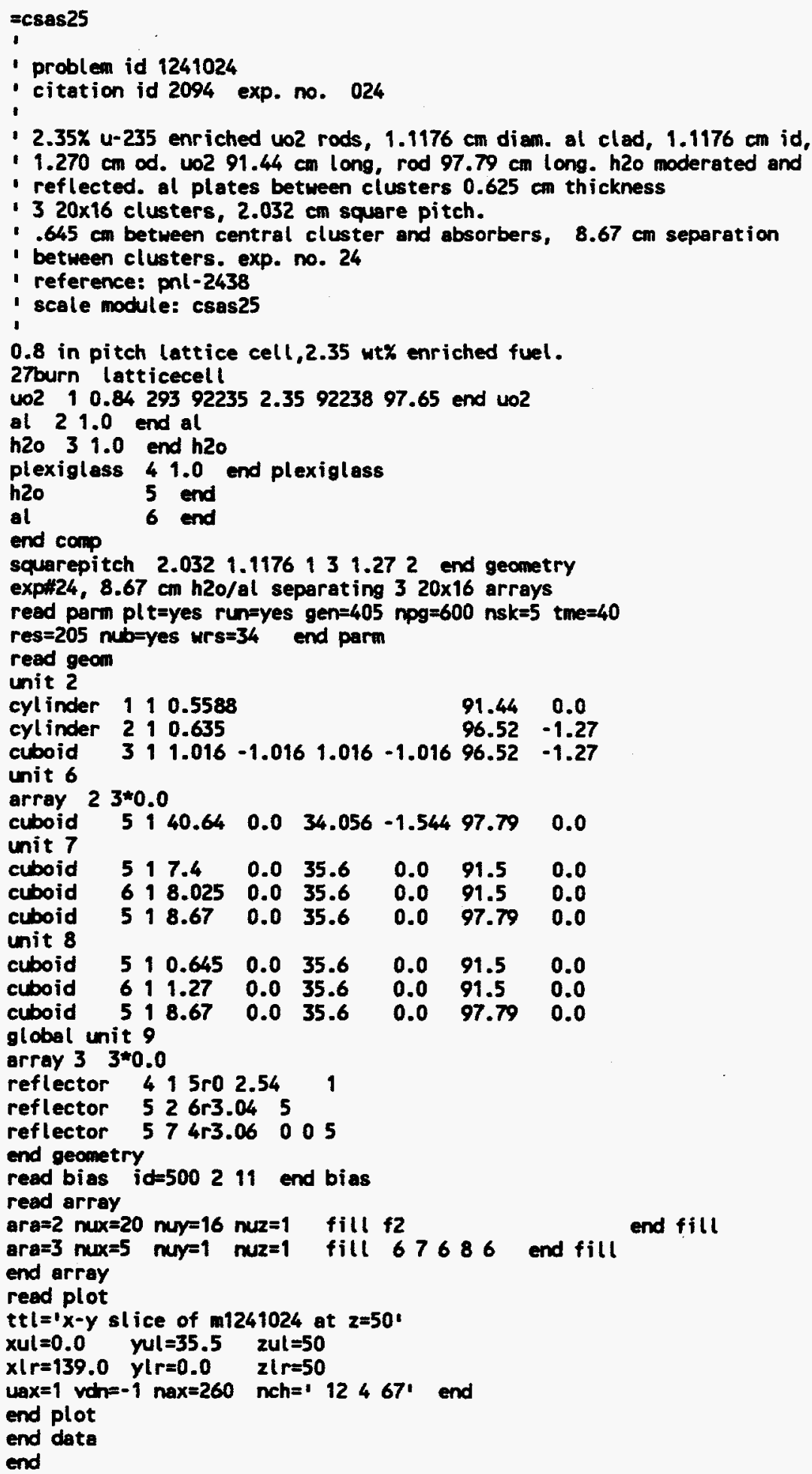




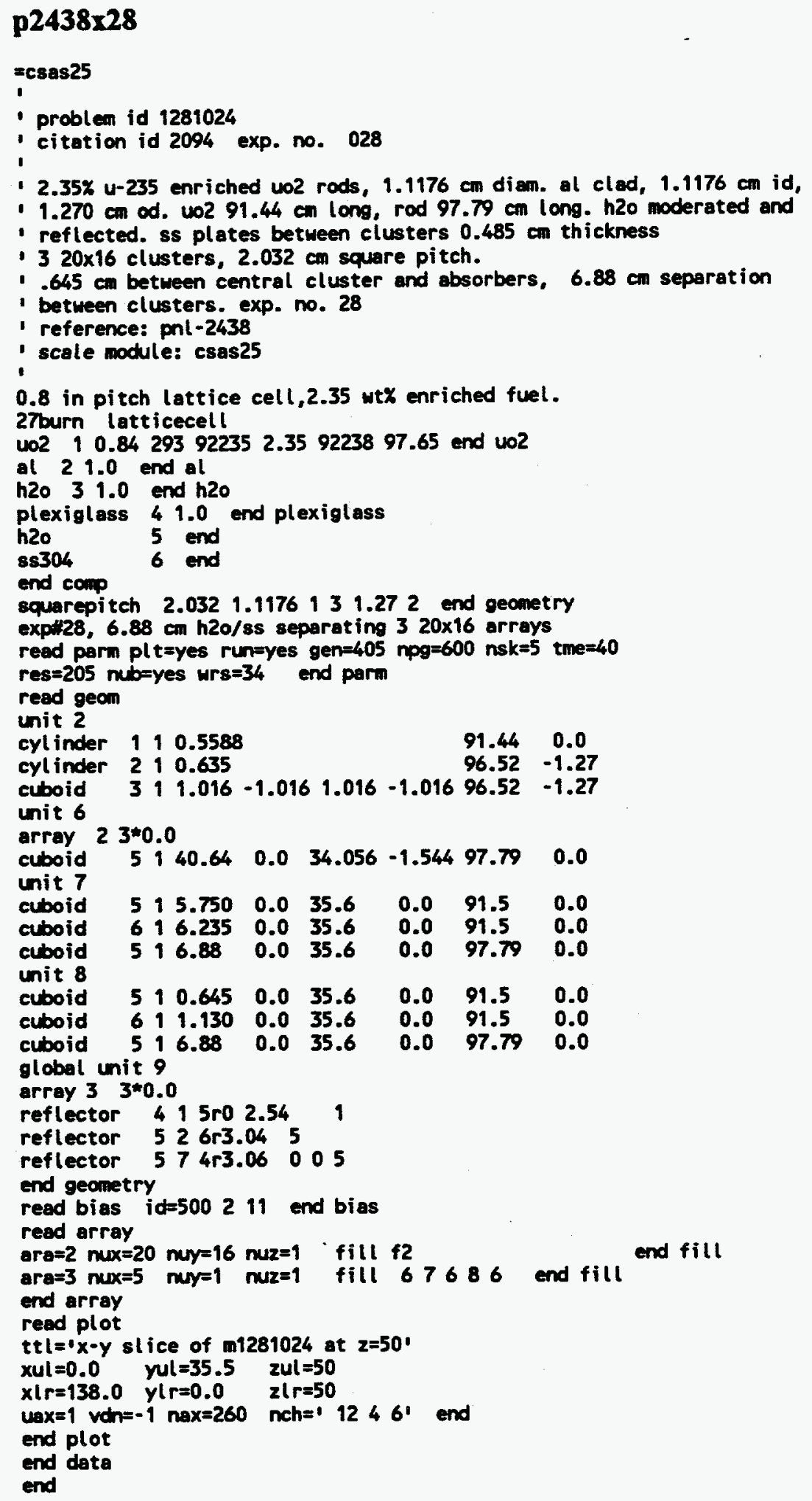




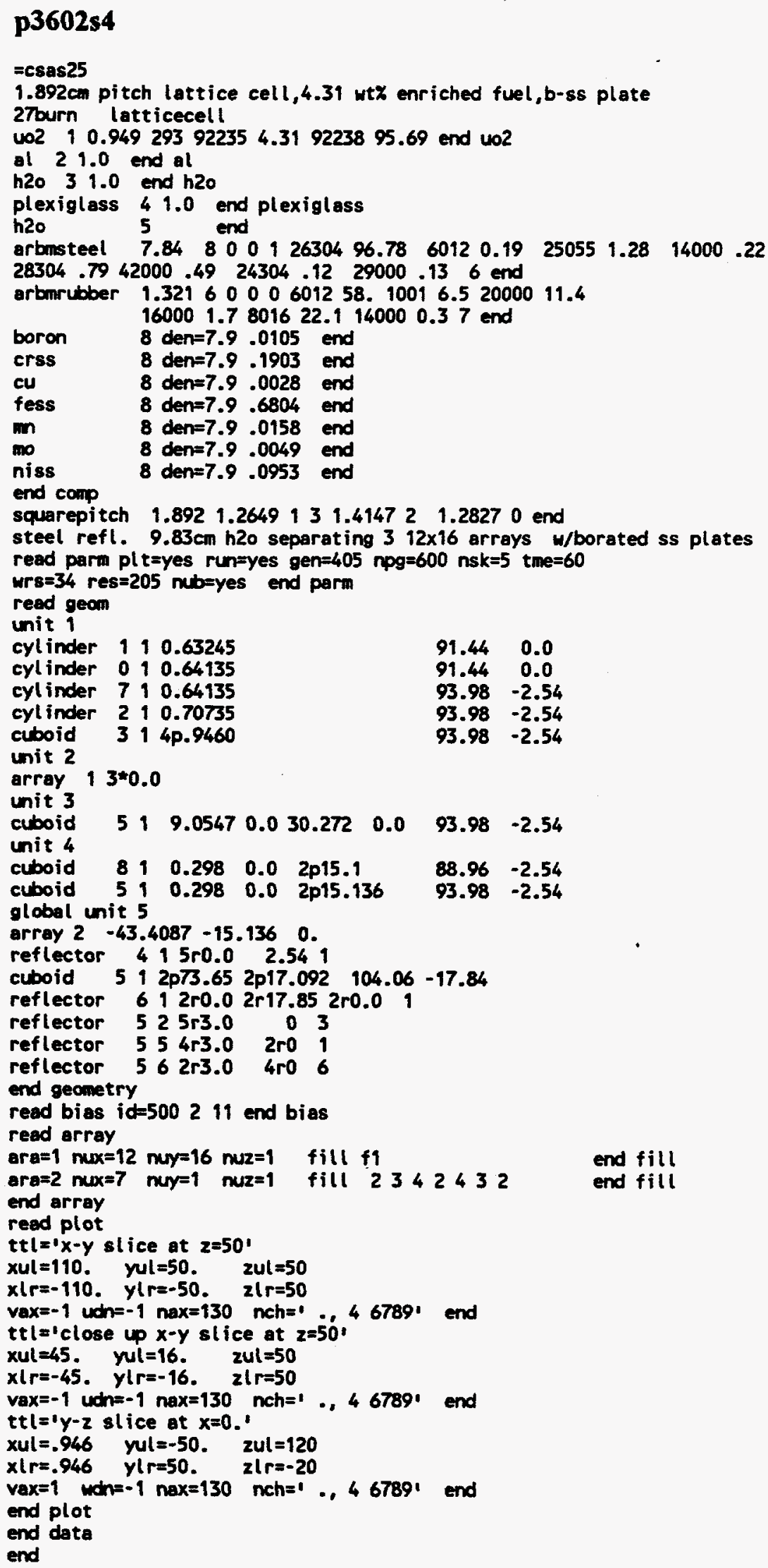




\section{p392614a}

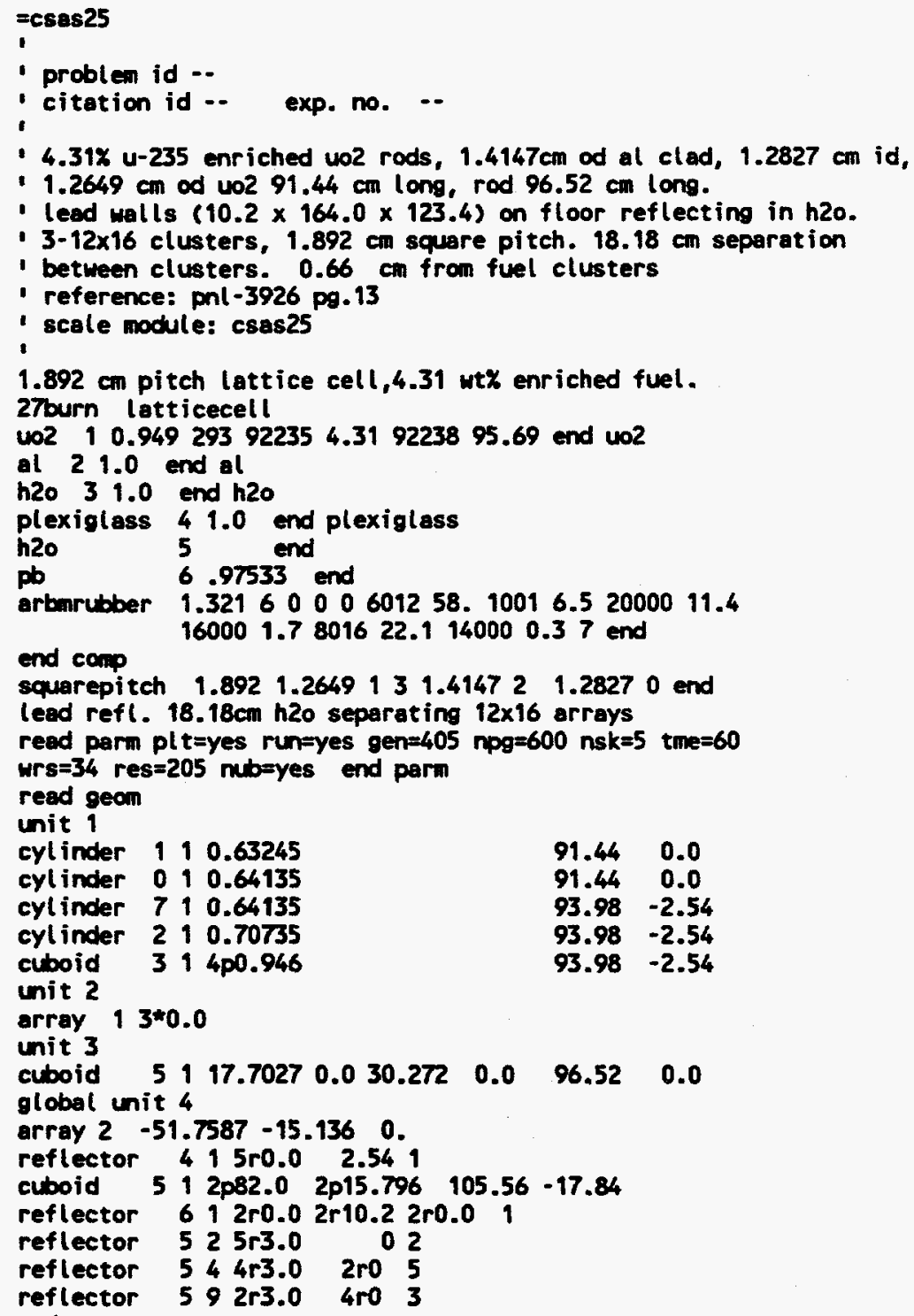




\section{p3926u4a}

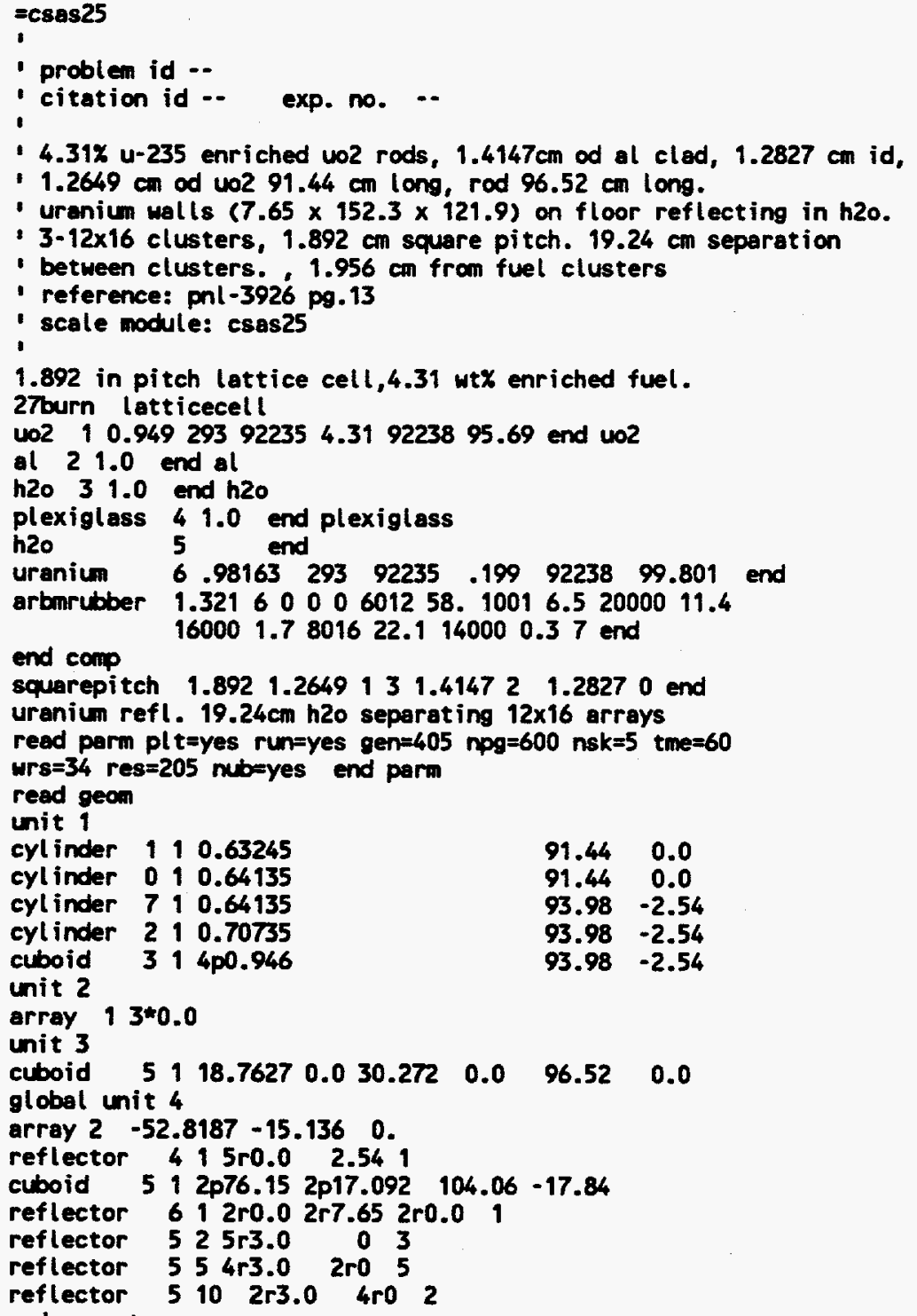




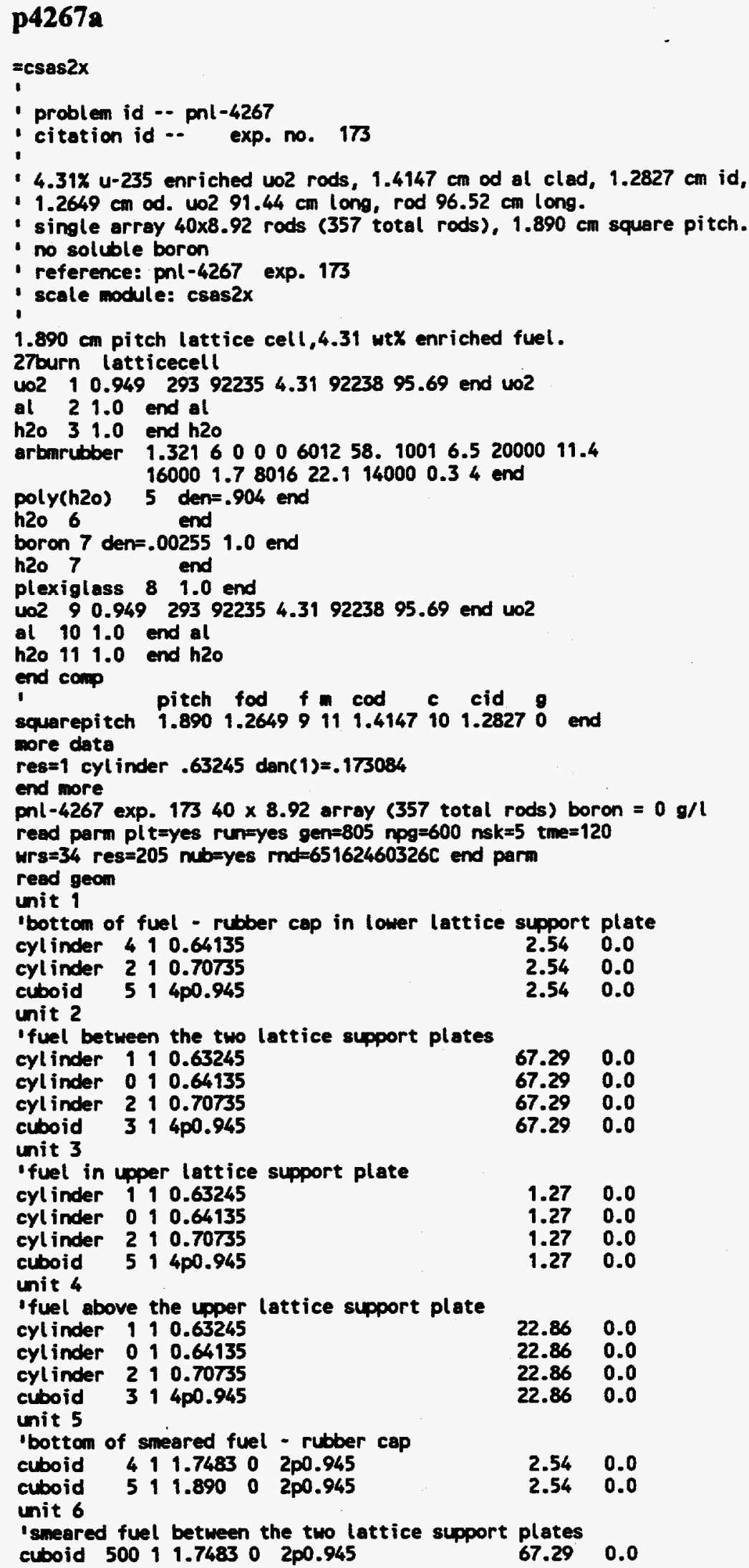




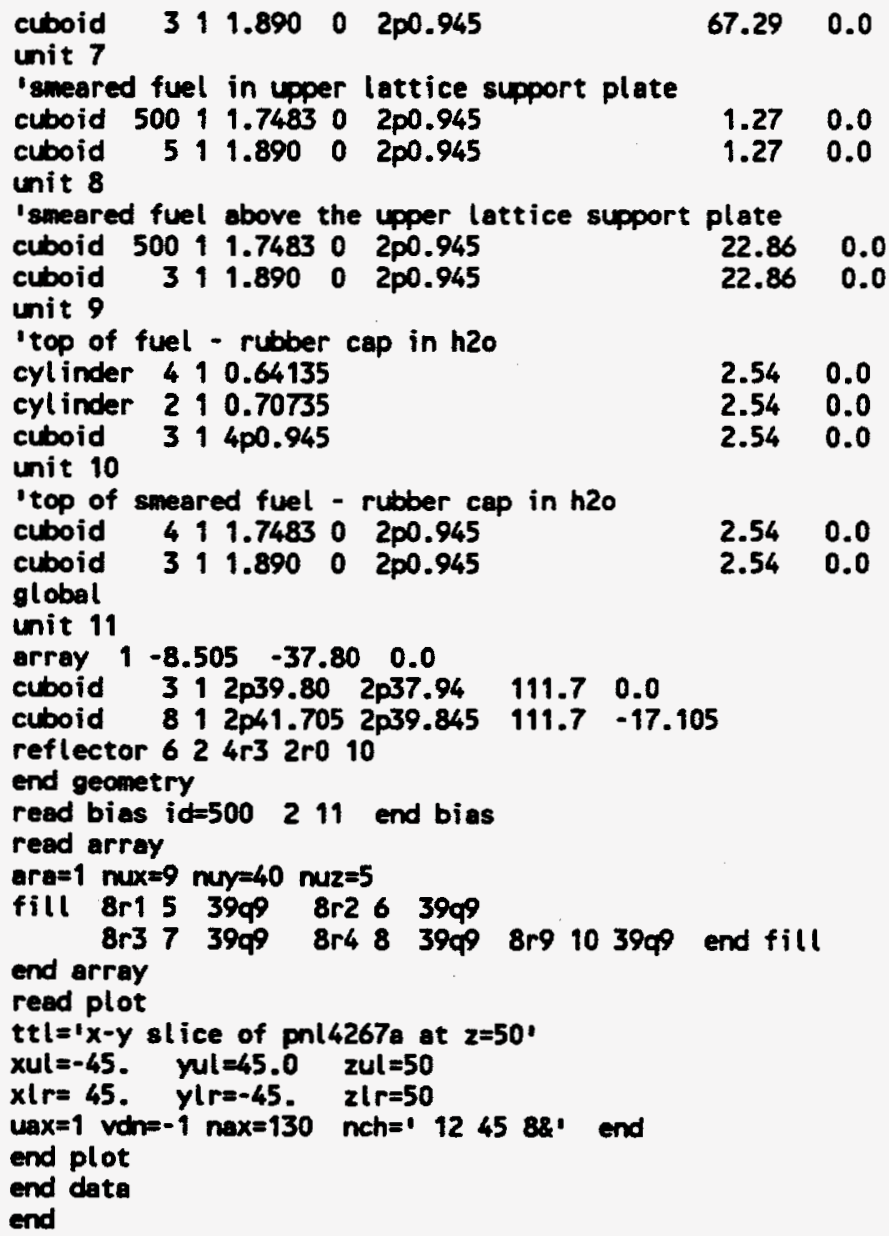


p4267b

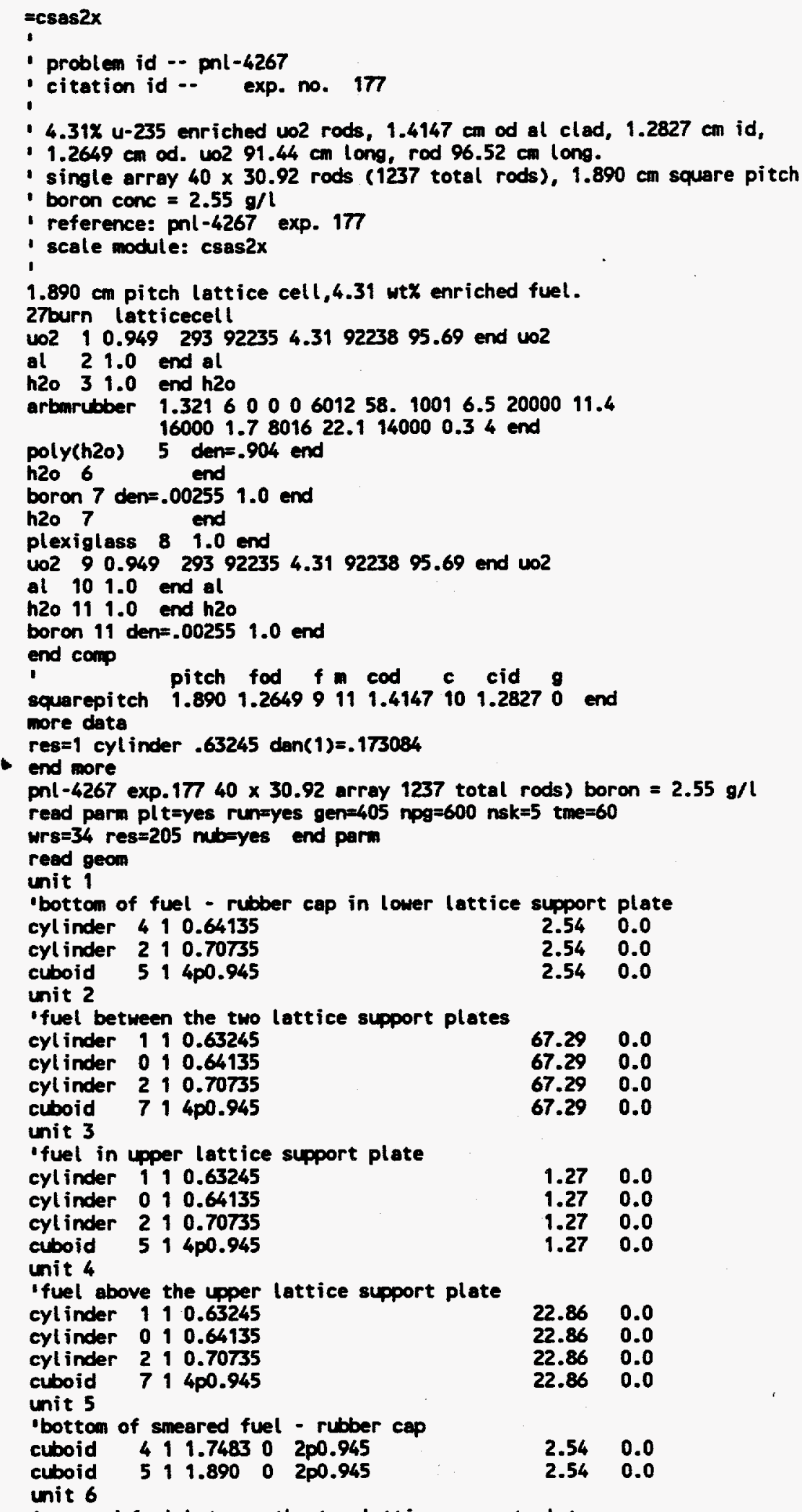




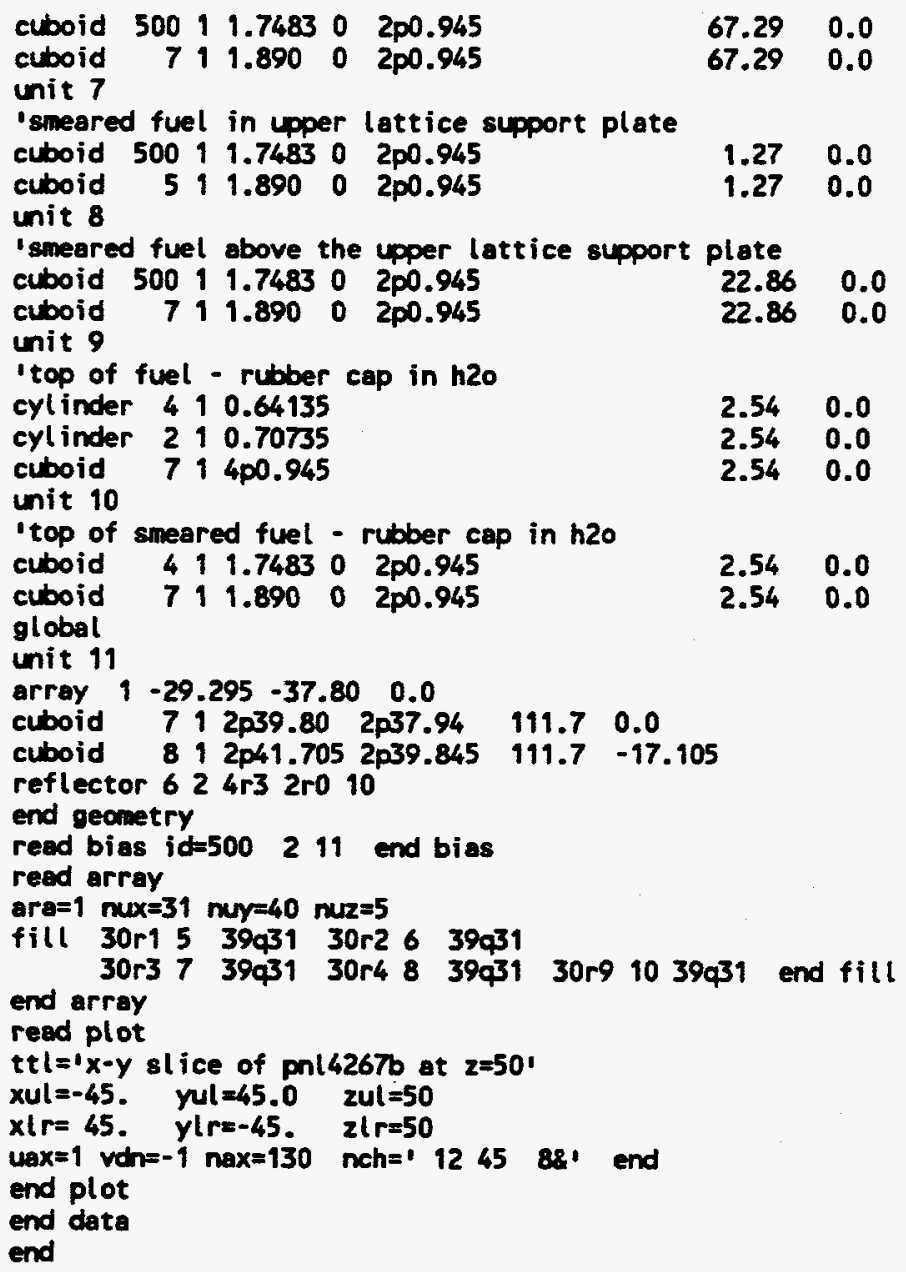


p4267c

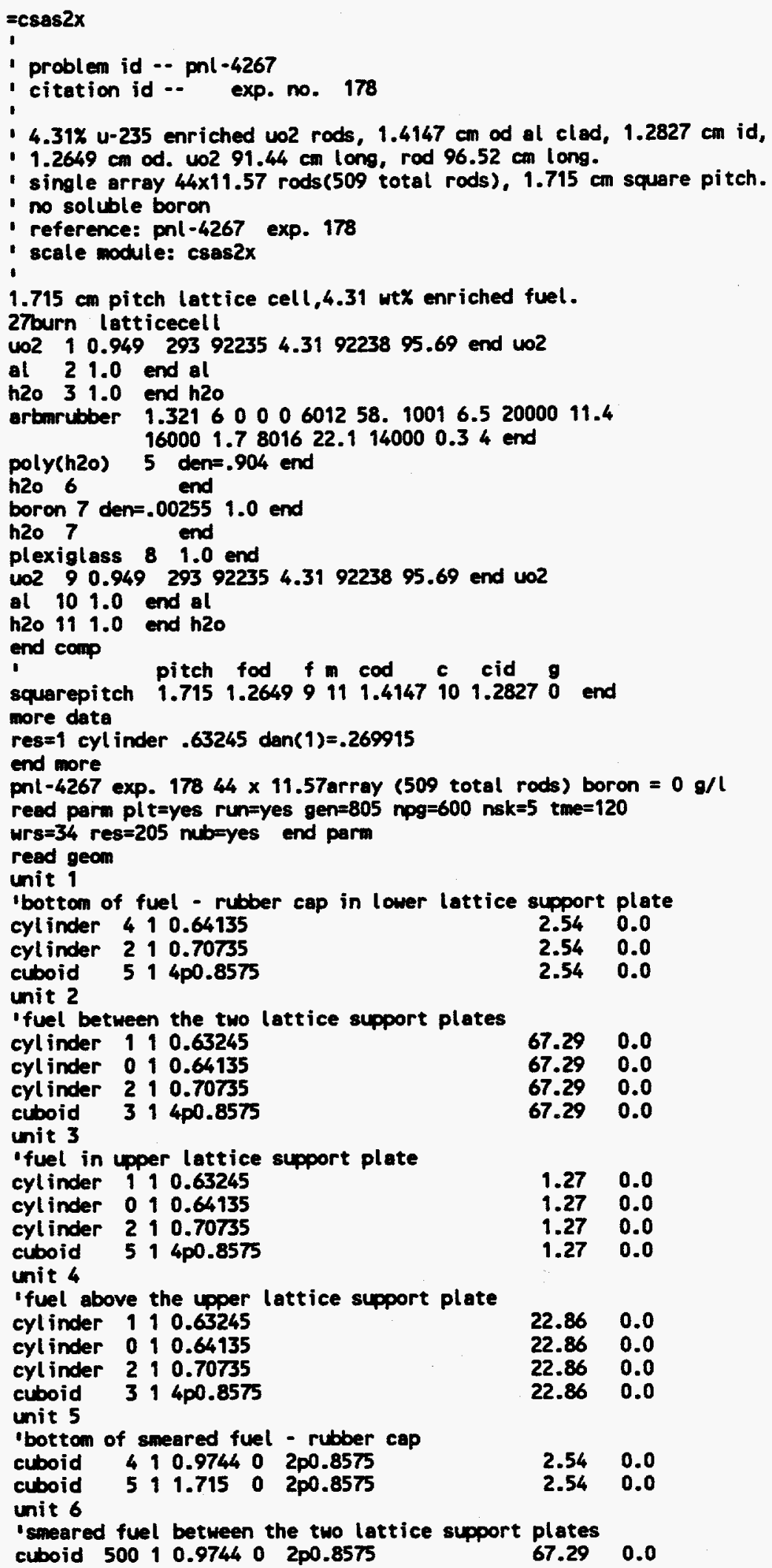




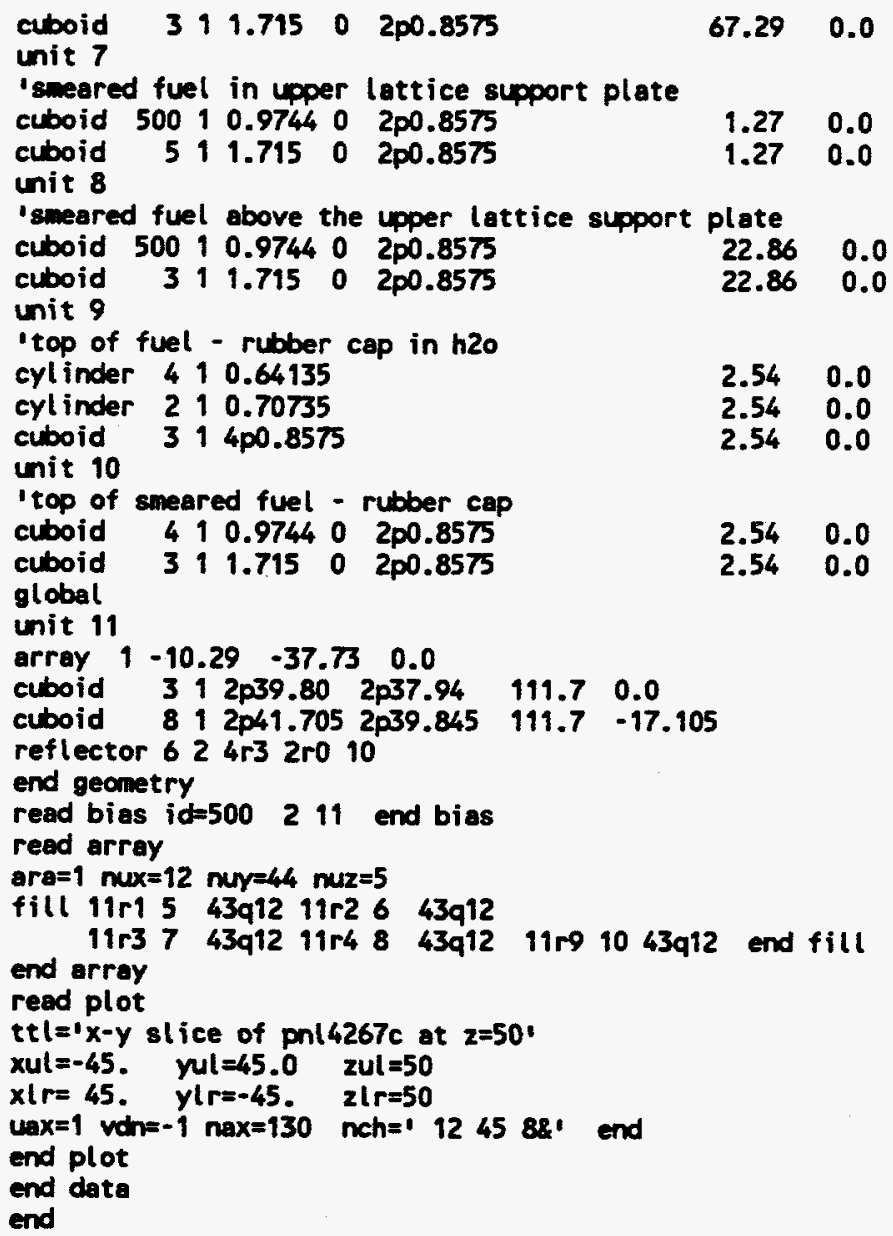




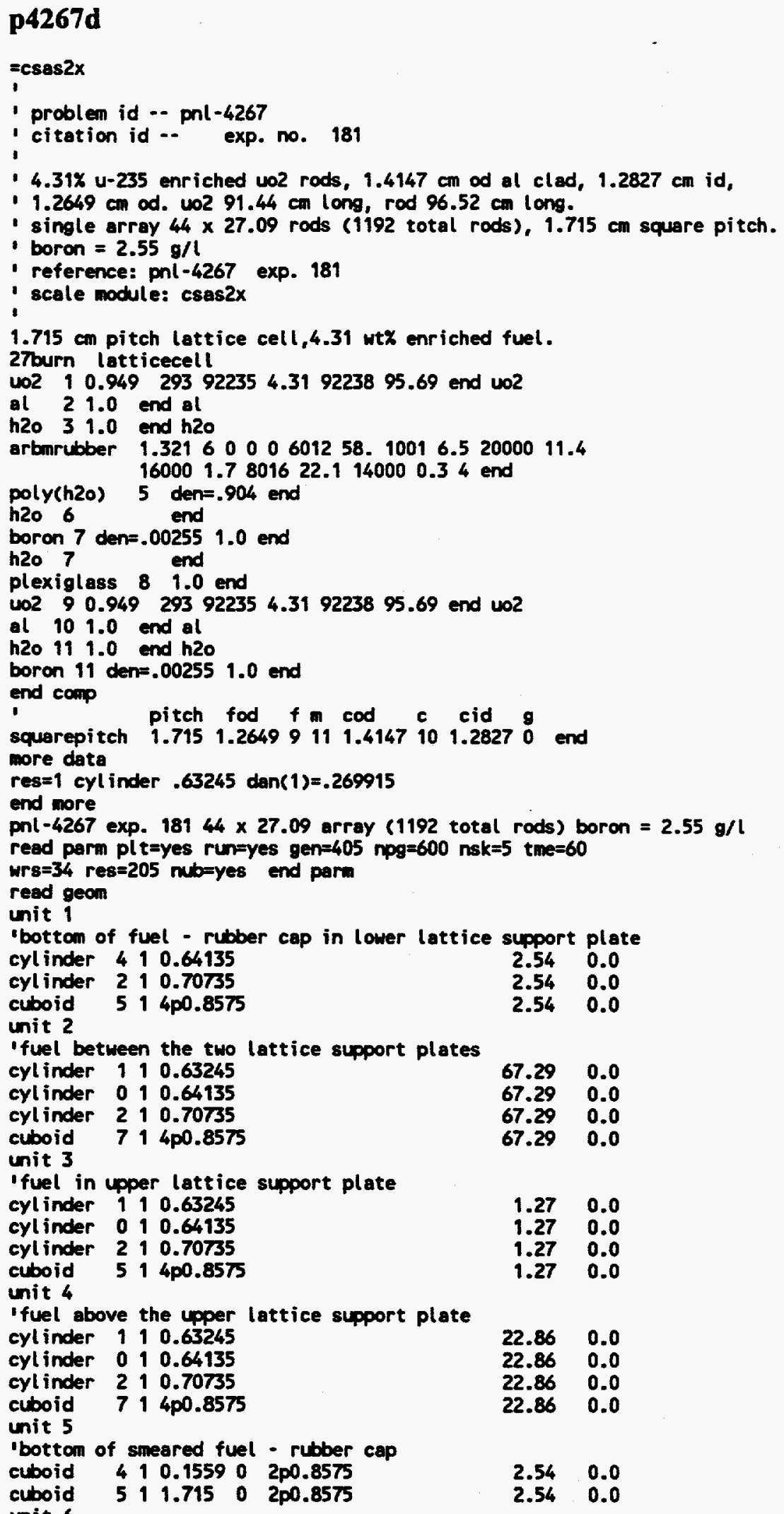

unit 6

'sneared fuel between the two lattice support plates 


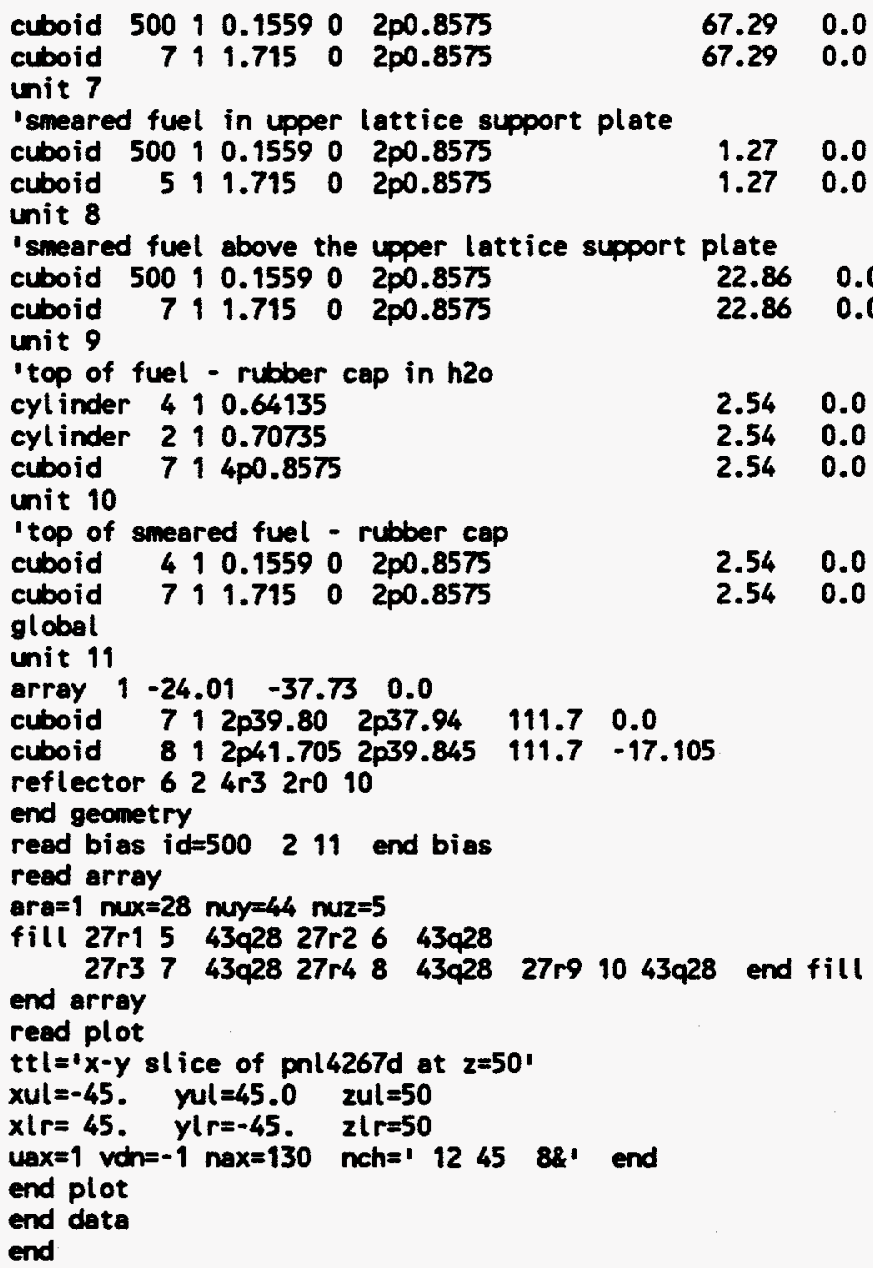




\section{pnI4976}

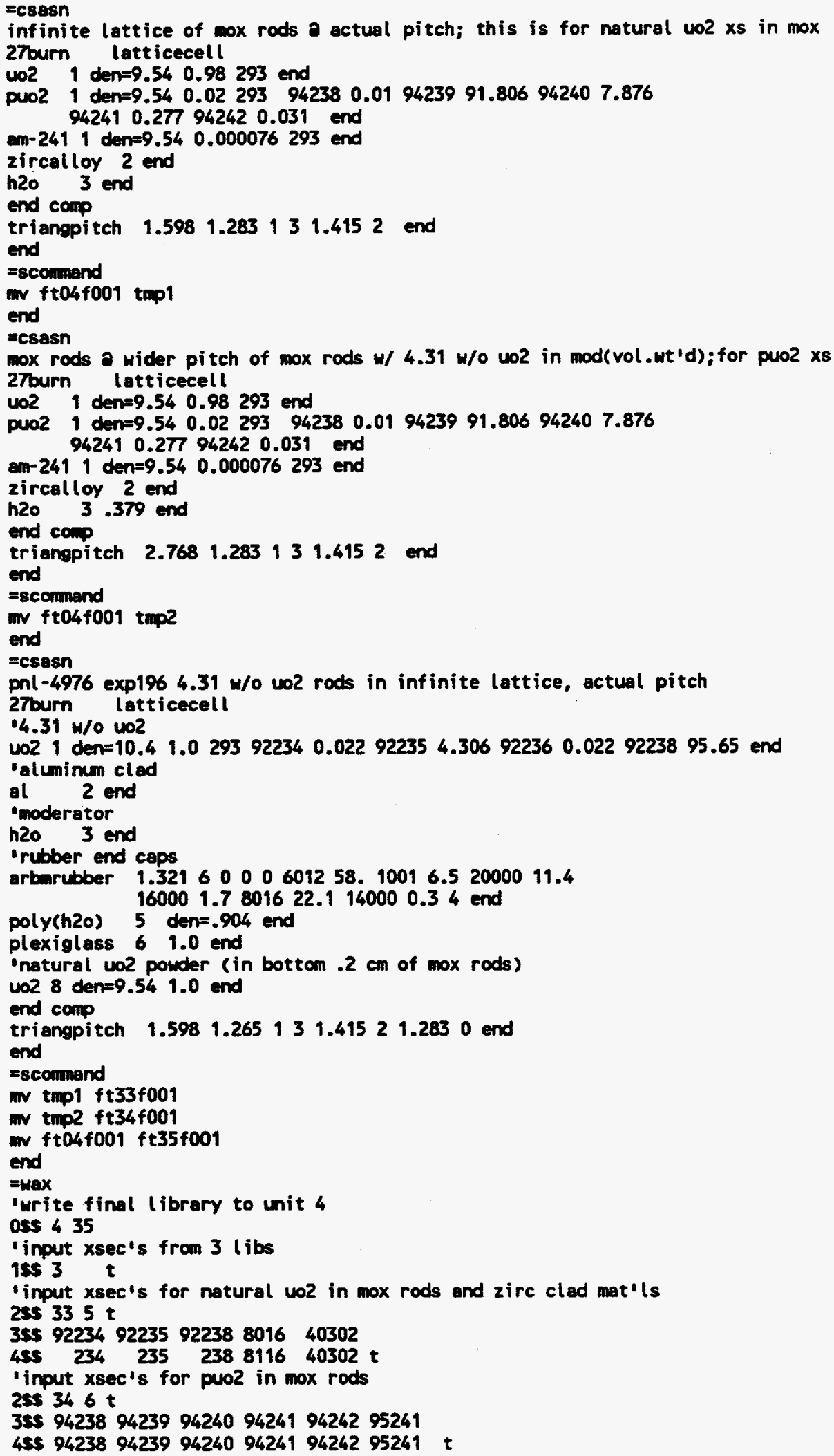


'input all other xsec's from third lib (4.31 w/0) 2ss 350 t

end

zkenov

pni4976 exp196 $1174 \omega 02$ \& 583 mo2 rods to approx. 20,000 mud/mtu assy

read paran tme $=60 \mathrm{pl} t=y e s \mathrm{npg}=600$ gen $=505$ nsk $=5$ run=yes $(\mathrm{ib}=4$

urs $=44$ res $=205$ nubeyes end param

read mixt

set $=2$

mix $=1$

$14.31 \mathrm{w} / \mathrm{O} 102$

92234

92235

92236

$5.18950 \mathrm{e}-06$

$1.01139 \mathrm{e}-03$

$5.14542 e-06$

92238

2.21824e-02

$8016 \quad 4.64083 \mathrm{e}-02$

mix=2

'al clad

13027

mix $=3$

$6.02374 e-02$

'h2o moderator

$1001 \quad 6.67514 \mathrm{e}-02$

$308016 \quad 3.33757 e-02$

mix $=4$

- rubber end caps

$401001 \quad 5.13089 \mathrm{e}-02$

$408016 \quad 1.09913 \mathrm{e}-02$

$6012 \quad 3.84503 e-02$

$20000 \quad 2.26270 \mathrm{e}-03$

$16000 \quad 4.21784 e-04$

$14000 \quad 8.49759$ e- 05

mi $x=5$

'polypropylene lattice plates

5010017.76850 e-02

$5060123.88425 e-02$

mix $=6$

'acrylic plates

$601001 \quad 5.68187 \mathrm{e}-02$

$608016 \quad 1.42047 e-02$

$606012 \quad 3.55117 e-02$

mix $=7$

'mixed oxide $=$ natural $102+p \omega 2$

$234 \quad 1.18851$ e-06

$235 \quad 1.48879 \mathrm{e}-04$

$238 \quad 2.07010$ e-02

$94238 \quad 4.25437 e-08$

$94239 \quad 3.89206 \mathrm{e}-04$

$94240 \quad 3.32505 \mathrm{e}-05$

$94241 \quad 1.16460 \mathrm{e}-06$

$94242 \quad 1.29791 \mathrm{e}-07$

$95241 \quad 1.81131 \mathrm{e}-06$

$8116 \quad 4.25498 \mathrm{e}-02$

nix $=8$

'natural 102 powder

$892234 \quad 1.21277$ e-06

$892235 \quad 1.51917 e-04$

$892238 \quad 2.11235 \mathrm{e}-02$

$808016 \quad 4.25533 e-02$

mix $=9$

izirc elad

40302

end mixt

read geom

unit 1

zhemicyl-y 11.6325

zhenicyl-y 010 . 1415

zhemicyl-y 21 .7075

unit 2

zhenicyl-x 11.6325

$42.774 \quad 0.0$

$42.774 \quad 0.0$

$\begin{array}{lll}42.774 & 0.0\end{array}$

$\begin{array}{ll}42.774 & 0.0\end{array}$ 
zhenicyl-x 001 . 0415 zhemicyl-x 21.7075 unit 3

zhemicyl+x 11.6325

zhemicyl+x 01.6415

zhemicyl+x 2 i .7075

unit 4

zhemicyl+y 11.6325

zhemicyl+y 01.6415

zhemicylty 21.7075

unit 5

zhenicyl-y 71.6495

zhenicyl-y 91.7175

unit 6

zhemicyl-x $7, .6415$

zhemicyl-x $9, .7175$

unit 7

zhemicyl+x 71.6415

zhemicyltx $9, .7175$

unit 8

zhemicylty 71.6415

zhemicylty $91 \quad .7175$

unit 11

zhemicyl-y $4 \quad 1 \quad .6415$

zhemicyl-y 21 .7075

unit 12

zhenicyl-x $4 \quad 1 \quad .6415$

zhemicyl-x 21.7075

unit 13

zhemicyl+x $4, \quad 6415$

zhemicyl+x 21.7075

unit 14

zhemicylty $4 \quad 1 \quad .6415$

zhemicylty 21.7075

unit 15

zhemicyl-y 81.6415

zhemicyl-y $7, .6415$

zhemicyl-y 91.7175

unit 16

zhemicyl-x 81.6415

zhemicyl-x 71.6415

zhemicyl-x 91.7175

unit 17

zhemicyl+x 81.6415

zhenicyl $+x 79.6415$

zhenicyl+x 91.7175

unit 18

zhemicylty 81.6415

zhemicylty 71.6415

zhemicylty $91 \quad 1.7175$

unit 21

zhenicyl-y 111.6325

zhemicyl-y 01 . 1415

zhemicyl-y 21 .7075

unit 22

zhemicyl-x 11 .6325

zhenicyl-x 011 .6415

zhemicyl-x 21.7075

unit 23

zhemicyltx 19.6325

zhenicyl+x 011.6415

zhemicyl+x 21.7075

unit 24

zhemicylty 11 .6325

zhemicylty 01 . 1415

zhemicylty 21 .7075

unit 25

zhemicyl-y 71.6415

zhemicyl-y 91.7175 $\begin{array}{ll}42.774 & 0.0\end{array}$

$\begin{array}{lll}42.774 & 0.0\end{array}$

$42.774 \quad 0.0$

$42.774 \quad 0.0$

$42.774 \quad 0.0$

$\begin{array}{ll}42.774 & 0.0\end{array}$

$42.774 \quad 0.0$

$\begin{array}{lll}42.774 & 0.0\end{array}$

$42.774 \quad 0.0$

42.7740 .0

$42.774 \quad 0.0$

42.7740 .0

$42.774 \quad 0.0$

$42.774 \quad 0.0$

$42.774 \quad 0.0$

42.7740 .0

$2.54 \quad 0.0$

$2.54 \quad 0.0$

2.540 .0

2.540 .0

2.540 .0

2.540 .0

$\begin{array}{ll}2.54 & 0.0\end{array}$

2.540 .0

$0.898 \quad 0.698$

$2.540 \quad 0.698$

$2.540 \quad 0.0$

$0.898 \quad 0.698$

$2.540 \quad 0.698$

2.5400 .0

$0.898 \quad 0.698$

$2.540 \quad 0.698$

2.5400 .0

$0.898 \quad 0.698$

$2.540 \quad 0.698$

$2.540 \quad 0.0$

1.350 .0

1.350 .0

1.350 .0

1.350 .0

1.350 .0

1.350 .0

1.350 .0

1.350 .0

1.350 .0

1.350 .0

1.350 .0

1.350 .0

1.350 .0

1.350 .0 
unit 26

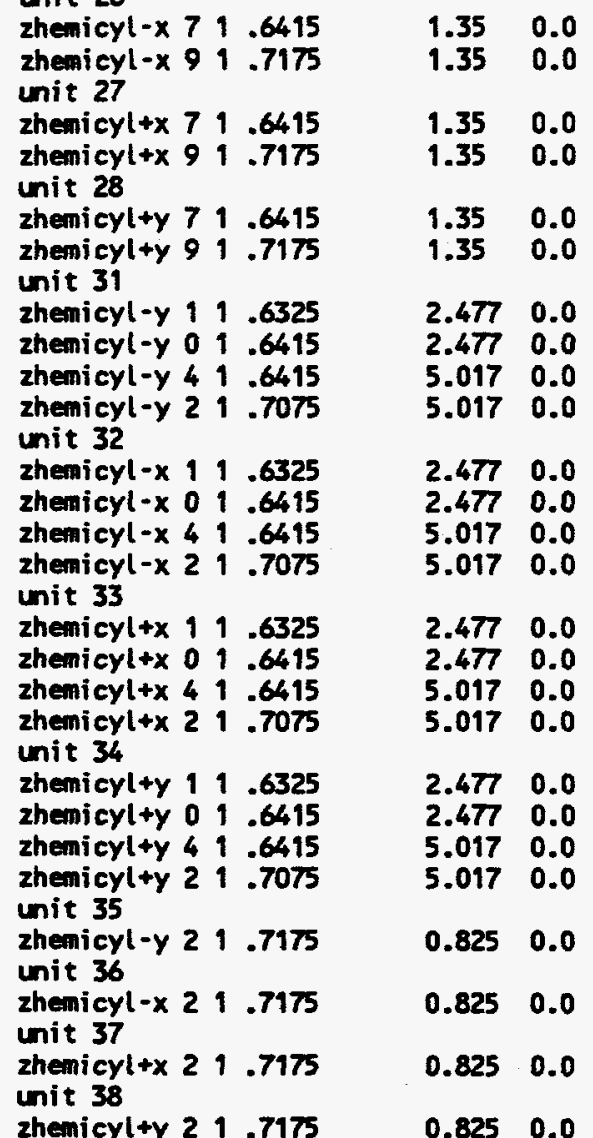

zhemicyl+1

cuboid

unit 91

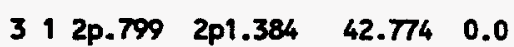

cuboid

unit 92

cuboid

unit 93

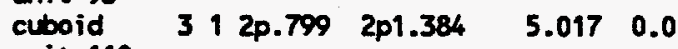

unit 110

zhemicylty $11.6325 \quad 42.774 \quad 0.0$

zhemicylty $01.6415 \quad 42.7740 .0$

zhemicylty $21.7075 \quad 42.774 \quad 0.0$

$\begin{array}{llllllll}\text { cuboid } & 3 & 1 & 2 p .799 & 2.768 & 0.0 & 42.774 & 0.0\end{array}$

hole $\quad 6.7991 .384 \quad 0.0$

hole $\quad 3=.7991 .3840 .0$

hole $\quad \begin{array}{llll}1 & 0.0 & 2.768 & 0.0\end{array}$

unit 111

zhemicylty $71.6415 \quad 42.774 \quad 0.0$

zhenicylty $91.7175 \quad 42.774 \quad 0.0$

$\begin{array}{llllllll}\text { cuboid } & 3 & 1 & 2 p .799 & 2.768 & 0.0 & 42.774 & 0.0\end{array}$

hole $\quad 2.7991 .3840 .0$

hole $\quad 3=.7991 .3840 .0$

$\begin{array}{llllll} & \text { hole } & 5 & 0.0 & 2.768 & 0.0\end{array}$

unit 112

zhemicyl-y $71.6415 \quad 42.7740 .0$

zhemicyl-y $91.7175 \quad 42.774 \quad 0.0$

$\begin{array}{llllllll}\text { cuboid } \quad 3 & 1 & 2 p .799 & 0.0 & -2.768 & 42.774 & 0.0\end{array}$

unit 113

zhemicyl-y $79.6415 \quad 42.7740 .0$

zhenicyl-y $91.7175 \quad 42.774 \quad 0.0$

$\begin{array}{llllllll}\text { cuboid } \quad 31 & 2 p .799 & 0.0 & -2.768 & 42.774 & 0.0\end{array}$

hole $3=.799-1.3840 .0$ 


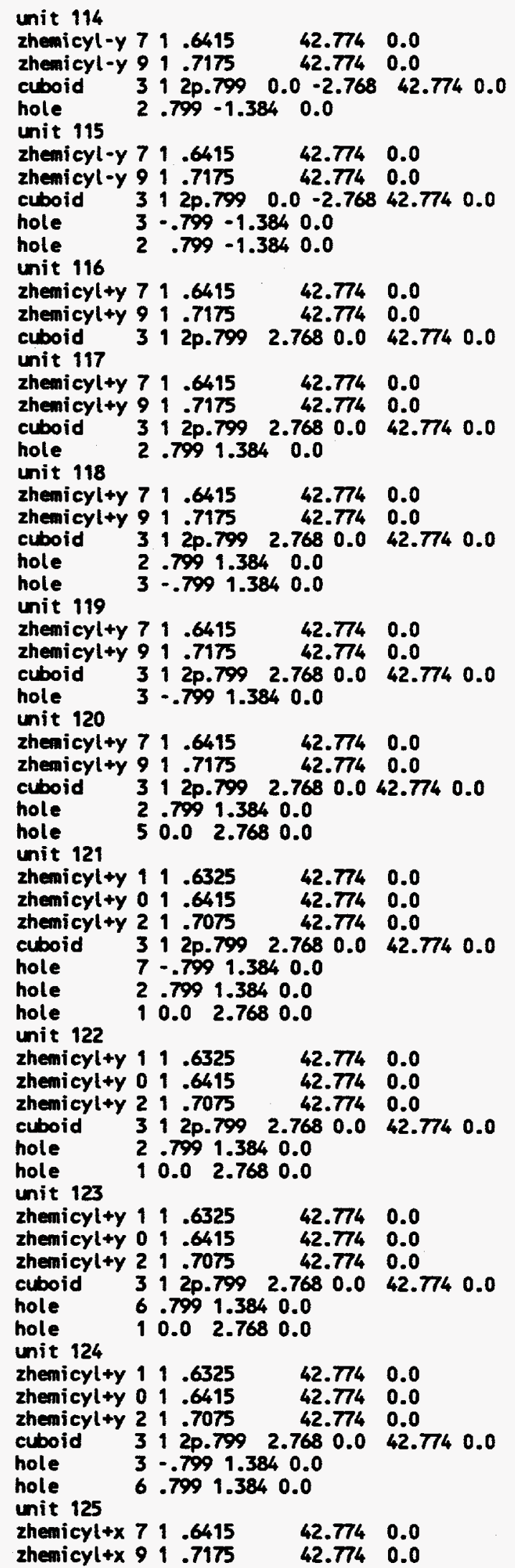




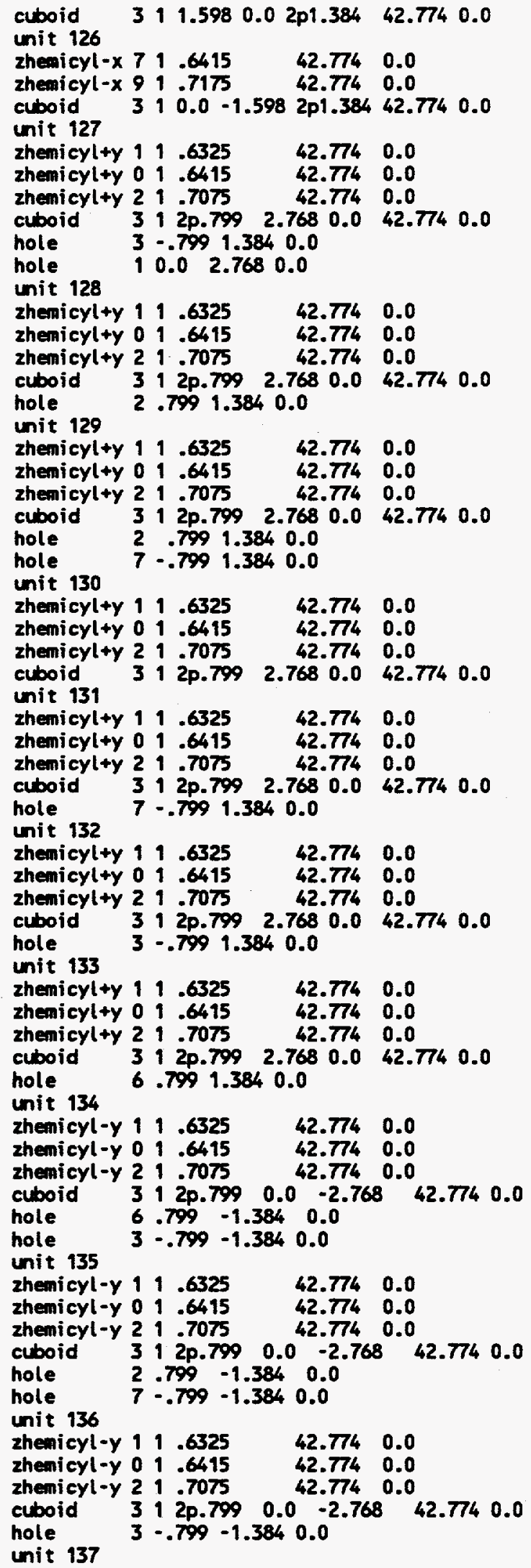




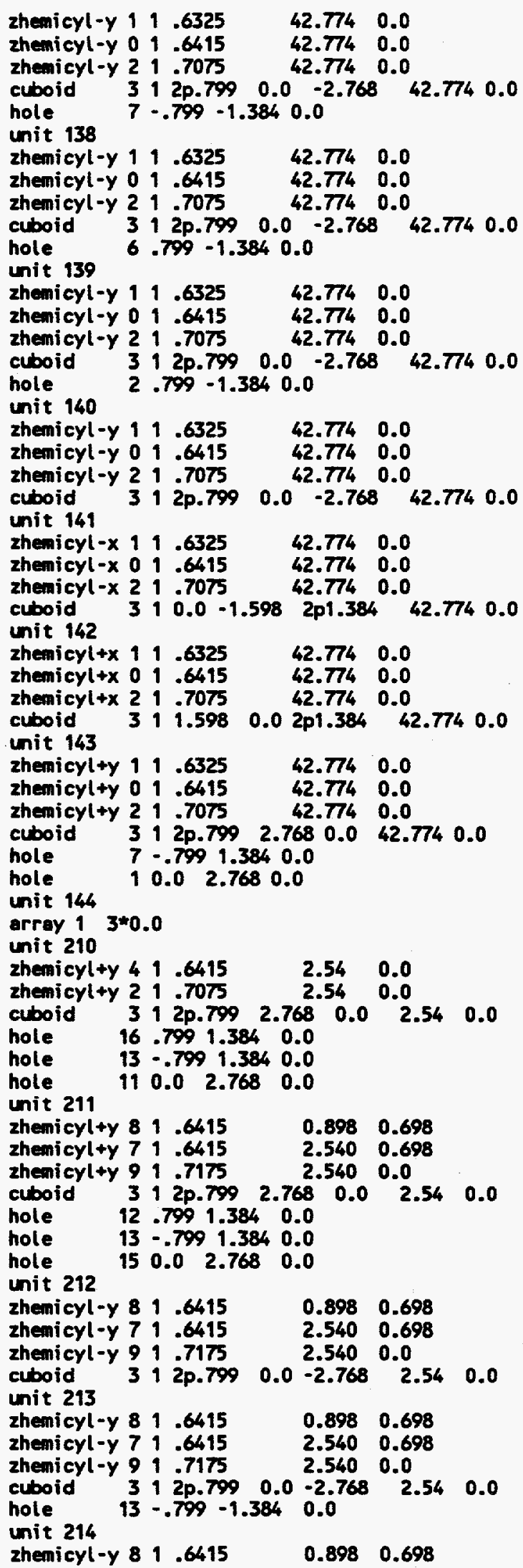




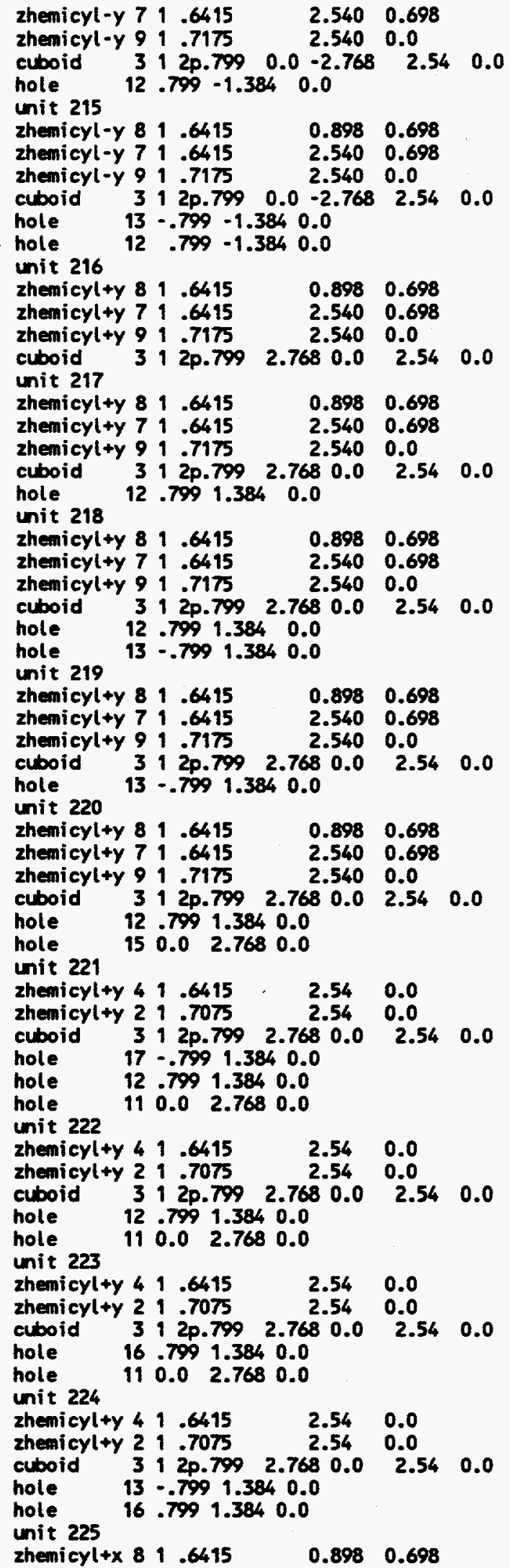




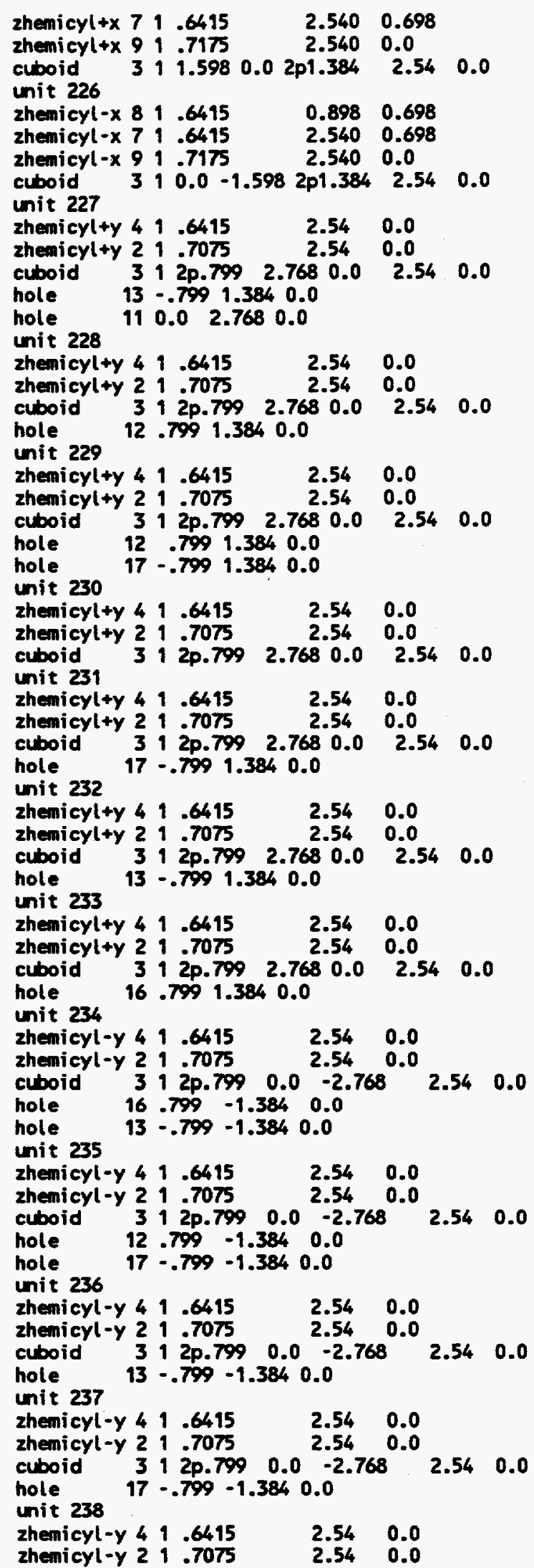




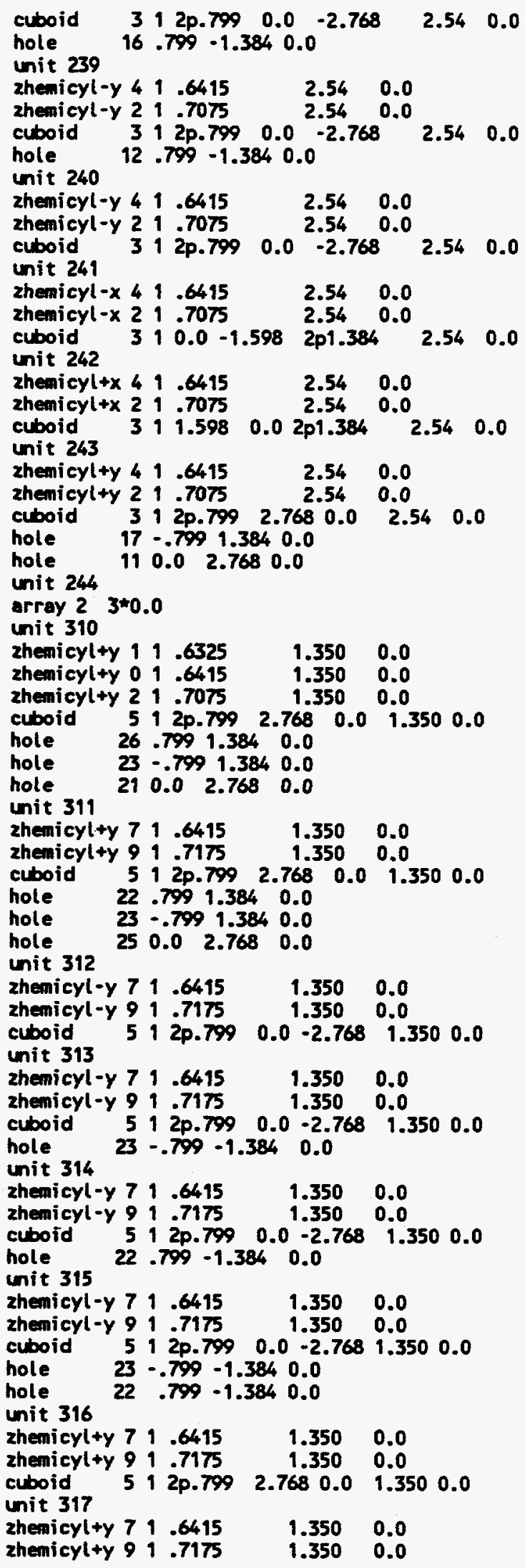




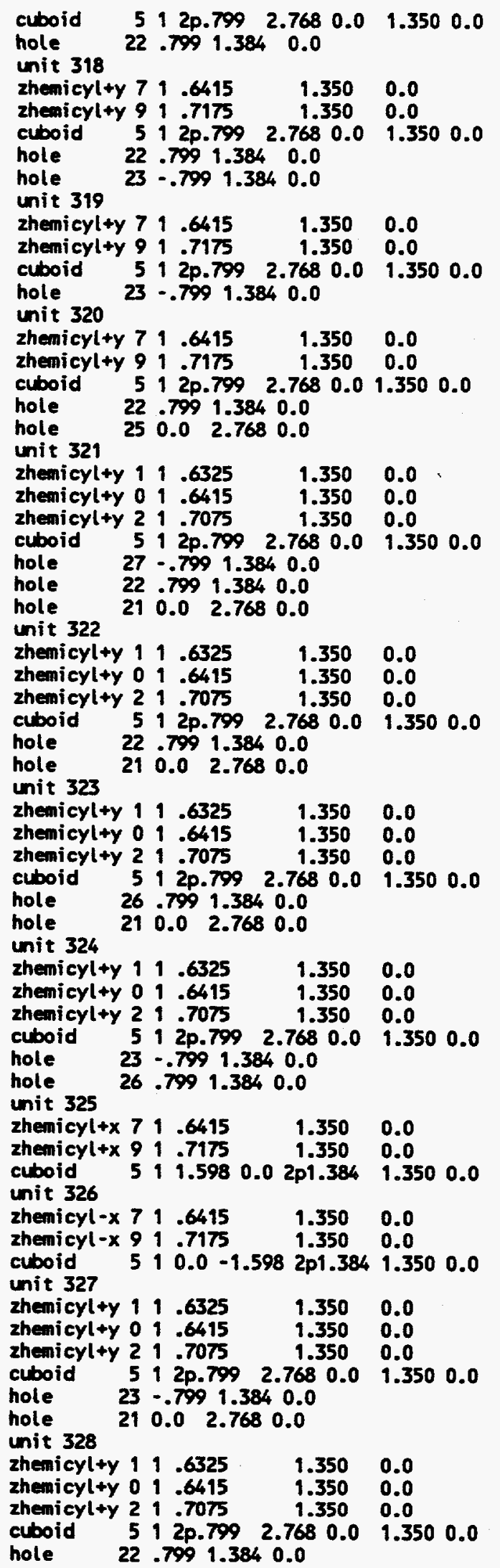


unit 329

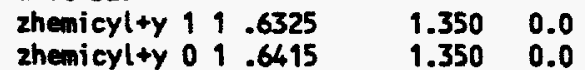

zhemicylty $21.7075 \quad 1.350 \quad 0.0$

$\begin{array}{lllllllll}\text { cuboid } \quad 5 & 1 & 2 p .799 & 2.768 & 0.0 & 1.350 & 0.0\end{array}$

hole $22 \quad .7991 .3840 .0$

hole $27-.7991 .3840 .0$

unit 330

zhemicylty $11.6325 \quad 1.350 \quad 0.0$

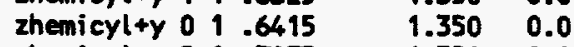

zhemicylty $21.7075 \quad 1.350 \quad 0.0$

$\begin{array}{lllllll}\text { cuboid } 5.1 & 2 p .799 & 2.768 & 0.0 & 1.350 & 0.0\end{array}$

unit 331

zhemicylty $1.6325 \quad 1.350 \quad 0.0$

zhemicylty $01.6415 \quad 1.350 \quad 0.0$

zhenicylty $21.7075 \quad 1.350 \quad 0.0$

$\begin{array}{lllllllll}\text { cuboid } 5 & 1 & 2 p .799 & 2.768 & 0.0 & 1.350 & 0.0\end{array}$

hole $27-.799 \quad 1.3840 .0$

unit 332

zhemicylty $11.6325 \quad 1.350 \quad 0.0$

zhemicylty $01.6415 \quad 1.350 \quad 0.0$

zhemicylty $21.7075 \quad 1.350 \quad 0.0$

$\begin{array}{llllllll}\text { cuboid } \quad 5 & 1 & 2 p .799 & 2.768 & 0.0 & 1.350 & 0.0\end{array}$

hole $23-.7991 .3840 .0$

unit 333

zhemicyl+y $11.6325 \quad 1.350 \quad 0.0$

zhemicylty $01.6415 \quad 1.350 \quad 0.0$

zhemicyl+y $21.7075 \quad 1.350 \quad 0.0$

$\begin{array}{llllllll}\text { cuboid } 5 & 12 p .799 & 2.768 & 0.0 & 1.350 & 0.0\end{array}$

hole 26.7991 .3840 .0

unit 334

zhemicyl-y $11.6325 \quad 1.350 \quad 0.0$

zhemicyl-y $01.6415 \quad 1.350 \quad 0.0$

zhemicyl-y $21.7075 \quad 1.350 \quad 0.0$

$\begin{array}{llllllll}\text { cuboid } \quad 5 & 1 & 2 p .799 & 0.0 & -2.768 & 1.350 & 0.0\end{array}$

hole $26.799-1.3840 .0$

hole $23-.799-1.384 \quad 0.0$

unit 335

zhemicyl-y $11.6325 \quad 1.350 \quad 0.0$

zhemicyl-y $011.6415 \quad 1.350 \quad 0.0$

zhemicyl-y $21.7075 \quad 1.350 \quad 0.0$

$\begin{array}{lllllll}\text { cuboid } \quad 5 & 1 & 2 p .799 & 0.0 & -2.768 & 1.350 & 0.0\end{array}$

hole $22.799-1.3840 .0$

hole $\quad 27-.799-1.3840 .0$

unit 336

zhemicyl-y $11.6325 \quad 1.350 \quad 0.0$

zhemicyl-y $01.6415 \quad 1.350 \quad 0.0$

zhenicyl-y $21.7075 \quad 1.350 \quad 0.0$

$\begin{array}{lllllll}\text { cuboid } \quad 5 & 1 & 2 p .799 & 0.0 & -2.768 & 1.350 & 0.0\end{array}$

hole

$23-.799-1.3840 .0$

unit 337

zhemicyl-y $11.6325 \quad 1.350 \quad 0.0$

zhemicyl-y $01.6415 \quad 1.350 \quad 0.0$

zhenicyl-y $21.7075 \quad 1.350 \quad 0.0$

$\begin{array}{lllllll}\text { cuboid } \quad 5 & 1 & 2 p .799 & 0.0 & -2.768 & 1.350 & 0.0\end{array}$

hole $27-.799-1.3840 .0$

unit 338

zhenicyl-y $11.6325 \quad 1.350 \quad 0.0$

zhemicyl-y $01.6415 \quad 1.350 \quad 0.0$

zhemicyl-y $29.7075 \quad 1.350 \quad 0.0$

$\begin{array}{llllllll}\text { cuboid } \quad 5 & 1 & 2 p .799 & 0.0 & -2.768 & 1.350 & 0.0\end{array}$

hole $26.799-1.3840 .0$

unit 339

zhemicyl-y $11.6325 \quad 1.350 \quad 0.0$

zhemicyl-y $01.6415 \quad 1.350 \quad 0.0$

zhemicyl-y $21.7075 \quad 1.350 \quad 0.0$

$\begin{array}{lllllll}\text { cuboid } \quad 5 & 1 & 2 p .799 & 0.0 & -2.768 & 1.350 & 0.0\end{array}$

hole $22.799 \cdot 1.3840 .0$

unit 340 


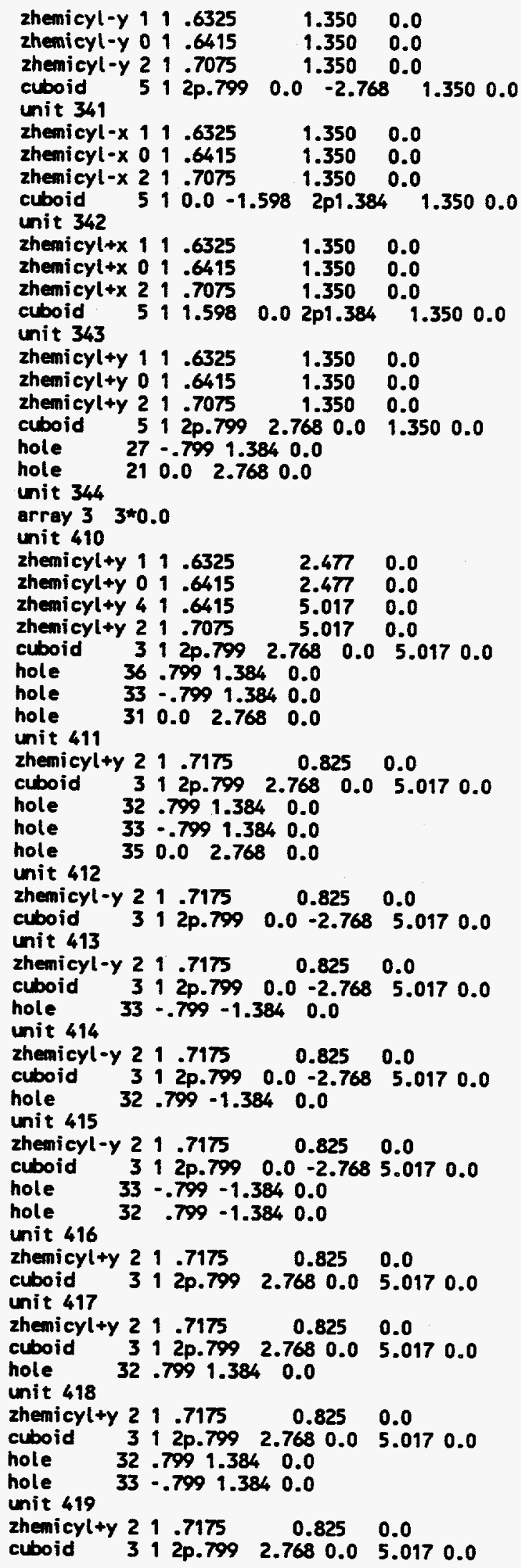




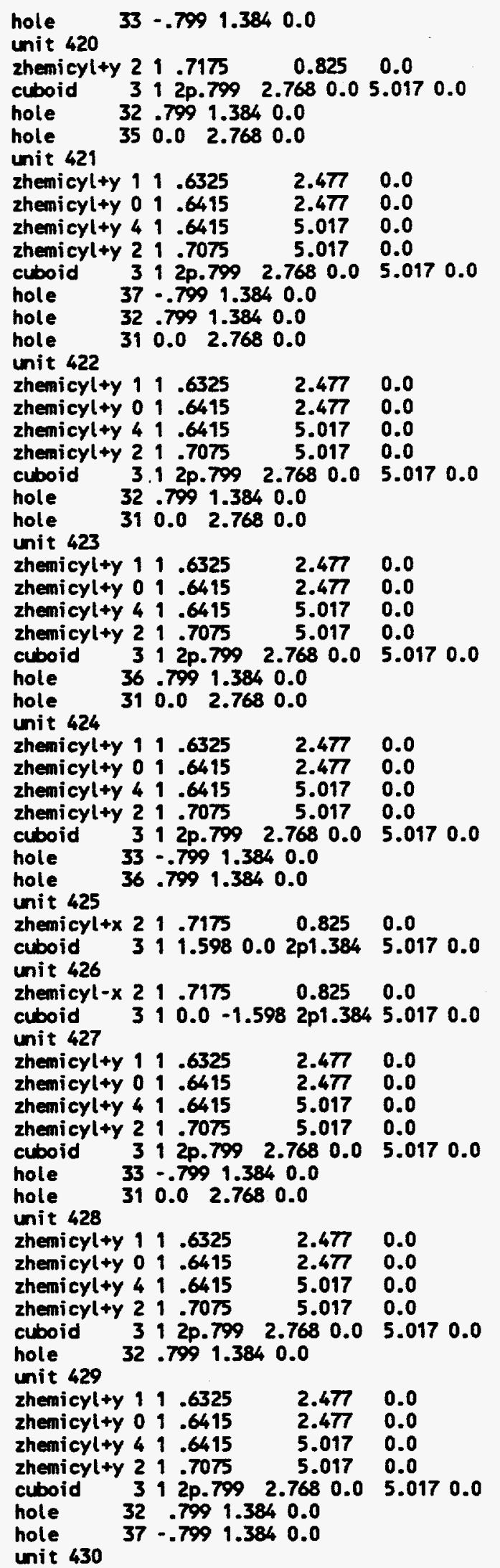




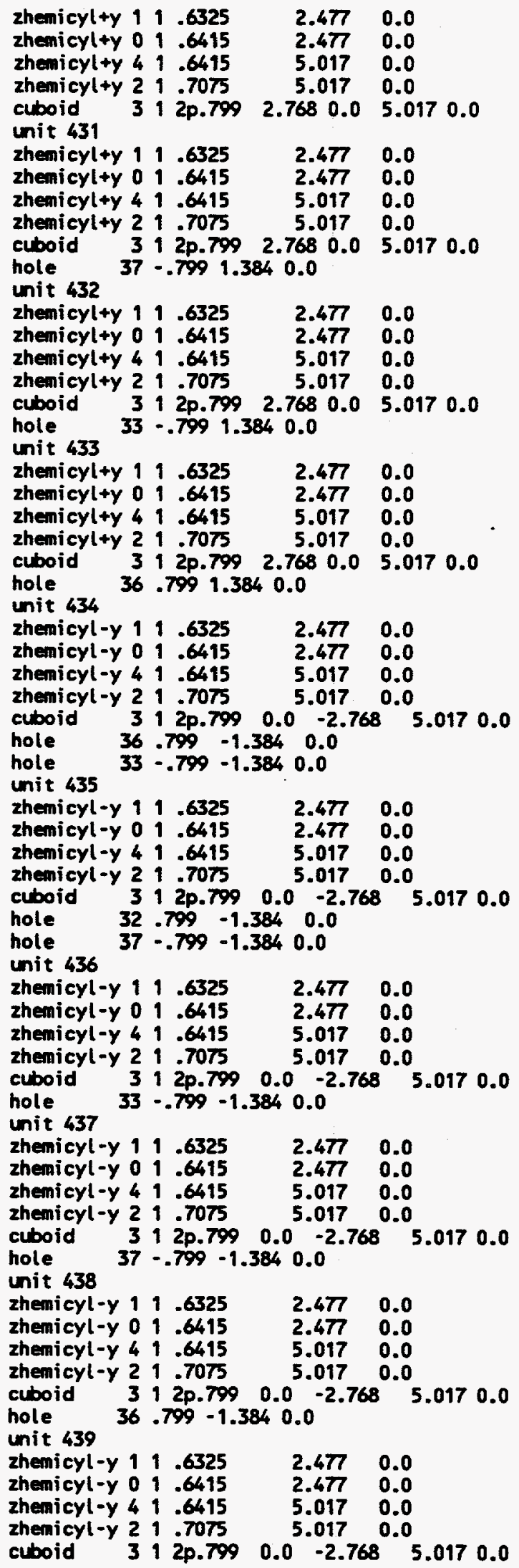




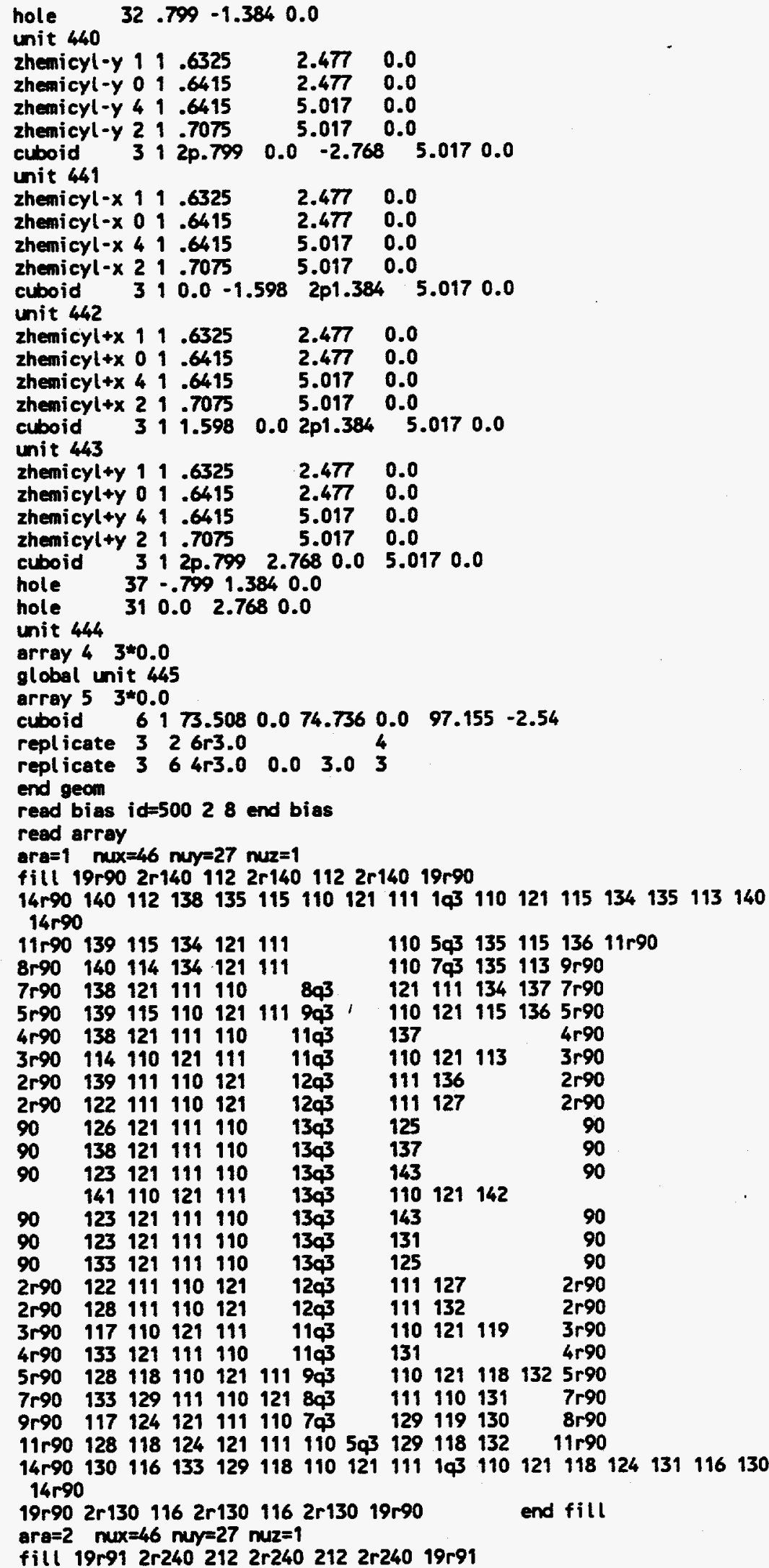


140

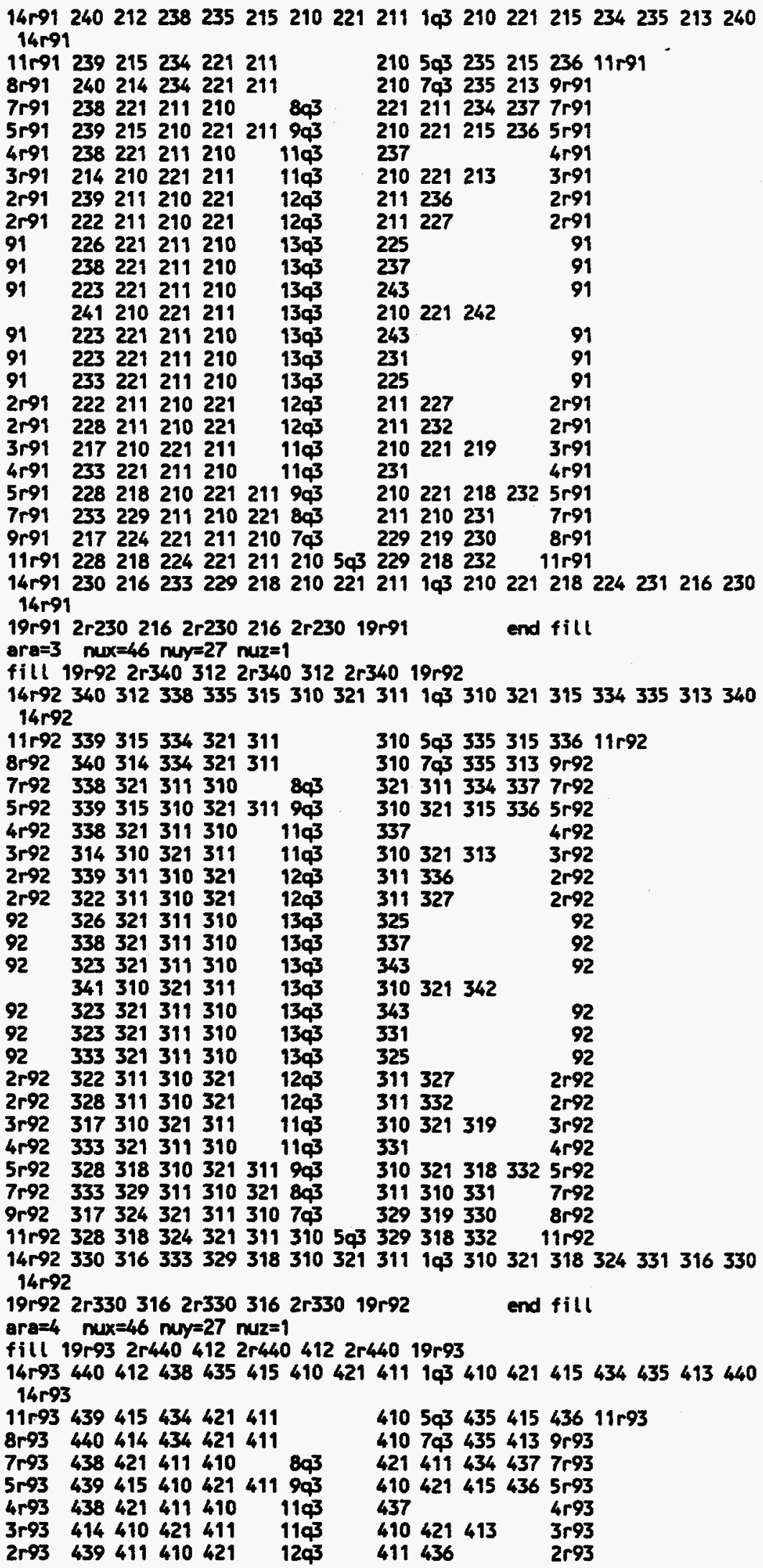




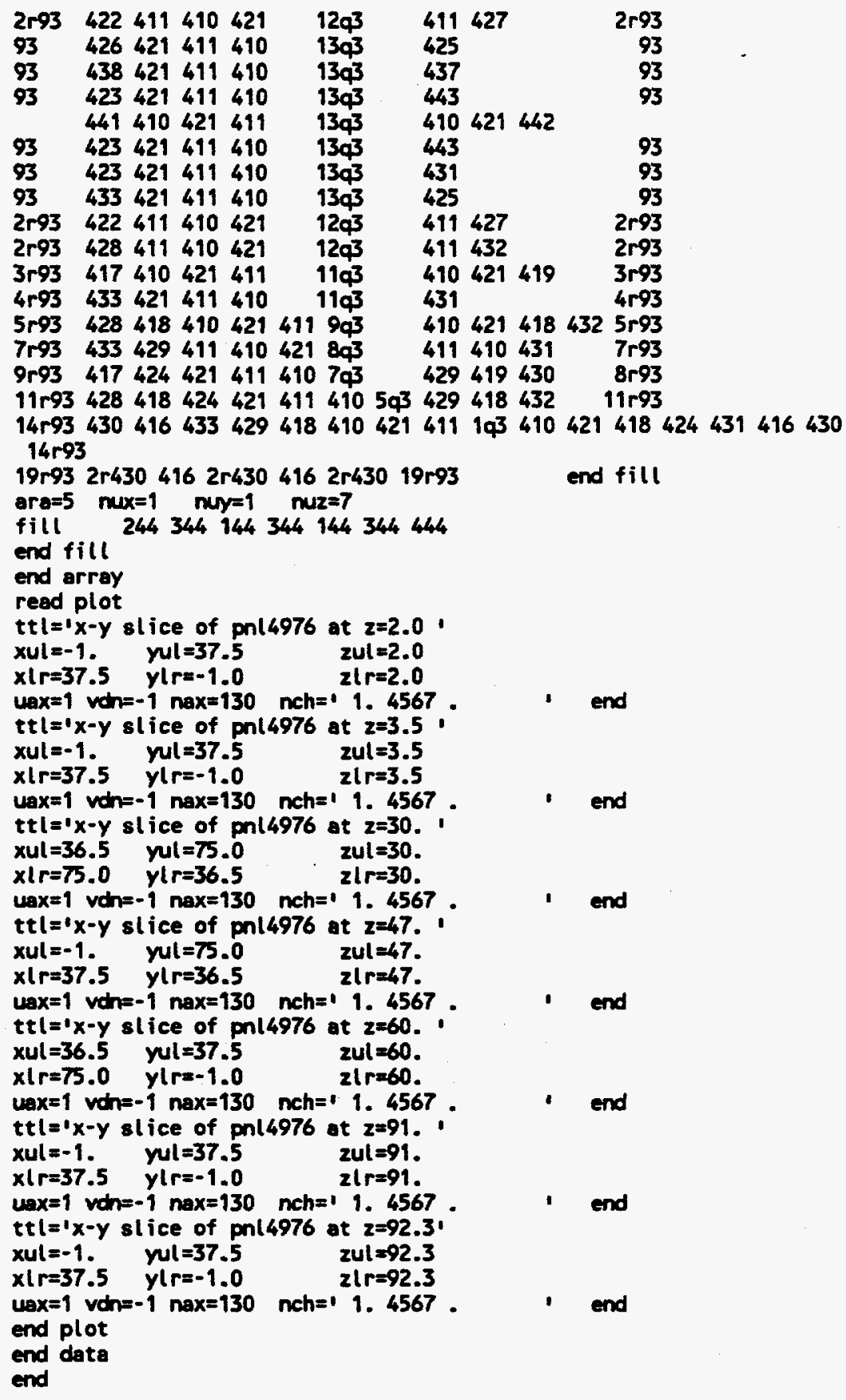




\section{$\operatorname{saxtn104}$}

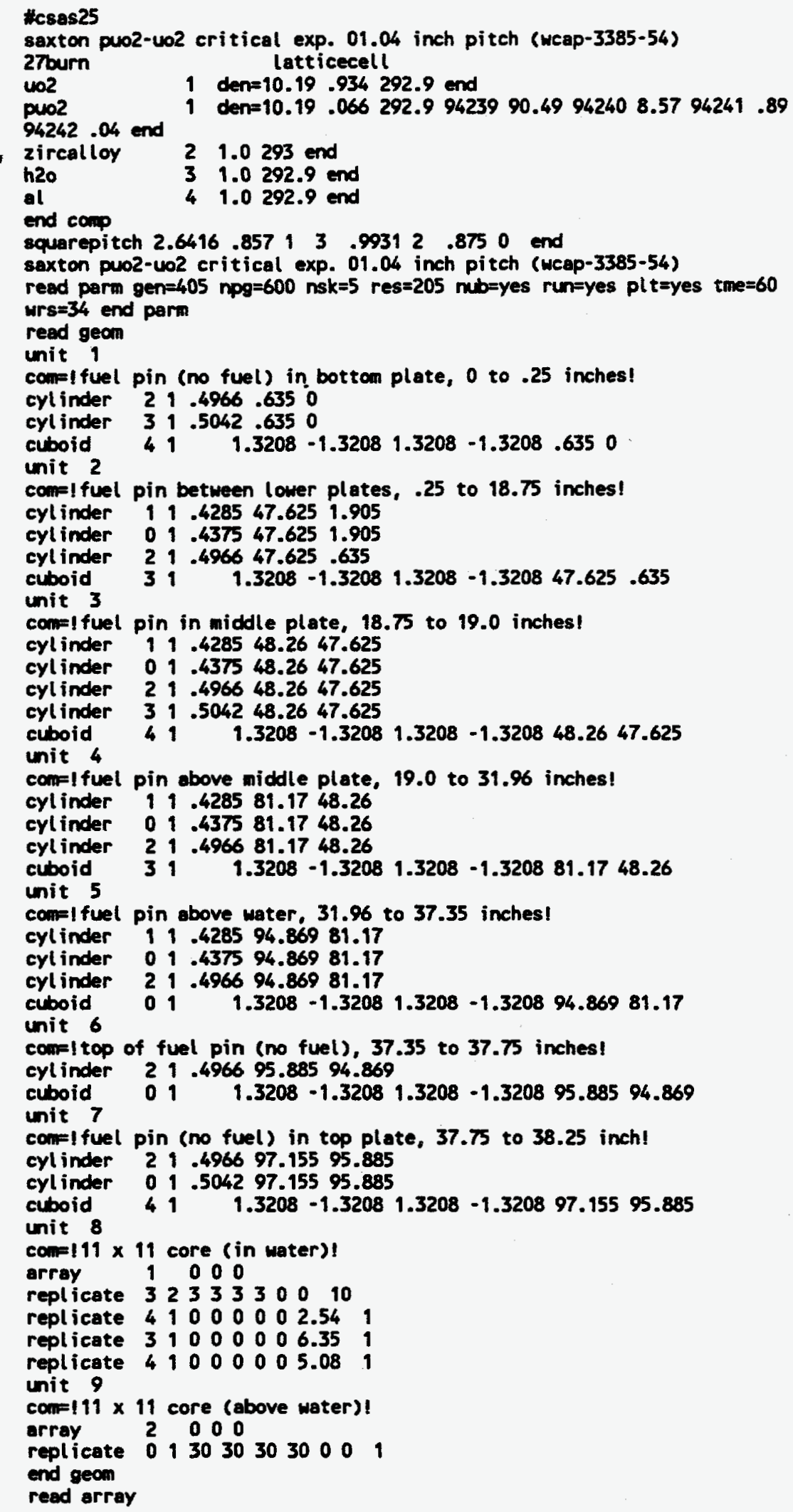


aras mux=11 nuy=11 nuz=4

comin!11 $\times 11$ fuel pin array (in water)!

fill 121ri 121r2 121r3 121r4 end fill

ar $a=2$ nux=11 nuy=11 nuz=3

com=!11 $\times 11$ fuel pin array (above water)!

fill 121r5 121r6 121r7 end fill

ara=3 gbl=3 nux=1 nuy=1 nuz=2

confl complete fuel core!

fill 89 and fill

end array

read bias id=500 211 end bias

read plot

$t t l=\mid x-y$ view of core!

pl $t=y e s$ picmixture $x u l=28$ yul=45 $z u l=62 \quad x \mid r=45$ ylr=28 $z l r=62$ uax=1 vax=0 wax $=0$ uch $=0$ vadn $=-1$ woh $=0$ nax $=130$

nch $=$ ! 12.-

! end

$t=l x-z$ vieu of core

$\operatorname{vax}=0$

plt=yes piczmixture $x$

wax $=0$ udin=0 voln $=0$ wdn $=-1$ nax $=130$

nch $=$ ! 12.1

! end

end plot

end date

end 


\section{$\operatorname{sartn56b}$}

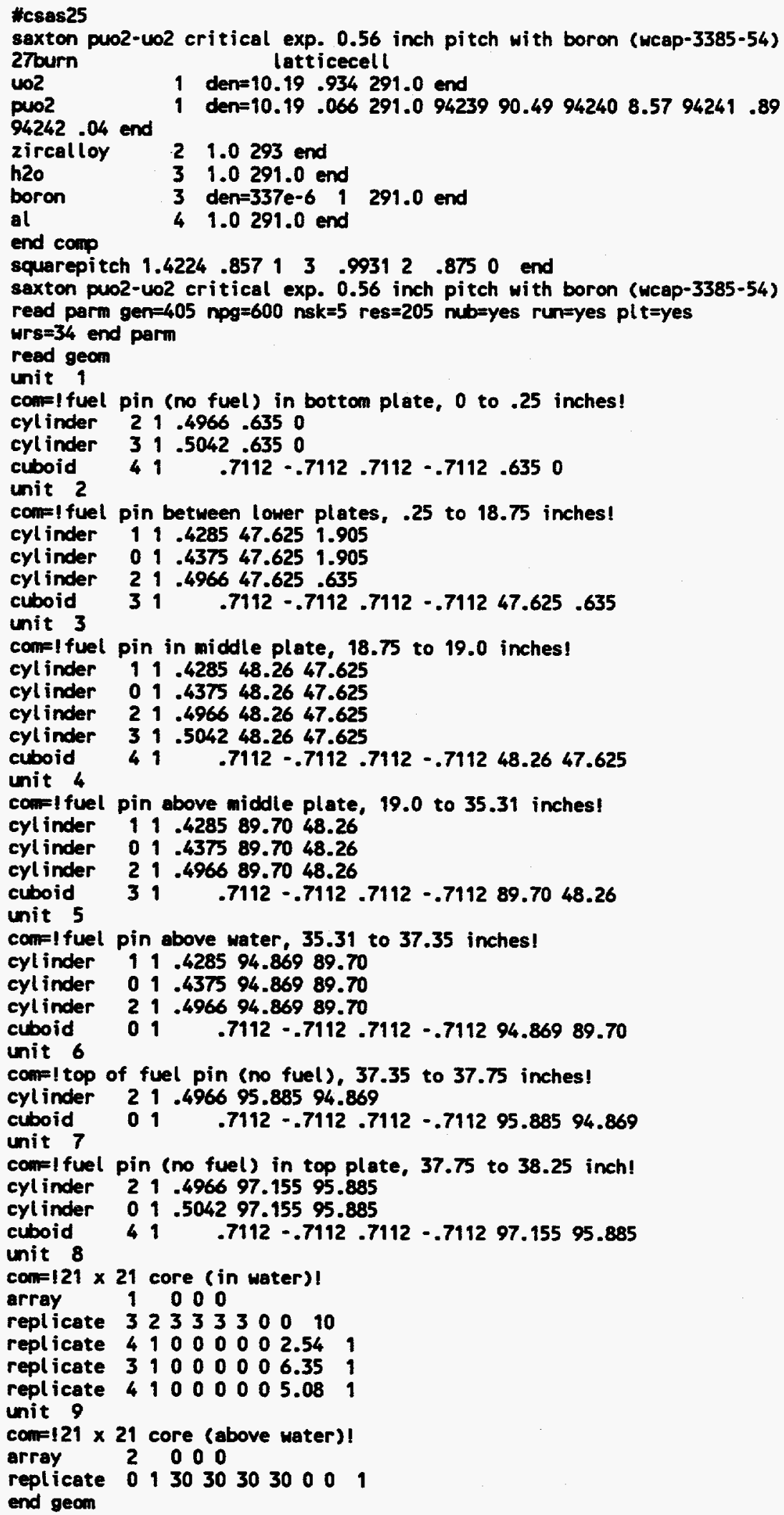


read array

ars $=1$ mux=21 nuy=21 nuz=4

con=121 $\times 21$ fuel pin array (in water)!

fill 441ri 441r2 441r3 $441 \mathrm{r} 4$ end fill

ar $\theta=2$ nux=21 nuy=21 nuz=3

$c o n=121 \times 21$ fuel pin array (above water)!

fill 441 r5 441 r6 $441 \mathrm{rt}$ end till

are $=3$ gbl=3 nux=1 nuy=1 nuz=2

comf! complete fuel core!

fill 89 end fill

end array

read bias id $=500211$ end bies

read plot

$t t l=\mid x-y$ view of core!

pl $t=y e s$ pic=mixture $x u l=28$ yul=46 $2 u l=62 \quad x \mid r=46$ yl $r=28 \quad z l r=62$ uax=1 vax=0

wax $=0$ udn $=0$ vdn $=-1$ whn=0 nax $=130$

nch $=$ ! 12.-

! end

$t t l=\mid x-z$ view of core $\mid$

plt=yes pic=mixture $x u l=28$ yul=35 zul=113 $x l r=46$ yl $r=35 \quad z l r=65$ uax=1 vax=0

wax $=0$ whn=0 vohn=0 whn=-1 $\operatorname{nax}=130$

nch $=112.1$

1 end

end plot

end date

end 


\section{$\operatorname{saxtn} 735$}

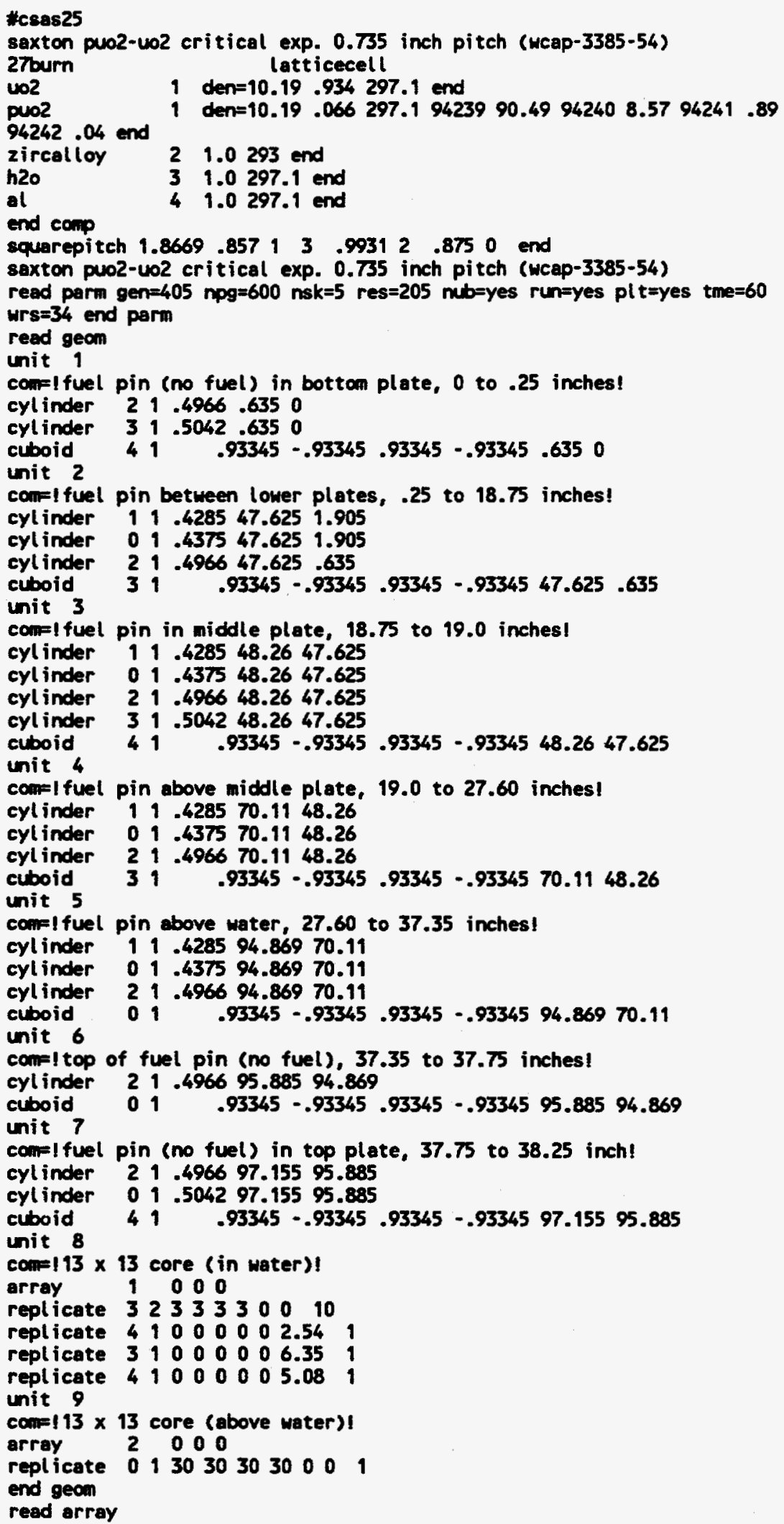


ara=1 nux=13 muy=13 nuz=4

com $=! 13 \times 13$ fuel pin array (in water)!

fill 169r1 169r2 169r3 169r4 end fill

ara=2 nux=13 nuy=13 nuz=3

com=!13 $\times 13$ fuel pin array (above water)!

fill 169r5 169r6 169r7 end fill

aras obl $=3$ nux=1 nuy=1 nuz=2

confl complete fuel core!

fill 89 end fill

end array

read bias id=500 211 end bias

read plot

$t t l=! x-y$ view of core!

plt=yes pic=mixture $x u l=28$ yul=42 $2 u l=62$ xlr=42 ylr=28 zl $r=62$ uax=1 vax=0 wax $=0$ udn $=0$ voth $=-1$ whn=0 nax $=130$

nch $=1$ 12.-

! end

$t t l=1 x-2$ view of core!

plt=yes pic=mixture $x u l=28$ yul=44 $2 u l=113 \quad x i r=42$ ylr=44 $2 l r=0$ uax=1 vax=0 wax $=0$ udn $=0$ vdh $=0$ wdn $=-1$ nax $=130$

nch=! 12./

end plot

end date

end 
$\operatorname{sax} \operatorname{tn} 792$

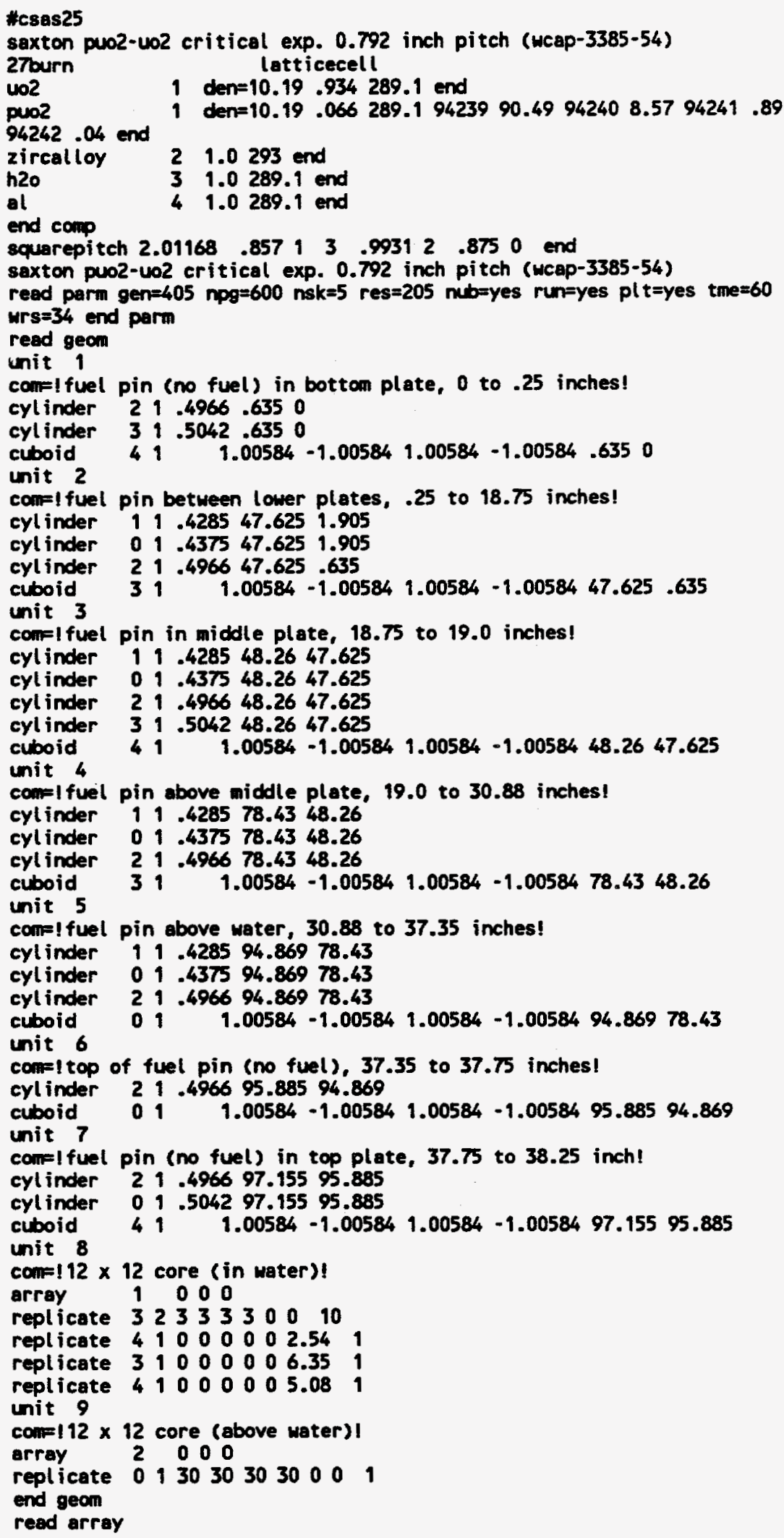


ara $=1$ nux=12 muy=12 nuz=4

com=112 $\times 12$ fuel pin array (in water)!

fill 144ri 144r2 144r3 144r4 and fill

ara $=2$ nux $=12$ muy=12 nuz=3

com=! $12 \times 12$ fuel pin array (above water)!

fill 144r5 $144 r 6144 r 7$ end fill

arg=3 $\mathrm{gbl}=3$ nux=1 nuy=1 nuz=2

com=l complete fuel core!

fill 89 end fill

end array

read bias id=500 211 end bias

read plot

$t t l=l x-y$ view of core!

plt $=$ yes pic=mixture $x u l=28$ yul=42 $2 u l=60 \quad x l r=42$ ylr=28 $z l r=60$ uax=1 vax=0

wax $=0$ wh $=0$ voln $=+1$ wod $=0$ nax $=130$

nch $=!$ 12.-

I end

$t t l=\mid x-2$ view of core!

pl $t=y e s$ pic=nixture $x u l=28$ yul=31 zul $=113 \quad x l r=42$ yl $r=31$ zl $r=0$ uax=1 vax=0

wax $=0$ udh $=0$ vdh $=0$ woh $=-1$ nax $=130$

nch $=$ ! 12.1

! end

end plot

end data

end 


\section{$\operatorname{sarton} 52$}

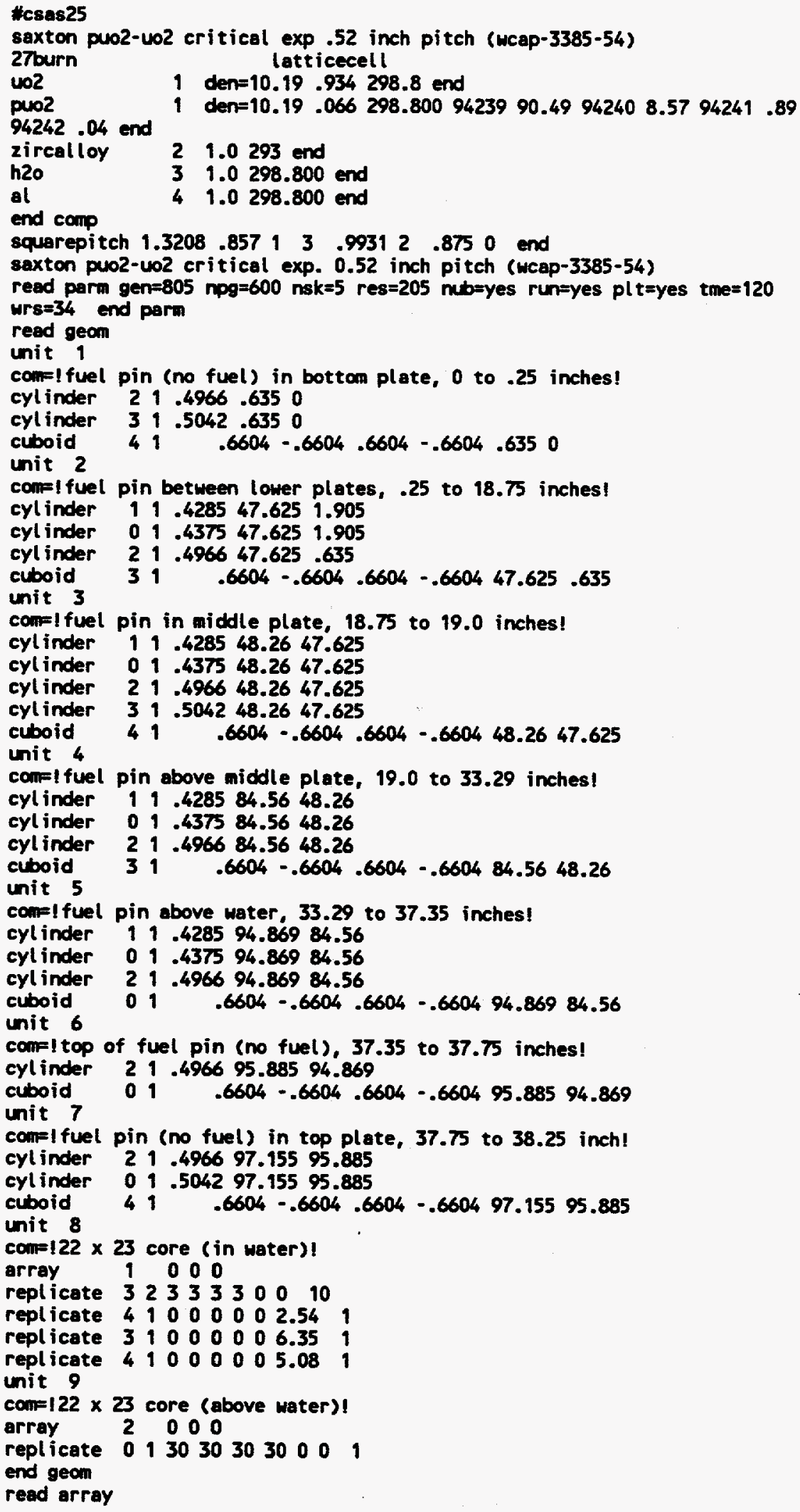


ara=1 nux=22 nuy=23 nuz=4

$c o=122 \times 23$ fuel pin array (in water)!

fill 506r1 506r2 506r3 506r4 and fill

arax 2 mux=22 nuy $=23$ nuz=3

compl $122 \times 23$ fuel pin array (above water)!

fill 506r5 506r6 506r7 and fill

ara $=3 \mathrm{gbl}=3$ nux=1 ruy $=1$ nuz=2

con=! complete fuel core!

fill 89 end fill

end array

read bias id=500 211 end bias

read plot

$t t l=! x-y$ view of core!

plt=yes pic=mixture $x u l=29$ yul=47 $2 u l=62$ xlr=47 ylr=29 $z l r=62$ uax=1 vax=0

wax $=0$ udh $=0$ vah $=-1$ wdh=0 nax $=130$

nch $=! 12$ -

1 end

$t t l=! x-2$ view of core!

plt=yes pic=mixture $x u l=29$ yul $=45$ zul $=113$ xlr=47 ylr=45 zlr=-1 uax=1 vax=0

wax $=0$ udh $=0$ vdn=0 wdn=-1 $\max =130$

nch $=$ ! 12.1

! end

end plot

end data

end 


\section{saxton56}

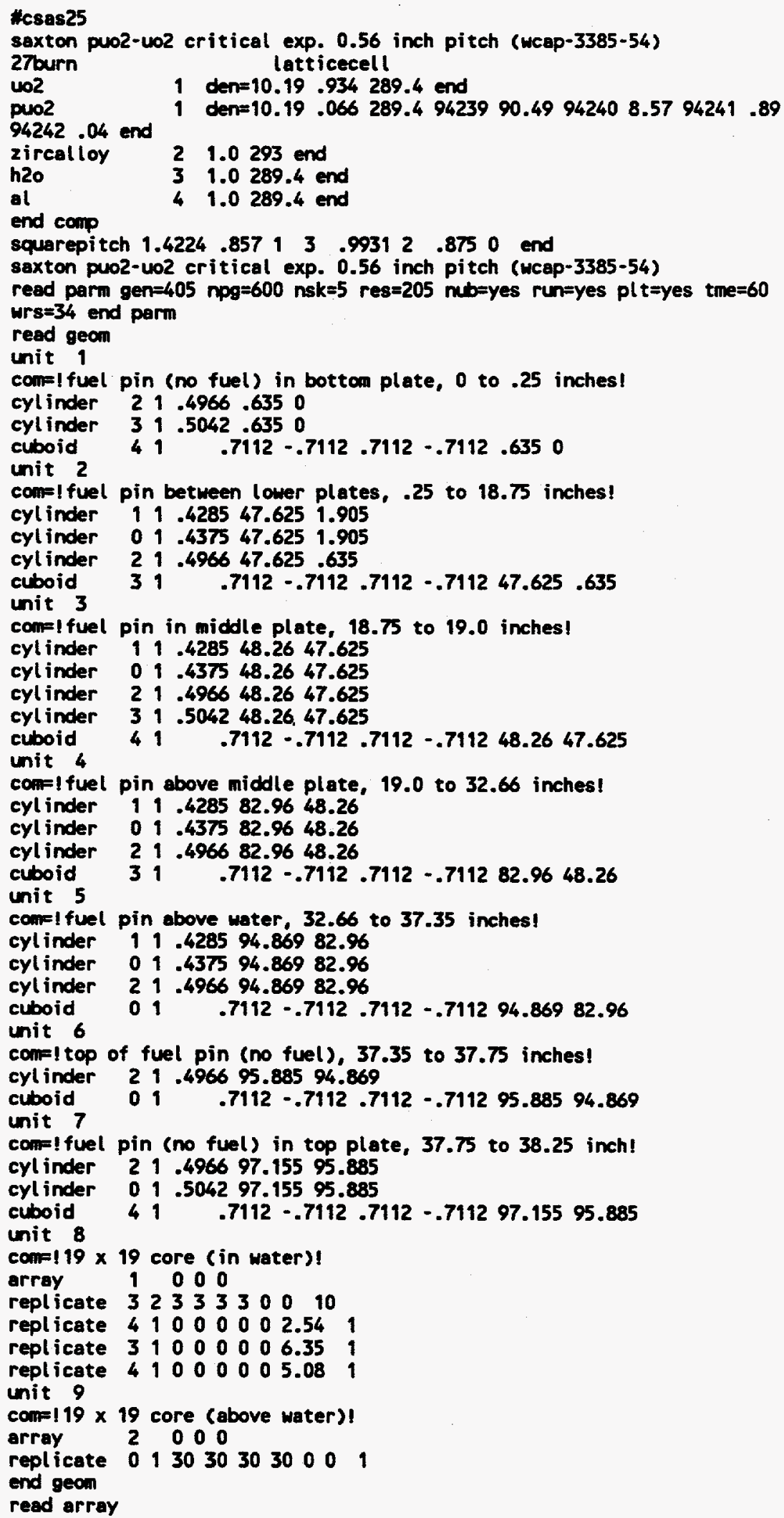


are=1 nux=19 nuy=19 nuz=4

com=119 $\times 19$ fuel pin array (in water)!

fill $361 \mathrm{rl} 361 \mathrm{r2} 361 \mathrm{r3} 361 \mathrm{r} 4$ end fill

ara $=2$ mux=19 nuy=19 nuz=3

$c 0 m=! 19 \times 19$ fuel pin array (above water)!

fill $361 \mathrm{r} 5361 \mathrm{r} 6361 \mathrm{r} 7$ and fill

are $=3 \mathrm{gbl}=3$ nux=1 mur=1 nuz=2

comil complete fuel core!

fill 89 end fill

end array

read bias id=500 211 end bias

read plot

$t t l=! x-y$ view of core!

plt=yes pic=mixture $x u l=28$ yul=44 zul=62 $x l r=44$ ylr=28 $z l r=62$ uax=1 vax=0

wax $=0$ udh $=0$ vodn $=-1$ won $=0$ nax $=130$

nch $=$ ! 12.-

! end

$t t=! x-2$ view of core $!$

plt $t=y e s$ pic=mixture $x u l=28$ vul=35 $z u l=113 \quad x / r=44$ ylr=35 $z \mid r=65$ uax=1 vax=0

wax $=0$ uth=0 vodn=0 wodn=-1 $\operatorname{nax}=130$

nch $=$ ! 12./

I end

end plot

end data

end 


\section{$\operatorname{saxu56}$}

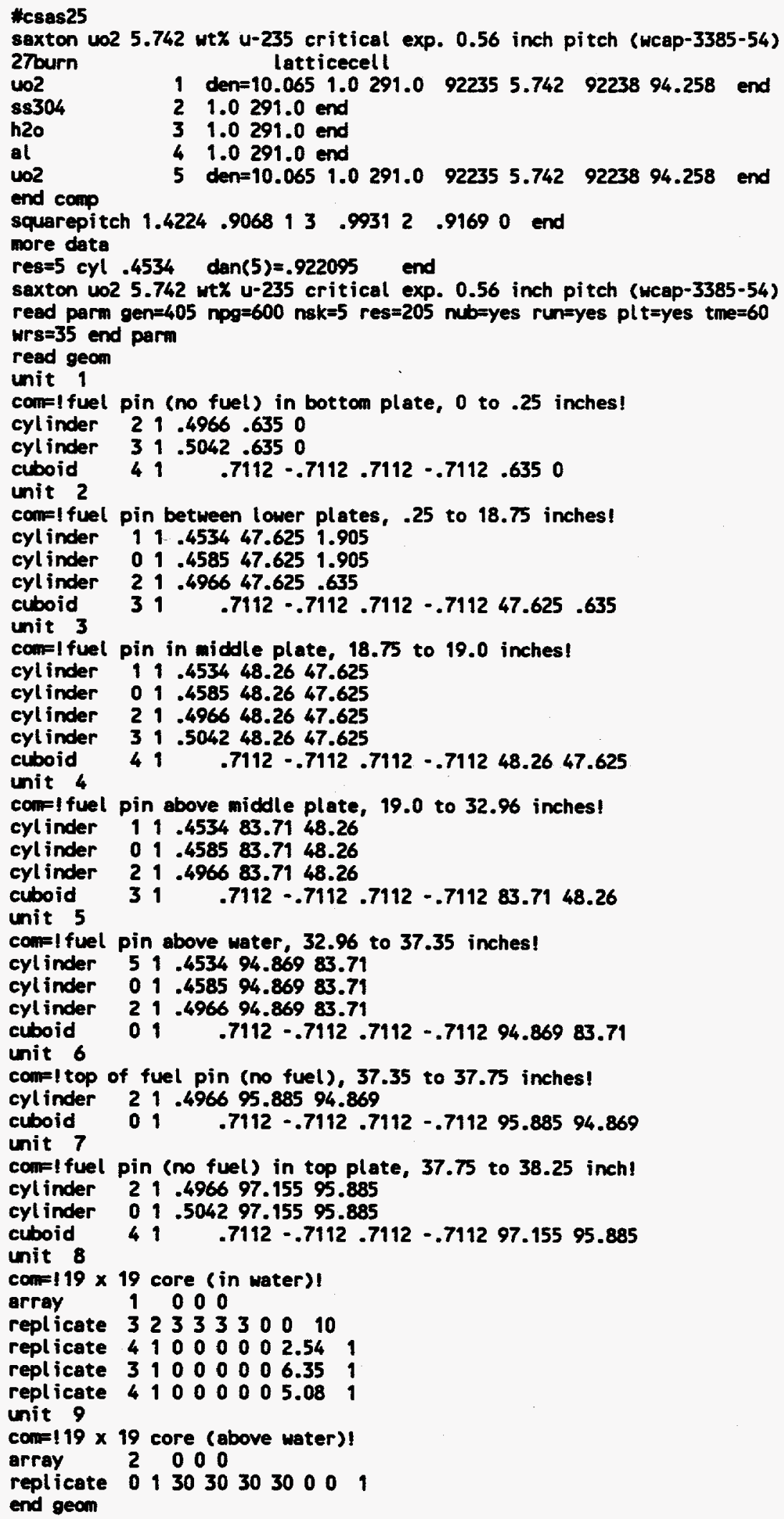


read array

ara $=1$ nux=19 nuy=19 muz=4

com=119 $\times 19$ fuel pin array (in water)!

fill 361r1 361r2 $361 \mathrm{r3} 361 \mathrm{r4}$ end fill

ara=2 nux=19 nuy=19 nuz=3

comll $19 \times 19$ fuel pin array (above water)!

fill 361 r5 361 r6 $361 \mathrm{r} 7$ end fill

ara $=3$ gbl $=3$ nux $=1$ nuy $=1$ nuz $=2$

com=! complete fuel core!

fill 89 end fill

end array

read bias id $=500211$ end bias

read plot

$t t l=! x-y$ view of core!

plt=yes pic=mixture $x u l=28$ pul $=44 \quad z u l=62 \quad x l r=44$ ylr=28 $z l r=62$ uax=1 vax=0

wax $=0$ udn $=0$ vdh $=-1$ wdn $=0$ nax $=130$

nch=1 12.-

$t t l=! x-z$ view of core!

$p l t=y e s$ pic=mixture $x u l=28$ pul=35 $z u l=113 \quad x \mid r=44$ ylr=35 $z l r=0$ uax=1 vax=0

wax $=0$ udh $=0$ vahn=0 wdn=-1 $\max =130$

nch $=$ ! 12.1

1 end

end plot

end dete

end 


\section{saxu792}

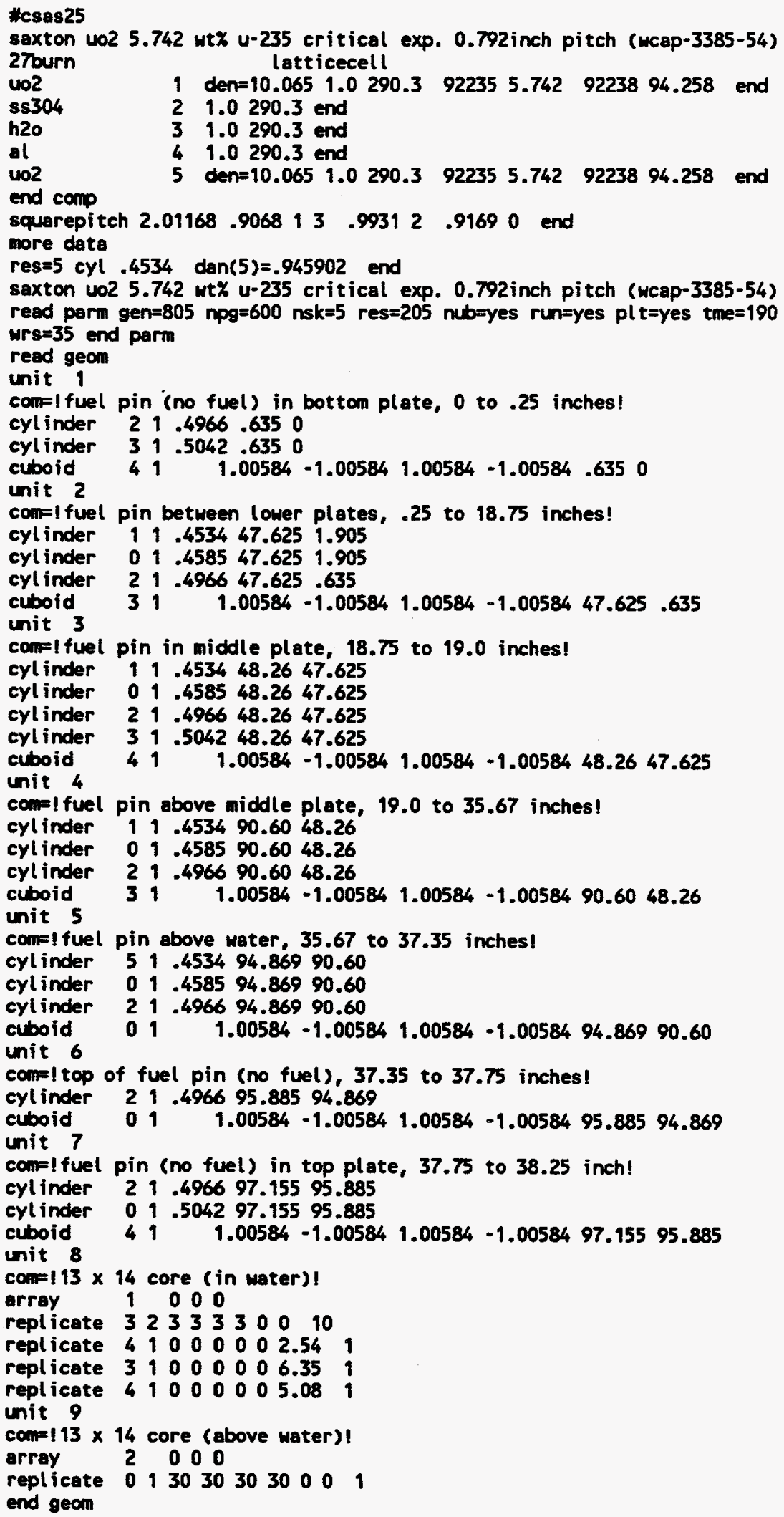


read array

ar $a=1$ mux $=13$ muy=14 nuz $=4$

con=! $13 \times 14$ fuel pin array (in water)!

fill 182ri 182r2 182r3 182r4 end fill

ara=2 nux $=13$ nuy $=14$ nuz=3

confl13 1314 fuel pin array (above water)!

fill 182r5 182r6 182r7 and fill

$a r a=3 \mathrm{gbl}=3$ nux $=1$ nuy $=1$ nuz=2

com= I complete fuel core!

fill 89 end fill

end array

read bias id $=500211$ end bias

read plot

$t t l=! x-y$ view of corel

plt=yes pic=mixture $x u l=28$ yul=44 zul=62 $x \mid r=44$ ylr=28 zlr=62 wax=1 vax=0 wax $=0$ udn=0 vdn=- 1 wdn=0 nax $=130$ nch=! 12.-

! end

$t t l=! x-z$ view of core

plt $=$ yes pic=mixture $x u l=28$ yul=35 zul=113 $x / r=44$ ylr=35 zlr=0 uax=1 vax=0

wax $=0$ udh $=0$ vdh $=0$ wdh $=-1$ nax $=130$

nch=! 12./

end plot

end date

end 
a 


\section{APPENDIX C}

\section{RESULTS OF ADDITIONAL CRITICAL CALCULATIONS}

In addition to the 34 fresh fuel criticals described in this report, numerous other critical calculations have been performed and may be considered in reducing calculational biases and uncertainties. Such additional experiments are described in Sect. 4.3 of this report. This appendix provides the results of calculations for two sets of related experiments: seven reactor critical experiments (Table C.1) and 59 fresh fuel experiments (Table C.2). All calculations were performed using SCALE-4.2 and the SCALE 27-group burnup cross-section library, consistent with the results of the 34 fresh fuel criticals.

Table C.1. Results of reactor critical calculations

\begin{tabular}{llll}
\hline Designation & $\mathrm{k}_{\text {eff }}$ & \pm 0 & AEG \\
\hline Sequoyah BZ & 1.0039 & 0.0005 & 20.49 \\
Sequoyah BF & 1.0067 & 0.0005 & 20.38 \\
Sequoyah MF & 1.0046 & 0.0005 & 20.44 \\
Surry BZ & 1.0014 & 0.0005 & 21.02 \\
Surry EF & 1.0113 & 0.0005 & 20.97 \\
TMI BZ & 0.9978 & 0.0004 & 20.78 \\
North Anna BZ & 1.0040 & 0.0005 & 20.38 \\
\hline
\end{tabular}

Source: ref. 29. 
Table C.2. Results of additional fresh fuel calculations

\begin{tabular}{|c|c|c|c|}
\hline Designation & $k_{\text {eff }}$ & $\pm \sigma$ & AEG \\
\hline ans $33 b b 2^{a}$ & 1.0055 & 0.0012 & 22.47 \\
\hline ans $33 b h 2^{a}$ & 1.0083 & 0.0012 & 22.54 \\
\hline ans $33 b p 2^{a}$ & 0.9975 & 0.0013 & 22.34 \\
\hline ans $33 \mathrm{~h} 2^{a}$ & 0.9929 & 0.0012 & 22.54 \\
\hline baw1231a $a^{a}$ & 0.989 & 0.0009 & 20.64 \\
\hline baw $1231 b^{a}$ & 0.9901 & 0.0007 & 19.93 \\
\hline baw $1273 \mathrm{~m}^{a}$ & 0.9912 & 0.001 & 21.25 \\
\hline baw1484b $b^{a}$ & 0.9905 & 0.0013 & 23.07 \\
\hline baw1484c $c^{a}$ & 0.9919 & 0.0013 & 22.58 \\
\hline baw1484d $d^{a}$ & 0.9876 & 0.0013 & 22.93 \\
\hline baw1645s $\mathrm{s}^{a}$ & 0.9891 & 0.0012 & 19.85 \\
\hline baw1645t ${ }^{a}$ & 0.9905 & 0.0009 & 19.25 \\
\hline bw1645so ${ }^{a}$ & 0.9911 & 0.0011 & 21.53 \\
\hline cr1071as & 1.0149 & 0.0011 & 21.36 \\
\hline cr1653as & 1.0059 & 0.0011 & 21.56 \\
\hline cr1653b & 1.0068 & 0.0012 & 19.17 \\
\hline cr $2500 \mathrm{~s}$ & 1.011 & 0.0011 & 21.83 \\
\hline epru615b $b^{a}$ & 0.9914 & 0.0014 & 21.91 \\
\hline epru75 $5^{a}$ & 0.9921 & 0.001 & 23.34 \\
\hline epru $75 b^{a}$ & 0.9949 & 0.0009 & 23.02 \\
\hline epru87b ${ }^{a}$ & 0.9986 & 0.0011 & 23.62 \\
\hline or 260901 & 1.0053 & 0.0014 & 24.94 \\
\hline or260906 & 1.0049 & 0.0012 & 24.99 \\
\hline or $2968 \mathrm{al}$ & 1.0067 & 0.0011 & 24.4 \\
\hline or $2968 \mathrm{~s} 1$ & 0.9877 & 0.0016 & 24.29 \\
\hline
\end{tabular}


Table C.2 (continued)

\begin{tabular}{|c|c|c|c|}
\hline Designation & $k_{\text {eff }}$ & $\pm \sigma$ & AEG \\
\hline or2968s2 & 0.9967 & 0.0009 & 24.73 \\
\hline $\mathrm{p} 2615 \times 14^{a}$ & 0.9966 & 0.0015 & 23.31 \\
\hline $\mathrm{p} 2615 \times 23^{a}$ & 0.9948 & 0.0015 & 23.31 \\
\hline $\mathrm{p} 2615 \times 31^{a}$ & 0.9964 & 0.0016 & 23.3 \\
\hline p282712a $a^{a}$ & 1.0005 & 0.0013 & 23.56 \\
\hline $\mathrm{p} 282712 \mathrm{~b}^{\mathrm{a}}$ & 1.0077 & 0.0008 & 23.27 \\
\hline p2827non & 0.9943 & 0.0014 & 23.59 \\
\hline p2827u2a & 0.9971 & 0.0013 & 22.85 \\
\hline $\mathrm{p} 2827 \mathrm{u} 2 \mathrm{~b}^{2}$ & 0.9969 & 0.0014 & 22.25 \\
\hline p3314a & 0.9941 & 0.0016 & 21.85 \\
\hline p3314b & 0.9966 & 0.0011 & 21.85 \\
\hline p3602b4" & 0.9983 & 0.0016 & 21.91 \\
\hline p3602c $4^{2}$ & 0.9968 & 0.0011 & 21.92 \\
\hline $\mathrm{p} 3602 \mathrm{n} 2^{a}$ & 0.9953 & 0.0014 & 23.52 \\
\hline p3602non ${ }^{a}$ & 0.9986 & 0.0016 & 21.99 \\
\hline p392612a & 0.995 & 0.0014 & 22.79 \\
\hline p3926n $2^{a}$ & 0.9901 & 0.0015 & 22.87 \\
\hline p3926nob $^{a}$ & 0.9928 & 0.0016 & 22.06 \\
\hline p3926u2a $a^{a}$ & 0.9894 & 0.0013 & 21.93 \\
\hline p5803x21 & 1.0117 & 0.0011 & 20.22 \\
\hline p5803x32 & 1.0109 & 0.0015 & 23.27 \\
\hline p5803x43 & 1.0117 & 0.0011 & 21.87 \\
\hline p5803x67 & 1.0063 & 0.0011 & 18.55 \\
\hline p5803x68r & 1.0066 & 0.0016 & 22.71 \\
\hline
\end{tabular}


Table C.2 (continued)

\begin{tabular}{llll}
\hline Designation & $\mathrm{k}_{\text {eff }}$ & $\pm \sigma$ & AEG \\
\hline pn1194 & 0.9944 & 0.0015 & 18.47 \\
rfp2710r & 1.0099 & 0.0021 & 22.02 \\
rf22710u & 1.0154 & 0.002 & 23.61 \\
w3269a & 1.0002 & 0.0009 & 20.77 \\
w3269b & 0.9994 & 0.0013 & 21.41 \\
w3269c & 0.9901 & 0.001 & 22.2 \\
ydr14p12 & 0.996 & 0.0013 & 23.68 \\
ydr14p13 & 1.0062 & 0.0014 & 22.2 \\
ydr14un2 & 0.9956 & 0.0013 & 23.04 \\
ydr14un3 & 1.0102 & 0.0015 & 21.78 \\
\hline
\end{tabular}

${ }^{\mathrm{C}} \mathrm{UO}_{2}$-only criticals.

Source: ref. 30. 